\title{
SILICA-REINFORCED NATURAL RUBBER TIRE COMPOUNDS WITH SAFE COMPOUNDING INGREDIENTS
}


SILICA-REINFORCED NATURAL RUBBER TIRE COMPOUNDS WITH SAFE COMPOUNDING INGREDIENTS 


\section{TiV The

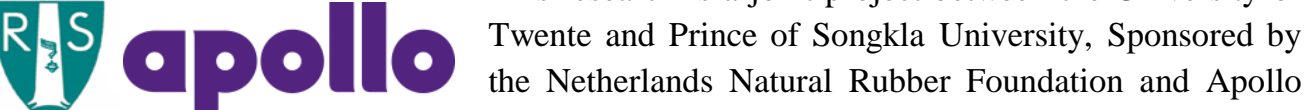 Tyres Global R\&D B.V.}

Graduation committee

Chairman: Prof. Dr. G.P.M.R. Dewulf

Secretary: $\quad$ Prof. Dr. G.P.M.R. Dewulf

Supervisor: $\quad$ Prof. Dr. Ir. J.W.M. Noordermeer

Co-supervisor: Dr. K. Sahakaro

University of Twente, ET

University of Twente, ET

University of Twente, ET and

Prince of Songkla University,

Science and Technology

Members: $\quad$ Prof. Dr. Ir. D.J. Schipper

University of Twente, ET

Prof. Dr. J.F.J. Engbersen

University of Twente, TNW

Prof. Dr. K. Naskar

Indian Institute of Technology,

Kharagpur, India

Prof. Dr. Dipl. -Ing. H.-J. Radusch

Martin-Luther-Universität

Halle-Wittenberg, Germany

Referee: $\quad$ Dr. A. Chapman

Tun Abdul Razak Research

Center, UK

Silica-reinforced natural rubber tire compounds with safe compounding ingredients

By Chesidi Hayichelaeh

Ph.D. Thesis, University of Twente, Enschede, the Netherlands, and Prince of Songkla University, Pattani Campus, Thailand, 2018.

With references - With summary in English, Dutch and Thai.

Copy right @ Chesidi Hayichelaeh, 2018.

All rights reserved.

Printed at Ipskamp printing, Auke Vleerstraat 145, 7547 PH Enschede, the Netherlands.

ISBN: 978-90-365-4676-8

DOI: $10.3990 / 1.9789036546768$

USL: https://doi.org/10.3990/1.9789036546768 


\title{
SILICA-REINFORCED NATURAL RUBBER TIRE COMPOUNDS WITH SAFE COMPOUNDING INGREDIENTS
}

\author{
DISSERTATION
}

to obtain

the degree of doctor at the University of Twente, on the authority of the rector magnificus, Prof. Dr. T.T.M. Palstra,

on account of the decision of the graduation committee, to be publicly defended on Wednesday, December $12^{\text {th }}, 2018$ at 10:45

by

Chesidi Hayichelaeh

born on December $17^{\text {th }}, 1987$

in Pattani, Thailand 
This dissertation has been approved by:

Supervisor: $\quad$ Prof. Dr. Ir. J.W.M. Noordermeer

Co-supervisor: Dr. K. Sahakaro 



\section{Table of Contents}

Chapter 1 Introduction: The concept of safe green-tire technology based on silicareinforced natural rubber compounds

Chapter 2 An overview of silica-reinforced rubber compounds with safe compounding ingredients

Chapter 3 Enhancing the silanization reaction of the silica-silane system by different amines in model compounds

Chapter 4 Reinforcement of natural rubber by silica/silane in dependence of different amine types

Chapter 5 Promoting interfacial compatibility of silica-reinforced natural rubber tire compounds by aliphatic amine

Chapter 6 The silanization efficiency of silica/silane systems in dependence of different functional groups in modified palm oils

Chapter 7 Silica-reinforced natural rubber tire tread compounds containing bio-based process oils: I. Aspect of mixing sequence and epoxide content

Chapter 8 Silica-reinforced natural rubber tire tread compounds containing bio-based process oils: II. Influence of epoxide and amino functional groups

Chapter 9 Summary

Symbols and abbreviations

Bibliography

Acknowledgements

Curriculum vitae 



\section{INTRODUCTION:}

\section{THE CONCEPT OF SAFE GREEN-TIRE TECHNOLOGY BASED ON SILICA-REINFORCED NATURAL RUBBER COMPOUNDS}

\subsection{INTRODUCTION}

Natural rubber (NR) is a renewable resource that is used for several applications in which tires take up a large portion of NR consumption. NR is used in many parts of the tires, especially for truck tire tread compounds as it provides low heat build-up and excellent mechanical properties derived from its ability to form crystals upon being stretched, i.e. strain-induced crystallization. Reinforcing fillers are a crucial ingredient in tire compounds, added to improve tire performances. For rubber-tire technology, carbon black has been conventionally used as reinforcing filler for a long time. Later, the innovation of the "Green Tire" based on silica-reinforced rubber tire compounds by Michelin led to a new facet of tire technology. ${ }^{[1]}$ Silica-reinforced tire tread compounds show improvement of key tire performances, i.e. lower rolling resistance and better wet traction, while maintaining the abrasion resistance, when compared to carbon black-filled tire compounds. ${ }^{[2]}$ The silica-filled tire rubber compounds could reduce $20 \%$ of rolling resistance compared to carbon black-based compounds. ${ }^{[3]}$ A reduction of rolling resistance of about $20 \%$ of silica-filled rubber compounds can save $3-6 \%$ of fuel. ${ }^{[4]}$

The silica surface consists of highly polar silanol groups, while the NR is a hydrocarbon material. Thus, mixing of silica with NR encounters incompatibility problems and silane coupling agents, e.g. bis(3triethoxysilylpropyl) tetrasulfide (TESPT), are commonly used to improve the compatibility between rubber and filler. The use of silanes increases filler-rubber interaction and reduces filler-filler interaction. The reaction of TESPT silane in the rubber compounds filled with silica is complicated due to the presence of two reactive sites, i.e. polysulfide and ethoxy groups. The ethoxy groups in the silane react with the silanol groups on the silica surface during mixing, the so called silanization reaction. ${ }^{[5]}$ During vulcanization, the polysulfide part reacts with the rubber chains contributing to network formation. ${ }^{[6]}$ The silanization reaction, which is a condensation reaction requires a catalyst, either acid or alkali, to promote the condensation reaction, where an alkali catalyst is preferred for the rubber compound for the benefit of the vulcanization reaction. ${ }^{[7]} 1,3$-Diphenylguanidine (DPG) is an alkaline secondary accelerator that is widely used in the silica filled rubber compounds as it acts as a silanization booster. ${ }^{[8]}$ However, DPG can liberate toxic free aniline during mixing and vulcanization ${ }^{[9]}$, where aniline has been reported to be a probable carcinogen for humans by the United States Environmental Protection Agency (2000). ${ }^{[10-11]}$ 
Therefore, alternative substances for DPG are needed for a safe working environment. Alternative noncarcinogenic substances such as dithiophosphates ${ }^{[12-13]}$ and amine derivatives ${ }^{[8,14]}$ have been reported to efficiently act as a secondary accelerator and silanization booster.

Another toxicity concern about the compounding ingredients is related to the use of aromatic process oils. Process oils are generally added into the rubber compounds with high loading of fillers to improve the processibility and dispersibility of fillers in the rubber matrix. The petroleum-based Distillate Aromatic Extract (DAE) was conventionally used in carbon black-filled tire compounds. Based on the report of investigation of tire particles on the road surface by The Swedish National Chemicals Inspectorate (1993), ${ }^{[15]}$ DAE oil contains substantial amounts of polycyclic aromatic hydrocarbons (PAHs) of which some of them are classified as carcinogenic substances. So DAE oil has been banned by the European Union since January $1^{\text {st }}, 2010$ according to Directive 2005/69/EC ${ }^{[16]}$ and Commission Regulation (EC) No. 552/2009. ${ }^{[17]}$ Safe process oils such as Treated Distillate Aromatic Extract (TDAE), Mild Extracted Solvate (MES) and Naphthenic (NAP) oils are alternatives. However, in addition to toxicity, scarceness of the supply of petroleum-based process oils in the future is another concern. Therefore, vegetable oils in their original and/or modified forms have been considered as alternative process oils for rubber compounds. Researchers from Goodyear Innovation Center developed tire compounds by using soybean oil as a replacement for petroleum-based process oils. It was found that rubber compounds with soybean oil have the potential to increase tread life of a tire by 10 percent and give advantages in mixing capabilities of the manufacturing process. ${ }^{[18]}$ In addition, Flanigan et al. (2013) studied the effect of bio-based process oils on the properties of silica-filled rubber compounds compared to the use of TDAE oil. Based on the mechanical and dynamic properties of the resulting rubber vulcanizates, the results showed that bio-based oil could replace the TDAE oil in rubber compounds. ${ }^{[19]}$

This research work focuses on a feasibility study of safe compounding ingredients for tire natural rubber compounds with the emphasis on DPG and aromatic oil alternatives. In the first part, different types of amines are investigated as alternatives for DPG in silica-silane reinforced natural rubber tire compounds. The influence of the amine as secondary accelerator on the vulcanization reaction is analyzed with respect to cure kinetics and as silanization booster, characterized by filler-rubber interaction as well as mechanical and dynamic properties of the silica-filled natural rubber. The second part is executed using the most suitable curing system determined from the first part. TDAE oil is replaced by modified plant oils, i.e. epoxidized palm oils and amine modified-epoxidized palm oils. The resulting silica-filled natural rubber compounds are fully analyzed regarding the flow properties of the uncured compounds and rubber vulcanizate properties with emphasis on tire specifications. The compatibility between oils and rubber and filler-rubber interactions are evaluated. 


\subsection{AIM OF THE PROJECT}

The use of silica as reinforcing filler for tire tread compounds leads to production of more environmental friendly products, because the tires made thereof have lower rolling resistance that means lower fuel consumption and give less $\mathrm{CO}_{2}$ emission. As the tire compounds are composed of several ingredients, the toxicity of some rubber compounding ingredients, e.g. secondary accelerator and process oil, is of concern. In order to enhance safe working conditions and favor the ecological environment to conform with the tightened regulations and/or new legislations for the tire industry, the use of less or nontoxic compounding ingredients and reduced dependence on petroleum-based products by e.g. bio-based process oils leads to safer and "greener" products. As the rubber industry needs to prepare for such changes, therefore the concept of energy-saving tires in combination with safe compounding ingredients for silicareinforced "green" tires is developed.

\subsection{CONCEPT OF THE THESIS}

CHAPTER 1 - The main focus of this thesis is to develop "safer and greener" Green Tires based silica-reinforced NR compounds with safe compounding ingredients, as introduced in this chapter.

CHAPTER 2 - This chapter gives an overview of the reinforcement of rubber compounds focusing on the silica/silane system. Silica characteristics and the silanization reaction with kinetics aspects are described. Then, the literature of rubber compounds with safe compounding ingredients that are targeted in this study is reviewed. A review on investigations of the different types of amines as alternatives for DPG in the rubber compounds is first presented. Then, various studies on the use of natural oils in both original and modified forms in rubber compounds are reviewed. Previous works on modified plant oils, i.e. epoxidized palm oils and amine modified-epoxidized palm oils, as a replacement for petroleum-based process oils in the rubber compounds are elaborated. The chapter ends by stating the motivation for this project.

CHAPTER 3 - To understand the role of the chemical structures of amines on the silanization reaction, a model study of the silica/silane system with different amine types on the silanization reaction is shown in this chapter. The influence of different chemical structures of amines with similar $\mathrm{pK}_{\mathrm{a}}$ value, i.e. hexylamine (HEX), decylamine (DEC), octadecylamine (OCT), cyclohexylamine (CYC), dicyclohexyl amine (DIC) and quinuclidine (QUI), on the rate constant of the primary and secondary silanization reactions are studied. In addition to the different amine types, the effect of amounts of amines on the silanization reaction is also evaluated.

CHAPTER 4 - The use of amines as alternatives for DPG in practical rubber compounds is studied. The effect of different amine types on the properties of the rubber compounds such as Payne effect, flocculation rate constant and heat capacity increment which are used as indicators for filler-filler and filler- 
rubber interactions is investigated. Due to the fact that the main role of DPG is as secondary accelerator, the cure characteristics, i.e. scorch time, cure time, cure rate index and cure reaction rate constant, of the rubber compounds containing different amine types are also considered. Moreover, the properties of rubber vulcanizates are assessed in terms of mechanical and dynamic mechanical properties.

CHAPTER 5 - Based on the results obtained that demonstrated the potential of OCT as a DPG alternative in silica-reinforced rubber compounds as determined by its lower filler-filler interaction and good mechanical properties that are closest to the reference compound with DPG, the use of OCT is further elaborated in this chapter. The work focuses on the improvement of compatibility between the silica surface and rubber molecules, by taking an amine-free rubber compound as a reference. The amount of amines, i.e. DPG and OCT, was varied in the range of 2.4-9.5 mmol per 100 parts of rubber by weight (i.e., 0.5-2.5 phr). Several properties, i.e. bound rubber content, Payne effect, heat capacity increment and immobilized polymer layer, are comparatively investigated in order to prove the enhancement of interfacial compatibility of silica-reinforced rubber compounds. The influence of amines in the rubber compounds on the cure characteristics and crosslink density is also studied.

CHAPTER 6 - To replace petroleum-based process oil of the TDAE type in the silica-reinforced rubber compounds with vegetable-based oils, modified palm oils, i.e. epoxidized palm oil (EPO) and aminemodified EPO (m-EPO), are investigated in this work. This chapter gives information about the preparation of the modified palm oils and the characterization of their chemical structures. Due to an increase of polarity in the oil molecules, the effect of the chemical structures of oils on the silanization reaction is also investigated by using a model study.

CHAPTER 7 - Due to the effect of polarity in the EPO oil structures, the mixing procedures or sequences that are applied for preparing the silica-reinforced rubber compounds are of interest. The effect of various mixing sequences on the properties of the rubber compounds are elaborated in this chapter. Based on the mixing sequence that gives the best properties, the effect of oxygen oxirane levels in the EPO oils on the properties of rubber compounds is thereafter studied by taking the compounds with TDAE and without oil as references.

CHAPTER 8 - This chapter reports comparative studies of the influence of EPO and EPO modified by N-phenyl-p-phenylenediamine (m-EPO) as process oils on the properties of rubber compounds, compared to the reference compounds having TDAE and no oil. The properties of the rubber compounds, i.e. complex viscosity, Payne effect, cure characteristics, tensile and dynamic mechanical properties, are discussed.

CHAPTER 9 - This chapter summarizes all the findings and knowledge derived from the experimental studies. 


\subsection{REFERENCES}

${ }^{[1]}$ R. Rauline, E.P. Pat 0501227A1, (Feb. 2, 1992).

${ }^{[2]}$ H.-D. Luginsland, W. Niedermeier, Rubber World, 228, 34 (2003).

${ }^{[3]}$ J. Neubauer, Tire Technol. Int., p. 10-12 (2009).

${ }^{[4]}$ D.E. Hall, J.C. Moreland, Rubber Chem. Technol., 74, 525 (2001).

${ }^{[5]}$ U. Goerl, A. Hunsche, A. Mueller, H.G. Koban, Rubber Chem. Technol., 70, 608 (1997).

${ }^{[6]}$ J.W. ten Brinke, S.C. Debnath, L.A.E.M. Reuvekamp, J.W.M. Noordermeer, Compos. Sci. Technol. 63, 1165 (2003).

${ }^{[7]}$ K-J. Kim, J. VanderKooi, Rubber Chem. Technol. 78, 84 (2005).

${ }^{[8]}$ S. Mihara, R.N. Datta, A.G. Talma, J.W.M. Noordermeer, U.S. Pat 7923493B2, (Apr. 12, 2011).

[9] T.A. Okel, Rubber World. 244, 30 (2011).

${ }^{[10]}$ Internet page, http://www.atsdr.cdc.gov/toxfaqs/tfacts171.pdf, (May 23, 2014).

${ }^{[11]}$ Internet page, http://www.epa.gov/ttnatw01/hlthef/aniline.html, (May 25, 2014).

${ }^{[12]}$ H.-M. Issel, L. Steger, A. Bischoff, Kautsch. Gummi Kunstst. 58, 529 (2005).

${ }^{[13]}$ W. Kaewsakul, K. Sahakaro, W.K. Dierkes, J.W.M. Noordermeer, Kautsch. Gummi Kunstst. 66, 33 (2013).

${ }^{[14]}$ S. Mihara, "Reactive Processing of Silica-Reinced Tire Rubber: New Insight Into the Time- and Temperature-Dependence of Silica Rubber Interaction”, PhD. Thesis: 2005, Dept. of Rubber Technology, Univ. of Twente, Enschede, the Netherlands.

${ }^{[15]}$ Internet page, http://www.kemi.se/Documents/Publikationer/Trycksaker/Rapporter/Rapport5_03.pdf, (October 8, 2013).

${ }^{[16]}$ Directive 2005/69/EC, Off. J. Eur. Union L323, 51 (2005).

${ }^{[17]}$ Commission Regulation (EC) No 552/2009, Off. J. Eur. Union L164, 7 (2009).

${ }^{[18]}$ Internet page, https://www.goodyear.ca/en-CA/company/tire-technology/green-tires, (August 17, 2018)

${ }^{[19]}$ C. Flanigan, L. Beyer, D. Klekamp, D. Rohweder, D. Haakenson, Rubber and Plastics News. 15 (2013). 


\section{AN OVERVIEW OF SILICA-REINFORCED RUBBER COMPOUNDS WITH SAFE COMPOUNDING INGREDIENTS}

\subsection{INTRODUCTION}

Gum or unfilled rubbers are seldom used due to their low performance, i.e. lack of hardness, strength properties and abrasion resistance, to fulfill practical requirements for many applications especially for tires. In order to enhance the properties, several types of fillers are utilized in the rubber compounds. The classification of fillers employed in rubber formulations is shown in Figure. 2.1.

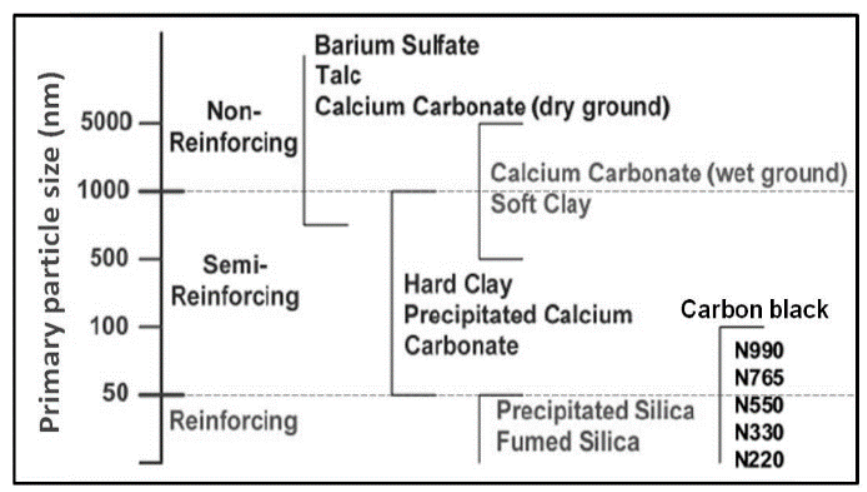

Figure 2.1 Classification of fillers based on the size of the primary filler particles. ${ }^{[1]}$

The reinforcement efficiency by incorporating the filler particles into the rubber compounds is dependent on many factors, such as particle surface activity, particle size, specific surface area, and filler structure. ${ }^{[2-3]}$

Particle surface activity: The surface nature of the fillers used in the rubber compounds is of either active or inactive type. The silica surface consists of highly polar silanol groups that are active to react with other functional groups and can form strong hydrogen bonding between silica particles themselves. The silanol groups on the silica surface enable the reaction with a silane coupling agent to enhance filler-rubber interaction and to finally chemically bond to rubber molecules via silane bridges. In case of carbon black, the surface consists of only a very small amount of polar functional groups such as carboxyl, quinone, lactone, phenol and hydroxyl groups where these functional groups have almost a 
negligible effect on the reinforcement efficiency. The reinforcement of rubber compounds by carbon black is derived from the much weaker interactions between the carbon black surface and rubber molecules via physical adsorption and mechanical interlocking.

Particle size and specific surface area: The most important parameter for the reinforcement efficiency is the primary particle size of the filler materials. According to Figure 2.1, there are three groups of fillers, i.e. non-reinforcing, semi-reinforcing and reinforcing fillers. The smaller particle sizes give higher reinforcement efficiency. The fillers with particle size over $1000 \mathrm{~nm}$ are classified as non-reinforcing fillers, while a filler size in the range of $50-1000 \mathrm{~nm}$ is categorized as semi-reinforcing. Silica and carbon black that have very small primary particle size, i.e. lower than $50 \mathrm{~nm}$, are classified as a reinforcing filler. The specific surface area of fillers relates to the particle size, that is a reduction in particle size increases the specific surface area. The specific surface area of fillers is generally determined by using the BrunauerEmmett-Teller (BET) adsorption method. The BET method based on nitrogen adsorption provides the outer geometrical surface and inner surface which is the surface within the porous structure. In addition to the BET, the Cetyl-Trimethyl-Ammonium Bromide (CTAB) method is applied to evaluate the surface area especially for silica while the size of a CTAB molecule is similar to that of a silane coupling agent. The $\mathrm{CTAB}$ method is useful to characterize the outer surface of silica due to the bulky nature of the molecule of CTAB, as shown in Figure 2.2. ${ }^{[4]}$

Filler structure: Even though silica and carbon black have a very small particle size, they occur mainly in agglomerate and aggregate forms due to interaction between adjacent particles. The aggregate and agglomerate forms are described as "structure". The higher structure gives more potential to promote filler-rubber interaction and so reinforcement.
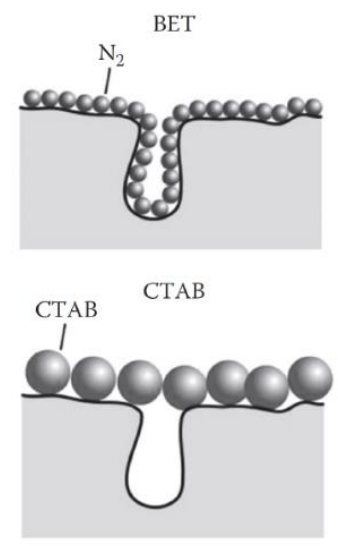

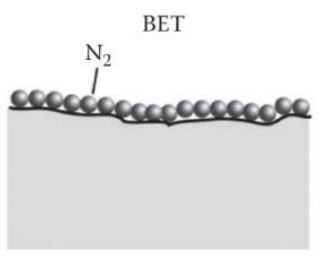

C'ТАB

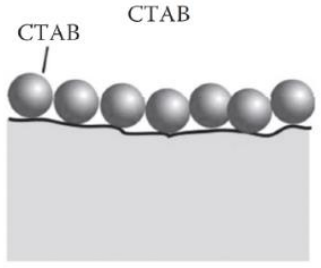

Figure 2.2 Difference of nitrogen $\left(\mathrm{N}_{2}\right)$ and CTAB adsorption on porous and nonporous silica. ${ }^{[4]}$ 
The reinforcing fillers for tire rubber compounds are carbon black and silica. Carbon black has been conventionally used as reinforcing filler for more than a century. Later, the innovation of the "Green Tire" by Michelin led to a new facet of tire technology. ${ }^{[5]}$ Silica-reinforced tire tread compounds show lower rolling resistance and better wet traction while maintaining the abrasion resistance when compared to carbon black-filled tire compounds, as shown in Figure 2.3. ${ }^{[6]}$ A reduction of rolling resistance of about $20 \%$ of a silica-filled tire tread rubber compared to one with carbon black can save $3-6 \%$ of fuel. ${ }^{[7-8]}$

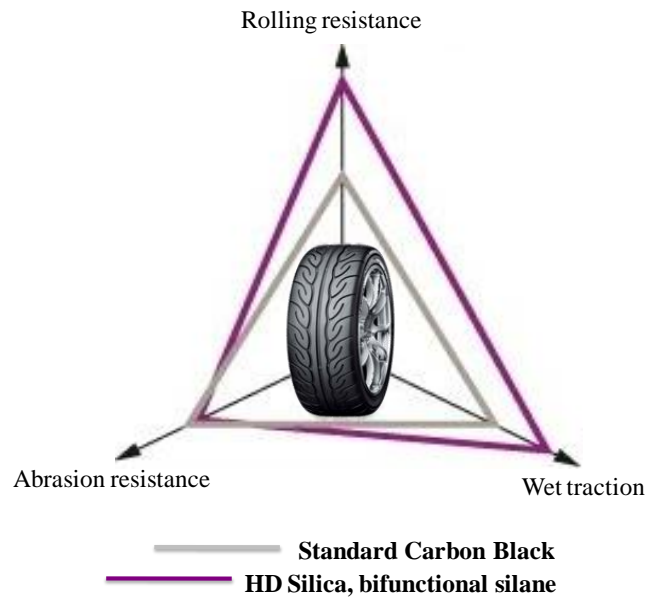

Figure 2.3 Magic triangle of tire performances of tread compounds with carbon black and silica. ${ }^{[6]}$

\subsection{SILICA AS REINFORCING FILLER}

\subsubsection{SILICA CHARACTERISTICS}

The surface chemistry of silica can be characterized by several methods, such as nuclear magnetic resonance spectroscopy (NMR) and infrared spectroscopy (IR), to determine the functional groups contained therein. It has been shown that the silica surface contains a large number of siloxane and silanol groups in different configurations, i.e. isolated-, geminal-, and vicinal silanols, as shown in Figure 2.4; ${ }^{[4,9-}$ 11]

- Isolated silanol group: a single hydroxyl group on a silicon atom;

- Vicinal silanol group: two hydroxyl groups on adjacent silicon atoms;

- Geminal silanol group: two hydroxyl groups on the same silicon atom;

- Siloxane: one oxygen atom bonded to two silicon atoms. 

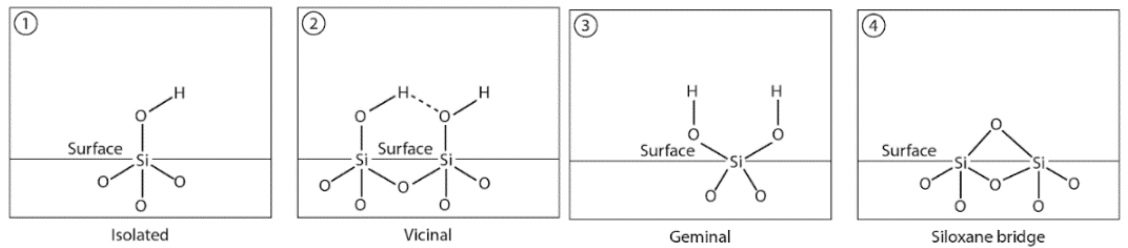

Figure 2.4 Surrounding of Si in silica: isolated, vicinal and geminal silanols; siloxane bridges. ${ }^{[4]}$

The dimension of the primary particle of silica is about $20 \mathrm{~nm}$. However, due to the highly polar silanol groups on the silica surface, the silica particles easily form interactions with adjacent particles via hydrogen bonding to generate aggregates and agglomerates. The silica particles form aggregates or "string of pearl" structures with dimensions of 50-500 nm. The dimension of a silica agglomerate or silica cluster which is formed by combination of aggregates is in a range of $1-100 \mu \mathrm{m}$, as shown in Figure 2.5. ${ }^{[12]}$ The silica aggregate structure in which primary silica particles are connected to each other, as determined by transmission electron microscope (TEM), is shown in Figure 2.6.

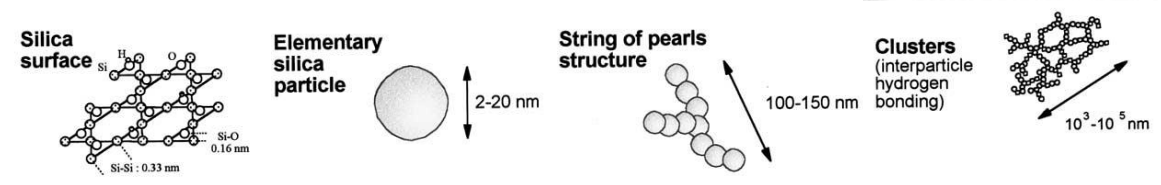

Figure 2.5 Structures of silica particles, agglomerates and aggregates. ${ }^{[12]}$

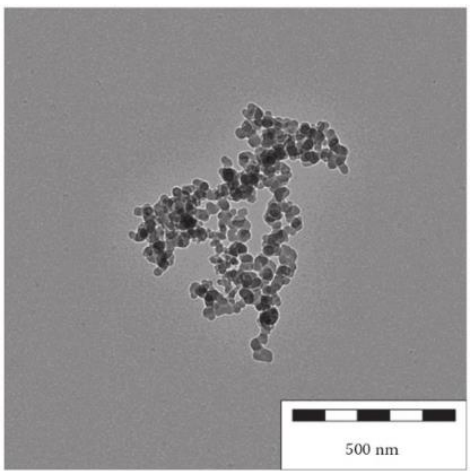

Figure 2.6 TEM image of silica aggregate. ${ }^{[4]}$ 


\subsubsection{SILANE TECHNOLOGY}

Because of the highly polar functional groups on the silica surface, and the hydrocarbon nonpolar Natural Rubber (NR), the compatibility of silica and NR is very poor. Simple mixing of silica into NR gives not only very poor dispersibility of silica in the NR matrix, but also inferior overall properties. Therefore, enhancement of compatibility between the two is required, for which silane coupling agents, especially bis(TriEthxoySilylPropyl) Tetrasulfide (TESPT), are commonly used. The bifunctional groups on TESPT molecules, i.e. ethoxy and tetrasulfide, can react with the silica surface and NR molecules during mixing and vulcanization, respectively.

\subsubsection{SILANIZATION REACTION}

The reaction between silane and silica, the so-called silanization reaction, is quite complicated as primary and secondary condensation reactions take place. The primary reaction can proceed via two pathways either by direct condensation between the silanol groups of the silica surface with the alkoxy group of TESPT or by hydrolysis of the alkoxy group of TESPT to form a reactive hydroxyl group prior to the condensation reaction, as exhibited in Figure 2.7(A). Both pathways release ethanol as byproduct. The secondary reaction occurs between adjacent TESPT molecules on the filler surface, as shown in Figure 2.7(B). ${ }^{[13-14]}$

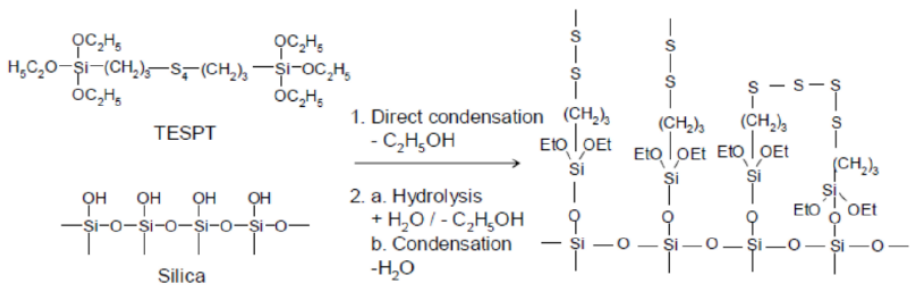

(A) Primary reaction mechanism of silica with TESPT
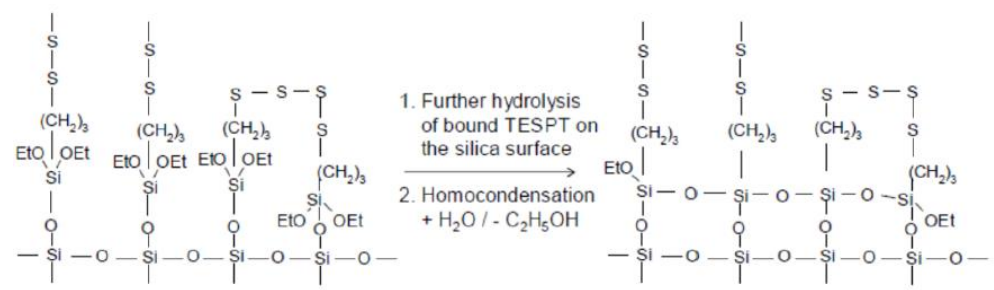

(B) Secondary reaction mechanism of silica with TESPT

Figure 2.7 Mechanism of silanization reaction between TESPT and silanol groups on the silica surface. [13] 
Recently it has been reported that only the isolated and geminal silanol groups on the silica are involved in the silica-silane reaction, and that only approximately $25 \%$ of the $\mathrm{Si}-\mathrm{OH}$ groups react with silanes due to limited accessibility of the other silanol groups for incoming silane molecules. ${ }^{[15]}$ Based on molecular modeling using a (3-mercaptopropyl)triethoxysilane (Si263) silane coupling agent, two molecules can only react with two silanol groups at a distance higher than $0.4 \mathrm{~nm}$, so the number of silanes grafted on the silica surface is limited. The additional use of small molecules such as alcohols and amines or of silanes with high shielding potential to increase the hydrophobation of the silica surface is therefore beneficial. ${ }^{[16]}$

\subsubsection{COUPLING REACTION}

During the vulcanization reaction, the coupling reaction between the sulfur moiety in the silane molecules and the rubber chains takes place through reactive sulfur that is generated by disproportionation of TESPT or elemental sulfur added into the compounds, as schematically shown in Figure 2.8. The reaction between the silane and rubber that occurs during vulcanization completes the silica-silane-rubber coupling and gives rise to strong filler-rubber interactions, resulting in maximum reinforcement. ${ }^{[14]}$ Previous studies reported that the coupling reaction between the sulfur atom in the TESPT-silane coupling agent and natural rubber molecules occurs at high temperature, i.e. higher than $120^{\circ} \mathrm{C}$, and the reaction rate clearly rises with increasing temperature. ${ }^{[17-18]}$

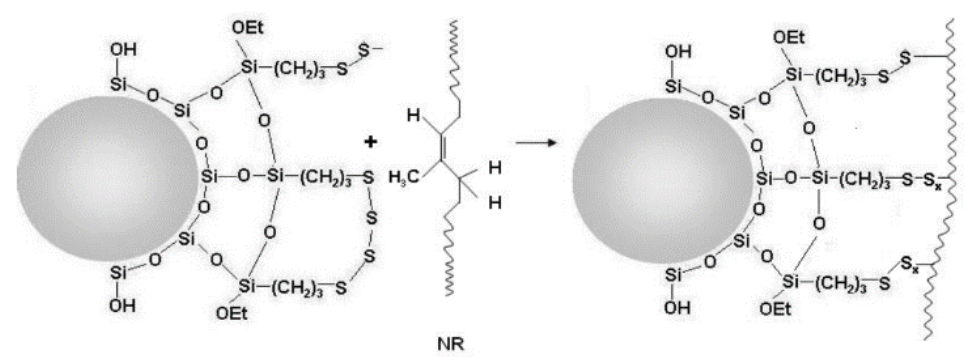

Figure 2.8 Silica-silane-rubber bridge formation ${ }^{[19]}$

\subsubsection{AMINES AS SILANIZATION BOOSTERS}

In order to enhance the silanization reaction which is a condensation reaction in nature, a catalyst is necessary in order to have an efficient reaction within the time frame of a mixing cycle. An acid catalyst is not a choice for rubber compounds as it retards the vulcanization reaction later on. Basic substances like amines are therefore the preferred candidates. The amines catalyze the condensation reaction between the $\mathrm{Si}-\mathrm{OH}$ on the silica surface and the alkoxy groups in the TESPT molecules. The catalyzed condensation reaction occurs after the amine entered into interaction with the silanol groups on the silica surface via 
hydrogen bonding, enhancing more nucleophilicity on the silica surface. Thus, the silica surface can interact easier with the silicon atom in the TESPT molecule that leads to the condensation reaction. This role of an amine as catalyst for the silanization reaction is depicted in Figure 2.9. ${ }^{[20-23]}$ In addition, the hydrolysis of the silane can readily occur under basic condition. Thus, amines provide a catalytic effect on the hydrolysis of alkoxy groups in the silane molecules to form reactive hydroxyl moieties prior to the condensation reaction. In the presence of amine and water, a hydroxyl ion $\left(\mathrm{OH}^{-}\right)$is formed, and $\mathrm{EtOH}$ is released from the TESPT molecules via a pentacoordinate intermediate, forming $\mathrm{Si}-\mathrm{OH}$, as shown in Figure 2.10. ${ }^{\text {[24-25] }}$

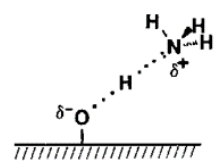

A

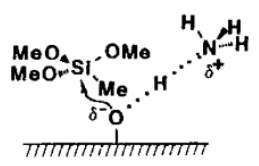

B

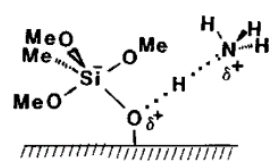

C

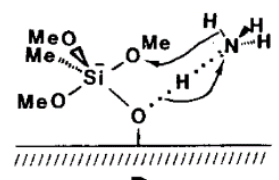

D

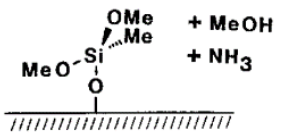

E

Figure 2.9 Mechanism of silanization reaction with amine as silanization catalyst. ${ }^{20]}$

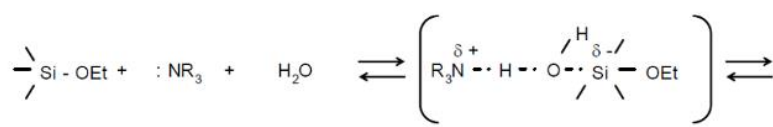

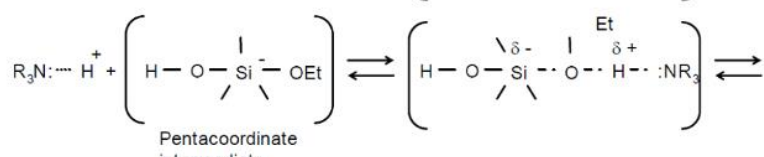

$$
\begin{aligned}
& \frac{1}{1} \mathrm{Si}-\mathrm{OH}+: \mathrm{NR}_{3}+\mathrm{EtOH}
\end{aligned}
$$

Figure 2.10 Mechanism of hydrolysis of alkoxy group in silane molecules. [25] 


\subsubsection{SILANIZATION KINETICS}

The kinetics of the silanization reaction can be studied by utilizing model compounds. The silanization reaction comprises a primary and secondary step in which the primary reaction between the ethoxy groups in the TESPT molecules and silanol groups on the silica surface releases ethanol (EtOH) ${ }^{[13]}$

Primary silanization reaction: The evolution of ethanol can be linked to the primary silanization reaction, assuming that 1 mole of TESPT releases 2 moles of ethanol. The primary silanization reaction is then described by Equation (2.1) as follows:

$$
-\frac{d[T E S P T]}{d t}=k_{a}[T E S P T]=\frac{1}{2} \frac{d[E t O H]}{d t}
$$

Where $[T E S P T]$ is the concentration of TESPT, $[E t O H]$ is the concentration of EtOH, $t$ is time in minutes and $k_{a}$ is the rate constant of the primary silanization reaction.

Based on an assumed first order primary silanization reaction rate constant, the activation energy of the reaction can be calculated by using Equation (2.2):

$$
\ln k_{a}=\ln A-\frac{E_{A}}{R T}
$$

Where $A$ is the Arrhenius factor, $E_{a}$ is the activation energy in $\mathrm{kJ} / \mathrm{mol}, R$ is the gas constant, and $T$ is temperature in $\mathrm{K}$.

Secondary silanization reaction: There are three possible reaction paths in this step. However, the overall reaction rate constants are assumed to have similar values. The overall reaction can be described as follows;

$$
\begin{gathered}
\frac{d[E t O H]}{d t}=2 k_{a}[T E S P T]+k_{b}[Z 1]+k_{b}[Z 2]+k_{b}[Z 3] \\
\ln k_{b}=\ln A-\frac{E_{A}}{R T}
\end{gathered}
$$

Where [Z1], [Z2] and [Z3] are concentrations of intermediate products and $k_{b}$ is the rate constant of the secondary silanization reaction.

Goerl et al. (1997) studied the silanization reaction of TESPT and silica by using a model compound. It was reported that the primary silanizaion reaction is about 10-20 times faster than the secondary silanization reactions. The activation energy can be evaluated from a plot of $\ln k_{a}$ versus $1 / R T$. The activation energy of the primary silanization reaction was equal to $47 \mathrm{~kJ} / \mathrm{mol}$, while the activation 
energy of the secondary silanization reactions was equal to $28 \mathrm{~kJ} / \mathrm{mol}$. ${ }^{[13]}$ In the presence of amines as silanization booster, the silanization reaction of TESPT and silica could be boosted up to 5 times faster when compared to a system without amine. ${ }^{[26]}$

\subsection{SAFE COMPOUNDING INGREDIENTS}

\subsubsection{ALTERNATIVES FOR DIPHENYL GUANIDINE (DPG)}

DiPhenyl Guanidine (DPG) is widely used in rubber compounds as a secondary accelerator in combination with sulfenamide primary accelerators, such as N-Cyclohexyl-2-Benzothiazole Sulfenamide (CBS), in sulfur vulcanization systems due to the fact that the DPG provides a synergistic effect for the curing reaction. The DPG itself gives a short scorch time but slow cure rate, while the CBS provides a long scorch time but fast cure rate, as shown in Figure 2.11. The combination of CBS and DPG leads to rubber compounds with some delay actions to provide its scorch safety with short cure times and fast cure rate.

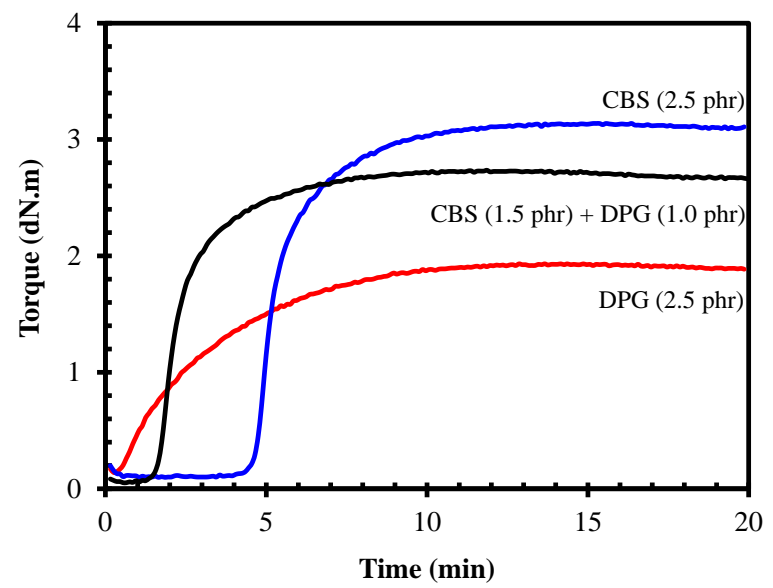

Figure 2.11 Cure behaviors of unfilled NR compounds with different accelerators.

As discussed earlier, an alkaline catalyst can promote the silanization reaction. DPG is widely used in rubber compounds, especially in silica-filled rubber compounds, due to the fact that the DPG gives an additional effect which is more than just being the secondary accelerator for the vulcanization reaction. That is, the DPG can promote the silanization reaction and also deactivate free silanol groups that are left over after the silanization reaction. Liu et al. (2017) studied the kinetics of the silanization reaction of silica and TESPT using DPG as catalyst. In this study it was shown that the use of DPG promotes both reaction pathways of the silanization, i.e. the hydrolysis of the TESPT followed by the condensation reaction and the direct condensation reaction of TESPT and silica. DPG could decrease the activation energy of the condensation reaction from $90.4 \mathrm{~kJ} / \mathrm{mol}$ to $70.8 \mathrm{~kJ} / \mathrm{mol}$. The mechanism of the silanization reaction using DPG as catalyst is shown in Figure 2.12. ${ }^{[27]}$ 


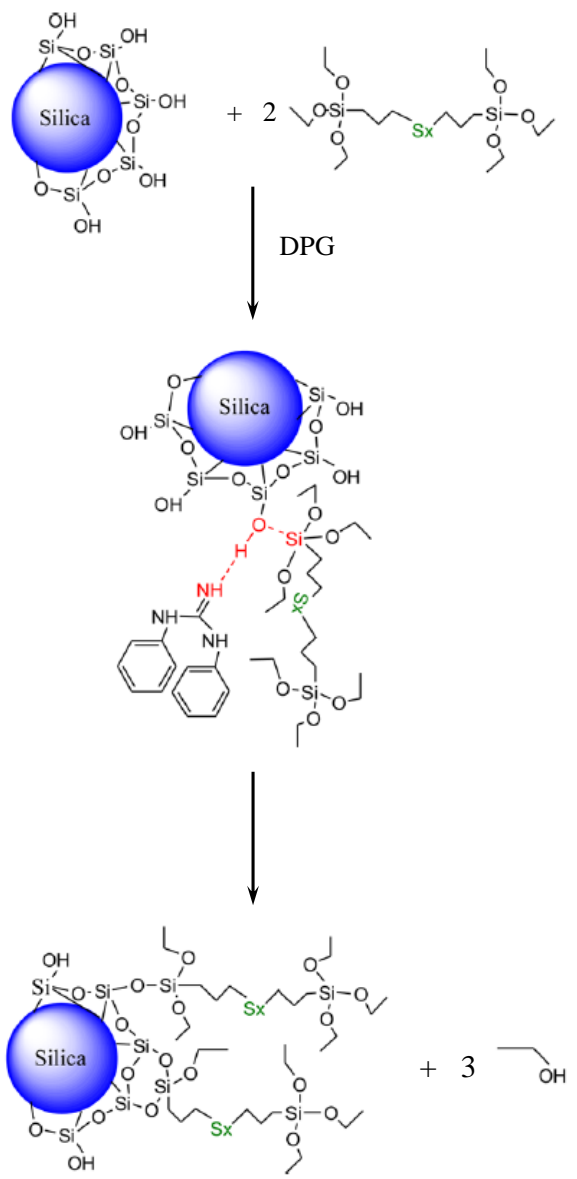

Figure 2.12 Mechanism of the silanization reaction between silanol groups on the silica surface and TESPT using DPG as a silanization catalyst. ${ }^{[27]}$ 

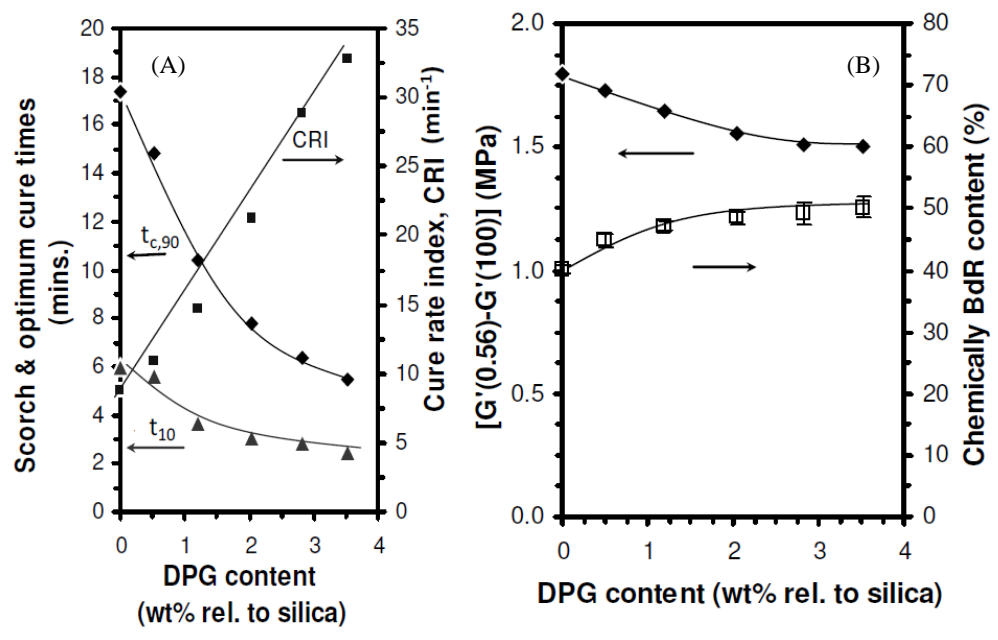

Figure 2.13 Properties of silica-filled rubber compounds with different DPG contents, (A) cure characteristics and (B) Payne effect and chemically bound rubber content. ${ }^{[28]}$

For the silica-filled natural rubber compounds, the cure rate index and chemically bound rubber content increase with increasing DPG contents, while the scorch time, cure time and Payne effect decrease, as shown in Figure 2.13. This evidence confirms that the DPG can promote the silanization reaction as indicated by the increased filler-rubber interaction and the decreased filler-filler interactions. ${ }^{[18,28]}$ However, DPG can liberate toxic aniline at high mixing temperatures ${ }^{[29]}$ classified as a probable carcinogen. ${ }^{[30]}$ The release of aniline from the decomposition of DPG at high temperature is illustrated in Figure 2.14 based on GC analysis. ${ }^{[31]}$ Aniline shows its peak at 6.5 mins while DPG appears at 21 mins. The integrated peak area is related to the concentration of each corresponding substance. Figure 2.15 shows that the concentration of aniline generated is dependent on temperature and a substantial amount of aniline can readily be observed above a temperature of $130^{\circ} \mathrm{C}$. The rate of liberated aniline rises with increasing temperature. ${ }^{[31]}$ For silica-silane-rubber mixing that requires a high temperature for the silanization, it is therefore unavoidable for aniline to be generated from DPG and so a safe alternative is needed. 


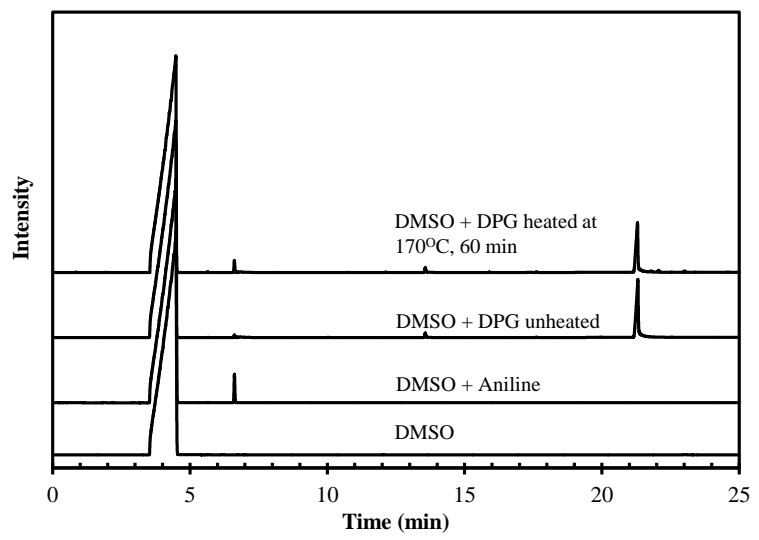

Figure 2.14 GC results showing aniline liberation from DPG.
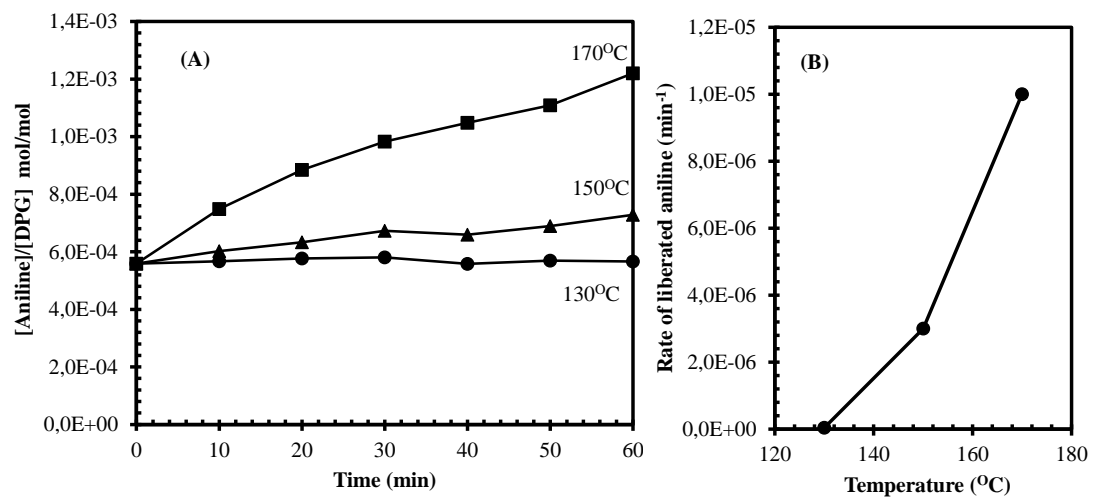

Figure 2.15 Concentration of aniline under heating DPG at 130,150 and $170^{\circ} \mathrm{C}$ with different times (A) and the rate constant of aniline liberation (B).

Mihara (2005) studied the effect of several amines and amine derivatives which have different $\mathrm{pK}_{\mathrm{a}}$ values, i.e. quinuclidine ( $\mathrm{Q}$-ine) $\left(\mathrm{pK}_{\mathrm{a}}=11.5\right)$, ethylenediamine (E-ine) $\left(\mathrm{pK}_{\mathrm{a}}=10.7\right)$, 3-quinuclidinol (Qnol) $\left(\mathrm{pK}_{\mathrm{a}}=10.1\right), 1,3$-diphenylguanidine (DPG) $\left(\mathrm{pK}_{\mathrm{a}}=10.1\right)$, 1,4-diazabicyclo[2,2,2]octane (D-ane) $\left(\mathrm{pK}_{\mathrm{a}}=8.80\right)$, picolinic amine (P-nic) $\left(\mathrm{pK}_{\mathrm{a}}=7.70\right), 2$-picoline (P-ine) $\left(\mathrm{P}-\left(\mathrm{pK}_{\mathrm{a}}=5.90\right)\right.$, picolinic acid (P-cid) $\left(\mathrm{pK}_{\mathrm{a}}=4.40\right)$ and picoline-N-oxide $(\mathrm{P}-\mathrm{ide})\left(\mathrm{pK}_{\mathrm{a}}=1.30\right)$, on the kinetic parameters of the silanization reaction between TESPT and silica in a model olefin system. Based on the kinetic parameters such as the reaction rate and activation energy according to the Arrhenius equation, the results show that the rate constants of the primary and secondary silanization reactions when amines or amine derivatives having higher $\mathrm{pK}_{\mathrm{a}}(>$ 6.5) were used tended to increase and the activation energy to decrease. This means that the presence of 
amines or amine derivatives having high $\mathrm{pK}_{\mathrm{a}}$ values accelerates the silanization reaction. Quinuclidine and 3-quinuclidinol showed a high silanization rate, as illustrated in Figure 2.16. [26]
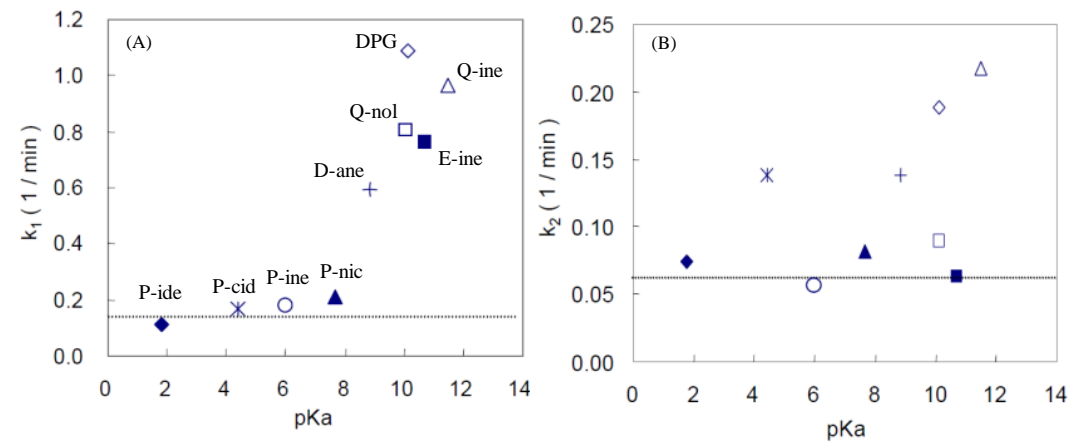

Figure 2.16 Rate constants of primary and secondary silanization reactions of silica/silane systems with different amine types.

The quinuclidine (Q-ine) and 3-quinuclidinol (Q-nol) which have similar $\mathrm{pK}_{\mathrm{a}}$ values as DPG were then applied in silica-filled SBR/BR blends tire tread compounds. The results showed that the scorch times of rubber compounds with quinuclidine and 3-quinuclidinol decreased whereas it increased with increasing amounts of the secondary accelerators when these amines were mixed in the first mixing step. The results indicated that DPG was consumed during mixing due to interactions between DPG and the silica surface. It has been previously reported that DPG was easily adsorped onto the silica surface. ${ }^{[32]}$ The bound rubber content increased and the Payne effect and $\tan \delta$ at $60^{\circ} \mathrm{C}$ decreased with increasing amounts of the secondary accelerators in the silica-filled SBR/BR compounds. The two amines: Q-ine and Q-nol showed lower $\tan \delta$ at $60^{\circ} \mathrm{C}$ compared to DPG, which would indicate lower rolling resistance of tires made thereof. ${ }^{[26]}$

An alternative for DPG in silica-filled rubber compounds was also reported by Debnath et al. ${ }^{[33]}$ based on their work on naturally occurring amino acid L-cystine (L-cys) and its derivative Lcystine dimethyl ester dihydrochloride (ELCH) in solution styrene budiene rubber (SSBR). ELCH was found to provide the properties, including tensile strength, modulus, maximum torque, elongation at break in the gum vulcanization as well as in the silica-filled compounds, closed to standard DPG. In this work, the roles of DPG in promoting silanization and accelerating the vulcanization reaction in the presence of CBS as primary accelerator were also discussed. The adsorption of DPG and ELCH on the silica surface by hydrogen bonding that limits CBS adsorption onto silica resulting in better cure behaviors and decreased filler-filler interactions. 
In addition to amines or amine derivatives, dithiophosphates (DTP), i.e. bis(ethylhexylphosphoryl) polysulfide (SDT) and zinc dibutyldithiophosphate (TP) were studied as secondary accelerators in silica-filled NR compounds by Kaewsakul et al. (2013). ${ }^{[18,34]}$ The combination of sulfenamide accelerator and dithiophosphate raised the crosslink density and lowered the polysulfidic proportion in the compounds. Therefore, dithiophosphate gave advantages in terms of reversion resistance and aging properties in accordance with the work previously reported by Issel et al. (2005) ${ }^{[35]}$ in which dithiophosphate was investigated in silica-filled SBR/BR/NR blend compounds. It showed that zincdithiophosphate could effectively reduce filler-filler interactions in the compounds as attributed to network contributions which include filler-rubber interactions and rubber-rubber linkages. It was proposed that the dipolar zinc soap of TP would easily partially attach to the polar silica surface, and then the alkoxy groups of dithiophosphate would react with the silanol groups of the silica contributing to the silanization reaction. The sulfur atom on the other side of the dithiophosphates molecules then potentially reacts with rubber molecules, leading to silica-rubber bridge formation as shown in Figures 2.17 and 2.18. In the case of SDT with a polysulfidic structure, it can liberate free sulfur to the system under high thermal mixing conditions and produce a higher extent of network contributions. Based on the mechanical and dynamic mechanical properties, DTP and DPG provide comparable overall properties.
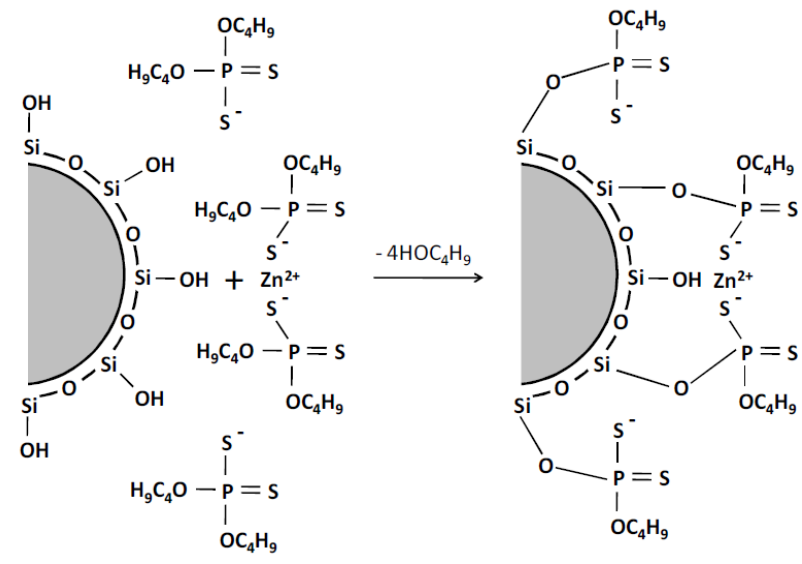

Figure 2.17 Postulated reactions between silica and zinc dithiophosphate. ${ }^{[34]}$ 


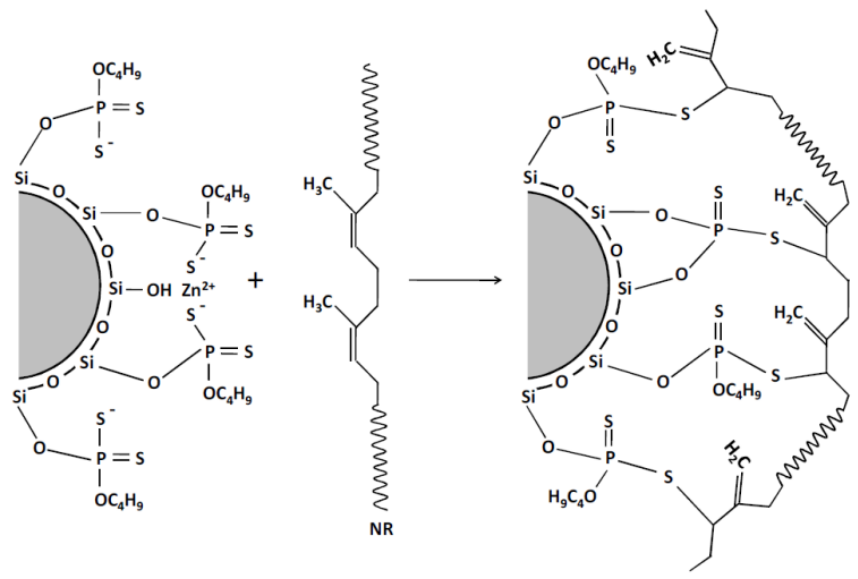

Figure 2.18 Proposed coupling reaction of zinc dithiophosphate towards silica and natural rubber. ${ }^{[34]}$

\subsubsection{ALTERNATIVES FOR PETROLEUM-BASED PROCESS OILS}

The process oils used in rubbers/polymers can be named differently, such as softeners, plasticizers, and extenders depending on their roles or functional applications. ${ }^{[36]}$ Plasticizers are divided into two groups according to the plasticizing action; primary and secondary plasticizers that are termed according to their solvating power and compatibility with polymers. Primary plasticizers exhibit good compatibility with polymers, whereas secondary plasticizers show only partial compatibility with the polymers and cannot be used alone. In the presence of a primary plasticizer, the use of secondary plasticizer should enhance the plasticizing performance. ${ }^{[37-39]}$ It is known that plasticizers are required for rubber compounds with high filler loading to improve processibility and also to give better filler dispersion in the rubber matrix which will finally enhance the properties of the filled rubber vulcanizates.

The mechanism of plasticizer action has been proposed by using four main theories, i.e. lubricity, gel, free volume, and mechanistic theories to explain the phenomenon of plasticizers in the polymeric materials. ${ }^{[40]}$

Lubricity theory: The lubricity theory states that plasticizers act as lubricant between polymer molecules. As a polymer is flexed, it is believed that their molecules glide back and forth with the plasticizer providing the gliding planes, as shown in Figure 2.19. The theory assumes that the polymer molecules have, at most, very weak bonds away from their crosslinked sites. In this theory, the plasticizer is supposed to act by reducing intermolecular friction. 


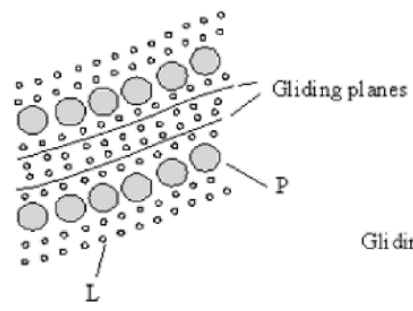

(A)

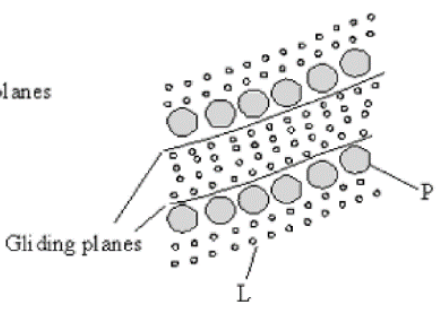

(B)

Figure 2.19 Two possibilities of gliding. ${ }^{[40]} \mathrm{P}$ is polymer and $\mathrm{L}$ is lubricant. (A) the gliding planes are in the bulk of the plasticizers and (B) the gliding planes are at the polymer-lubricant interface.

Gel theory: The gel theory is explained by a model of the polymer molecules in a three dimensional structure. The stiffness of the polymer results from a gel of weak attachments at intervals along the polymer chains that might be the result of Van der Waals forces, hydrogen bonding, or a crystalline structure. These points of gel are close together, thus, reducing molecular movement. The gel sites can interact with plasticizer, thus separating gel sites or points of attachment of adjacent polymer chains. The plasticizer by its presence separates the polymer chains allowing the polymer molecules to move more freely, as shown in Figure 2.20.
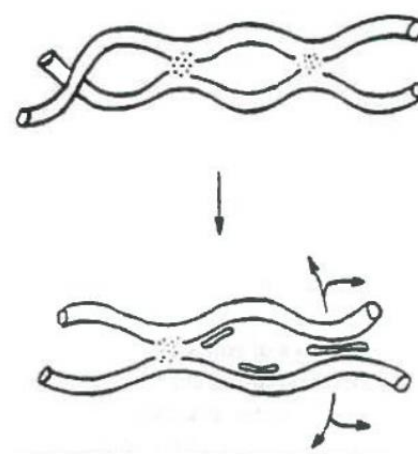

Figure 2.20 The gel theory of plasticization.

Free volume theory: The free volume theory is most widely accepted today. ${ }^{[39]}$ Free volume is the space in a solid or liquid sample which is not occupied by polymer molecules, i.e. the empty space between molecules. Addition of plasticizer to a polymer increases the free volume of the system and the free volume increases with rising temperature. An important application of the theory to external plasticization is to clarify the lowering of the glass transition temperature of a compound by a plasticizer. Because of the smaller molecular size compared to polymers, plasticizers assist with greater polymer mobility and impart a higher free volume, as shown in Figure 2.21. 


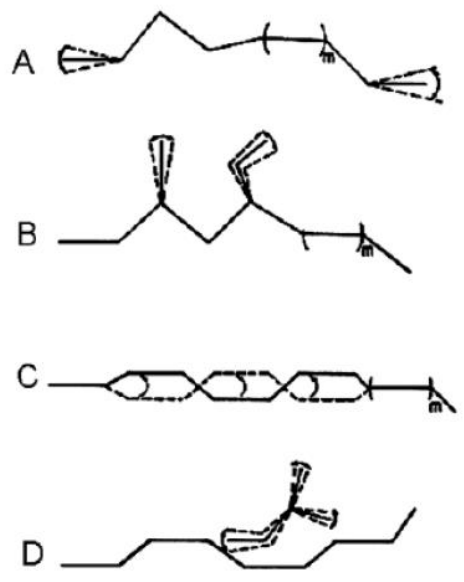

Figure 2.21 Sources of free volume for plasticization. ${ }^{[40]}$ (A) chain end motion, (B) side chain motion, (C) main chain movement and (D) external plasticizer motion.

Mechanistic theory: The mechanistic theory of plasticization (also referred to as solvationdesolvation equilibrium) supplements the other three theories as previously discussed. This theory can be depicted as having some resemblance to the gel theory. The essential difference is that in the gel theory, the plasticizer stays attached to a site along the polymer chain, whereas the mechanistic theory states that the plasticizer can move from one polymer location to another or can exchange with other plasticizer molecules, i.e. the plasticizer can exchange in an equilibrium mechanism of solvation-desolvation with the polymer.

\subsubsection{PETROLEUM-BASED PROCESS OILS}

Oils that are generally added into rubber compounds can be divided into 3 types of different chemical structures, i.e. unsaturated rings (aromatic), saturated rings (naphthenic) and saturated side chains (paraffinic) as shown in Figure 2.22. The most widely used process oils are Paraffinic, Naphthenic and Aromatic oils.

Paraffinic oils: The major composition of paraffinic oils is highly isoparaffinic molecules. This oil type contains similar amounts of monoaromatics, but much lower amounts of multi-ring aromatics when compared to aromatic oils. They have more oxidative stability than the naphthenic and aromatic oils.

Naphthenic oils: The amount of saturated rings in naphthenic oils is higher than those in aromatic and paraffinic oils. However, the naphthenic oils contain similar amounts of unsaturated side chains compared to aromatic oils.

Aromatic oils: These oils contain high amounts of unsaturated aromatic moieties, i.e. single- and multi-rings. They have lower oxidation stability and higher reactivity compared to the two other oil types. 


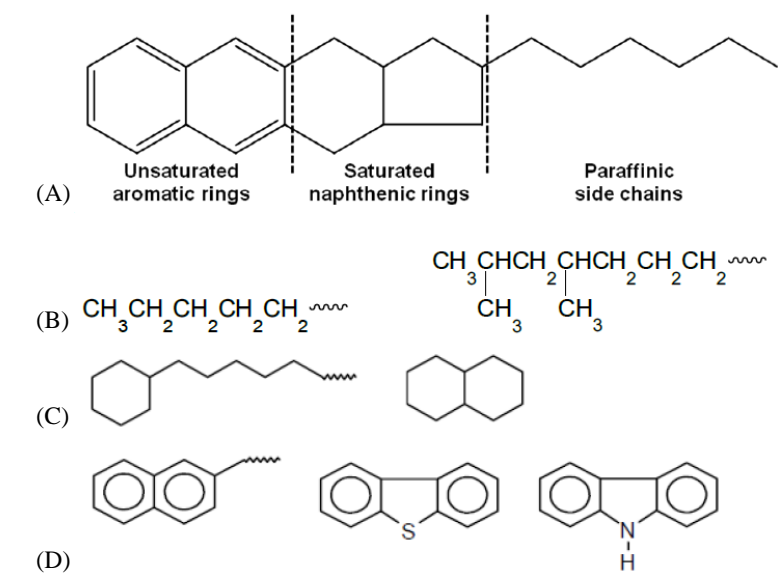

Figure 2.22 Typical molecular groups in process oils ${ }^{[41]}(\mathrm{A})$ and examples of various components in process oils (B-D): (B) paraffins and isoparaffins, (C) derivatives of cyclohexane or decalin, and (D) derivatives of naphthalene, dibenzothiophene and carbazole.

The compatibility of polymers and plasticizers determines the choice of plasticizer type for materials. Compatibility is the ability of a plasticizer to form a homogeneous system with the polymer. Hence, the rule "like dissolves like" was the earliest compatibility concept. ${ }^{[40]}$ Because the conventional petroleum-based process oils, such as aromatic and naphthenic oils, are not only well compatible with natural and synthetic rubbers but also inexpensive, these oils especially the aromatic oils are widely used in rubber compounds. However, the highly aromatic oil, the so-called distillate aromatic extract (DAE), contains a high amount of polycyclic aromatic hydrocarbons (PAHs) of which some are classified as carcinogenic substances as reported by KEMI in 2003. So far, eight types of PAHs: Benzo[a]pyrene (BaP), Benzo[e]pyrene (BeP), Benzo[a]anthracene (BaA), Benzo[b]fluoranthene (BbFa), Benzo[j]fluoranthene $(\mathrm{BjFa})$, Benzo[k]fluoranthene (BkFa), Dibenzo[a,h]anthracene (DBahA), and Chrysene (CHR) have generally been classified as carcinogens. The structures of PAHs are shown in Figure 2.23. These substances can be released to the environment by tire wear. ${ }^{[42]}$ 


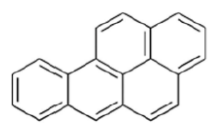

$\mathrm{BaP}$

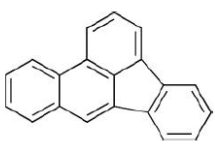

$\mathrm{BbFa}$

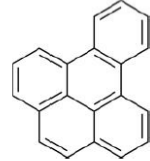

$\mathrm{BeP}$

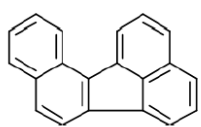

$\mathrm{BjFa}$<smiles>c1ccc2cc3ccccc3cc2c1</smiles>

$\mathrm{BaA}$

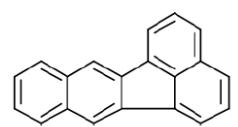

$\mathrm{BkFa}$<smiles>c1ccc2c(c1)ccc1c3ccccc3ccc21</smiles>

CHR<smiles>c1ccc2cc3c(ccc4ccccc43)cc2c1</smiles>

DBahA

Figure 2.23 Eight PAHs designated as carcinogen in Europe.

Therefore, process oils with low content of polycyclic aromatic hydrocarbons such as treated distillate aromatic extract (TDAE), mild extracted solvate (MES), and naphthenic (NAP) oils, are presently used as safe process oils in rubber compounds to replace DAE oil. The properties and amounts of aromatic components in the oils are summarized in Table 2.1. Null (1999) studied the effect of safe process oils on carbon black-filled E-SBR/BR/NR and silica-filled S-SBR/BR blends compared to the use of DAE. The results showed no drastic differences in cure properties, but MES gave a larger decrease of Mooney viscosity. No significant impact on tensile properties and hardness by the change of oil types was observed, but the use of all safe process oils improved abrasion resistance. With regard to wet grip and rolling resistance as monitored by $\tan \delta$ at $0^{\circ} \mathrm{C}$ and $60^{\circ} \mathrm{C}$ respectively, the tan $\delta$ values at $0^{\circ} \mathrm{C}$ of carbon black-filled and silica-filled vulcanizates showed different trends with oil types but $\tan \delta$ at $60^{\circ} \mathrm{C}$ showed comparable values for all safe process oils, lower than for DAE. For tan $\delta$ at low temperature of carbon black-filled compounds: $\mathrm{DAE}>\mathrm{NAP} \approx \mathrm{TDAE}>\mathrm{MES}$; whereas for silica-filled compounds: $\mathrm{DAE} \approx \mathrm{NAP}>\mathrm{TDAE} \approx$ MES. So, overall the use of MES and TDAE gave slightly poorer wet grip compared to DAE. It was reported in this work that the DAE oil contains approximately 100 times higher PAH concentrations compared to all non-carcinogenic process oils, and replacing DAE by safe process oils will reduce the PAH emissions from tires very significantly, although the carbon black reinforcing filler also brings some PAH's along. ${ }^{43]}$ 
Table 2.1 The properties of DAE, TDAE and MES oils. ${ }^{[4]}$

\begin{tabular}{|c|c|c|c|c|}
\hline Properties & $\begin{array}{l}\text { Standard test } \\
\text { method }\end{array}$ & $\begin{array}{c}\text { DAE } \\
\text { (Tudalen 6) }\end{array}$ & $\begin{array}{c}\text { TDAE } \\
\text { (VivaTec 500) }\end{array}$ & $\begin{array}{c}\text { MES } \\
\text { (VivaTec 200) }\end{array}$ \\
\hline Color & ASTM D156 & $8.0 \mathrm{D}$ & $8.0 \mathrm{D}$ & $8.0 \mathrm{D}$ \\
\hline Density at $15^{\circ} \mathrm{C}\left(\mathrm{kg} / \mathrm{m}^{3}\right)$ & ASTM D1298 & 990 & 950 & 915 \\
\hline Density at $20^{\circ} \mathrm{C}\left(\mathrm{kg} / \mathrm{m}^{3}\right)$ & & 987 & 947 & 912 \\
\hline Refractive index at $20^{\circ} \mathrm{C}$ & ASTM D1218 & 1.56 & 1.53 & 1.51 \\
\hline $\begin{array}{l}\text { Kin. Viscosity at } 40^{\circ} \mathrm{C} \\
\left(\mathrm{mm}^{2} / \mathrm{s}\right)\end{array}$ & ASTM D445 & 1240 & 410 & 210 \\
\hline $\begin{array}{l}\text { Kin. Viscosity at } 100^{\circ} \mathrm{C} \\
\left(\mathrm{mm}^{2} / \mathrm{s}\right)\end{array}$ & & 26.0 & 18.8 & 16.0 \\
\hline Flash point $\mathrm{COC}\left({ }^{\circ} \mathrm{C}\right)$ & $\begin{array}{l}\text { ASTM D92 or } \\
\text { D93 }\end{array}$ & 260 & 272 & 270 \\
\hline Pour point $\left({ }^{\circ} \mathrm{C}\right)$ & ASTM D97 & 20 & 27 & -6 \\
\hline Sulfur (wt\%) & & 1.2 & 0.8 & 0.5 \\
\hline Aniline point $\left({ }^{\circ} \mathrm{C}\right)$ & ASTM D611 & 41 & 68 & 97 \\
\hline VGC & ASTM D2501 & 0.94 & 0.89 & 0.84 \\
\hline Carbon distribution (wt\%) & ASTM D2140 & & & \\
\hline $\mathrm{C}_{\text {Aromatic }}$ & & 40 & 25 & 15 \\
\hline $\mathrm{C}_{\text {Naphthenic }}$ & & 25 & 30 & 27 \\
\hline CParaffinic & & 35 & 45 & 58 \\
\hline DMSO extract (wt\%) & IP346 & 20 & $<3$ & $<3$ \\
\hline $\begin{array}{l}\text { Glass transition temperature } \\
\left({ }^{\circ} \mathrm{C}\right)\end{array}$ & & -37 & -48 & -58 \\
\hline
\end{tabular}

The influence of non-carcinogenic PAH-low oils, i.e. TDAE, MES, and paraffinic (PAR) oils, in comparison with DAE on the properties of natural rubber and epoxidized natural rubber compounds filled with carbon black and silica was studied by considering several aspects including the compatibility between polymer and oil, processibility, cure characteristics, dynamic mechanical and physical properties. ${ }^{[45]}$ The compatibility of plasticizers with polymers was investigated by studying the impact of oil addition on the glass transition temperature $\left(\mathrm{T}_{\mathrm{g}}\right)$ and the relationship between the oil incorporation time and degree of swelling. The change of $\mathrm{T}_{\mathrm{g}}$ of the compounds is in accordance with the $\mathrm{T}_{\mathrm{g}}$ of oil and rubbers. The results showed that an increase of aromatic rings in oil structures increases the solubility parameter of the oils, that leads to a good compatibility with polar rubbers like epoxidized natural rubber ENR-25 and ENR-50, as shown by the results of higher swelling and shorter oil incorporation times. The Mooney viscosities of rubber compounds with different types of oils indicated that DAE and TDAE oils had a good plasticizing efficiency in ENR that was better than MES and PAR. For silica-filled compounds without silane, the Payne effect was improved with increasing aromatic content of the oil, but for silica-silane mixes the Payne effect remained practically unchanged with aromatic content of the oils. The use of DAE and TDAE oils in silica-silane filled NR compounds decreased $\tan \delta$ at $60^{\circ} \mathrm{C}$, which provided lower rolling resistance. For 
silica-ENR compound, the rolling resistance was not affected by oil loading and composition. With regard to wet grip, the compounds with DAE and TDAE showed better performance than those with MES and PAR. Overall, filled NR compounds were more sensitive to change of oil types than filled ENR compounds. TDAE in both NR and ENR compounds exhibited similar or even equal results to DAE confirming that TDAE is a suitable replacement for DAE.

Bowman et al. (2004) ${ }^{[46]}$ concluded that for SBR compounds, the replacement of high aromatic oil with TDAE was easier than the use of MES because of a better compatibility of SBR with TDAE compared to MES. The study on solubility parameters and swelling degrees of DAE, TDAE and MES oils in NR, SBR and their blend by Petchkaew and co-workers ${ }^{[44,47]}$ showed that the difference in solubility parameter $(\Delta \delta)$ between oil and rubber correlated well with the mass swelling at different temperatures. At high temperature, MES oil was less compatible with the rubbers compared to TDAE and DAE oils. Due to the different proportions of aromatics and saturated hydrocarbons in petroleum-based process oils, i.e. DAE, TDAE, and MES, they have different physico-chemical characteristics and so have an influence on the properties of oil-extended rubber. The change of oil types showed only a small effect on Mooney viscosity, cure characteristics and tensile properties but had a larger influence on the dynamic mechanical properties due to a shift of $T_{g}$ in accordance with the $T_{g}$ of the oils. The incorporation of DAE which has a higher $T_{g}$ than the oil-free NR, increased the $T_{g}$ of a compound, whereas the use of MES with a lower $T_{g}$ showed no effect on the $\mathrm{T}_{\mathrm{g}}$ of NR. ${ }^{[44-45,48]}$

\subsubsection{BIO-BASED PROCESS OILS}

The bio-based oils are renewable resources and potentially have a lower carbon footprint than petroleum-based oils. The basic structure of vegetable oil is a triglyceride extracted from plants, where the triglyceride is an ester derived from glycerol and three fatty acids. Triglyceride types depend on the types of fatty acids. There are many types of fatty acids occurring in vegetable oils including both saturated and unsaturated structures. An example of the chemical structure of palm oil is shown in Figure 2.24. Palmitic and oleic acid groups are the major components. The unsaturated chains in the oil structure are active for chemical reactions. It has been reported that natural oils consume some curatives in rubber compounds due to the unsaturation in the oil structures as shown in Figure 2.25, causing retardation of the cure rate and a lower crosslink density. ${ }^{[49]}$ 


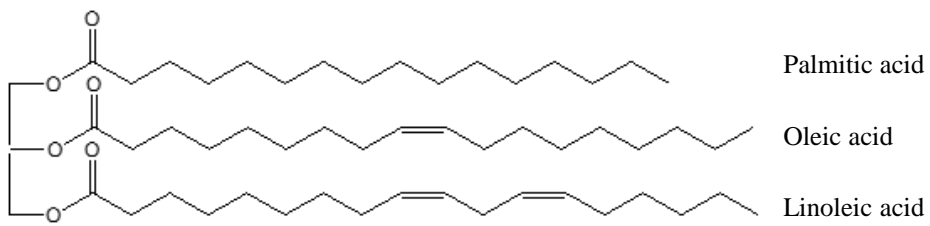

Figure 2.24 An example of the chemical structure of palm oil.

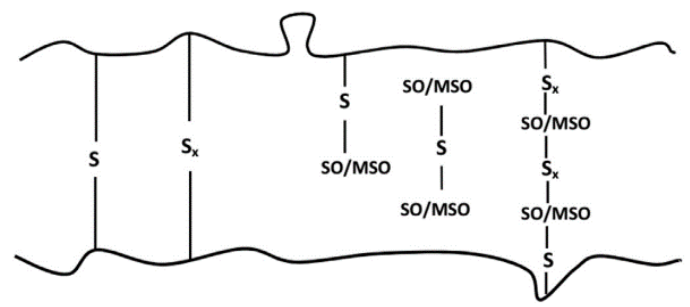

Figure 2.25 Postulated model of possible crosslinks between rubber chains and vegetable oils; where SO is a soybean oil molecule and MSO is a modified soybean oil molecule. ${ }^{[49]}$

The bio-based process oils obtained from agricultural sources such as palm-, soybean-, rubber seed-, neem-, dolma-, coconut oils, etc., are of interest for replacement of conventional petroleum-based process oils, because these oils are not only free of PAH compounds, but also give reduced pollution and consume less energy in production. The effect of bio-based plasticizers in silica-filled S-SBR/NR blends based model tread compounds was investigated by Flanigan et al. ${ }^{[50]}$ The use of cashew nut shell-, lowsaturated soybean-, palm- and flaxseed oils as plasticizers in the model tread compounds resulted in a slight decrease of hardness and an increase of tensile strength and elongation at break, but a decrease of $300 \%$ modulus when compared with the compounds containing petroleum-based TDAE oil. In addition, the use of low-saturated soybean-, flaxseed-, and palm-oils in silica-filled rubber-based tread compounds decreased the rolling resistance but deteriorated wet traction according to DMA results.

In addition to the silica-filled rubber based tire compounds, the effect of bio-oils on the properties of carbon black-filled rubber based tire formulations was investigated. Dasgupta et al. $(2007)^{[51]}$ studied the effect of 10 types of natural oils (i.e. rubber seed-, neem-, dolma-, soybean-, alsi-, kurunj-, sesamum-, mustard-, ground nut-, and arandi oils) in natural rubber-based truck-tire tread cap compounds. The compounds that contained the natural oils exhibited lower viscosity compared to those with petroleum oils, indicating a better processing behavior. In the case of compounds with rubber seed and neem oils, the dispersion of fillers in the rubber matrix was better than with other oils. The rubber compounds with the natural oil having high sulfur content, i.e. arandi oil, showed an increased crosslink density. ${ }^{[52]}$ In addition 
to straight use of natural oils, modified natural oils are also of interest to increase the compatibility with the rubber polymer. A study of epoxidized palm oil (EPO) and epoxidized soybean oil (ESBO) in carbon black-filled rubber-based tire tread compounds showed that EPO was a potential candidate for the replacement of DAE oil in rubber compounds, as demonstrated by comparable mechanical and dynamic properties of the resulting vulcanizates. ${ }^{[53]}$

Due to the fact that aromatic structures of the oil enhance polarity and compatibility with rubber as well as filler dispersion, many researchers attempted to modify natural oils by adding aromatic components for use as rubber process oils. Boontawee et al. (2012) ${ }^{[54]}$ studied the effect of benzyl esters which were prepared by esterification of benzyl alcohol and fatty acids based on three types of vegetable oils, i.e. coconut-, palm-, and soybean oils, on the properties of carbon black-filled NR compounds. The results showed that the tensile strength of NR compounds with benzyl ester oils was higher than with aromatic oil while the natural-based oils also acted as activators for the sulfur vulcanization system of the rubber compounds and gave a positive effect on network formation. The NR compound with aromatic oil, however, showed better elasticity than that with benzyl ester oils because of good compatibility between the aromatic oil and NR.

The effect of N-phenyl-p-phenylenediamine modified epoxidized palm oil on bound rubber content, total mixing energy, Mooney viscosity, curing characteristics, as well as mechanical and morphological properties of carbon black-filled NR compounds was investigated in comparison with the use of petroleum-based oils, i.e. highly aromatic and treated distillate aromatic extract oils ${ }^{[5]}$. This report showed that a carbon black-filled NR compound with modified bio-oil displayed inferior properties compared with aromatic oil, but superior to those with treated distillate aromatic extract. The different properties obtained by the use of different oils could be attributed to different levels of compatibility between the oils and rubber. The N-phenyl-p-phenylenediamine modified epoxidized bio-oil was also tested in polar nitrile (NBR) rubber compounds filled with carbon black ${ }^{[56]}$. On comparing the properties of compounds such as total mixing energy, dump temperature, Mooney viscosity, and curing characteristics, the phenylenediamine modified soybean oil and dioctyl phthalate (DOP) gave comparable properties.

\subsection{MOTIVATION AND FOCUS OF THE PROJECT}

Silica-reinforced natural rubber tire tread compounds with safe compounding ingredients are studied. This research work focuses on the use of safe compounding ingredients, i.e. DPG alternatives and natural oils as replacement for petroleum-based process oil. In the first part, different types of amines, such as hexylamine, decylamine, octadecylamine, cyclohexylamine, dicyclohexylamine and quinuclidine, are investigated as alternatives for DPG in silica-silane reinforced natural rubber tire compounds. The silanization efficiency is studied by using model compounds of silica/silane systems with the different 
amine types. Kinetic studies are conducted to evaluate the rate constants of the primary and secondary silanization reactions. The properties of practical silica-reinforced rubber compounds with different amine types are then investigated. The use of amines as alternatives for DPG is further investigated to explore the optimum amounts of amines by taking the rubber compound with DPG as reference. The properties of rubber compounds, i.e. bound rubber content, Payne effect, heat capacity increment and flocculation rate constant, are characterized to support the improvement of interfacial compatibility between the silica surface and rubber matrix in the rubber compounds. The second part of the study is executed using the most suitable curing system determined from the first part. Modified palm oils, i.e. epoxidized palm oils and amine-modified epoxidized palm oils, are prepared. The chemical structures of the modified oils are analyzed by FTIR and ${ }^{1} \mathrm{H}-\mathrm{NMR}$. For epoxidized palm oils, the epoxide contents are evaluated by titration with $\mathrm{HBr}$. The silanization efficiency of silica/silane systems with the different types of process oils is investigated in a model study. The effect of adsorbed oils on the silica surface on the compatibility of the silica surface with the rubber matrix is studied by means of varying mixing sequences. The dependence of the properties of rubber compounds on the various types of process oils are finally evaluated.

\subsection{REFERENCES}

${ }^{[1]}$ Internet page, http://www.rtvanderbilt.com/NonBlackFillers.pdf, (July 15, 2012).

${ }^{[2]}$ C.M. Blow, C. Hepburn, "Rubber Technology and Manufacture", Butterworths, London, second edition, 1982.

${ }^{[3]}$ J. Frohlich, W. Niedermeier, H.-D. Luginsland, Composites: Part A, 36, 449 (2005).

${ }^{[4]}$ A. Blume, L. Gatti, H.-D. Luginsland, D. Maschke, R. Moser, J.C. Nian, C. Roben and A. Wehmeier, "Silica and Silanes," in Rubber Compounding: Chemistry and Applications, B. Rodgers, Ed., 2nd Ed. CRC Press, Taylor and Francis Group, Boca Raton, 2015.

${ }^{[5]}$ R. Rauline, E.P. Pat 0501227A1 Feb. 2, 1992.

${ }^{[6]}$ H.-D. Luginsland, W. Niedermeier, Rubber World, 228, 34 (2003).

[7] J. Neubauer, Tire Technol. Int., p. 10-12 (2009).

${ }^{[8]}$ D.E. Hall, J.C. Moreland, Rubber Chem. Technol., 74, 525 (2001).

${ }^{[9]}$ J. Nawrocki, J. Chromatogr. 29, 799 (1997).

[10] E.F. Vansant, P. Van der Voort, K.C. Vrancken, "Studies in Surface Science and Catalysis: Characterization and Chemical Modification of the Silica Surface", Elsevier Science B.V., Amsterdam, the Netherlands, 1995.

${ }^{[11]}$ L.T. Zhuravlev, Colloids Surf. A Physicochem. Eng. Asp. 1, 173 (2000).

${ }^{[12]}$ J.L. Leblanc, Prog. Polym. Sci. 27, 627 (2002).

${ }^{[13]}$ U. Goerl, A. Hunsche, A. Mueller, H.G. Koban, Rubber Chem. Technol. 70, 608 (1997).

${ }^{[14]}$ J.W. ten Brinke, S.C. Debnath, L.A.E.M. Reuvekamp, J.W.M. Noordermeer, Compos. Sci. Technol. 63,1165 (2003). 
${ }^{[15]}$ A. Blume, F. Thibault-Starzyk, Rubber Fibres Plast. Int. 12, 152 (2017).

${ }^{[16]}$ A. Blume, F. Thibault-Starzyk, Rubber Fibres Plast. Int. 12, 236 (2017).

[17] W. Kaewsakul, K. Sahakaro, W.K. Dierkes, J.W.M. Noordermeer, Rubb. Chem. Technol. 85 , 277 (2012).

${ }^{[18]}$ W. Kaewsakul, "Silica-Reinforced Natural Rubber for Low Rolling Resistance, Energy-Saving Tires; Aspect of Mixing, Formulation and Compatibilization”, PhD. Thesis: 2013, Dept. of Elastomer Technology and Engineering, Univ. of Twente, Enschede, the Netherlands.

[19] S. Sarkawi, "Nano-Reinforcement of Tire Rubbers: Silica-Technology for Natural Rubber", PhD. Thesis: 2013, Dept. of Elastomer Technology and Engineering, Univ. of Twente, Enschede, the Netherlands.

${ }^{[20]}$ J.P. Blitz, R.S. Shreedhara Murthy, D.E. Leyden, J. Colloid Interface Sci. 126, 387 (1988).

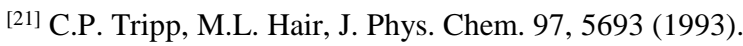

${ }^{[22]}$ L.D. White, C.P. Tripp, J. Colloid Interface Sci. 232, 400 (2000).

${ }^{[23]}$ S.M. Kanan, W.T.Y. Tze, C.P. Tripp, Langmuir. 18, 6623 (2002).

${ }^{[24]}$ H.-L. Li, A.P. Fu, D.-S. Xu, G.-L. Guo, L.-L. Gui, Y.-Q. Tang, Langmuir. 18, 3198 (2002).

${ }^{[25]}$ K.-J. Kim, J. VanderKooi, Rubber Chem. Technol. 78, 84 (2005).

[26] S. Mihara, "Reactive Processing of Silica-Reinced Tire Rubber: New Insight Into the Time- and Temperature-Dependence of Silica Rubber Interaction”, PhD. Thesis: 2005, Dept. of Elastomer Technology and Engineering, Univ. of Twente, Enschede, the Netherlands.

[27] J. Liu, C. Li, C. Sun, S. Zhao, Ind. Eng. Chem. Res. 56, 5164 (2017).

[28] W. Kaewsakul, K. Sahakaro, W.K. Dierkes, J.W.M. Noordermeer, Rubb. Chem. Technol. 86, 313 (2013).

[29] T.A. Okel, Rubber World. 244, 30 (2011).

${ }^{[30]}$ Internet page, http://www.atsdr.cdc.gov/toxfaqs/tfacts171.pdf, (May 23, 2014).

${ }^{[31]}$ C. Hayichelaeh, L.A.E.M. Reuvekamp, W.K. Dierkes, A. Blume, J.W.M. Noordermeer, K. Sahakaro, Polymers. 10. 584 (2018).

${ }^{[32]}$ M. Zaborski, J.B. Macromol. Symp. 87, 194 (2003).

[33] S.C. Debnath, A. Das, D. Basu, G. Heinrich, Kautsch. Gummi Kunstst. 66, 25 (2013).

${ }^{[34]}$ W. Kaewsakul, K. Sahakaro, W.K. Dierkes, J.W.M. Noordermeer, Kautsch. Gummi Kunstst. 66, 33 (2013).

${ }^{[35]}$ H.-M. Issel, L. Steger, A. Bischoff, Kautsch. Gummi Kunstst. 58, 529 (2005).

[36] B. Rodgers, W.-H. Waddell, S. Solis, W. Klingensmith, Kirk-Othmer Encyclopedia of Chemical Technology. 21, 805 (2004).

[37] A.D. Godwin, "Plasticizers". Elsevier Science., Oxford, England, (2000).

[38] R. Hofer, K. Hinrichs, “Additive for manufacture and processing of polymer”. Springer-Verlag, Heidelberg, Germany, (2010). 


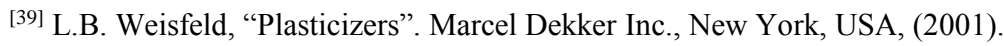

${ }^{[40]}$ A. Marcilla, M. Beltran, "Mechanism of plasticizers action". ChemTec Publishing, Ontario, Canada, (2004).

${ }^{[41]}$ G. Morris, "Developments in Rubber Technology-1 Improving Product Performance”, Applied Science Publishers Ltd., Essex, UK, (1979).

${ }^{[42]}$ Internet page, http://www.kemi.se/Documents/Publikationer/Trycksaker/Rapporter/Rapport5_03.pdf (October 8, 2013).

${ }^{[43]}$ V. Null, Kautsch. Gummi Kunstst. 52, 799 (1999)

${ }^{[44]}$ A. Petchkaew, "Implications of Non-carcinogenic PAH-free Extender Oils in Natural Rubber based Tire Compounds", PhD. Thesis: 2015, Dept. of Elastomer Technology and Engineering, Univ. of Twente, Enschede, the Netherlands.

${ }^{[45]}$ C. Bergmann, J. Trimbach, Kautsch. Gummi Kunstst. 67, 40 (2014).

[46] J. Bowman, M. da Via, M.E. Pattnelli, P. Tortoreto, S. Donato, Kautsch. Gummi Kunstst. 57, 31 (2004).

${ }^{[47]}$ A. Petchkaew, K. Sahakaro, J.W.M. Noordermeer, Kautsch. Gummi Kunstst. 66, 43 (2013).

${ }^{[48]}$ A. Petchkaew, K. Sahakaro, J.W.M. Noordermeer, Kautsch. Gummi Kunstst. 66, 21 (2013).

${ }^{[49]}$ J. Li, A.I. Isayev, X. Ren, M.D. Soucek, Polymer. 60, 144 (2015).

${ }^{[50]}$ C. Flanigan, L. Beyer, D. Klekamp, D. Rohweder, D. Haakenson, Rubber and Plastics News. 15 (2013).

${ }^{[51]}$ S. Dasgupta, S.L. Agrawal, S. Bandyopadhyay, S. Chakraborty, R. Mukhopadhyay, R.K. Malkani, S.C. Ameta, Polym. Test. 26, 489 (2007).

${ }^{[52]}$ S. Dasgupta, S.L. Agrawal, S. Bandyopadhyay, S. Chakraborty, R. Mukhopadhyay, R.K. Malkani, S.C. Ameta, Polym. Test. 27, 277 (2008).

${ }^{[53]}$ K. Sahakaro, A. Beraheng, Rubber Chem. Technol. 84, 200 (2011).

${ }^{[54]}$ H. Boontawee, C. Nakason, A. Kaesaman, A., Thitithammawong, S. Chewchanwuttiwong, Adv. Mater. Res. 415-417, 1164 (2012).

${ }^{[55]}$ S. Ieadsang, A. Thitithammawong, C. Nakason, A. Kaesaman, Adv. Mater. Res. 844, 239 (2014).

${ }^{[56]}$ K. Chanpon, A. Thitithammawong, C. Nakason, A. Kaesaman, Adv. Mater. Res. 844, 49 (2014). 
ENHANCING THE SILANIZATION REACTION OF THE SILICA-SILANE SYSTEM BY DIFFERENT AMINES IN MODEL COMPOUNDS

\begin{abstract}
Diphenyl guanidine (DPG) is an essential ingredient in silica-reinforced rubber compounds for low rolling resistance tires, as it not only acts as a secondary accelerator but also as a catalyst for the silanization reaction. However, because of concern over the toxicity of DPG that liberates aniline during high temperature processing, safe alternatives are required. The present work studies several amines as potential alternatives for DPG. Different amines, i.e. hexylamine (HEX), decylamine (DEC), octadecylamine (OCT), cyclohexylamine $(C Y C)$, dicyclohexylamine $(D I C)$ and quinuclidine $(Q U I)$, are investigated in a model system by taking the ones with DPG and without amine as references. The kinetics of the silanization reaction of the silica/silane mixtures are evaluated by using model compounds. The mixtures with amines show up to 3.7 times higher rate constants of the primary silanization reaction compared to the compound without amine. Linear aliphatic amines promote the rate constant of the primary silanization reaction to a greater extent compared to amines with a cyclic structure. The amines with shortalkyl chains that provide better accessibility towards the silica surface, enhance the primary silanization reaction more than the ones with long-alkyl chains. The different amines have no significant influence on the rate constant of the secondary silanization reaction.
\end{abstract}




\subsection{INTRODUCTION}

Driven by the need for more environmentally friendly and regulated products, low rolling resistance tires have been developed based on utilization of silica/silane technology for rubber reinforcement. ${ }^{[1]}$ Highly dispersible silica fillers in combination with a silane coupling agent need to be mixed into the rubber under optimized mixing conditions ${ }^{[2,3]}$ using a suitable formulation ${ }^{[4]}$ to ensure the occurrence of the silanization reaction that leads to bonding of the silane moiety onto the silica surface. As a consequence of the silanization reaction during mixing between the alkoxy groups of the silane molecules and silanol groups on the silica surface, and the subsequent coupling reaction between the bound silane moieties and elastomer molecules during the curing process, chemical linkages between the silica and the elastomer molecules are created forming the basis for low rolling resistance tire treads. This filler-elastomer network in combination with elastomer crosslinks leads to low hysteresis of the silica-filled rubber vulcanizates.

The extent of the silanization reaction is a crucial factor to be optimized in order to maximize the end-use properties of the rubber vulcanizates. The functional groups of the silane molecules play an important role in the silica/rubber system affecting filler-to-elastomer interfacial adhesion. ${ }^{[5]}$ The silanization reaction enhances silica-elastomer interactions, reduces filler-filler interactions and lowers the compound viscosity which is beneficial for both processing and vulcanizate properties. The most commonly used silane coupling agent is bis(3-triethoxysilylpropyl) tetrasulfide (TESPT) with alkoxy- and sulfurfunctional groups. ${ }^{[2,5]}$ For silica/TESPT-filled rubber compounds, the optimum discharge temperature of mixing has a strong influence on the extent of the silanization reaction ${ }^{[2,3]}$, where the recommended discharge temperature for silica-reinforced Natural Rubber (NR) compounds is in the range of $135-150^{\circ} \mathrm{C}^{[3]}$ The presence of an amine-based secondary accelerator such as DiPhenyl Guanidine (DPG) in the silicareinforced rubber compounds plays an additional role as catalyst booster for the silanization reaction. ${ }^{[6,7]}$ However, due to the potential liberation of toxic aniline by $\mathrm{DPG}^{[8]}$ during high processing temperatures, i.e. during mixing and vulcanization, and consequent concerns over its safety, safe alternatives for DPG are required.

Indirect indications for the extent of the silanization reaction in practical rubber compounds which relate to filler-elastomer interactions are such as the chemically bound rubber content ${ }^{[9]}$, the Payne effect $^{[10]}$, flocculation rate constant ${ }^{[11]}$ and heat capacity increment. ${ }^{[12-13]}$ In order to obtain an in-depth insight into the silanization reaction, a study on the kinetics of the silica-silane system is needed. Based on the silanization study by Goerl et al. ${ }^{[14]}$ using a model system, it was concluded that the reaction proceeds in two steps. The primary reaction involves the first out of three ethoxy-groups on one TESPT silicon atom. The secondary follow-up reaction involves the second and potentially third ethoxy-groups. The primary reaction is about 10-20 times faster than the secondary reaction. The reaction can occur via two pathways: direct condensation and hydrolysis prior to condensation, while the secondary reaction encompasses 34 
condensation between adjacent alkoxy groups of TESPT already bound to the silica surface. A recent report on the silica-silane reaction mechanism characterized by in situ Infrared spectroscopy by Blume and Thibault-Starzyk revealed that only the isolated and geminal silanol groups are involved in the reaction. Only $25 \%$ of the $\mathrm{Si}-\mathrm{OH}$ groups are estimated to react with silanes as only these silanol groups are accessible to incoming silane molecules. Based on molecular modeling using (3-mercaptopropyl) triethoxysilane (Si263) silane coupling agent, two molecules can only react with two silanol groups at a distance higher than $0.4 \mathrm{~nm}$; so the number of silanes grafted on the silica surface is limited. An increase of the hydrophobation of the silica surface is possible by the use of small molecules such as alcohols and amines or silanes with high shielding potential. ${ }^{[15-16]}$ The reactions are accelerated by an increase in temperature and by acidic or alkaline conditions. The study on the kinetics of different silanes with varying functional groups in model systems revealed that, although only the alkoxy group reacts with the silanol group of the silica, the chemical structure of the whole silane influences the rate of the reaction. ${ }^{[17]}$ Mihara ${ }^{[18]}$ studied the silanization kinetics of silica/silane in a model olefin system in the presence of different amines with various acid dissociation constant $\left(\mathrm{pK}_{\mathrm{a}}\right)$ values ranging from 1.30 to 11.5 . It was shown that for $\mathrm{pK}_{\mathrm{a}} \geq 6.5$ the rate constant increases and the activation energy decreases with increasing $\mathrm{pK}_{\mathrm{a}}$. Quinuclidine and 3quinuclidinol with respective $\mathrm{pK}_{\mathrm{a}}$ values of 11.5 and 10.1 gave high silanization rates and were tested in a tire tread compound in comparison to DPG with a $\mathrm{pK}_{\mathrm{a}}$ of 10.1 .

The present work explores the potential of amines having different structures with $\mathrm{pK}_{\mathrm{a}}$ 's in the range of 10-12 as alternatives for DPG. Different amine types, i.e. HEXylamine (HEX), DECylamine (DEC), OCTadecylamine (OCT), CYClohexylamine (CYC), DICyclohexylamine (DIC) and QUInuclidine (QUI), are used while taking silica/silane systems with DPG and without amine as references. The rate constants of the primary and secondary silanization reactions are determined based on a study in a model system.

\subsection{EXPERIMENTAL}

\subsubsection{Materials}

Highly dispersible silica ULTRASIL 7005 (Evonik, Germany), characterized by BET- and CTAB specific surface areas of 180 and $171 \mathrm{~m}^{2} / \mathrm{g}$, respectively, was used in this study. Diphenylguanidine (DPG) was obtained from Flexys, Belgium, and the other amines as detailed in Table 3.1 were from SigmaAldrich Chemie, Germany. The chemicals for the model compound study were anhydrous-grade decane (Sigma-Aldrich Chemie, Germany), bis(3-triethoxysilylpropyl) tetrasulfide (TESPT) (Evonik, Germany) and diethyleneglycol monobutylether (Sigma-Aldrich Chemie, Germany). 


\subsubsection{Preparation and characterization of the model reaction mixtures}

Silica was first heated in an oven at $100^{\circ} \mathrm{C}$ for $2 \mathrm{~h}$ prior to being used. Then, $0.5 \mathrm{~g}$ of silica was then added into a vial before adding $0.094 \mathrm{mmol}$ of TESPT and $0.30 \mathrm{mmol}$ of the respective amines. Reactions with DPG and without amine were also prepared as references. Thereafter, $4 \mathrm{ml}$ of $\mathrm{n}$-decane was added. The vials containing the reaction mixtures were then flushed with inert nitrogen gas, before being immersed into an oil bath at $135 \pm 2^{\circ} \mathrm{C}$ for different reaction times under continuous stirring. After reaching the required time, the reactions were quenched by cooling in an ice bath. All physical interactions on the silica surfaces were removed by adding $2 \mathrm{ml}$ of diethyleneglycol monobutylether to the reaction mixtures, following the method reported by Blume ${ }^{[17]}$. This step also desorbed ethanol from the silica surface, generated by the silanization reaction. The resulting mixtures were subsequently filtered and then the concentration of ethanol (EtOH) was determined by Gas Chromatography (GC) using a GC-2010 plus (Shimadzu, Kyoto, Japan). The chromatographic conditions are as given in Table 3.2.

Table 3.1 Typical information of amines used in this study

\begin{tabular}{|c|c|c|c|c|}
\hline Chemical name & Code & Structure & $\mathrm{pK}_{\mathrm{a}}$ & $\begin{array}{c}\text { MW } \\
(\mathrm{g} / \mathrm{mol})\end{array}$ \\
\hline Diphenyl guanidine & DPG & & 10.10 & 211.3 \\
\hline Hexylamine & HEX & & 10.56 & 101.2 \\
\hline Decylamine & DEC & & 10.64 & 157.3 \\
\hline Octadecylamine & OCT & & 10.60 & 269.5 \\
\hline Cyclohexylamine & CYC & & 10.64 & 99 \\
\hline Dicyclohexylamine & DIC & & 10.40 & 181 \\
\hline Quinuclidine & QUI & & 11.50 & 111 \\
\hline
\end{tabular}


Table 3.2 GC chromatographic conditions

\begin{tabular}{lc}
\hline \multicolumn{1}{c}{ Items } & Conditions \\
\hline Column type & BPX5 \\
Length of column & $15 \mathrm{~m}$ \\
Internal diameter & $0.32 \mathrm{~mm}$ \\
Film thickness & $0.25 \mu \mathrm{m}$ \\
Detector & Flame ionization detector (FID) \\
Flow rate & $2 \mathrm{ml} / \mathrm{min}$ \\
Temperature & $250^{\circ} \mathrm{C}$ \\
\hline
\end{tabular}

\subsection{RESULTS AND DISCUSSION}

The success of TESPT as silane coupling agent in silica/rubber systems is due to two main chemical reactions: silanization of the silica and coupling towards the elastomers, that finally lead to chemical bridges between the silica surfaces and elastomer molecules. As stated before, the silanization reaction is divided into a primary and secondary reaction: Figure 3.1. The primary reaction can proceed via two pathways: either by direct condensation between the silanol groups of the silica surface and one alkoxy group of TESPT, or by hydrolysis of the alkoxy groups of TESPT to form reactive hydroxyl groups prior to the condensation reaction. ${ }^{[14]}$ Both pathways release ethanol (EtOH) as byproduct. The secondary reaction often occurs between adjacent TESPT molecules on the filler surface, also releasing ethanol. 


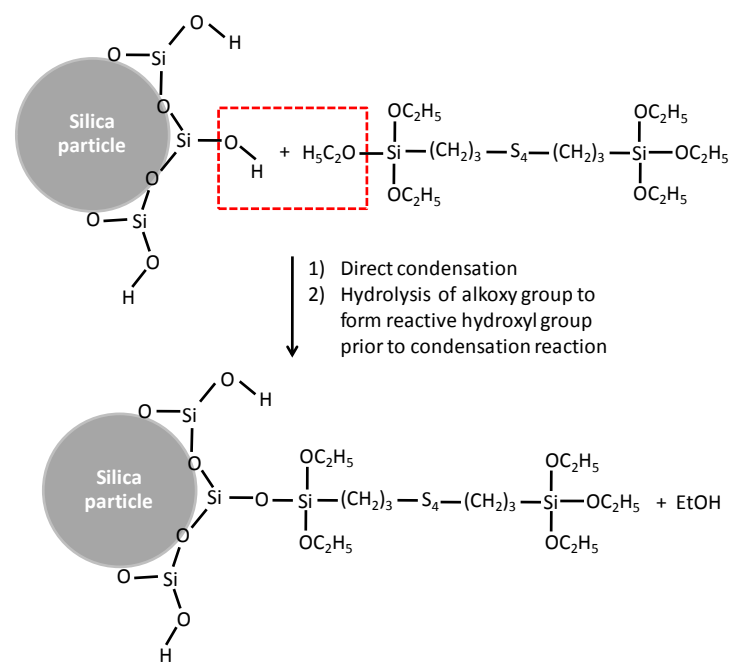

(A) Primary silanization reaction
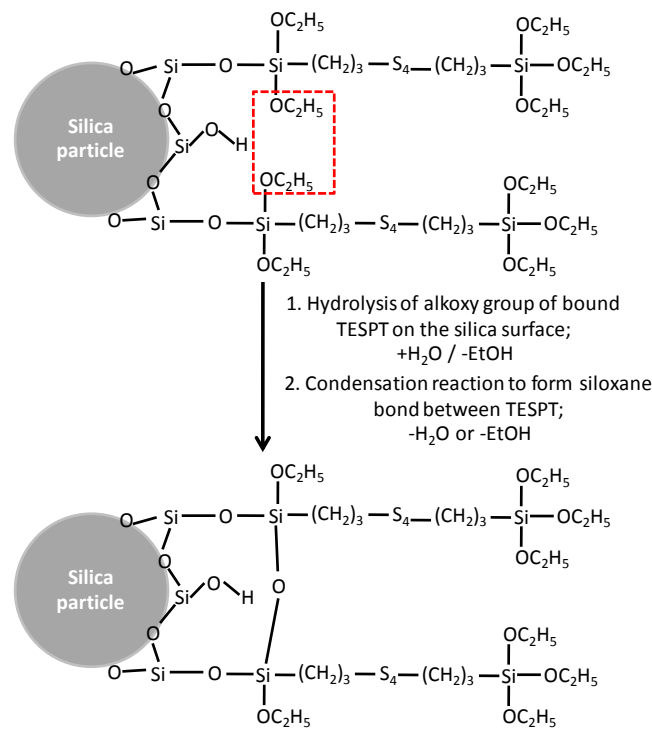

(B) Secondary silanization reaction

Figure 3.1 The primary and secondary silanization reactions in a silica/TESPT system (adapted from [14]). 
The EtOH released from the silanization reaction of the silica/silane system in the $n$-decane model compounds as calculated in relation to the concentration of TESPT used is shown in Figure 3.2. The concentration of released $\mathrm{EtOH}$ increases with increasing reaction time. In the presence of amines, the ethanol concentration rises sharply within 10 minutes to exceed 2 moles per mole of TESPT due to the primary reaction, and thereafter rises more slowly. The silica/silane systems with all amine types show significantly higher concentrations of EtOH than the one without amine due to the enhanced silanization reaction catalyzed by the alkaline amines. Hydrolysis of the silane can readily occur under basic conditions. ${ }^{[19]}$ Thus amine provides a catalytic effect on the hydrolysis of alkoxy groups in the silane molecules to form reactive hydroxyl moieties prior to the condensation reaction. ${ }^{[19-20]}$ In the presence of amine and water, a hydroxyl ion (OH-) is formed and EtOH is released from the TESPT molecules via a pentacoordinate intermediate, forming $\mathrm{Si}-\mathrm{OH} .{ }^{[19-20]}$ In addition to hydrolyzed alkoxy group in TESPT molecules, the amines catalyze the condensation reaction between the $\mathrm{Si}-\mathrm{OH}$ on the silica surface and the alkoxy groups in the TESPT molecules. ${ }^{[21-23]}$ The catalyzed condensation reaction occurs after the amine has entered into interaction with the silanol group on the silica surface via hydrogen bonding, enhancing the nucleophilicity on the silica surface. So the silica surface can more easily interact with the silicon atom in the TESPT molecule that leads to the condensation reaction. ${ }^{[21]}$ This role of amine as catalyst for the silanization reaction is depicted in Figure 3.3.

In case of the primary silanization reaction, it is assumed that 1 mol of TESPT which reacts with silanol groups on the silica surface releases 2 mols of EtOH as byproduct. The rate constant of the silanization reaction depends on the TESPT concentration, which can be described by a first order rate law. Based on the concentration of TESPT and released EtOH, the rate of the silanization reaction can be calculated by using Equation (3.1) as shown below; ${ }^{[14]}$

$$
-\frac{d[T E S P T]}{d t}=k_{a}[T E S P T]=\frac{1}{2} \frac{d[E t O H]}{d t}
$$

Where $[T E S P T]$ is concentration of TESPT; $[E t O H]$ is a concentration of EtOH; $k_{a}$ is rate constant of primary silanization reaction, and $t$ is time

Based on Equation 3.1 and the model reaction procedure as laid out in the Section 3.2.2, the rate constant of the primary silanization reaction can be calculated in the usual manner by plotting $\ln [T E S P T]_{t}$ - $\ln [\text { TESPT }]_{o}$ against time $t$; where $[T E S P T]_{t}$ is the TESPT concentration at time $t$ which is calculated based on the EtOH generated, and $[T E S P T]_{o}$ is the initial TESPT concentration. The slopes of the plot are taken as the reaction rate constants, as demonstrated in Figure 3.4. 


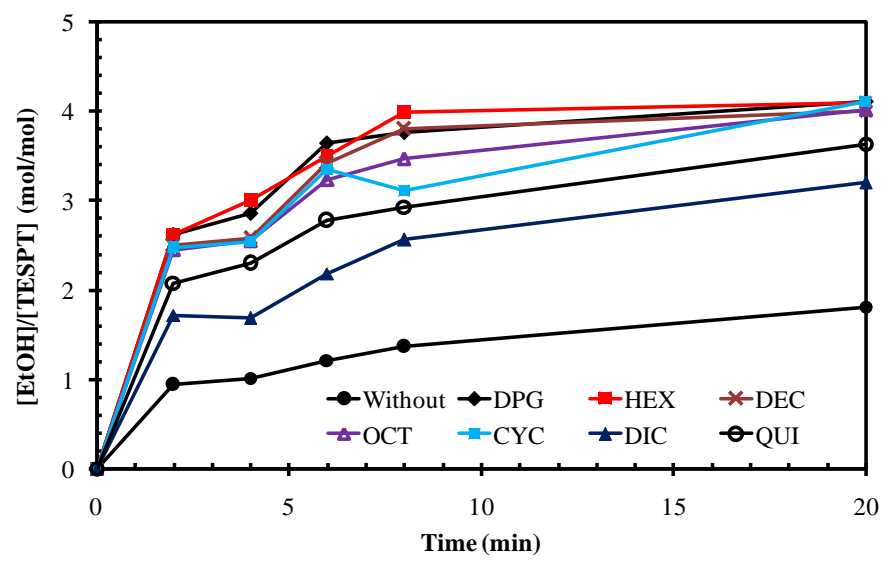

Figure 3.2 Ethanol released during the silanization reaction of silica/silane mixtures with different amine types.

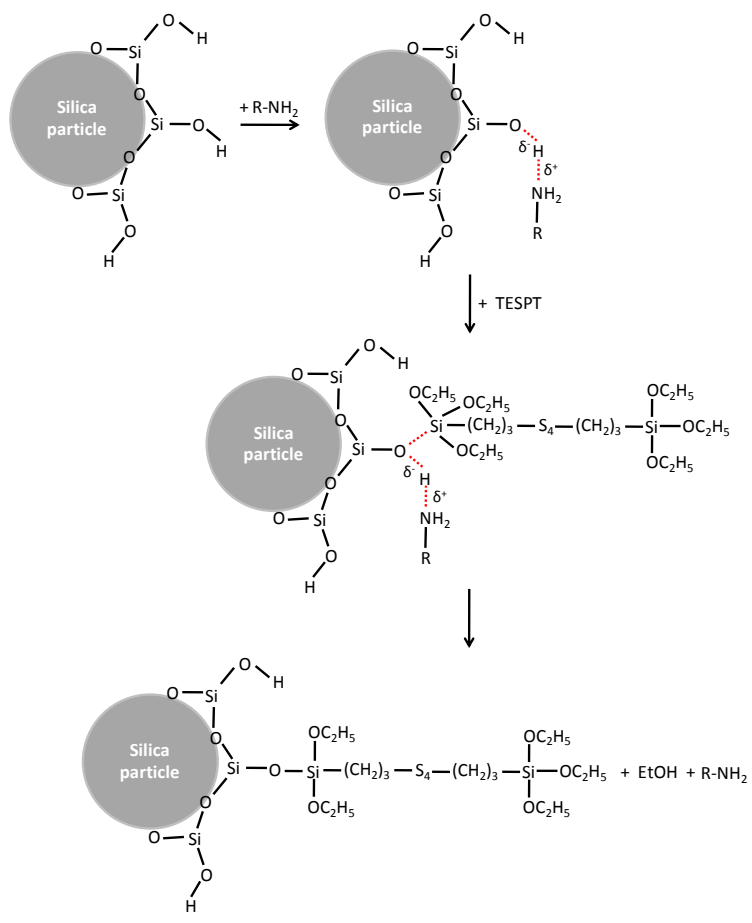

Figure 3.3 Interaction of amine with the silanol group and its contribution to the silanization (adapted from [21]). 


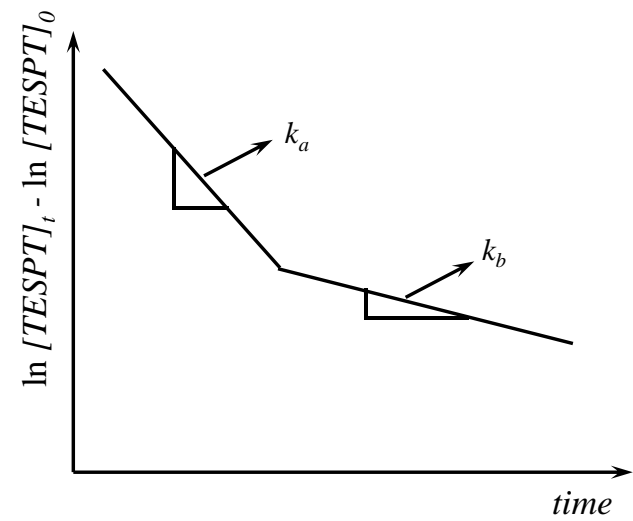

Figure 3.4 A simplified example of the plot used to determine the rate constants of the primary and secondary silanization reactions.

Figure 3.5 shows the rate constants of the primary silanization reaction of silica/TESPT with different amine types in comparison with the reference without amine. It shows that the reaction mixture of silica/TESPT without amine displays the lowest rate constant of the primary silanization reaction, equal to $0.039 \mathrm{~min}^{-1}$. The reference with DPG has a primary silanization reaction rate constant of $0.139 \mathrm{~min}^{-1}$, where the rate constants for the systems with alternative amines are in the range of 0.070 to $0.143 \mathrm{~min}^{-1}$. This demonstrates indeed that the use of amines promotes the primary silanization reaction 1.8 to 3.7 times.

The different amine types with similar $\mathrm{pK}_{\mathrm{a}}$ values but different structures show variation in the rate constant of the primary silanization reaction as shown in Figure 3.5. The amines with linear aliphatic chains, i.e. HEX, DEC and OCT, show higher rate constants compared with the amines with a cyclic structure, i.e. CYC, DIC and QUI. Of the primary amines with linear alkyl chains with the best catalytic effect, HEX with the shortest alkyl chain does give the highest rate constant of $0.143 \mathrm{~min}^{-1}$. Longer alkyl chains of the aliphatic amines apparently decrease the reaction rate and the presence of a cyclic aliphatic structure further reduces the rate. The bi-cyclic structure of DIC results in the lowest rate constant. The difference in promoting the silanization by amines having similar $\mathrm{pK}_{\mathrm{a}}$ values in the silica/silane system may be attributed to the different adsorption efficiency of the amine molecules on the silica surface. The cyclic ring hampers the adsorption on the silica surface due to steric hindrance, while straight alkyl-chains allow for easy access to the silanol groups on the silica surface. The increase of one cyclic ring in CYC to two cyclic rings in DIC drastically reduces the primary silanization reaction rate by $39 \%$, whereas the increase of the linear aliphatic chain length from $\mathrm{C} 6$ to $\mathrm{C} 10$ and $\mathrm{C} 18$ decreases the reaction rate constants only by about $18 \%$ and $20 \%$, respectively. The adsorption of amines with the long aliphatic chains from C10 to C18 on the silica surface introduces slightly more steric effects that may interfere with the silanization reaction. 
When compared with the short chain amine, the long tail of the amines could shield the silica surface and deactivate the free silanol groups, as displayed in Figure 3.6.

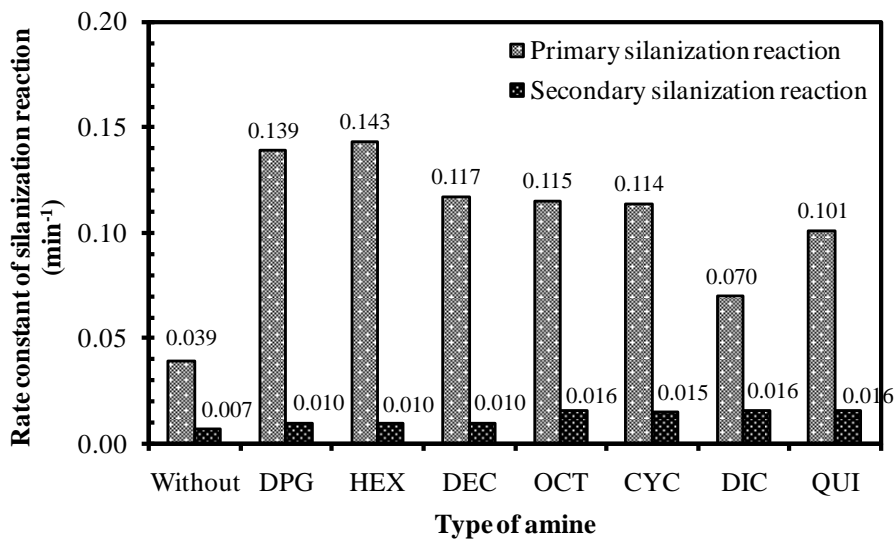

Figure 3.5 Rate constant of the silanization reaction of silica/silane mixtures with different amine types.
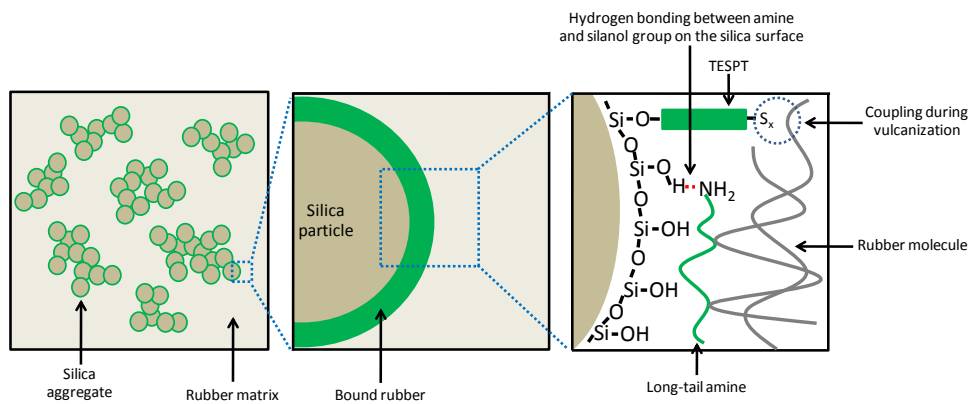

Figure 3.6 Adsorption of linear aliphatic amine on the silica surface.

The secondary silanization reaction that takes place between the left-over alkoxy groups in adjacent silane molecules bound on the silica surface, has a much lower rate constant compared to the primary reaction. The data are in agreement with the rate constants reported by Goerl et al. ${ }^{[14]}$ for the silica/TESPT system in a n-decane model reaction system in which at $140^{\circ} \mathrm{C}$ the primary vs. secondary reaction rate constants were found as $0.122 \mathrm{vs.} 0.008 \mathrm{~min}^{-1}$, respectively. The rate constants of the secondary silanization reaction of the silica/silane mixture is also shown in Figure 3.6 in which all mixtures with amines show higher rate constants than the mix without amine. However, the different amine structures have only a small influence on the rate constant of this secondary silanization reaction, found in the range of 0.01 to $0.02 \mathrm{~min}^{-1}$. This very low or almost negligible secondary reaction may be attributed to the limited 
number of silanes grafted on adjacent isolated silanol sites as a minimum distance between the two $\mathrm{SiOH}$ groups of greater than $0.4 \mathrm{~nm}$ is estimated in order to be accessible for the incoming silane molecules. ${ }^{[16]}$

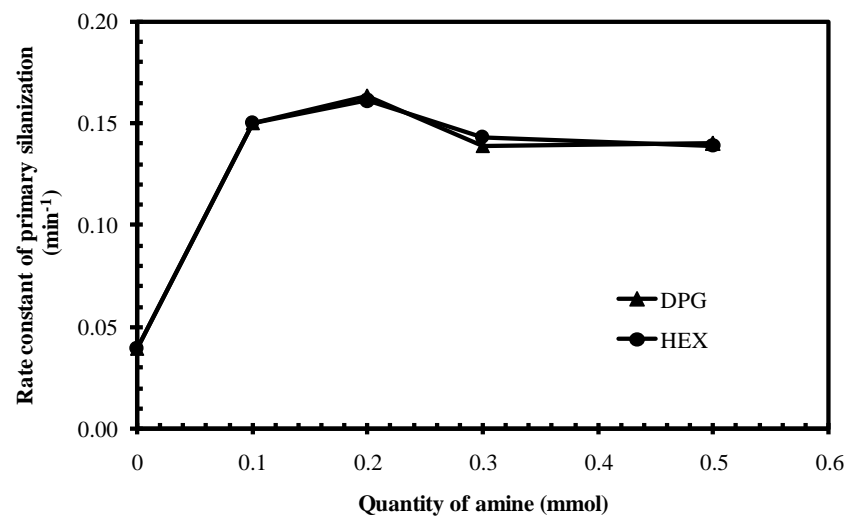

Figure 3.7 Rate constants of the primary silanization reaction of silica/silane mixtures with different quantities of DPG and HEX.

As displayed in Figure 3.5, among the amine types studied HEX gives the highest rate constant of the primary silanization reaction, slightly higher than that of the reference mixture of silica/silane with DPG. HEX is a primary amine with C6 aliphatic tail while DPG is a secondary amine with aromatic rings, but containing 3 polar - NH groups. These two types of amines were further studied for the effect of the amount on the primary silanization reaction rate constant: the results are shown in Figure 3.7.

Both DPG and HEX show the same trend of changes in the rate constants of the primary silanization reaction against the molar quantities used in the model system. With increasing amine loading till $0.2 \mathrm{mmol}$, the rate constant increases, and thereafter decreases slightly and tends to level off at an excessive amine loading, as shown in Figure 3.7. The presence of amine in the silica/silane model system promotes the rate constant of the primary silanization reaction about threefold. The decrease of the silanization reaction rate constant with increasing amounts of amines to more than $0.2 \mathrm{mmol}$ is due to amine adsorption on the silica surface via hydrogen bonding between the amino groups in the amine molecule and the silanol groups on the silica surface causing reduced accessibility for the silane molecules.

\subsection{CONCLUSIONS}

The kinetics of the silanization reaction in the silica/silane model systems containing various amine types reveal that such amines with different chemical structures provide quite diverse influences on the rate constant of the primary silanization reaction, but almost do not change the rate constant of the secondary silanization reaction. The presence of all amine types in the silica/silane systems increases the 
rate constant of the primary silanization reaction compared to the system without amine. The primary silanization reaction rate constants in model systems with DPG and HEX reach an optimum when 0.2 mmol of amines is used.

\subsection{REFERENCES}

${ }^{[1]}$ R. Rauline, E.P. Patent 0501227A1, (Feb. 12, 1992).

${ }^{[2]}$ L.A.E.M. Reuvekamp, J.W. ten Brinke, P.J. van Swaaij, J.W.M. Noordermeer, Kautsch. Gummi Kunstst. 55,41 (2002).

${ }^{[3]}$ W. Kaewsakul, K. Sahakaro, W.K. Dierkes, J.W.M. Noordermeer, Optimization of mixing conditions for silica-reinforced natural rubber tire tread compounds, Rubber Chem. Technol. 85 (2012) 277-294.

${ }^{[4]}$ W. Kaewsakul, K. Sahakaro, W.K. Dierkes, J.W.M. Noordermeer, Rubber Chem. Technol. 86, 313 (2013).

${ }^{[5]}$ W. Kaewsakul, K. Sahakaro, W.K. Dierkes, J.W.M. Noordermeer, Polym. Eng. Sci. 55, 836 (2015).

${ }^{[6]}$ S. Mihara, R.N. Datta, A.G. Talma, J.W.M. Noordermeer, US Patent 7923493B2, (Apr. 12, 2011).

${ }^{[7]}$ C. Hayichelaeh, L.A.E.M. Reuvekamp, A. Blume, J.W.M. Noordermeer, K. Sahakaro, Rubber Chem. Technol. 90, 651 (2017).

${ }^{[8]}$ Internet page, http://www.atsdr.cdc.gov/toxfaqs/tfacts171.pdf (May 23, 2014).

${ }^{[9]}$ S. Wolff, M.J. Wang, E.H. Tan, Rubber Chem. Technol. 66, 163 (1993).

${ }^{[10]}$ A.R. Payne, Rubber Chem. Technol. 33, 365 (1966).

${ }^{[11]}$ S. Mihara, R.N. Datta, J.W.M. Noordermeer, Rubber Chem. Technol. 82, 524 (2009).

${ }^{[12]}$ B. Zhong, Z. Jia, D. Hu, Y. Luo, D. Jia, Composites Part A 78, 303 (2015).

${ }^{[13]}$ D. Fragiadakis, L. Bokobza, P. Pissis, Polymer 52, 3175 (2011).

${ }^{[14]}$ U. Goerl, A. Hunsche, A. Mueller, H.G. Koban, Rubber Chem. Technol. 70, 608 (1997).

${ }^{[15]}$ A. Blume, F. Thibault-Starzyk, Rubber Fibres Plast. Int. 12, 152 (2017).

${ }^{[16]}$ A. Blume, F. Thibault-Starzyk, Rubber Fibres Plast. Int. 12, 236 (2017).

${ }^{[17]}$ A. Blume, Kautsch. Gummi Kunstst. 64, 38 (2011).

${ }^{[18]}$ S. Mihara, "Reactive Processing of Silica-Reinforced Tire Rubber: New Insight into the Time- and Temperature- Dependence of Silica Rubber Interaction”, PhD. Thesis: 2009, Univ. of Twente, Enschede, the Netherlands.

${ }^{[19]}$ H-L. Li, A-P. Fu, D-S. Xu, G-L. Guo, L-L. Gui, Y-Q. Tang, Langmuir 18, 3198 (2002).

${ }^{[20]}$ K-J. Kim, J. VanderKooi, Rubber Chem. Technol. 78, 84 (2005).

${ }^{[21]}$ C.P. Tripp, M.L. Hair, J. Phys. Chem. 97, 5693 (1993).

${ }^{[22]}$ L.D. White, C.P. Tripp, J. Colloid Interface Sci. 232, 400 (2000).

${ }^{[23]}$ S.M. Kanan, W.T.Y. Tze, C.P. Tripp, Langmuir 18, 6623 (2002). 


\title{
REINFORCEMENT OF NATURAL RUBBER BY SILICA/SILANE IN DEPENDENCE OF DIFFERENT AMINE TYPES
}

\begin{abstract}
Diphenyl guanidine (DPG) is the most commonly used secondary accelerator in silicareinforced rubber compounds due to its additional positive effect on the silanization reaction and deactivation of free silanol groups that are left over after the silanization. However, due to health and safety concerns about the use of DPG, that decomposes to give highly toxic aniline during high processing temperature, safe alternatives are required. This work investigates the effect of various types of aliphatic amines having alkyl or cyclic structures and similar $p K_{a}$, i.e. hexylamine (HEX), decylamine (DEC), octadecylamine (OCT), cyclohexylamine (CYC), dicyclohexylamine (DIC) and quinuclidine (QUI), on the properties of silica-reinforced natural rubber (NR) compounds by taking the ones with DPG and without amine as references. When compared to the compound without amine, the use of all amine types reduces filler-filler interaction, i.e. Payne effect, and enhances filler-rubber interaction as indicated by bound rubber content and decreased heat capacity increment. The amines with alkyl-chains can reduce the Payne effect and enhance cure rate to a greater extent compared to the amines with cyclic rings as a result of better accessibility towards the silica surface and a shielding effect because of less steric hindrance. The longer carbon-tails on linear aliphatic amines ranging from HEX, DEC to OCT lead to a lower Payne effect, lower heat capacity increment, higher bound rubber content, and higher modulus as well as tensile strength. Overall, the use of OCT provides silica-reinforced NR compounds with properties closest to the reference one with $D P G$, and can act as a potential alternative for $D P G$.
\end{abstract}




\subsection{INTRODUCTION}

Since the introduction of "Green Tires" by Michelin in 1990s, silica has been widely known as a reinforcing filler for tire tread compounds that provide significant improvements of key tire performance, especially rolling resistance, compared to conventional carbon black-reinforced tire compounds. ${ }^{[1]} \mathrm{A}$ reduction of rolling resistance of about $20 \%$ of the silica-reinforced tire rubber compared with the use of carbon black can save $3-6 \%$ of fuel. ${ }^{[2-3]}$ However, mixing of silica into the non-polar rubber encounters difficulties due to the different polarities between the silica surface and rubber matrix. The state-of-the-art bis(triethoxysilylpropyl)tetrasulfide (TESPT) silane has been widely used as coupling agent in silica-filled rubber systems to improve compatibility and bonding between silica and elastomer. The improvement of silica-rubber interfacial interaction is introduced via a chemical reaction, the so-called silanization reaction which takes places between the silanol-groups on the silica surface and ethoxy-groups in the TESPT molecules. This reaction occurs during mixing and proceeds through primary and secondary reactions, ${ }^{[4,5]}$ for which the mechanism ${ }^{[4]}$ and kinetics ${ }^{[6]}$ have been described based on model compound studies. Due to the polar functional groups in the silane molecule, it absorbs on the silica surface and stabilization of the intermediate takes place before the primary reaction between silica and silane. The secondary reaction occurs later between adjacent silane molecules fixed on the filler surface. ${ }^{[4,5]}$ The polysulfide part in the silane coupling agent can later react with the rubber molecules during vulcanization, leading to silica-silanerubber bridge formation. ${ }^{[5]}$ The enhanced filler-rubber interactions and improved compatibility result in the preferable properties of the silica-filled rubber compounds.

In order to enhance the silanization reaction which is a condensation reaction in nature, a catalyst is necessary in order to have an efficient reaction within the time frame of a mixing cycle. An acid catalyst is not a choice for rubber compounds as it retards the vulcanization reaction. Basic substances like amines are therefore the preferred candidates. Diphenylguanidine (DPG), normally used as a secondary accelerator in rubber compounding, has been reported to act as such a silanization booster in silica-filled rubber systems. ${ }^{[7]}$ The effect of the amount of DPG on the properties of silica-reinforced natural rubber compounds was studied ${ }^{[8]}$ and the results showed that not only the cure properties, i.e. scorch time, cure time and cure rate index, were improved, but also the bound rubber contents that indicate filler-rubber interactions were increased with increasing DPG contents. The increased bound rubber contents by use of suitable amounts of DPG enhance the mechanical properties and lower the Payne effect. ${ }^{[8]}$ Even though DPG has been shown to work well and has become an essential ingredient for silica-reinforced rubber compounds, there is a concern about safety on the use of DPG, because it can liberate highly toxic aniline at high temperatures, such as occur during mixing and vulcanization. ${ }^{[9]}$ Aniline has been reported to be a probable carcinogen for humans by the United States Environmental Protection Agency (2000). ${ }^{[10]}$ Therefore, alternatives for DPG are in need to enhance a safe working environment. 
The commonly used accelerators for rubber vulcanization consist of basic nitrogen-containing groups in which the alkali-nature enhances the vulcanization reaction in the rubber compounds. It has been known for long that the use of amines promotes sulfur ring splitting and enhances sulfur to form reactive sulfurating agents. ${ }^{[11]}$ The use of DPG as secondary accelerator with sulfenamide primary accelerators for rubber compound formulations results in efficient crosslink formation and consequently enhances other properties. Examples of works dealing with the use of nitrogen-based substances in silica-filled rubber compounds are as follows. Surya and co-workers ${ }^{[12]}$ reported that the use of alkanolamide provided advantages for silica-filled natural rubber compounds, especially in terms of cure behaviors, as it helps to decrease scorch and cure times. The use of alkanolamide up to $5 \mathrm{phr}$ resulted in the rubber compounds with good properties, such as high vulcanization torque difference, high crosslink density and good mechanical properties like modulus and tensile strength, due to the fact that the alkanolamide not only accelerated the vulcanization but also enhanced silica-rubber interactions and improved the silica dispersion in the natural rubber matrix. Liu et al. (2008) ${ }^{[13]}$ studied the use of cyclohexylamine as silica modifier in natural rubber compounds. The use of modified silica promoted cure properties of the rubber compounds, enhanced crosslink density, and improved silica dispersion that led to better mechanical properties and decreased the dynamic mechanical losses expressed as $\tan \delta\left(=\mathrm{G}^{\prime \prime} / \mathrm{G}^{\prime}\right.$, where $\mathrm{G}^{\prime \prime}$ is the loss modulus and $\mathrm{G}^{\prime}$ is the storage modulus) of the rubber vulcanizates.

The structure of lewis acid/base adducts which are used as a silanization booster in the silicafilled rubber compounds were studied by Tanabe and co-workers. They found that the different structures of chemical substances showed a significant effect on the key tire performances, i.e. rolling resistance and wet traction, due to changing the silanization efficiency. ${ }^{[14]}$ Furthermore, it has been reported previously that amines enhance the release of an ethoxy group from TESPT to accelerate the primary reaction, and that the activation energy of the silanization depends on the $\mathrm{pK}_{\mathrm{a}}$-values of the amines. The results showed that amines with $\mathrm{pK}_{\mathrm{a}}>6.5$ could decrease the activation energy of silanization and act as catalysts for the reaction. ${ }^{[15]}$ DPG has a $\mathrm{pK}_{\mathrm{a}}$ of 10.1. Aiming for DPG alternatives for the silica-reinforced rubber compounds, the present work explores the potential of amines having different structures with $\mathrm{pKa}$ in the range of 10-12, that could play a role as silanization booster as well as curing accelerator. Different types of amines: hexylamine (HEX), decylamine (DEC) and octadecylamine (OCT), cyclohexylamine (CYC), dicyclohexylamine (DIC) and quinuclidine (QUI), are investigated by taking the rubber compounds with DPG and without amine as references. The properties of both uncured and cured rubbers are compared. 


\subsection{EXPERIMENTAL}

\subsubsection{Materials}

The natural rubber used was Ribbed Smoked Sheet (RSS\#3), locally produced in Thailand. The details of the amines (all from Sigma-Aldrich Chemie, Germany) are given in Table 3.1. The rubber compounding ingredients were highly dispersible silica (Ultrasil 7005) (Evonik, Germany), bis(3triethoxysilylpropyl) tetrasulfide (TESPT) (Evonik, Germany), treated distillate aromatic extract oil (TDAE oil) (Vivatec 500, Hansen \& Rosenthal, Germany), zinc oxide ( $\mathrm{ZnO}$ ), stearic acid and sulfur (all from Sigma-Aldrich Chemie, Germany) and N-cyclohexyl-2-benzothiazole sulfenamide (CBS), diphenyl guanidine (DPG) and 2,2,4-trimethyl-1,2-dihydroquinoline (TMQ) (all from Flexys, Belgium).

\subsubsection{Preparation of rubber compounds}

Rubber compounds were prepared in two steps; the first step was executed by using an internal mixer (Brabender Plasticorder 350S), with mixing conditions of fill factor 0.70, initial mixer temperature setting of $100^{\circ} \mathrm{C}$ and rotor speed of $60 \mathrm{rpm}$. The dump temperatures of all mixes having different amine types were in a range of $153-159^{\circ} \mathrm{C}$. The final step was the mixing of the curing agents into the rubber compound on a two-roll mill. The compounding formulations and mixing procedures are shown in Tables 4.1 and 4.2 .

Table 4.1 Compound formulations.

\begin{tabular}{cc}
\hline Ingredient & Quantity (phr) \\
\hline NR & 100 \\
Silica & 55 \\
TESPT & 5 \\
ZnO & 3 \\
Stearic acid & 1 \\
TMQ & 1 \\
TDAE oil & 8 \\
DPG* & 1.1 \\
CBS & 1.5 \\
Sulfur & 1.5 \\
\hline
\end{tabular}

*) Other types of amines were used based on molar equivalents to $1.1 \mathrm{phr}$ of DPG 
Table 4.2 Compound mixing procedures.

\begin{tabular}{cc}
\hline Cumulative mixing time (min) & Step of mixing \\
\hline $\mathbf{I}^{\text {st }}$ step: Internal mixer & $\mathrm{NR}$ \\
\hline 0 & $1 / 2$ Silica $+1 / 2$ TESPT $+1 / 4$ amine \\
2 & $1 / 2$ Silica $+1 / 2$ TESPT $+1 / 4$ amine + TDAE oil \\
7 & $\mathrm{ZnO}+$ Stearic acid $+\mathrm{TMQ}$ \\
12 & Dump \\
\hline $\mathbf{1 5}$ & $\mathrm{CBS}+1 / 2$ amine \\
\hline $2^{\text {nd }}$ step: Two-roll mill & $\mathrm{S}$ \\
\hline 0 & Mixing completed \\
\hline 2 &
\end{tabular}

4.2.3 Characterization of uncured compounds: Bound rubber content, Payne effect, flocculation rate constant and thermal behavior

Bound rubber content: Testing of bound rubber content was conducted using the rubber compounds without CBS and sulfur. The compounds were cut into small pieces and approximately $0.2 \mathrm{~g}$ was put into a metal cage and immersed in toluene at room temperature for 3 days, while the toluene was renewed every day. After that, the sample was removed from the toluene, dried at $105^{\circ} \mathrm{C}$ for $24 \mathrm{~h}$, and then immersed in toluene again for 3 days under either a normal or an ammonia atmosphere. The sample was finally dried at $105^{\circ} \mathrm{C}$ for $24 \mathrm{~h}$. The treatment with ammonia was to cleave the physical linkages between rubber and silica, so that the chemically bound rubber can be determined. The bound rubber content was calculated according to Equation (4.1). ${ }^{[16]}$

$$
\text { Bound rubber content }(\%)=\frac{\left(m-m_{s}\right)}{m_{r}} \times 100
$$

Where $\mathrm{m}$ is the weight of sample after toluene extraction, $m_{s}$ is the weight of silica in the sample and $m_{r}$ is the original weight of rubber in the sample

Payne effect: The storage shear moduli $\left(\mathrm{G}^{\prime}\right)$ of the rubber compounds without curatives were evaluated by using a Rubber Process Analyzer (RPA) (Alpha Technologies, Akron, USA) at a temperature of $100^{\circ} \mathrm{C}$, frequency of $0.5 \mathrm{~Hz}$ and varying strains in the range of $0.28-100 \%$. The Payne effect was calculated as the difference in storage shear moduli between low strain $(0.56 \%)$ and high strain $(100 \%)$. 
Flocculation rate constant: The flocculation rate constant $\left(K_{a}\right)$ of the uncured silica-reinforced NR compounds without curatives was studied by using the RPA at $100^{\circ} \mathrm{C}$, a strain of $0.56 \%$, frequency $1.00 \mathrm{~Hz}$, and test time of max. $12 \mathrm{~min}$. The storage shear moduli at different times were determined and then the $K_{a}$ was calculated following Equations (4.2) and (4.3): ${ }^{[17]}$

$$
x=\frac{s^{\prime}(t)-s^{\prime}(1)}{s(\infty)-s^{\prime}(1)}
$$

Where $x$ is the degree of flocculation, $s^{\prime}(t)$ is the storage modulus at $0.56 \%$ strain at test time $t$, $s^{\prime}(1)$ is the storage modulus after preheating for $1 \mathrm{~min}$, and $s^{\prime}(\infty)$ is the storage modulus after heating for $12 \min$.

$$
K_{a}\left[\min ^{-1}\right]=\frac{\ln \left(1-x_{1}\right)-\ln \left(1-x_{2}\right)}{t_{2}-t_{1}}
$$

Where $x_{1}$ and $x_{2}$ are the degree of flocculation at different heating times, i.e. $t_{1}$ and $t_{2}$, respectively.

Thermal behavior: The glass transition temperature $\left(\mathrm{T}_{\mathrm{g}}\right)$ and heat capacity increment $\left(\Delta \mathrm{C}_{\mathrm{p}}\right)$ of the uncured rubber compounds were assessed by using differential scanning calorimetry (DSC) (DSC214 Polyma, Netzsch, Selb, Germany). The rubber compounds were analyzed under nitrogen atmosphere in the temperature range of -100 to $+30^{\circ} \mathrm{C}$ at a heating rate of $10^{\circ} \mathrm{C} / \mathrm{min}$. The change of heat flow in the second heating scan was recorded after removing the material heating history in the first heating scan.

\subsubsection{Testing of cure characteristics and vulcanization}

Scorch time $\left(\mathrm{T}_{\mathrm{s1}}\right)$, cure time $\left(\mathrm{T}_{\mathrm{c} 90}\right)$ and cure rate index $(\mathrm{CRI})$ were tested using the RPA at $150^{\circ} \mathrm{C}$, frequency $0.833 \mathrm{~Hz}$ and $2.79 \%$ strain. The CRI was calculated as [100/(cure time - scorch time)].

The cure reaction rate constant $(k)$ of the rubber compounds with different types of amines was evaluated based on the equation commonly applied for the kinetics of first order chemical reactions as shown in Equation (4.4): ${ }^{[18]}$

$$
\ln (a-b)=-k t+\ln a
$$

Where $a$ is initial reactant concentration, $b$ is reacted quantity of reactant at time $t$, and $k$ is the first order rate constant.

For the rubber compounds, a crosslinking reaction rate can be derived by measuring the torque increase during the vulcanization reaction. The change of reactant concentration in Equation (4.3) is then replaced by the rheometer torque as described in Equations (4.5) and (4.6):

$$
\begin{aligned}
& (a-b)=M_{h}-M_{t} \\
& a=M_{h}-M_{0}
\end{aligned}
$$


Where $M_{h}$ is maximum rheometer torque, $M_{0}$ is minimum rheometer torque and $M_{t}$ is rheometer torque at time $\mathrm{t}$.

Therefore, the kinetics of the vulcanization reaction can be defined as Equation (4.7).

$$
\ln \left(M_{h}-M_{t}\right)=-k t+\ln \left(M_{h}-M_{0}\right)
$$

The cure reaction rate constant $(k)$ is then obtained from the slope of the plot of $\ln \left(M_{h}-M_{t}\right)$ versus $t$.

The rubber compounds were vulcanized to their respective optimum cure times ( $\left.\mathrm{t}_{\mathrm{c} 90}\right)$ by using a WLP 1600 laboratory compression press (Wickert Maschinenbau GmbH, Landau, Germany) at $150^{\circ} \mathrm{C}$ and 100 bar.

\subsubsection{Testing of tensile and dynamic properties of the vulcanizates}

Tensile test: Type 2 dumb-bell test specimens were prepared and the tensile properties (i.e. modulus at different strains, tensile strength and elongation at break) were tested with a Zwick tensile tester Model Z1.0/TH1S (Zwick Roell Group, Ulm, Germany) at a crosshead speed of $500 \mathrm{~mm} / \mathrm{min}$ according to ASTM D412.

Loss tangent at $60^{\circ} \mathrm{C}$ : The loss tangent of the vulcanizates was determined using the RPA at $60^{\circ} \mathrm{C}$, strain $3.49 \%$ with varying frequency sweeps in the range of $0.05-33.00 \mathrm{~Hz}$. The samples were cured prior to the loss tangent measurement in the RPA chamber at $150^{\circ} \mathrm{C}$ to their respective optimum cure times.

\subsection{RESULTS AND DISCUSSION}

\subsubsection{Filler-rubber interaction}

The effective use of TESPT as silane coupling agent in the silica-reinforced NR matrix introduces silica-TESPT-rubber bridge formation. The silica-TESPT interactions are introduced during mixing and enhance filler-rubber interaction, that can be registered by bound rubber contents. The total bound rubber content is affected by both physical and chemical interactions as shown in Figure 4.1. Considering the values of chemically bound rubber content, which is an indication for the extent of the silanization reaction, the compounds with amines tend to show higher chemically bound rubber contents compared to the one without amine, except for the amines with cyclic structures: CYC and DIC. The presence of basic amines catalyzes the silanization reaction between the silanol groups on the silica surfaces and the alkoxy groups of silane molecules, indeed. The alkoxy-groups in the silane molecules can be hydrolyzed by the amines to form hydroxyl-groups before reacting with the silanol groups on the silica. ${ }^{[19]}$ Therefore, the addition of amines in the silica-TESPT-rubber systems positively contributes to the silanization reaction. 


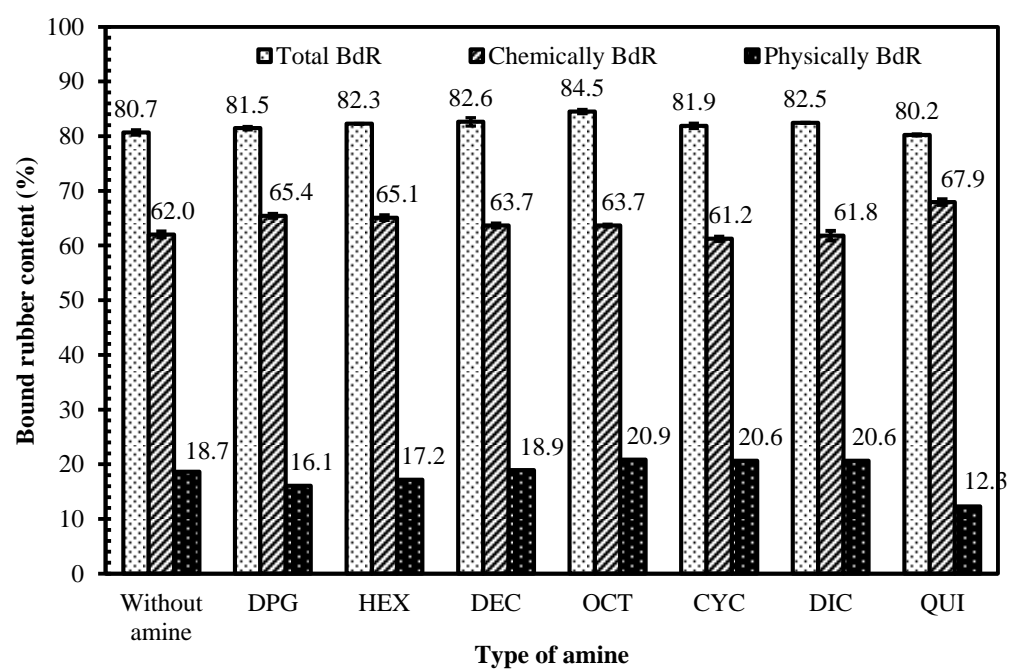

Figure 4.1 Bound rubber contents of silica-reinforced NR compounds.

The types of amines with different molecular structures, i.e. aliphatic and cyclic, show various influences on the bound rubber content. QUI that has the highest $\mathrm{pK}_{\mathrm{a}}$ is the strongest catalyst for the silanization reaction, yielding the highest chemically bound rubber content. When comparing among the amines with very similar $\mathrm{pK}_{\mathrm{a}}$ values, the results show that the amines with alkyl chains (i.e. HEX, DEC and OCT) give higher chemically bound rubber contents, compared to the use of amines with cyclic structures (i.e. CYC and DIC). This may be related to steric effects, as the bulky cyclic rings obstruct the access of silane and amine itself to the silanol groups on the silica surface, that could hinder the silanization reactions. Moreover, as only part of the silanol groups on the silica surface react with the ethoxy groups of the silane, leaving some free silanol groups unreacted, polar amines will adsorb on the silica surface giving an additional shielding effect of these acid silanol-groups which otherwise would hinder the vulcanization reaction. The use of amines with straight alkyl chains provides a greater level of shielding due to a better accessibility. However, the amines with longer alkyl chains show a decrease of chemically bound rubber content and an increase in physically bound rubber. This observation can be related to the adsorption of the long molecular chains of the aliphatic amines, that may interfere with the silanization reaction due to steric hindrance compared to the presence of short chains. However, the longer chains should on the other hand introduce more chain entanglement around the filler surface and enhance hydrophobicity of the surface, that leads to an increased compatibility between silica and the rubber. Moreover, the reactivity of the amines as catalyst should be also affected by their molecular sizes. It is an intricate balance between apparently opposing effects. Therefore, the use of OCT and DEC results in lower chemically bound rubber contents compared to the use of HEX, and the OCT that possesses the longest hydrocarbon chains clearly gives a higher physically bound rubber content than the use of DEC and HEX, respectively. The amines 
with cyclic rings, i.e. CYC and DIC, can shield the silica surface to a lesser extent and so give the lowest bound rubber contents. With the compound consisting of DPG as reference, the use of HEX, DEC and OCT provides similar chemically bound rubber contents.

\subsubsection{Payne effect and flocculation rate constant}

The Payne effect of the silica-filled rubber compounds is normally used to explain the degree of filler-filler interactions that are mainly caused by hydrogen bonding, leading to formation of the filler network in the rubber matrix. The changes of the storage moduli of the rubber compounds as a function of strain are exhibited in Figure 4.2. In general, the storage modulus of filled rubber compounds decreases with increasing strain due to the breakdown of the filler network and slip of polymer chains on the filler surface under dynamic deformation. The difference in storage moduli at low and high strains, i.e. G' (at $0.56 \%)-\mathrm{G}^{\prime}$ (at $100 \%$ ), can be taken as a measure for the level of filler-filler interaction within the rubber compounds: Table 4.3. As previously discussed for the chemically bound rubber contents, the polar silanol groups on the silica surfaces decrease after the silanization reaction in the presence of amines, and the hydrophobicity of the silica is enhanced. The use of all amines in the silica-reinforced rubber compounds results in lower Payne effects compared to the rubber compound without amine. The values of the Payne effect of the compounds with DEC, OCT and QUI are close to that of the reference compound with DPG. Among the different types of amines, QUI has the highest $\mathrm{pKa}$ value and so the strongest catalytic activity for the silanization reaction, while DEC and OCT gain benefit from the shielding effect of the longer alkyl chains on the silica surface.

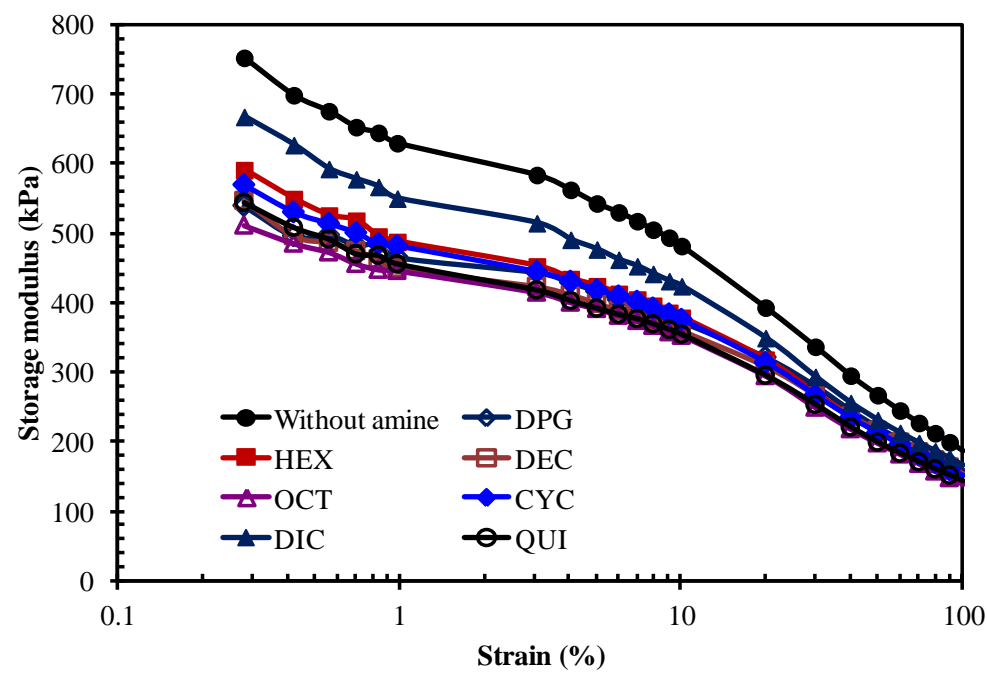

Figure 4.2 Storage moduli at varying strains of silica-reinforced NR compounds. 
Table 4.3 Payne effect and flocculation rate of silica-reinforced NR compounds.

\begin{tabular}{|c|c|c|}
\hline & $\mathrm{G}^{\prime}($ at $0.56 \%)-\mathrm{G}^{\prime}($ at $100 \%)(\mathrm{kPa})$ & $\begin{array}{l}\text { Flocculation rate constant, } K_{a} \\
\qquad\left(\mathrm{~min}^{-1}\right)\end{array}$ \\
\hline Without amine & 505 & 0.23 \\
\hline DPG & 338 & 0.13 \\
\hline HEX & 373 & 0.14 \\
\hline DEC & 333 & 0.19 \\
\hline OCT & 333 & 0.20 \\
\hline $\mathrm{CYC}$ & 364 & 0.16 \\
\hline DIC & 426 & 0.29 \\
\hline QUI & 348 & 0.16 \\
\hline
\end{tabular}

Comparing the aliphatic and cyclic structures, the Payne effect of the rubber compounds with the amines of cyclic structure especially DIC, show the highest values which may be related to steric hindrance for the silanes to react on the silica surface and their low accessibility to the left-over free silanol groups after the silanization reaction. On the other side, the amines with aliphatic alkyl chains can cover the silica surface via polarity interactions and reduce the polarity of the silica surface. Therefore, the filler-filler interactions of the silica-reinforced natural rubber compounds with aliphatic amines having linear alkyl chains tend to decrease with increasing chain length, because of greater hydrophobicity.

For the silica-reinforced rubber compounds, once the silica agglomerates are broken into aggregates and well dispersed in the rubber matrix, re-agglomeration or de-mixing or so-called flocculation can occur upon storage and especially under thermal treatment. The flocculation rate constant $\left(K_{a}\right)$ indicates how fast re-agglomeration takes place, i.e. the stability of the silica aggregates dispersion. The use of silica/silane with amines, except for the case of DIC, shows lower $K_{a}$ values compared to the one without: Table 4.3. DPG, HEX, CYC and QUI give similar $K_{a}$ values which may relate to their efficiency to enhance the silanization reaction. DEC and OCT that give similar Payne effects compared to DPG, exhibit higher flocculation rate constants. The longer alkyl chains of DEC and OCT help to disperse the silica, but the silica-amine interaction is via hydrogen bonding that is not stable at elevated temperatures. Reagglomeration can still take place after the disappearance of the silica-amine interactions during thermal treatment. In addition to the silanization reaction that induces chemical bonding between silica and silane molecules, adsorption of amine molecules promoting hydrophobicity by the shielding effect also plays a role in the Payne effect and flocculation rate. The physical adsorption of aliphatic amines with longer carbon atoms on the silica surface therefore reduces the Payne effect, but increases the flocculation rate 
constant of the rubber compounds due to the presence of weak physical interactions rather than strong chemical bonding.

\subsubsection{Thermal behavior}

The states of rubber materials depend on temperature. The glass transition temperature $\left(\mathrm{T}_{\mathrm{g}}\right)$ is influenced by the molecular structure, chain mobility and flexibility. A higher degree of freedom, higher chain mobility and more flexibility lead to lower $\mathrm{T}_{\mathrm{g}}$. It is well known that the abrasion or wear resistance of tires relates to the $\mathrm{T}_{\mathrm{g}}$ of the tread compounds and filler dispersion. The silica-reinforced natural rubber tire compounds with different amines show similar $\mathrm{T}_{\mathrm{g}}$ 's, as shown in Table 4.4. This may imply that all the rubber compounds have a similar abrasion resistance. With DSC analysis the heat capacity increment $\left(\Delta \mathrm{C}_{\mathrm{p}}\right)$ of the rubber compounds can also be evaluated. The $\Delta \mathrm{C}_{\mathrm{p}}$ at $\mathrm{T}_{\mathrm{g}}$ of the rubber compounds corresponds to the fraction of rubber molecules that change in chain mobility. In the presence of filler the mobility of rubber chains around the filler surface is changed, in which the filler dispersion, filler aspect ratio as well as fillerrubber interactions all play a role. The rubber chains on the filler surface that cannot move are called the immobilized polymer layer, indicating the interfacial adhesion between the filler-rubber phases. ${ }^{[18]}$ The silica-reinforced NR compounds with different amine types exhibit different $\Delta \mathrm{C}_{\mathrm{p}}$ values. The compounds with the amines display lower $\Delta \mathrm{C}_{\mathrm{p}}$ than the one without amine. The use of OCT and QUI results in the lowest $\Delta \mathrm{C}_{\mathrm{p}}$, which indicates the greatest change in mobility caused by the silanization reaction and the physical shielding effect. The use of amines accelerates the reaction to generate filler-rubber interactions and deactivates free silanol groups to promote hydrophobicity, and hence enhances the compatibility between silica surfaces and rubber chains. The lowest $\Delta \mathrm{C}_{\mathrm{p}}$ values of the compounds with OCT and QUI correspond well with the lowest Payne effects. But their difference in flocculation rate constants $\left(K_{a}\right)$ suggests that the immobilized polymer layers around the silica surface are predominantly generated by different causes. The silanization reaction that leads to chemical interactions is more prominent in the compound with DPG and HEX, while the physical shielding effect is prevailing in the one with OCT. Under thermal treatment, the weak physical interactions are destroyed and flocculation occurs faster. 
Table 4.4 Glass transition temperature and heat capacity increment, normalized by the value for the neat natural rubber, of silica-reinforced NR compounds.

\begin{tabular}{lcc}
\hline & Glass transition temperature $\left({ }^{\circ} \mathbf{C}\right)$ & Heat capacity increment \\
\hline Without amine & -70.4 & 0.325 \\
DPG & -71.2 & 0.261 \\
HEX & -71.0 & 0.295 \\
DEC & -68.4 & 0.238 \\
OCT & -69.9 & 0.218 \\
CYC & -70.8 & 0.255 \\
DIC & -69.4 & 0.266 \\
QUI & -72.3 & 0.219 \\
\hline
\end{tabular}

\subsubsection{Cure behaviors}

The scorch times $\left(\mathrm{T}_{\mathrm{s} 1}\right)$, cure times $\left(\mathrm{T}_{\mathrm{c} 90}\right)$, cure rate indices $(\mathrm{CRI})$ and cure reaction rate constants $(k)$ of the silica-reinforced NR compounds with the different types of amines are shown in Table 4.5. The inclusion of amines of all types improves the cure behaviors; scorch and cure times decrease while the cure rate index and cure reaction rate constants increase. Next to their accelerating effect, the amines are also known to deactivate the left-over silanol-groups on the silica surface so that the interference of such polar groups with the vulcanization is suppressed. The conventional DPG which is commonly used as a secondary accelerator in silica-silane systems effectively synergizes with the primary accelerator, the sulfenamide accelerator, and provides a high cure reaction rate.

Table 4.5 Cure behaviors of silica-reinforced NR compounds.

\begin{tabular}{lcccc}
\hline & $\begin{array}{c}\text { Scorch time, } \\
\mathbf{T}_{\mathbf{s} \mathbf{1}}(\mathbf{m i n})\end{array}$ & $\begin{array}{c}\text { Cure time, } \mathbf{T}_{\mathbf{c} 90} \\
(\mathbf{m i n})\end{array}$ & $\begin{array}{c}\text { Cure rate index, } \\
\text { CRI (min }\end{array}$ & $\begin{array}{c}\text { Cure reaction } \\
\text { rate constant, } \boldsymbol{k}\end{array}$ \\
\hline Without amine & 3.36 & 12.12 & 11.41 & 0.30 \\
DPG & 1.35 & 3.01 & 60.24 & 1.37 \\
HEX & 1.47 & 3.56 & 47.85 & 1.03 \\
DEC & 1.39 & 3.25 & 53.76 & 1.29 \\
OCT & 1.46 & 3.34 & 53.19 & 1.26 \\
CYC & 2.15 & 4.38 & 44.84 & 1.12 \\
DIC & 1.46 & 5.43 & 25.19 & 0.80 \\
QUI & 1.13 & 2.36 & 81.30 & 1.95 \\
\hline
\end{tabular}


Comparing the different types of amines as DPG alternatives for cure properties, QUI with the highest $\mathrm{pK}_{\mathrm{a}}$ value gives the fastest cure time and highest CRI, and consequently the cure reaction rate constant. The use of aliphatic amines with alkyl-structures displays faster scorch and cure times than the aliphatic amines with cyclic rings. In this case, the cure behaviors are affected by several factors including the $\mathrm{pK}_{\mathrm{a}}$ of the amines, the extent of silanization, the availability of amine and its shielding effect for the left-over silanol groups, and sulfur donation by TESPT. The chemistry of the silica surface with polar silanol groups enhances adsorption of other polar molecules in the system, especially TESPT and amines. However, the molecules not only locate around the silica surface but also remain in the rubber matrix. ${ }^{[21]}$ In the case of adsorption of amine molecules on the silica surface, the chemistry of silica surface changes. As only part of the TESPT reacts with the silanol groups, free TESPT in the rubber matrix remains available and this TESPT can donate free sulfur atoms to participate in the crosslinking reaction between the rubber chains. The presence of DPG alternatives promotes the vulcanization reaction.

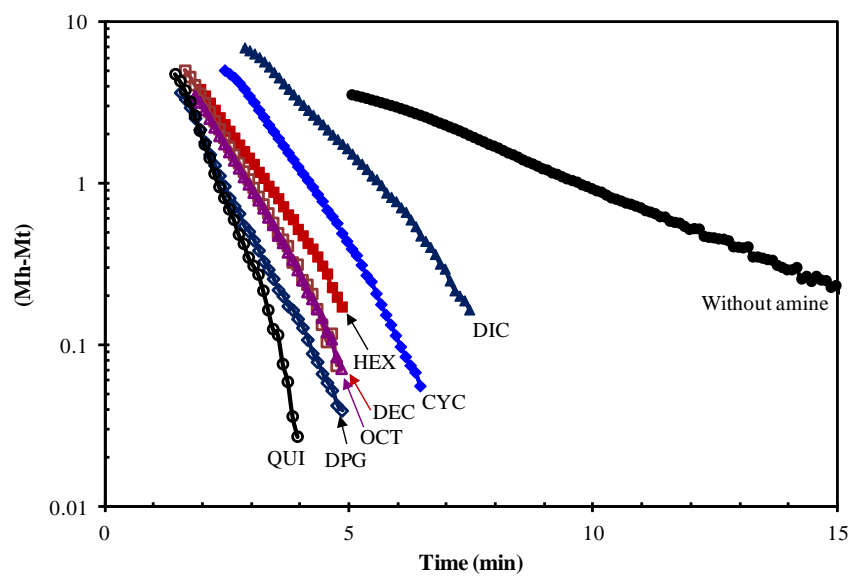

Figure 4.3 (Mh-Mt) against time of silica-reinforced NR compounds.

Based on the kinetics of the vulcanization reaction as defined in Equation (7), a plot of $\ln \left(M_{h}-M_{t}\right)$ against $t$ is shown in Figure 4.3 for the silica-filled NR compounds containing the different amine types. The cure reaction rate constant $(k)$ as determined by the slope of these plots is summarized in Table 4.5. Obviously, the rate constant corresponds well with the cure rate index. The strongest base QUI exhibits the highest cure reaction rate constant, followed by DPG. In the case of DPG alternatives, the compounds with aliphatic amines with long $\mathrm{C}$-atom linear chains, i.e. DEC and OCT, exhibit faster cure reaction rates than the ones with amines having cyclic rings. The reason is as discussed for their cure behaviors. DIC has the lowest $k$ because its bulky two rings structure obstructs the access of itself and TESPT to the silica surface. Its reactivity as accelerator is also affected by the steric hindrance. 


\subsubsection{Tensile properties}

The moduli at different strains, 100, 200 and 300\%, of the rubber vulcanizates are summarized in Table 4.6. The use of amines in the silica-reinforced rubber compounds improves the moduli compared to the compound without amine while the amines promote both the silanization and vulcanization reactions. The use of DPG leads to higher moduli than the use of the other amines, except for DIC, which gives even higher moduli, whereas the use of QUI gives the lowest values. The superior moduli obtained for the compound with DPG reflects the effective vulcanization synergistically accelerated by both primary and secondary accelerators. The compound with DIC exhibits the highest moduli but relatively low tensile strength and elongation at break (Figure 4.4), due to the highest Payne effect, i.e. the highest filler-filler interactions, and poorest CRI as well as lowest cure reaction rate constant, that lead to poor silica dispersion and an inferior crosslink network in the rubber matrix.

Table 4.6 Moduli at 100, 200 and 300\% strains, and reinforcement index of silica-reinforced NR compounds.

\begin{tabular}{lcccc}
\hline & M100 $(\mathbf{M P a})$ & M200 $(\mathbf{M P a})$ & M300 $(\mathbf{M P a})$ & M300/M100 \\
\hline Without amine & $1.3 \pm 0.1$ & $3.9 \pm 0.1$ & $8.6 \pm 0.2$ & $6.5 \pm 0.2$ \\
DPG & $2.0 \pm 0.1$ & $6.7 \pm 0.3$ & $13.6 \pm 0.6$ & $6.8 \pm 0.1$ \\
HEX & $1.4 \pm 0.1$ & $4.3 \pm 0.3$ & $9.8 \pm 0.5$ & $7.1 \pm 0.3$ \\
DEC & $1.4 \pm 0.1$ & $4.5 \pm 0.4$ & $10.4 \pm 0.8$ & $7.3 \pm 0.6$ \\
OCT & $1.6 \pm 0.1$ & $5.3 \pm 0.4$ & $11.6 \pm 0.6$ & $7.5 \pm 0.4$ \\
CYC & $1.6 \pm 0.1$ & $5.6 \pm 0.3$ & $12.5 \pm 0.7$ & $7.9 \pm 0.1$ \\
DIC & $2.5 \pm 0.3$ & $9.2 \pm 0.9$ & $17.9 \pm 1.5$ & $7.1 \pm 0.4$ \\
QUI & $1.2 \pm 0.1$ & $4.0 \pm 0.6$ & $9.5 \pm 1.4$ & $7.7 \pm 0.9$ \\
\hline
\end{tabular}




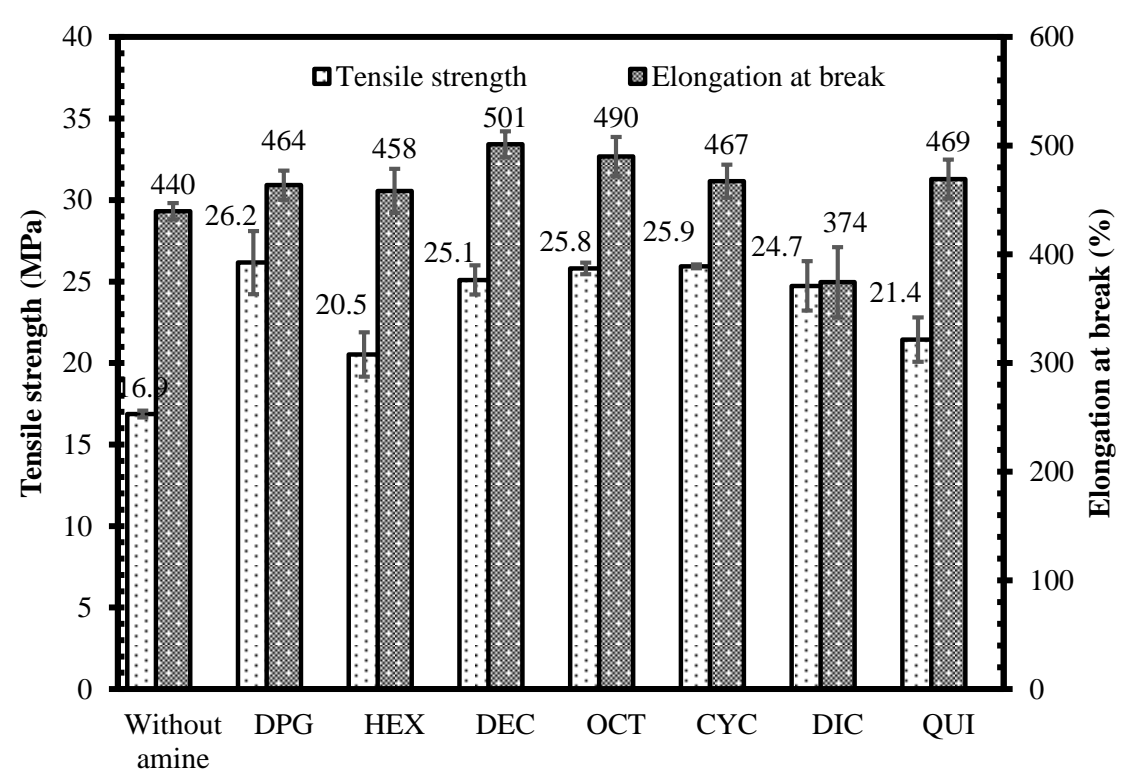

Type of amine

Figure 4.4 Tensile strength and elongation at break of silica-reinforced NR vulcanizates for various amines.

The amines promote filler-rubber interfacial compatibility and crosslinking of the rubber matrix, so enhancing the tensile properties as shown in Figure 4.4. Based on the stress-strain test data, the rubber network and silica-rubber interactions in the rubber compounds can be further evaluated by plots of the reduced stress $\left(\sigma^{*}\right)$ against the reciprocal of the extension ratio $(\lambda)$ following the Mooney-Rivlin equation, as shown below: ${ }^{[22]}$

$$
\sigma^{*}=\frac{\sigma}{\lambda-\lambda^{-2}}=2 C_{1}+2 C_{2} \lambda^{-1}
$$

Where $\sigma$ is the stress and $2 C_{I}$ and $2 C_{2}$ are constants that are independent of $\lambda$. The Mooney-Rivlin curves of the silica-reinforced NR vulcanizates with different types of amines are shown in Figure 4.5. To the lower strain side, the reduced stress decreases to a flat region and later increases to give an upturn. This upturn point of the rubber vulcanizate can be used to indicate the interfacial interaction between rubber and filler, respectively the crosslinking network within the rubber, as the upturn point is ascribed to the finite extensibility of the rubber chains bridging neighboring filler particles during stretching. ${ }^{[23]}$ The occurrence of the upturn point at lower strain indicates that rubber chain orientation in between the filler particles occurs more easily. Moreover, induced crystallization also affects the upturn point for NR compounds. ${ }^{[24]}$ The results in Figure 4.5 show that the use of OCT and CYC exhibits upturn points at high value of $\lambda^{-1}$, i.e. low $\lambda$, close to the behavior of the reference compound with DPG. It demonstrates that the use of OCT, CYC and DPG in the silica-reinforced NR compounds provides an overall balance between interfacial 
interaction and the crosslink network, to facilitate orientation of the rubber chains which can arise from both chemical crosslinks and physical entanglement points.

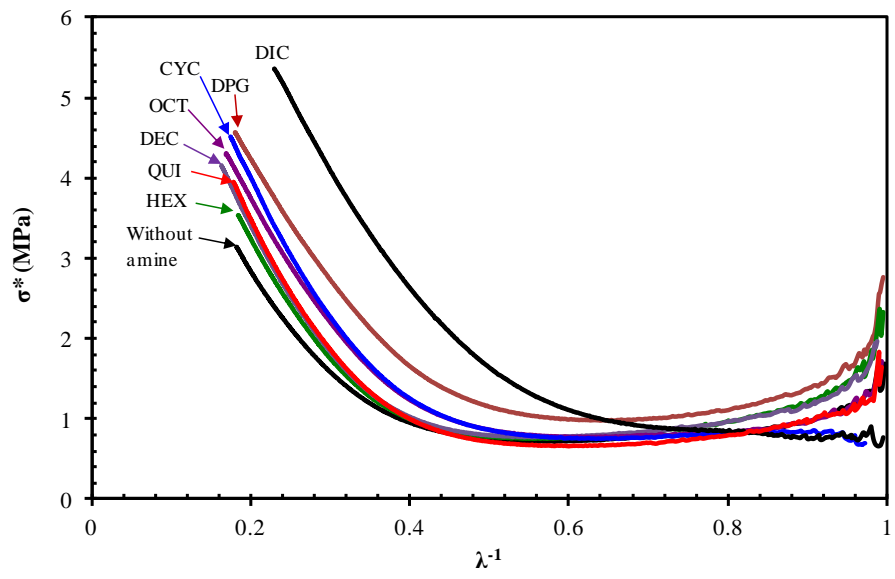

Figure 4.5 Mooney-Rivlin plots of silica-reinforced NR vulcanizates for various amines.

The compound without amine shows the upturn point at the highest strain, i.e. chain orientation is difficult, which can be because of less filler-rubber interactions and less crosslinking affected by its inferior cure behavior. In the case of the DIC containing compound, the reduced stress is lowest at low strain, i.e. the highest $\lambda^{-1}$, and there is no clear upturn point as observed for the other compounds. Among the amine containing compounds, the DIC containing has the highest Payne effect, highest flocculation rate constant and highest moduli, the trapped chains within the silica aggregates are most constrained and have the lowest extensibility between the filler particles. Therefore, the compound with DIC shows the worst behavior compared to others.

\subsubsection{Loss tangent at $60^{\circ} \mathrm{C}$}

Because the silica-reinforced NR compounds in this study are aimed for tire tread applications, one of the properties of interest is the tire rolling resistance that can be indicated by the loss tangent or tan $\delta$ at $60^{\circ} \mathrm{C}$, obtained from dynamic testing of the vulcanizates. The $\tan \delta$ at $60^{\circ} \mathrm{C}$ of the silica-reinforced NR vulcanizates with different types of amines are shown in Figure 4.6 against frequency, in comparison with the values of the reference compounds with DPG and without amine. The results show that the $\tan \delta$ of the rubber compound without amine is obviously higher than those of the compounds with amines. The different types of amines show no significant differences amongst each other on the tan $\delta$ at $60^{\circ} \mathrm{C}$ of the rubber vulcanizates, implying similar rolling resistance for tires made therefrom. 


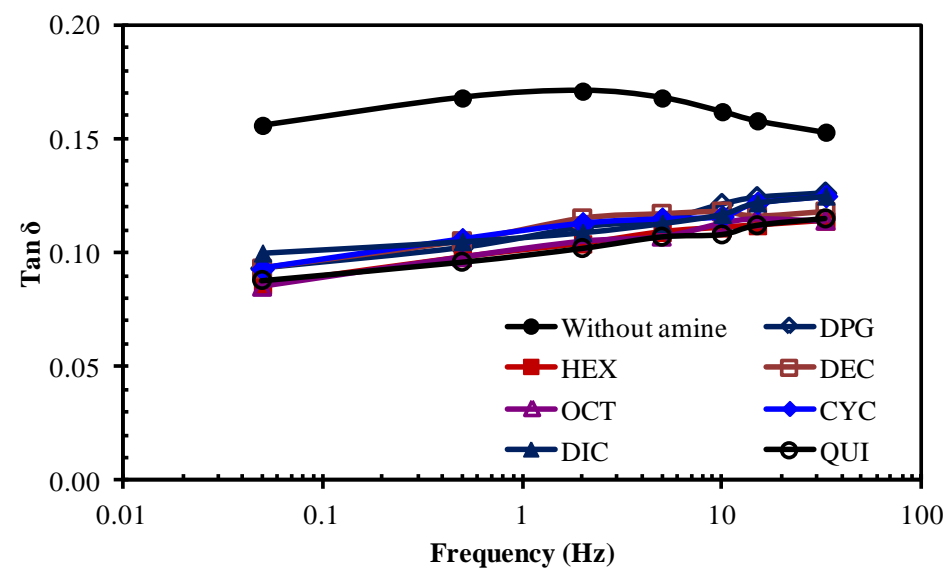

Figure 4.6 Tan $\delta$ at $60^{\circ} \mathrm{C}$ of silica-reinforced NR vulcanizates for various amine types.

\subsection{CONCLUSIONS}

The study on the effect of several types of amines having different structures in silica-reinforced NR compounds, as alternatives for DPG and in comparison with a compound without any amine, clearly shows that the presence of amines in the compounds promotes both the silanization and vulcanization reactions, as reflected in changes of the Payne effects, bound rubber contents and cure properties. The use of aliphatic amines with alkyl chains, i.e. HEX, DEC and OCT, gives lower Payne effects but higher flocculation rate constants with increasing aliphatic chain length. The amine with a bicyclic ring structure: DIC is less effective than the one with one cyclic ring CYC, due to steric hindrance effects. In the presence of amines, the filler-rubber compatibility is promoted as revealed by the change of the heat capacity increment $\Delta \mathrm{C}_{\mathrm{p}}$ at $\mathrm{T}_{\mathrm{g}}$ due to the immobilized rubber layer around the filler surface. The use of all types of amines enhances the vulcanization reaction in which QUI with the highest $\mathrm{pK}_{\mathrm{a}}$ gives the fastest cure. With very similar $\mathrm{pK}_{\mathrm{a}}$ values, i.e. DEC, OCT and CYC, the amines with alkyl structures lead to higher cure reaction rates. The bulky structure of DIC prevents its accessibility to the left-over silanol groups on the silica surface after the silanization, so that the cure reaction is retarded to a larger extent compared to the other amines. After vulcanization, the vulcanizates with DEC, OCT and CYC show similar tensile strength with slightly higher elongation at break compared to DPG. The addition of all amines clearly enhances the tensile properties and lowers $\tan \delta$ at $60^{\circ} \mathrm{C}$ compared to the one without amine. QUI gives uncured properties closest to DPG but poorer tensile properties. Overall, DEC and OCT show the highest potential to be used as alternatives for DPG in silica/silane reinforced natural rubber. 


\subsection{REFERENCES}

[1] R. Rauline, E.P. Patent 0501227A1 (to Michelin and Cie), Feb. 12, 1992.

${ }^{[2]}$ J. Neubauer, Tire Technol. Int., p. 10-12 (2009).

${ }^{[3]}$ D.E. Hall, J.C. Moreland, Rubber Chem. Technol., 74, 525 (2001).

[4] U. Goerl, A. Hunsche, A. Mueller, H.G. Koban, Rubber Chem. Technol. 70, 608 (1997).

${ }^{[5]}$ J.W. ten Brinke, S.C. Debnath, L.A.E.M. Reuvekamp, J.W.M. Noordermeer, Compos. Sci. Technol. 63, 1165 (2003).

${ }^{[6]}$ A. Blume, Kautsch. Gummi Kunstst. 64, 38 (2011).

${ }^{[7]}$ S. Mihara, R.N. Datta, A.G. Talma, J.W.M. Noordermeer, U.S. Patent 7923493B2, (Apr. 12, 2011).

${ }^{[8]}$ W. Kaewsakul, K. Sahakaro, W.K. Dierkes, J.W.M. Noordermeer, Rubber Chem. Technol. 86, 313 (2013).

${ }^{[9]}$ T.A. Okel, Rubber World 244, 30 (2011).

${ }^{[10]}$ Internet page, http://www.atsdr.cdc.gov/toxfaqs/tfacts171.pdf (May 23, 2014).

${ }^{[11]}$ H. Krebs, Rubber Chem. Technol. 30, 962 (1957).

${ }^{[12]}$ I. Surya, H. Ismail, A.R. Azura, Polym. Test. 32, 1313 (2013).

[13] J. Liu, C. Wu, P. Zhang, S. Zhao, J. Macromol. Sci. B. 47, 689 (2008).

${ }^{[14]}$ Y. Tanabe, K. Miyoshi, Y. Kirino, Rubber Chem. Technol. 89, 349 (2016).

${ }^{[15]}$ S. Mihara, "Reactive Processing of Silica-Reinforced Tire Rubber: New Insight into the Time- and Temperature- Dependence of Silica Rubber Interaction", PhD. Thesis: 2009, Dept. of Elastomer Technology and Engineering, Univ. of Twente, Enschede, the Netherlands.

${ }^{[16]}$ S. Wolff, MJ. Wang, EH. Tan, Rubber Chem. Technol. 66, 163 (1993).

${ }^{[17]}$ S. Mihara, R.N. Datta, J.W.M. Noordermeer, Rubber Chem. Technol. 82, 524 (2009).

${ }^{[18]}$ G. Mathew, R.P. Singh, N.R. Nair, S. Thomas, J. Mater. Sci. 38, 2469 (2003).

${ }^{[19]}$ K-J. Kim, J. VanderKooi, Rubber Chem. Technol. 78, 84 (2005).

${ }^{[20]}$ D. Fragiadakis, L. Bokobza, P. Pissis, Polymer 52, 3175 (2011).

${ }^{[21]}$ H. Dohi, S. Horiuchi, Langmuir 23, 12344 (2007).

${ }^{[22]}$ L.R.G. Treloar, "The Physics of Rubber Elasticity", Oxford University Press, New York, 1975.

${ }^{[23]}$ Z. Tang, J. Huang, X. Wu, B. Guo, L. Zhang, F. Liu, Ind. Eng. Chem. Res. 54, 10747 (2015).

${ }^{[24]}$ S. Joly, G. Garnaud, R. Ollitrault, L. Bokobza, Chem. Mater. 14, 4202 (2002). 


\begin{abstract}
Octadecylamine (OCT) as alternative for diphenyl guanidine (DPG) in silica-reinforced NR tire compounds with bis(3-triethoxysilyl-propyl)tetrasulfide (TESPT) as silane coupling agent was investigated with focus on the improvement of compatibility between the silica surface and rubber molecules, by taking the amine-free rubber compound as a reference. The quantity of OCT and DPG was varied in a range of 2.4-9.5 mmol per 100 parts of rubber by weight, i.e.0.5-2.5 phr. Bound rubber contents, changes in heat capacity $\left(\Delta C_{p}\right)$ and immobilized polymer layer $\left(X_{i m}\right)$ data prove an enhanced interfacial compatibility as the amines are absorbed on the polar silica surface and catalyze the silanization reaction. Comparing the two different amine types, the rubber compounds with OCT show higher interfacial compatibility than the ones with DPG, due to an additional shielding effect promoted by the long alkylchain that leads to more hydrophobicity. Thus, the rubber compounds with OCT show higher physically bound rubber contents and consequently higher total bound rubber, higher immobilized polymer layer as well as a lower Payne effect. However, the compounds with OCT show a higher flocculation rate constant due to the fact that the physical interactions between amine and silanol groups decrease under thermal treatment. The compounds with OCT show a lower cure torque difference that indicates a lower crosslink density, but due to the good interfacial interaction combining both chemical and physical interactions, the vulcanized rubber with OCT at optimum loading shows better mechanical properties and tan $\delta$ at $60^{\circ} \mathrm{C}$ when compared to the DPG counterpart. At high (excessive) loading of amines, the compounds with DPG clearly have higher crosslink density and thus higher modulus as well as tensile strength compared to the use of OCT.
\end{abstract}




\subsection{INTRODUCTION}

A filler is one of the crucial components in rubber compounds, added to enhance their properties to match the requirements for a variety of rubber applications. The most commonly used reinforcing fillers are carbon black and silica. ${ }^{[1]}$ Highly dispersible silica has been introduced for tire tread compounds, for production of low rolling resistance or fuel-saving tires. ${ }^{[2]}$ Due to hydrophilic silanol groups on the surface silica particles easily interact via hydrogen bonding with adjacent particles to form aggregates and agglomerates, and are thus difficult to disperse in hydrocarbon rubber matrices ${ }^{[3-4]}$ such as natural rubber (NR), styrene butadiene rubber (SBR) and polybutadiene rubber (BR). Good dispersion and strong silicarubber interactions are the main factors to provide the key tire performances: rolling resistances, wet and dry traction and wear or abrasion resistance.

Several approaches in surface modification of silica particles to improve the compatibility between the silica surface and rubber matrix are known, in which silica-silane technology is the most widely used method. Silane coupling agents with bifunctional reactive groups to bridge the silica with rubber molecules are successfully used and have been widely studied for silica-filled rubber compounds. ${ }^{[4-9]}$ Among a wide variety of silanes available, the state-of-the-art bis(triethoxysilylpropyl) tetrasulfide (TESPT) is most commonly used for the silica/rubber technology with sulfur vulcanization. The alkoxygroups will react with the silanol groups on the silica surface via a condensation reaction, the so-called silanization reaction ${ }^{[10-11]}$ during mixing, and later the sulfur atoms in the silane molecules will be involved in the curing stage to form chemical bonds with the rubber molecules. ${ }^{[12]}$

The crucial factors to promote the silanization reaction are mixing temperature and time. The compound dump or discharge temperature has been reported to have a strong influence on the extent of the silanization reaction, and thus on the properties of the rubber compounds both before and after vulcanization. ${ }^{[13-14]}$ By mixing silica/silane with rubber at high temperature in an attempt to drive the reaction forward, the rubber phase can already undergo degradation, especially NR. ${ }^{[14]}$ Moreover, NR is well known for its sensitivity to mastication and so it cannot be mixed for an extended period of time. Therefore, the working temperature window is relatively narrow for silica-reinforced NR compounds. To enhance the reaction rate, a base catalyst is commonly used to promote the silanization reaction ${ }^{[15-19]}$ and in practical applications diphenyl guanidine (DPG) which is normally used as secondary accelerator for the sulfenamide-accelerated vulcanization system, performs this task in promoting the condensation reaction and to shield the left-over silanol-groups after the reaction. The amine-catalyzed reaction of alkoxy- and silanol-groups has been demonstrated to attach silane molecules onto the silica surface. ${ }^{[20]}$ Pre-adsorbed amines such as ethylenediamine (EDA) on the silica surface catalyzed the reaction of an aminosilane carrying one alkoxy group with a silanol group on the silica-surface, to result in a higher amount of the silane molecules anchored on the silica surface. Aminosilane itself was considered to have a built-in catalyst structure, but its catalytic activity was poorer than the pre-adsorbed amines. ${ }^{[20]}$ Lewis acid/base adduct 64 
containing boron atoms have also been reported for example to effectively catalyze the silanization in the silica-reinforced rubber compound leading to enhanced properties and a better balance of the dynamic mechanical $\tan \delta$ at high and low temperatures as indicators for rolling resistance and wet skid resistance of tire treads made thereof. ${ }^{[21]}$

For silica-filled rubber compounds, diphenyl guanidine (DPG) is considered an essential ingredient as it helps to promote both the vulcanization reaction as secondary accelerator and the silanization reaction. ${ }^{[15,22]}$ However, DPG can liberate aniline at elevated temperatures such as during mixing and vulcanization of the rubber compounds. ${ }^{[23]}$ Aniline has been classified as a probable carcinogen for humans by the United States Environmental Protection Agency (2000). ${ }^{[24]}$ A concern over the use of DPG in the rubber industry with respect to health and safety is therefore raised, and a safe alternative is in need. Based on our latest study of various amine types having either aliphatic or cyclic structures in comparison with DPG in silica-reinforced NR compounds ${ }^{[25]}$, OCT provided properties closest to the reference compound with DPG. It was suggested that octadecylamine (OCT) could be a potential candidate as DPG alternative. ${ }^{[25]}$ DPG itself is regarded as a nitrosamine-free vulcanization agent ${ }^{[26]}$. OCT, a primary amine, is also safe from nitrosamine generation in addition to an aniline-free by product, providing a better safety working environment. It should be noted that the real nitrosamine problem pertains to secondary amines in which the smaller the aliphatic groups, the worse. Moreover, the secondary amines containing aromatic rings are not an issue as the metabolism is not disturbed by secondary $\mathrm{N}$-nitrosamines containing aromatic rings. ${ }^{[27]}$

The use of amine as polar additive without coupling agent to reduce the silica surface energy and the self-association had been previously reported. ${ }^{[28-29]} \mathrm{N}, \mathrm{N}$-dimethyl-1-octadecylamine (DMOD) coated the silica surface during mixing to prevent filler flocculation, but as attachment of the DMOD and silica through hydrogen bonding was not strong enough at elevated temperature, flocculation could still occur during the thermal annealing process. ${ }^{[28]}$ DMOD was de-wetted from the silica surface at high temperature, but the alkoxy silanes that formed strong filler-rubber interaction could effectively suppress the silica flocculation. The tertiary amines were used in the silica-reinforced rubber compounds for pneumatic tires to result in the improved dispersibility of silica in the rubber and enhanced low heat generating property (i.e. an impact resilience factor determined at $25^{\circ} \mathrm{C}$ ) and abrasion resistance. ${ }^{[29]}$ The amount of tertiary amines was preferably used in the range of 3 to $10 \mathrm{wt} \%$ relative to the silica content.

Based on the study in Chapter 4, the present work extends the study on OCT in silica-reinforced NR compounds, in comparison with reference compounds with DPG and without amines, i.e. amine-free. The uncured compounds are tested for their cure characteristics, Payne effect, flocculation rate, thermal behaviors by DSC, and bound rubber contents; the rubber vulcanizates are assessed in terms of their mechanical and dynamic properties. 


\subsection{EXPERIMENTAL}

\subsubsection{Materials}

Rubber compounding ingredients used in this study, i.e. Ribbed Smoked Sheet (RSS\#3), highly dispersible silica (ULTRASIL 7005), bis(3-triethoxysilylpropyl) tetrasulfide (TESPT), octadecylamine, treated distillate aromatic extract oil (TDAE oil), zinc oxide (ZnO), stearic acid, N-cyclohexyl-2benzothiazole sulfonamide (CBS), diphenyl guanidine (DPG) and 2,2,4-trimethyl-1,2-dihydroquinoline (TMQ), and sulfur, are as described in Chapter 4.

\subsubsection{Preparation of rubber compounds}

Mixing procedure for preparation of rubber compounds is shown in Table 4.1 (see in Chapter 4). In this study, the quantity of OCT and DPG is varied in a range of 2.4-9.5 mmol per 100 parts of rubber by weight, i.e.0.5-2.5 phr. Rubber formulation is shown in Table 5.1.

\subsubsection{Properties and testing}

Properties of rubber compounds, i.e. bound rubber content, Payne effect, flocculation rate constant and cure characteristics, and rubber vucanizates, i.e. mechanical and dynamic mechanical properties, were tested, as described in Chapter 4.

Table 5.1 Rubber formulation

\begin{tabular}{ccc}
\hline Ingredient & \multicolumn{2}{c}{ Quantity (phr) } \\
\cline { 2 - 3 } & DPG & OCT \\
\hline NR & 100 & 100 \\
Silica & 55 & 55 \\
TESPT & 5 & 5 \\
ZnO & 3 & 3 \\
Stearic acid & 1 & 1 \\
TMQ & 1 & 1 \\
TDAE oil & 8 & 8 \\
Amine* & $0.5,1.0,1.5$ and 2.0 & $0.6,1.3,1.9$ and 2.5 \\
CBS & 1.5 & 1.5 \\
Sulfur & 1.5 & 1.5 \\
\hline
\end{tabular}

*) Amines as secondary accelerator were used based on molar equivalents (i.e. 2.4, 4.7, 7.1 and 9.5 mmol) 
Thermal behaviors: The glass transition temperature $\left(\mathrm{T}_{\mathrm{g}}\right)$ and heat capacity increment $\left(\Delta \mathrm{C}_{\mathrm{p}}\right)$ at $\mathrm{T}_{\mathrm{g}}$ of the uncured rubber compounds were analyzed by using differential scanning calorimetry (DSC 214 Polyma, Netzsch, Germany). The samples were weighed into the standard aluminum pan and analysis was carried out in the temperature range of -100 to $+30^{\circ} \mathrm{C}$ at a heating rate of $10^{\circ} \mathrm{C} / \mathrm{min}$ under nitrogen atmosphere. The heat history of the materials was removed in the first heating scan, and data from the second heating scan were evaluated for changes in heat flow. Based on $\Delta \mathrm{C}_{\mathrm{p}}$ values, the weight fraction of the immobilized polymer layer $\left(X_{\mathrm{im}}\right)$ was calculated following Equations (5.1) and (5.2): ${ }^{[30-31]}$

$$
\begin{aligned}
& \Delta C_{p n}=\frac{\Delta C_{p}}{1-w} \\
& \chi_{i m}=\frac{\Delta C_{p 0}-\Delta C_{p n}}{\Delta C_{p 0}}
\end{aligned}
$$

Where $\Delta C_{p}$ is the heat capacity increment at $\mathrm{T}_{\mathrm{g}} ; \Delta C_{p n}$ is $\Delta C_{p}$ normalized by the polymer weight fraction, $w$ is the weight fraction of filler, and $\Delta C_{p 0}$ refers to the normalized $\Delta C_{p}$ of the unfilled NR.

Crosslink density: The crosslink density of the rubber vulcanizates was tested by using the equilibrium swelling method. ${ }^{[32]}$ The samples having a dimension of approximately $10 \times 10 \times 2 \mathrm{~mm}^{3}$ were put into $20 \mathrm{ml}$ of toluene at room temperature for 7 days. The samples were then removed from the toluene, blotted to remove liquid on the surface, and weighed before drying at $105^{\circ} \mathrm{C}$ for $24 \mathrm{~h}$. The dried samples were then weighed again. The volume fraction of polymer in the swollen rubber $\left(V_{r}\right)$ was calculated following Equation (5.3), and then the crosslink density $\left(X_{c}\right)$ was calculated by using the Flory-Rehner theory according to Equation (5.4):

$$
V_{r}=\frac{m_{1} / \rho_{1}}{\left(m_{1} / \rho_{1}\right)+\left(m_{2} / \rho_{2}\right)}
$$

Where $m_{1}$ and $m_{2}$ are the weight of polymer and weight of solvent in the swollen sample at equilibrium swelling, respectively; $\rho_{1}$ is density of unswollen rubber vulcanizates and $\rho_{2}$ is the density of solvent.

$$
X_{c}=\frac{-\left(\ln \left(1-V_{r}\right)+V_{r}+\chi V_{r}^{2}\right)}{V_{2}\left(V_{r}^{1 / 3}-V_{r} / 2\right)}
$$

Where $\chi=$ the polymer-solvent interaction parameter $(0.391)^{[33]} ; V_{2}=$ molar volume of the solvent $\left(106.3 \mathrm{~cm}^{3} / \mathrm{mol}\right)$.

It has to be noted, that these crosslink densities are not the real ones, because they would need correction for the filler content. However, as all compounds contain the same amount of filler, this 
correction would be the same as well for all compounds. So, these crosslink densities may be considered as indicative for relative differences between the vulcanizates.

\subsection{RESULTS AND DISCUSSION}

\subsubsection{Filler-rubber interactions}

One of the methods to prove the extent of silanization in the silica-reinforced rubber compounds is by measuring the chemically bound rubber content. ${ }^{[34]}$ The bound rubber contents of the silica-reinforced NR compounds with DPG and OCT at different amounts are shown in Figure 5.1. In comparison with the amine-free compound, the use of both amines leads to higher chemically bound rubber contents that raise with increasing amine content. This increase in filler-rubber interactions is due to the amine catalyzed condensation reaction between the alkoxy groups of the silane molecules and silanol groups on the silica surface. ${ }^{[15]}$ Amines can form strong hydrogen bonds with silanol groups on the silica surface in which the bound amine gives the Si-O group of the silanol more nucleophilicity, which then reacts with the silicon atom in the silane molecule to form a pentacoordinate intermediate before the condensation between silica and silane occurs. ${ }^{[17-18]}$ In addition, the amines promote hydrolysis of the silane molecule to form a reactive silanol group prior to the condensation reaction. ${ }^{[19,35-36]}$ Besides the catalytic effect on the silanization reaction, the adsorbed amines shield the free silanol groups that are left over after the silanization reaction, to result in enhanced interfacial compatibility and higher filler-rubber interactions.

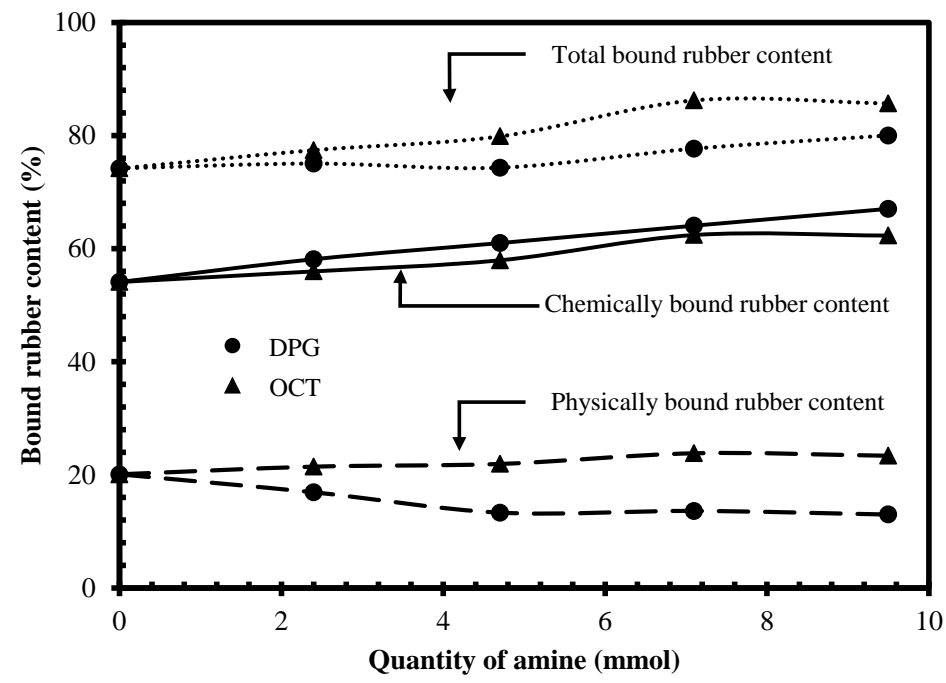

Figure 5.1 Bound rubber contents of silica-reinforced NR compounds with different quantities of OCT and DPG. 
Comparing the effects of DPG and OCT, the addition of DPG in silica-filled NR compounds gives slightly higher chemically bound rubber contents, which may indicate a greater extent of the silanization reaction. Based on the equimolar amounts used, the DPG molecules with 3 -NH- functional groups may attach easier to the silica surface compared to the one - $\mathrm{NH} 2$ with the long aliphatic tail of OCT, that gives more shielding effect and reduces the accessibility of the silane to the silica surface. Based on the work reported for the silica/TESPT/DPG/NR system ${ }^{[14]}$, some premature crosslinking may have taken place already during the mixing giving rise to the increased chemically bound rubber content.

The physically bound rubber content indicates physical interactions of the rubber chains towards the silica surface. The use of OCT gives higher physically bound rubber content compared to the mixes with DPG. With increasing amine concentration OCT gives slightly increasing physically bound rubber content while DPG tends to decrease. The long aliphatic chains in OCT may be considered to introduce entanglement of rubber chains around the silica surface and enhance hydrophobicity, while DPG mostly takes part in chemically bound rubber formation via the silanization reaction and vulcanization. Due to the rather close values of chemically bound rubber contents provided by DPG and OCT, the OCT-containing rubber compounds having higher physically bound rubber content therefore result in higher total bound rubber content, as shown in Figure 5.1.

\subsubsection{Payne effect and flocculation rate constant}

The reduction of storage modulus $\left(\mathrm{G}^{\prime}\right)$ from low to high strains has generally been accepted to register the filler-filler interaction or Payne effect in silica-filled rubber compounds. ${ }^{[37]}$ The decreasing storage modulus with increasing strain amplitude is due to the breakdown of the filler-filler network. For both DPG and OCT the Payne effect of the silica-reinforced NR compounds is dependent on the quantity of amine, as shown in Figure 5.2. The better interfacial compatibility due to the amines results in enhanced filler dispersion and thus less or a weaker filler network. The compounds with OCT show a somewhat lower Payne effect compared to the reference compounds, that could be caused by the long aliphatic chain structure of this amine that enhances the hydrophobicity, in addition to the catalytic effect on the silanization reaction. The reduction in Payne effect is observed when the amines are increased to a certain quantity, i.e. $4.7 \mathrm{mmol}(1.0 \mathrm{phr}$ ) for DPG and $7.1 \mathrm{mmol}(1.9 \mathrm{phr})$ for OCT, and thereafter the Payne effect shows an upturn. As basic amines can adhere well onto the silica surface, ${ }^{[17-18]}$ excess of amines may block the accessibility of silane molecules to the silica surface. The interactions between amines and silanol groups are basically via physical hydrogen bonding; whereas those between silane and silanol are chemical bonds. With the high amount of amine present in the system, hydrogen bonding between amines and silane molecules can additionally take place, leaving less active silane molecules to react and thus more free silanol groups available to cause higher filler-filler interactions. Moreover, an excessive amount of amines could lead to lower shear force during mixing and thus affects on filler dispersion within the rubber matrix. 


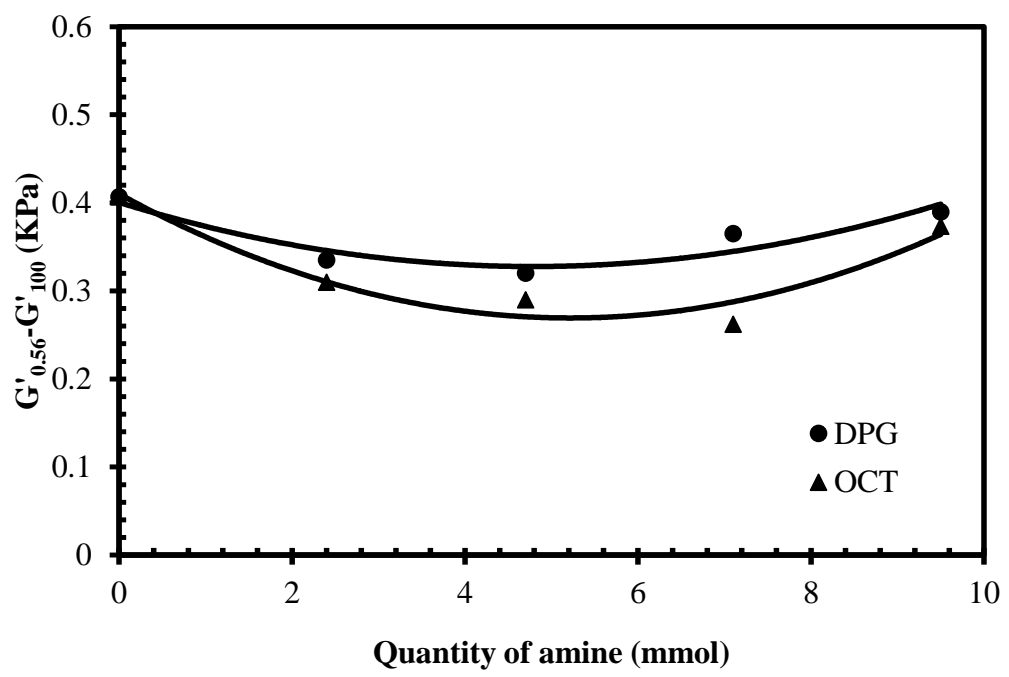

Figure 5.2 Payne effect of silica-reinforced NR compounds with different quantities of OCT and DPG.

The levels of chemical and physical interactions between the silica and rubber have an influence on the stability of silica aggregates as de-mixing or flocculation can occur during storage and especially under thermal treatment. ${ }^{[28,38]}$ The stability of silica aggregates can be improved by the silanization reaction, that enhances the chemically bound rubber. The flocculation rate constant of silica-reinforced NR compounds is shown in Figure 5.3. The compounds with OCT exhibit higher flocculation rate constants compared to the ones with $\mathrm{DPG}^{[25]}$ due to the more physically bound rubber, that is weakened under heating. ${ }^{[28]}$ At elevated temperature, the hydrogen bonding between silica and amine is lost ${ }^{[28]}$ and at the same time the viscosity of the rubber matrix decreases, which promotes the flocculation. Excessive amounts of amines may result in more free silanol groups on the silica surface, and thus higher interactions between fillers as well as higher flocculation rates. 


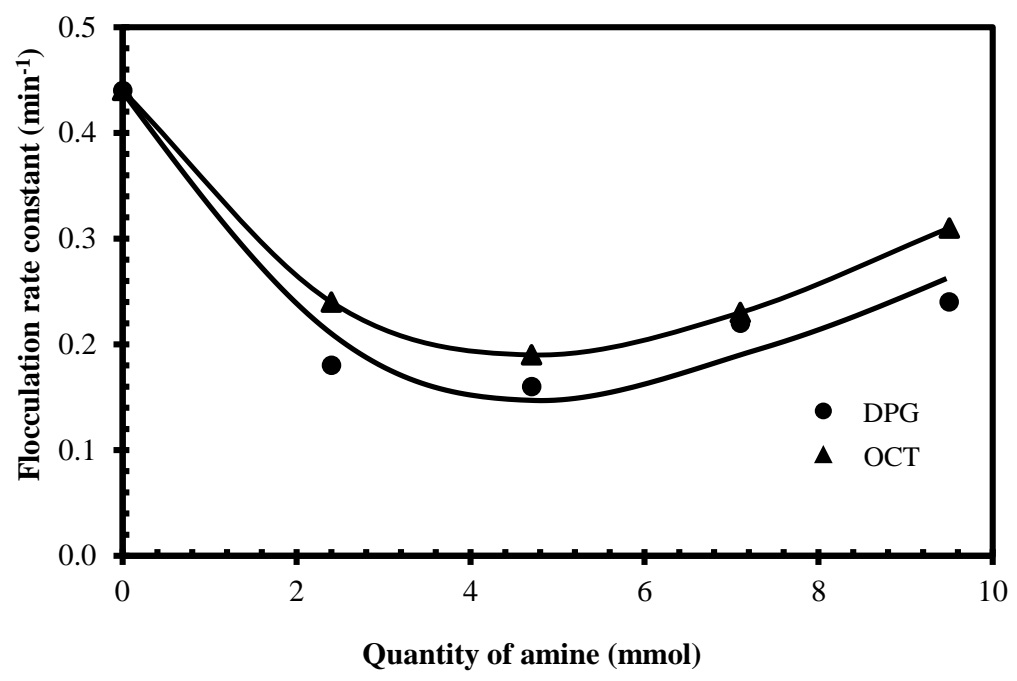

Figure 5.3 Flocculation rate constant of silica-reinforced NR compounds with different quantities of OCT and DPG.

\subsubsection{Thermal behavior}

Changes of heat flow with temperature of the uncured rubber compounds having different amounts of OCT and DPG were characterized by DSC as shown in Figure 5.4. The glass transition temperature $\left(\mathrm{T}_{\mathrm{g}}\right)$ taken at the middle point in the baseline shift and heat capacity increment $\left(\Delta \mathrm{C}_{\mathrm{p}}\right)$ at $\mathrm{T}_{\mathrm{g}}$ of the rubber compounds are summarized in Table 5.2. The $\mathrm{T}_{\mathrm{gS}}$ of all the compounds are practically not affected by the addition of amines as the values lie in a narrow range of -64.5 to $-65.5^{\circ} \mathrm{C}$. 

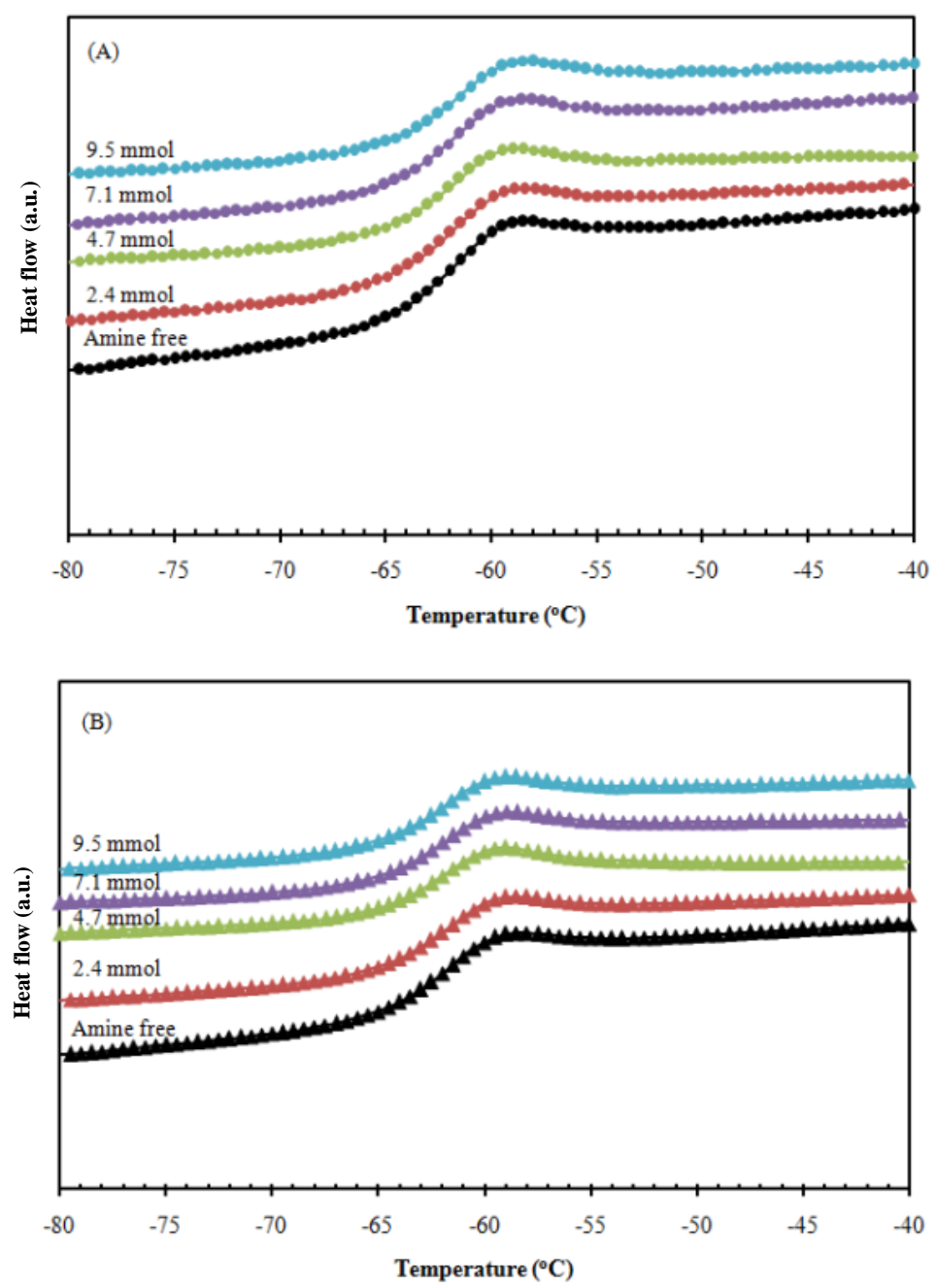

Figure 5.4 DSC results of silica-reinforced NR compounds with different amine quantities: (A) DPG and (B) OCT.

The heat capacity increment $\left(\Delta \mathrm{C}_{\mathrm{p}}\right)$ at the $\mathrm{T}_{\mathrm{g}}$ of the filled rubber compounds can be related to the fraction of rubber molecules that change in mobility. ${ }^{[30-31]}$ The promoted interfacial interactions between silica and rubber via the silanization reaction by the amines alters the chain mobility in the vicinity of the filler surface. Increasing amine contents reduce $\Delta C_{p}$ which indicates a reduction in mobility: Table 5.2. At the same amine loadings, the compounds with OCT have a somewhat lower $\Delta \mathrm{C}_{\mathrm{p}}$ as an additional effect from the physical shielding by its long alkyl chains in addition to the coupling induced by silanization. 
Table 5.2 Glass transition temperature $\left(T_{g}\right)$, heat capacity increment $\left(\Delta C_{p}\right)$ and immobilized polymer layer $\left(\chi_{\text {im }}\right)$ of silica-reinforced NR compounds

\begin{tabular}{|c|c|c|c|c|c|}
\hline \multirow[t]{2}{*}{ Type of amine } & \multicolumn{2}{|c|}{ Quantity of amine } & \multirow{2}{*}{$\begin{array}{c}\mathbf{T}_{\mathbf{g}} \\
\left({ }^{\circ} \mathbf{C}\right)\end{array}$} & \multirow{2}{*}{$\begin{array}{c}\Delta C_{p} \\
\left(\mathrm{Jg}^{-1} \mathbf{K}^{-1}\right)\end{array}$} & \multirow{2}{*}{$\begin{array}{c}\chi_{i m} \\
(w t \%)\end{array}$} \\
\hline & $(\mathbf{m m o l})$ & (phr) & & & \\
\hline Without amine & 0 & 0 & -64.6 & 0.114 & 0.567 \\
\hline \multirow[t]{4}{*}{$\overline{D P G}$} & 2.4 & 0.5 & -64.9 & 0.108 & 0.591 \\
\hline & 4.7 & 1.0 & -65.1 & 0.096 & 0.637 \\
\hline & 7.1 & 1.5 & -65.0 & 0.100 & 0.619 \\
\hline & 9.5 & 2.0 & -64.8 & 0.095 & 0.638 \\
\hline \multirow[t]{4}{*}{ OCT } & 2.4 & 0.6 & -65.1 & 0.102 & 0.611 \\
\hline & 4.7 & 1.3 & -65.0 & 0.087 & 0.668 \\
\hline & 7.1 & 1.9 & -65.2 & 0.093 & 0.646 \\
\hline & 9.5 & 2.5 & -65.1 & 0.093 & 0.649 \\
\hline
\end{tabular}

The weight fraction of immobilized polymer layer $\left(X_{i m}\right)$ within the rubber compounds, as given in Table 5.2, increases with the addition of amines, up to an amine quantity of $4.7 \mathrm{mmol}$ (1.0 phr for DPG and $1.3 \mathrm{phr}$ for OCT) as the optimum value, where after the values seem to level off. The changes indicate that there are more rubber chains confined to the filler surface. At the optimal amount of $4.7 \mathrm{mmol}$, the lower $\Delta \mathrm{C}_{\mathrm{p}}$ and higher $X_{i m}$ for OCT compared to DPG corresponds with its higher total bound rubber content and lower Payne effect. The results suggest that the alkyl-amine promotes compatibility between the silica surface and rubber chains better than DPG. In addition to the enhanced silanization by the amine catalyst, the shielding by the alkyl chains of OCT gives extra physical interactions/entanglements that promote hydrophobicity, resulting in more interfacial confinement of polymer chains next to the filler surface. An increasing trend in the plot of total bound rubber content against $X_{i m}$, as shown in Figure 5.5, confirms that the total bound rubber having both physical and chemical components increases with the immobilized polymer layer and may have the same basic mechanism. 


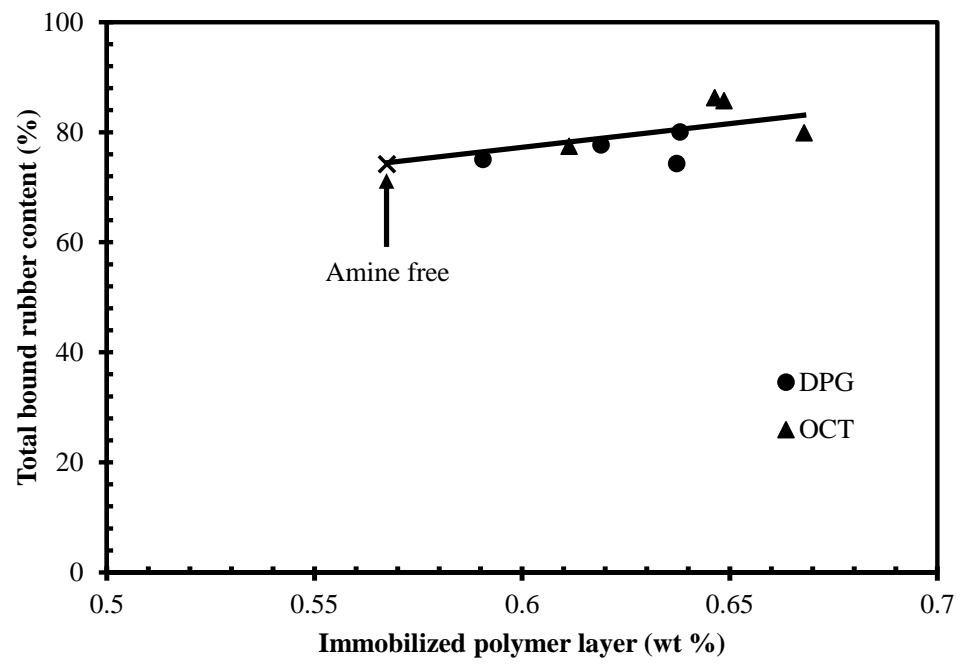

Figure 5.5 Total bound rubber content-immobilized polymer layer relationship of silica-reinforced NR compounds.

\subsubsection{Cure behaviors}

The main role of DPG in silica-reinforced NR compounds is to act as secondary accelerator, in combination with CBS as the primary one. In the present work we propose the use of OCT as alternative for DPG, following the previous report. ${ }^{[25]}$ The presence of DPG and OCT clearly enhances cure characteristics of the silica-filled NR compounds as shown in Figure 5.6. The cure curves of rubber compounds containing different amounts of DPG and OCT show reversion behavior whereas the compound without amine shows a marching cure, as displayed in Figure 5.6. The OCT-containing compounds exhibit less reversion, i.e. smaller reduction of cure torques after the optimum cure, compared to the use of DPG. As the cure reaction is commonly catalyzed by a base, the increasing amounts of both OCT and DPG decrease scorch time $\left(\mathrm{T}_{\mathrm{s} 1}\right)$, optimum cure time $\left(\mathrm{T}_{\mathrm{c} 90}\right)$, and increase the cure reaction rate $(k)$, as summarized in Table 5.3. The compounds with DPG exhibit slightly faster cure time and higher cure reaction rate compared to those with OCT at the same loading. The higher physically bound rubber content, i.e. more physical interactions, of the OCT compounds that can be broken at high temperature, leaving more free silanol groups to interfere the curing reaction, thus lead to poorer cure behavior. The use of DPG results in a higher torque difference indicating a higher crosslink density when compared with OCT. The crosslink densities as measured with equilibrium swelling are shown in Figure 5.7. With respect to the synergistic effect of the two amine types on cure, DPG is more effective than OCT, as demonstrated by the faster cure reaction and higher extent of crosslinking, particularly at higher dosages. As previously discussed for the results of the Payne effect and flocculation rate constant, excess amines may result in reduced accessibility of the silane to the silica surface due to the shielding effect of OCT and the occurrence of amine-silane 
interaction that can result in more free silanol groups left on the silica to interfere with the crosslinking reaction. Moreover, the excess aliphatic amine may also act as plasticizer in the rubber compounds, causing a dilution in crosslink points.
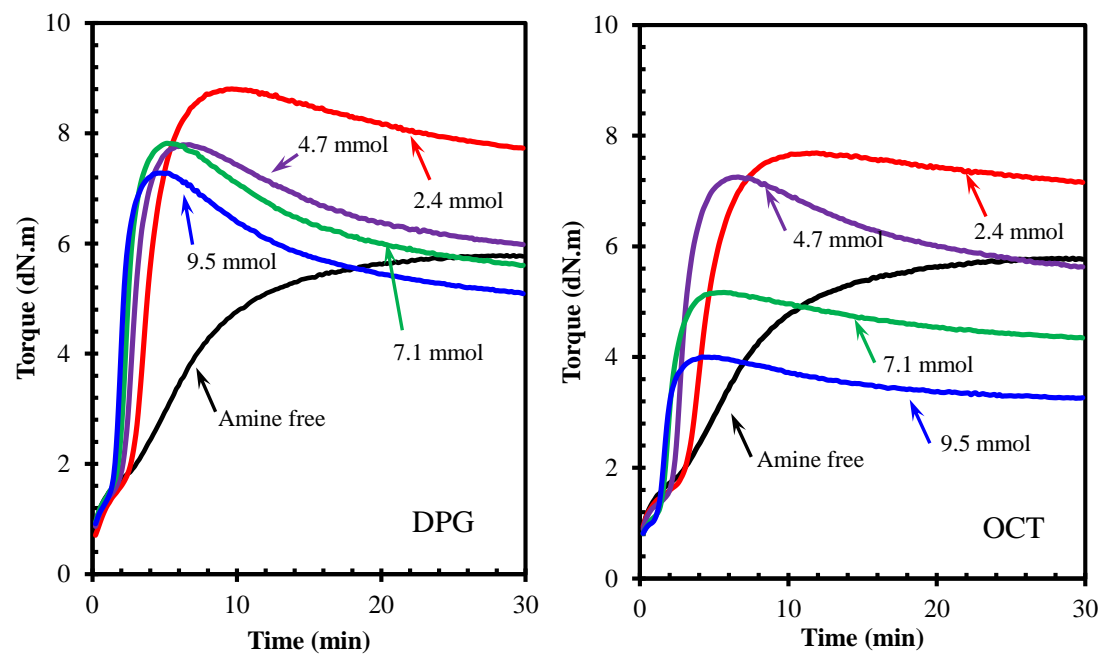

Figure 5.6 Cure curves at $150^{\circ} \mathrm{C}$ of silica-reinforced NR compounds with different amine types and content.

Table 5.3 Scorch time $\left(\mathrm{T}_{\mathrm{s} 1}\right)$, optimum cure time $\left(\mathrm{T}_{\mathrm{c} 90}\right)$, cure reaction rate constant $(k)$ and torque difference $\left(\mathrm{M}_{\mathrm{H}}-\mathrm{M}_{\mathrm{L}}\right)$ of silica-reinforced NR compounds.

\begin{tabular}{|c|c|c|c|c|c|c|}
\hline \multirow[t]{2}{*}{ Type of amine } & \multicolumn{2}{|c|}{ Quantity of amine } & \multirow{2}{*}{$\begin{array}{c}\mathbf{T}_{\mathrm{s} 1} \\
(\mathrm{~min})\end{array}$} & \multirow{2}{*}{$\begin{array}{c}\mathbf{T}_{\mathbf{c 9 0}} \\
(\mathbf{m i n})\end{array}$} & \multirow[t]{2}{*}{$k$} & \multirow{2}{*}{$\begin{array}{l}M_{H}-M_{L} \\
(d N . m)\end{array}$} \\
\hline & $(\mathrm{mmol})$ & (phr) & & & & \\
\hline Without amine & 0 & 0 & 2.57 & 14.05 & 0.21 & 4.95 \\
\hline \multirow[t]{4}{*}{ DPG } & 2.4 & 0.5 & 2.23 & 5.82 & 0.77 & 8.11 \\
\hline & 4.7 & 1.0 & 1.95 & 4.07 & 1.26 & 7.01 \\
\hline & 7.1 & 1.5 & 1.70 & 3.38 & 1.57 & 6.96 \\
\hline & 9.5 & 2.0 & 1.47 & 2.88 & 1.87 & 6.48 \\
\hline \multirow[t]{4}{*}{ OCT } & 2.4 & 0.6 & 2.87 & 6.75 & 0.64 & 6.83 \\
\hline & 4.7 & 1.3 & 2.17 & 4.18 & 1.20 & 6.49 \\
\hline & 7.1 & 1.9 & 1.60 & 3.17 & 1.44 & 4.46 \\
\hline & 9.5 & 2.5 & 1.47 & 2.53 & 1.81 & 3.28 \\
\hline
\end{tabular}




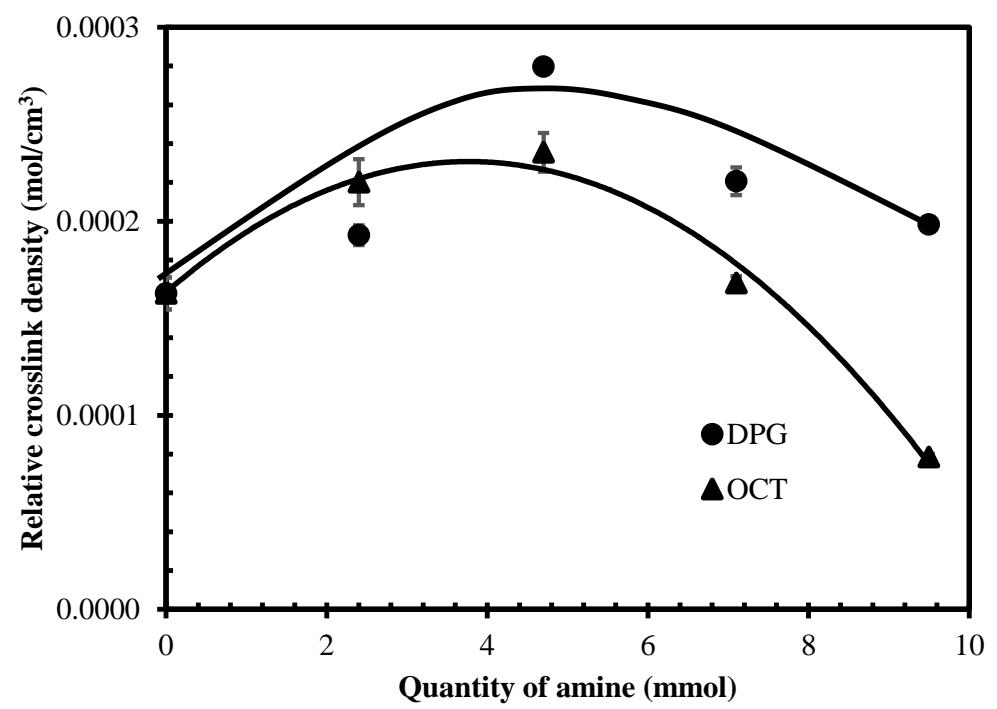

Figure 5.7 Relative crosslink density of silica-reinforced NR compounds with different quantities of OCT and DPG.

\subsubsection{Mechanical properties}

The modulus at $300 \%$ strain, tensile strength, elongation at break and reinforcement index (M300/M100) of the silica-reinforced NR compounds with different concentrations of OCT and DPG are summarized in Table 5.4. The OCT compounds show the maximum tensile strength at loading of $4.7 \mathrm{mmol}$ (1.3 phr), while the DPG ones give equal but lower tensile strengths in the range of 4.7-9.5 mmol (1.0-2.0 phr). At the optimal point, the use of OCT gives a slightly higher M300 and tensile strength compared to DPG. The addition of amines clearly enhances the tensile properties compared to the amine-free compound, confirming the need for amines for the silica-reinforced rubber compounds. A good interfacial compatibility between the silica surface and rubber chains via the coupling agent, and enhanced filler dispersion in the rubber compounds, enable the molecular chains to respond to stress and deformation with efficient stress transfer. However, as a lower crosslink density of the silica-reinforced NR compounds with OCT at 7.1 and $9.5 \mathrm{mmol}$ was obtained, the modulus and tensile strength of these vulcanizates rapidly decrease, as shown in Figure 5.8. When higher loadings of OCT are used, the bulky OCT groups on the silica surface may also hinder the linking of bound silane to rubber, causing a decrease of the strength. With regard to elongation at break of the vulcanizates having OCT and DPG (Table 5.4), the values show small differences with changing the types and concentrations of the amines. 
Table 5.4 Modulus at 300\% strain (M300), tensile strength (T.S.), elongation at break (E.B.) and reinforcement index (M300/M100) of silica-reinforced NR compounds

\begin{tabular}{|c|c|c|c|c|c|c|}
\hline \multirow[t]{2}{*}{ Type of amine } & \multicolumn{2}{|c|}{ Quantity of amine } & \multirow{2}{*}{$\begin{array}{l}\text { M300 } \\
\text { (MPa) }\end{array}$} & \multirow{2}{*}{$\begin{array}{l}\text { T.S. } \\
\text { (MPa) }\end{array}$} & \multirow{2}{*}{$\begin{array}{l}\text { E.B. } \\
(\%)\end{array}$} & \multirow[t]{2}{*}{ M300/M100 } \\
\hline & $(\mathbf{m m o l})$ & (phr) & & & & \\
\hline Without amine & 0 & 0 & $5.6 \pm 0.1$ & $14.3 \pm 0.6$ & $510 \pm 14$ & $5.0 \pm 0.2$ \\
\hline \multirow[t]{4}{*}{ DPG } & 2.4 & 0.5 & $10.2 \pm 0.7$ & $24.6 \pm 1.6$ & $530 \pm 8$ & $5.9 \pm 0.4$ \\
\hline & 4.7 & 1.0 & $9.0 \pm 0.2$ & $26.6 \pm 0.2$ & $580 \pm 4$ & $6.4 \pm 0.4$ \\
\hline & 7.1 & 1.5 & $9.4 \pm 0.2$ & $27.0 \pm 0.3$ & $580 \pm 5$ & $6.0 \pm 0.2$ \\
\hline & 9.5 & 2.0 & $9.4 \pm 0.2$ & $26.7 \pm 0.2$ & $580 \pm 10$ & $5.8 \pm 0.2$ \\
\hline \multirow[t]{4}{*}{ OCT } & 2.4 & 0.6 & $10.1 \pm 0.4$ & $24.1 \pm 0.4$ & $520 \pm 2$ & $6.4 \pm 0.3$ \\
\hline & 4.7 & 1.3 & $9.8 \pm 0.4$ & $29.1 \pm 0.5$ & $590 \pm 7$ & $6.0 \pm 0.2$ \\
\hline & 7.1 & 1.9 & $7.5 \pm 0.1$ & $23.9 \pm 0.8$ & $580 \pm 12$ & $5.6 \pm 0.2$ \\
\hline & 9.5 & 2.5 & $5.3 \pm 0.4$ & $19.0 \pm 0.9$ & $570 \pm 13$ & $5.5 \pm 0.3$ \\
\hline
\end{tabular}
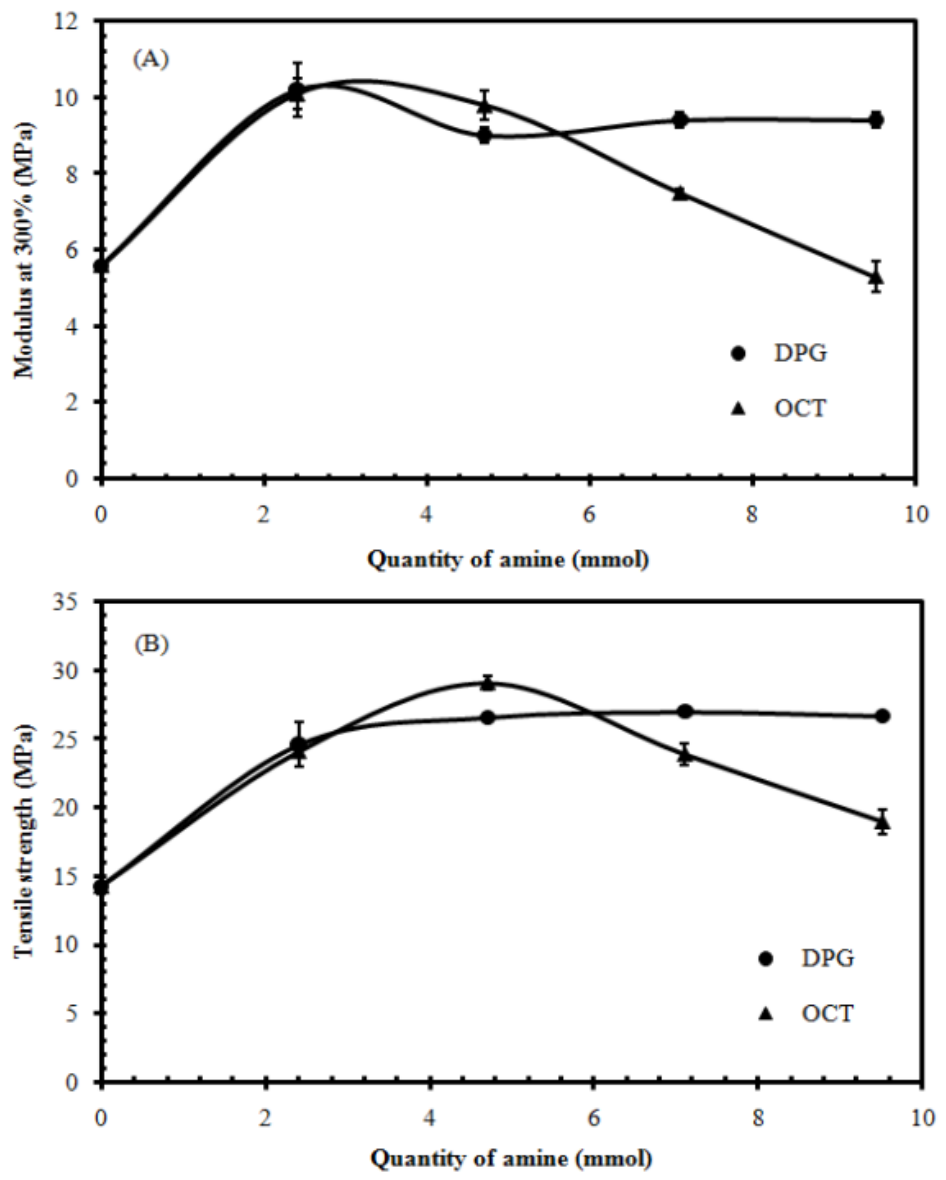

Figure 5.8 Modulus at 300\% strain (A) and tensile strength (B) of silica-reinforced NR compounds with different quantities of OCT and DPG. 
The plots of the reduced stress $\left(\sigma^{*}\right)$ against the reciprocal of the extension ratio $\left(\lambda^{-1}\right)$ of the silicareinforced NR compounds with different concentrations of OCT and DPG are shown in Figure 5.9. The reduced stress declines to a flat region when $\lambda^{-1}$ is decreased, then later rises to give an upturn in the large tensile ratio, ascribed to finite extensibility of the rubber chains during stretching. Therefore, the $\lambda^{-1}$ value at the upturn point may be taken as an indication of the interfacial interaction between filler and rubber as well as the crosslink network. The upturn point of rubber compounds with amines except with OCT 9.5 mmol occurs at higher $\lambda^{-1}$ value, i.e. at lower $\lambda$ than without amine, confirming that both amines promote interfacial compatibility and the crosslinking of the rubber network. For the DPG compounds the increasing amount of amine shows similar upturn points, whereas the OCT compounds with 7.1 and 9.5 mmol show a shift of the upturn points to lower $\lambda^{-1}$ or higher $\lambda$, in line with the lower crosslink density results in Figure 5.7. With the use of amines that enhance interfacial interaction and filler dispersion, the rubber chains reach finite extensibility during deformation at higher $\lambda^{-1}$ value, i.e. at lower $\lambda$, as affected by both chemical and physical crosslinks. 

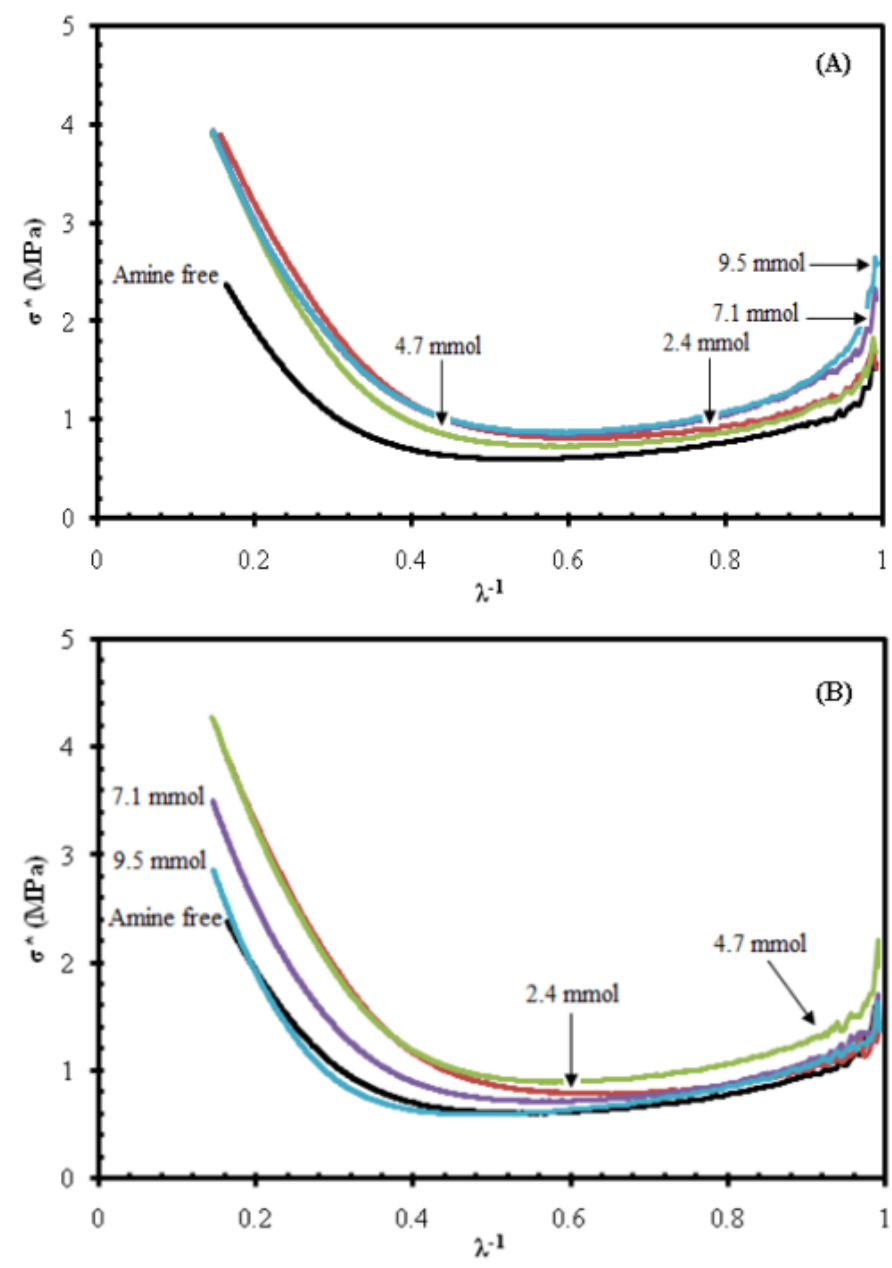

Figure 5.9 Mooney-Rivlin plots of silica-reinforced NR compounds with different amine quantities; (A) DPG and (B) OCT.

\subsubsection{Loss tangent at $60^{\circ} \mathrm{C}$}

One of the key tire performance characteristics of silica-reinforced NR-based truck tire tread compounds is rolling resistance as part of the "Magic Tire Triangle" together with wet skid resistance and wear. The most commonly used parameter to indicate tire rolling resistance of the rubber vulcanizates in a laboratory environment is the value of the dynamic mechanical $\tan \delta$ at $60^{\circ} \mathrm{C}$. The $\tan \delta$ at $60^{\circ} \mathrm{C}$ of the rubber vulcanizates having various amounts of amines are shown in Figure 5.10. Compared to the aminefree compound, the use of OCT decreases the $\tan \delta$ at $60^{\circ} \mathrm{C}$ to a greater extent than DPG. This lower value indicates a better elastic response and lower energy loss in the compounds with OCT due to the promoted interfacial interaction between the silica and rubber phases. From the perspective of low rolling resistance 
tires, the use of OCT is therefore beneficial over DPG. The rubber compound with OCT at $7.1 \mathrm{mmol}(1.9$ phr) shows the lowest $\tan \delta$ at $60^{\circ} \mathrm{C}$, but taking also other properties especially modulus and tensile strength into consideration, the amount of $4.7 \mathrm{mmol}(1.3 \mathrm{phr})$ of OCT gives a better balance in properties.

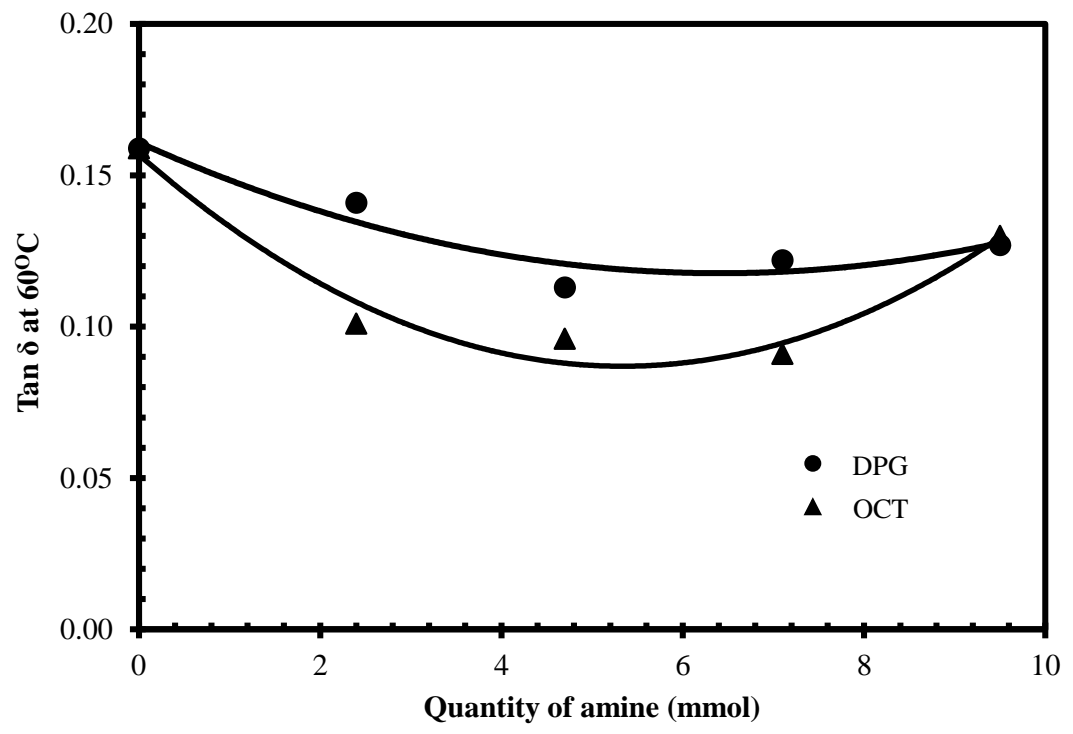

Figure 5.10 Tan $\delta$ at $60^{\circ} \mathrm{C}$ of silica-reinforced NR compounds at $10 \mathrm{~Hz}$ of frequency.

\subsection{CONCLUSIONS}

Silica-reinforced NR compounds with OCT as DPG alternative in the range of 2.4-9.5 mmol were investigated with emphasis on the interfacial compatibility between the silica and rubber phases, by taking compounds with DPG and without amine as references. The results demonstrate the strong influence of amines in the silica-reinforced rubber compounds, confirming the need of this ingredient. The chemically bound rubber content indicates that the use of DPG enhances to a greater extent the silanization reaction, but based on the total bound rubber content, the use of OCT with its long alkyl chain gives a higher value due to a higher physically bound rubber content as a result of its shielding effect on the silica surface which leads to a higher hydrophobicity. The OCT compounds therefore show lower Payne effects, but higher flocculation rate constant compared to the DPG ones. The interfacial compatibility is proven by the immobilized polymer layer $\left(X_{i m}\right)$ in which an increased $X_{i m}$ is observed in the presence of amine, where the OCT compounds show slightly higher values. The addition of both OCT and DPG improves cure properties significantly, resulting in lower optimum cure time, higher cure rate and increased torque difference, when compared with the amine-free compound. The use of OCT in the range of 2.4-4.7 mmol (0.6-1.3 phr) 80 
exhibits similar cure behavior compared to rubber compounds with DPG. However, the use of OCT at higher loadings, i.e. 7.1 and $9.5 \mathrm{mmol}$ (1.9 and $2.5 \mathrm{phr}$ ), results in lower crosslink density and a drop in modulus and tensile strength, while the use of DPG retains such properties. The shift of upturn points in the Mooney-Rivlin plots is in line with the changes of the other properties, supporting the enhanced interfacial compatibility between silica and NR by the use of amines. Moreover, tire rubber vulcanizates made thereof should have lower rolling resistance as indicated by the lower $\tan \delta$ at $60^{\circ} \mathrm{C}$.

\subsection{REFERENCES}

${ }^{[1]}$ J.L. White, and K-J. Kim, "Thermoplastic and Rubber Compounds; Technology and Chemistry”, Carl Hanser Verlag, Munich, Germany, 2008.

${ }^{[2]}$ R. Rauline, E.P. Patent 0501227A1 (to Michelin and Cie), Feb. 12, 1992.

${ }^{[3]}$ W.K. Dierkes, and A. Blume, "Silica reinforcement," in Encyclopedia of Polymeric Nanomaterials, K. Müllen, and S. Kobayashi, Eds., Springer-Verlag Berlin Heidelberg, Germany, 2015.

${ }^{[4]}$ A. Blume, L. Gatti, H-D. Luginsland, D. Maschke, R. Moser, J.C. Nian, C. Röben, and A. Wehmeier, "Silica and Silanes," in Rubber Compounding: Chemistry and Applications, B. Rodgers, Ed., $2^{\text {nd }}$ Ed. CRC Press, Taylor and Francis Group, Boca Raton, 2015.

${ }^{[5]}$ B.T. Poh, and C.C. NG, Eur. Polym. J. 34, 975 (1998).

${ }^{[6]}$ K. Murakimi, S. Iio, Y. Ikeda, H. Ito, M. Tosaka, and S. Kohjiya, J. Mater. Sci. 38, 1447 (2003).

${ }^{[7]}$ J.Y. Ko, K. Prakashan, and J.K. Kim, J. Elastorm. Plast. 44, 549 (2012).

${ }^{[8]}$ L. Qu, G. Yu, X. Xie, L. Wang, J. Li, and Q. Zhao, Polym. Compos. 34, 1575 (2013).

${ }^{[9]}$ Y. Li, B. Han, L. Liu, F. Zhang, L, Zhang, S. Wen, Y. Lu, H. Yang, and J. Shen, Compos. Sci. Technol. 88,69 (2013).

${ }^{[10]}$ U. Goerl, A. Hunsche, A. Mueller, and H.G. Koban, Rubber Chem. Technol. 70, 608 (1997).

${ }^{[11]}$ A. Blume, Kautsch. Gummi Kunstst. 64, 38 (2011).

${ }^{[12]}$ J.W. ten Brinke, S.C. Debnath, L.A.E.M. Reuvekamp, and J.W.M. Noordermeer, Compos. Sci. Technol. 63, 1165 (2003).

${ }^{[13]}$ L.A.E.M. Reuvekamp, J.W. ten Brinke, P.J. van Swaaij, and J.W.M. Noordermeer, Kautsch. Gummi Kunstst. 55, 41 (2002).

${ }^{[14]}$ W. Kaewsakul, K. Sahakaro, W.K. Dierkes, and J.W.M. Noordermeer, Rubber Chem. Technol. 85, 277 (2012).

${ }^{[15]}$ S. Mihara, "Reactive processing of silica-reinforced tire rubber", PhD. Thesis: 2009, Dept. of Elastomer Technology and Engineering, Univ. of Twente, Enschede, the Netherlands.

${ }^{[16]}$ W. Kaewsakul, K. Sahakaro, W.K. Dierkes, and J.W.M. Noordermeer, Rubber Chem. Technol. 86, 313 (2013).

${ }^{[17]}$ C.P. Tripp, and M.L. Hair, J. Phys. Chem. 97, 5693 (1993). 
${ }^{[18]}$ L.D. White, and C.P. Tripp, J. Colloid Interface Sci. 232, 400 (2000).

${ }^{[19]}$ H-L. Li, A-P. Fu, D-S. Xu, G-L. Guo, L-L. Gui, and Y-Q. Tang, Langmuir 18, 3198 (2002).

${ }^{[20]}$ S.M. Kanan, W.T.Y. Tze, and C.P. Tripp, Langmuir 18, 6623 (2002).

[21] Y. Tanabe, K. Miyoshi, and Y. Kirino, Rubber Chem. Technol. 89, 349 (2016).

[22] S. Mihara, R.N. Datta, A.G. Talma, and J.W.M. Noordermeer, U.S. Patent 7923493 B2 (to The Yokohama Rubber Co., Ltd.), Apr. 12, 2011.

${ }^{[23]}$ T.A.Okel, Rubber World 244, 30 (2011).

${ }^{[24]}$ Internet page: http://www.atsdr.cdc.gov/toxfaqs/tfacts171.pdf [May 23, 2014]

${ }^{[25]}$ C. Hayichelaeh, L.A.E.M. Reuvekamp, A. Blume, J.W.M. Noordermeer, and K. Sahakaro, Rubber Chem. Technol. 91, 433 (2018).

[26] Internet page: https://echa.europa.eu/documents/10162/861ffb27-274e-4a8e-abc6-f39add1a864b [August 15, 2017]

${ }^{[27]}$ H. Lohwasser. Gummi Fasern Kunstst. 50, 473 (1997).

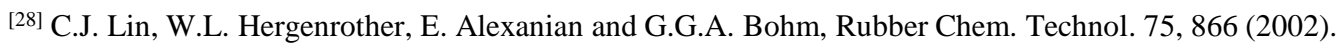

${ }^{[29]}$ S. Araki, M. Tsuchihashi, and I. Nishi, U.S. Patent 6,559,209 B1 (to Bridgestone Corporation and KAO Corporation), May 6, 2003.

${ }^{[30]}$ B. Zhong, Z. Jia, D. Hu, Y. Luo, and D. Jia, Composites Part A 78, 303 (2015).

${ }^{[31]}$ D. Fragiadakis, L. Bokobza, and P. Pissis, Polymer 52, 3175 (2011).

${ }^{[32]}$ P.J. Flory, and J. Rehner, Jr., J. Chem. Phys. 11, 521 (1943).

${ }^{[33]}$ P.W. Allen, and G.M. Bristow, J. Appl. Polym. Sci. 7, 603 (1963).

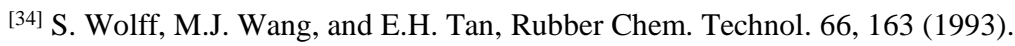

${ }^{[35]}$ K-J. Kim, and J. VanderKooi, Rubber Chem. Technol. 78, 84 (2005).

${ }^{[36]}$ H-L. Li, N. Perkas, Q-L. Li, Y. Koltypin, and A. Gedanken, Langmuir 19, 10409 (2003).

[37] A.R. Payne, Rubber Chem. Technol. 33, 365 (1966).

${ }^{[38]}$ S. Mihara, R.N. Datta, and J.W.M. Noordermeer, Rubber Chem. Technol. 82, 524 (2009). 


\title{
THE SILANIZATION EFFICIENCY OF SILICA/SILANE SYSTEMS IN DEPENDENCE OF DIFFERENT FUNCTIONAL GROUPS IN MODIFIED PALM OILS
}

\begin{abstract}
Towards an eco-friendly and more sustainable rubber technology, bio oils are applied as process oils in rubber compounds. Epoxidized palm oil (EPO) and amine modified EPO (mEPO) were prepared and their chemical structures were characterized by using FTIR and ${ }^{I} H$-NMR. The EPOs with different epoxide contents were prepared via epoxidation of palm oil by formic acid and hydrogen peroxide. The oxirane oxygen or epoxide contents were determined by titration with $\mathrm{HBr}$. The oxirane oxygen contents of EPO oils in this study are approximately 1, 2 and 3 wt\%. The EPO oil with 3\% oxirane oxygen content was further modified by reacting with $N$-Phenyl-p-PhenyleneDiamine (PPD) via generating a hydroxyl functional group from the epoxide ring-opening reaction to result in modified EPO (mEPO) oils. For the $M E P O$ oils, the amounts of PPD in $M E P O$ were determined by means of FTIR via a standard curve. The mEPOs contain 0.03 and $0.04 \mathrm{mmol}$ of PPD in $1 \mathrm{~g}$ of oil, so called 0.03 and $0.04 \mathrm{mEPO}$, respectively. The silanization efficiency of silica/silane systems in the presence of different types of oils was investigated by taking mixtures with TDAE oil and without oil as references. The use of TDAE and unmodified palm oil results in a similar efficiency of the silanization reaction. Among the modified oils, the use of EPOs promotes the silanization efficiency, while the $\mathrm{MEPO}$ s hinder the silanization reaction. As the silica surface is highly polar and agglomerates can easily form via strong hydrogen bonding, the presence of oil adsorbed on the silica surface could interrupt the agglomeration. During mixing, once the oil molecules are adsorbed on the surface of silica aggregates, the agglomeration is less and thus there are more silanol groups available for reacting with silane molecules to result in a higher silanization efficiency, as observed in the mixtures with EPOs. However, the system is being complicated in the presence of several polar moieties that cause some competitive phenomena, such as breaking of silica agglomerates that provides more active silanol groups, or strong interaction of polar and bulky oil molecules with the silica surface that introduces steric effects that limit the accessibility of the silanes towards the silica surface and thus hinder the silanization reaction. Moreover, the different polarity of these oils also has an effect on wettability on the silica surface. Therefore, EPO and $m E P O$ oils show contradicting effects on the silanization efficiency.
\end{abstract}




\subsection{INTRODUCTION}

Due to toxicity of the Polycyclic Aromatic Hydrocarbons (PAHs) in Distillated Aromatic Extract oil (DAE), the production of tires or the parts of tires with petroleum-based process oils that contain more than $1 \mathrm{mg} / \mathrm{kg}$ Benzo[a]pyrene, and more than $10 \mathrm{mg} / \mathrm{kg}$ of the sum of 8 types of PAHs identified as carcinogens, has been banned by the European Commission ${ }^{[1-2]}$ after the initiative report by the Swedish National Chemicals Inspectorate in $1993^{[3]}$ on the liberation of PAHs from tire debris. In addition to alternative safe petroleum-based process oils like Treated Distillate Aromatic Extract (TDAE) or Naphthenic (NAP) oils, use of bio-oils in the filled rubber compounds attracts interest widely due to the fact that it is not only to enhance environmental friendly products as it is the renewable nature and thus potentially low carbon footprint, but also to gain several benefits including a reduction of dependence on fossil fuel resources and enhancement of some material performance properties.

Dasgupta et al. (2007) ${ }^{[4]}$ studied the effects of 10 types of natural oils (i.e. rubber seed-, neem-, dolma-, soybean-, alsi-, kurunj-, sesamum-, mustard-, ground nut-, and arandi oils) in natural rubber (NR)based truck-tire tread cap compounds. Among the bio oils studied, the rubber compounds with seed and neem oils exhibited lower viscosity, indicating a better processing behavior, and better filler dispersion than those with petroleum oils. Sahakaro and Beraheng ${ }^{[5]}$ compared the effect of epoxidized palm oil (EPO) and epoxidized soybean oil (ESBO) used in carbon black-filled rubber-based tire tread compounds by taking the ones with conventional DAE oil as reference. Based on their mechanical and dynamic properties, EPO was recommended as a potential candidate for the replacement of DAE oil in rubber compounds. In addition, the presence of aromatic structures and amine in the bio oils could give a positive effect on the rubber properties. Boontawee et al. (2012) ${ }^{[6]}$ studied the effect of benzyl ester modification of vegetable oils on the properties of carbon black-filled NR compounds. Due to the activated sulfur vulcanization system and enhanced network formation, superior tensile strength of NR compounds with benzyl ester oils was obtained. The use of N-Phenyl-p-PhenyleneDiamine (PPD) modified epoxidized bio oils in carbon black-filled rubber compounds was investigated ${ }^{[7-8]}$. The rubber compounds with PPD-modified bio-oils displayed shorter cure time compared to those with petroleum-based process oils due to an accelerating effect of amino groups in the PPD structure. For silica-reinforced rubber compounds, a combination of silane coupling agents with epoxidized oil was studied and the results showed that the epoxidized oil could enhance the hydrophobicity of the silica surface via hydrogen bonding with oil molecules, resulting in an increased compatibility between the silica surface and rubber matrix. ${ }^{[9]}$

It has been realized that the successful use of silica/silane-reinforced tire compounds strongly depends on the extent of the silanization reaction that affects the reinforcement efficiency of such compounds. The silanization reaction, which is the condensation reaction between the silanol groups on the silica surface and alkoxy groups in the silane molecules, is quite complicated involving both primary and secondary condensation reactions. The primary reaction occurs via two pathways: direct condensation 84 
between the silanol groups on the silica surface with the alkoxy group of TESPT and hydrolysis prior to condensation, while the secondary reaction takes place between adjacent alkoxy groups of TESPT already bound to the silica surface. The primary reaction is about 10-20 times faster than the secondary reaction. ${ }^{[10]}$ During the silanization reaction, 1 mole of TESPT can release 6 moles of ethanol (EtOH) as a byproduct. ${ }^{[10-}$ 11] The extent of the silanization reaction in practical rubber compounds can be measured by indirect indicators only, such as chemically bound rubber content ${ }^{[12]}$, Payne effect ${ }^{[13]}$, flocculation rate constant ${ }^{[14]}$ and heat capacity increment. ${ }^{[15-16]}$

For an in-depth insight into the silanization reaction, a model compound of silica/silane system is applied in the present chapter. Based on the silanization reaction, the silanization efficiency can be evaluated by determining the concentrations of $\mathrm{EtOH}$ byproduct or of free silane that is left over after the silanization reaction. Due to the strong interaction of silanol groups on the silica surface with polar functional groups of low molecular weight substances utilized in the compound formulation, i.e. silane, amine and bio oil, this work aims to investigate the silanization efficiency of the silica/silane mixtures in the presence of different types of modified palm oils.

\subsection{EXPERIMENTAL}

\subsubsection{Materials}

Commercial palm oil was used in this study. Epoxidized palm oil (EPO) and amine-modified epoxidized palm oil (mEPO) were in-house prepared on laboratory scale. The chemicals used for the synthesis of modified palm oils were formic acid (98-100\%) (MerkKGaA, Germany), hydrogen peroxide $\left(\mathrm{H}_{2} \mathrm{O}_{2}\right)(34.01 \%)$ (Ajax Fine Chem, Netherlands), zinc chloride $\left(\mathrm{ZnCl}_{2}\right)$ (Asia Pacific Specialty Chemicals Limited, Australia), and N-phenyl-p-phenylenediamine (PPD) (Merck, Germany).

The chemicals used for the model study were highly dispersible silica ULTRASIL 7005 (Evonik, Germany) having BET- and CTAB specific surface areas of 180 and $171 \mathrm{~m}^{2} / \mathrm{g}$, respectively; bis-(3triethoxysilylpropyl) tetrasulfide (TESPT) (Evonik, Germany); anhydrous-grade decane (Sigma-Aldrich Chemie, Germany); acetonitrile for HPLC with purity $99.9 \%$ (Sigma-Aldrich Chemie, Germany) and diethyleneglycol monobutylether (Sigma-Aldrich Chemie, Germany). For the model study, pure and modified forms of palm oil were used. The reference oil was Treated Distillate Aromatic Extract oil (Vivatec 500) (Hansen \& Rosenthal, Germany). 


\subsubsection{Preparation of epoxidized palm oil}

The epoxidation reaction was carried out according to the method described by Derawi and Sakimon (2010) ${ }^{[17]}$ with some modifications. $150 \mathrm{~g}$ of palm oil was added into a $250 \mathrm{~mL}$ three necked flask equipped with a mechanical stirrer, thermometer and reflux condenser at $45^{\circ} \mathrm{C}$. Then, the palm oil was acidified with formic acid under continuous stirring. Hydrogen peroxide was subsequently added dropwise. The molar ratio of palm oil: $\mathrm{HCOOH}: \mathrm{H}_{2} \mathrm{O}_{2}$ was 1:2:4. After reaching the specific reaction time, i.e. 30,60 and $120 \mathrm{~min}$, the reaction mixture was taken out from the reactor, washed thoroughly with a sodium bicarbonate solution in water ( $5 \mathrm{wt} \%)$, distilled water and sodium chloride (5 wt $\%$ ), sequentially, to separate the organic layer from the mixture. The sample was then subjected to analysis for its structure.

\subsubsection{Preparation of amine-modified epoxidized palm oils}

The EPO was further modified with N-Phenyl-p-PhenyleneDiamine (PPD). ${ }^{[7]}$ The weight ratio of EPO oil: PPD: $\mathrm{ZnCl}_{2}$ catalyst was fixed at 10:1:0.5. The reaction mixture was heated at $100^{\circ} \mathrm{C}$ for 3 and $5 \mathrm{hrs}$ under continuous stirring. After that, the $\mathrm{ZnCl}_{2}$ was separated by filtration through cotton wool. The unreacted PPD in the oils was eliminated by absorbing with silica gel. For this step, the crude modified oil was diluted with a mixture of hexane and diethylacetate (1/1) before passing through the column packed with the silica gel. Then, the solvent was eliminated by means of a Rotary Evaporator. The structure of the purified modified EPOs was characterized.

\subsubsection{Characterization of compositions and chemical structures of palm oil and modified} palm oils

The compositions of palm oil were evaluated using Gas-Chromatography (Agilent (GC6890), USA). The chemical structures of palm oil and modified palm oils were analyzed by Fourier Transform Infrared Spectroscopy (FTIR) using a Tensor 27 spectrometer (Bruker Optics, Brussels, Belgium) with a diamond lens Attenuated Total Reflectance (ATR) accessory, and proton Nuclear Magnetic Resonance Spectroscopy ( ${ }^{1} \mathrm{H}-\mathrm{NMR}$ ) (Varian Unity Inova $500 \mathrm{MHz}$, Varian, USA). For FTIR analysis, the spectra were obtained from 32 scans at a resolution of $4 \mathrm{~cm}^{-1}$ in the wavenumber range of $4000-400 \mathrm{~cm}^{-1}$. The ${ }^{1} \mathrm{H}-\mathrm{NMR}$ measurements were performed using purified samples of modified palm oils dissolved in deuterated chloroform $\left(\mathrm{CDCl}_{3}\right)$. 


\subsubsection{Determination of oxirane oxygen contents}

The concentration of epoxide groups in epoxidized palm oil was determined by titration with hydrogen bromide (HBr) according to AOCS analysis method Cd9-57 as reported by Mohd Nor et al. (2017) ${ }^{[18]}$. The epoxidized palm oils were diluted in acetic acid solution and titrated with a HBr solution using crystal violet as an indicator to the blue-green end point. The \% oxirane oxygen content by weight was calculated using the equation below:

$$
\text { Oxirane oxygen content }(w t \%)=\frac{V \times N \times 0.016}{W} \times 100
$$

where $V$ is the volume of $\mathrm{HBr}$ solution used to titrate the sample $(\mathrm{mL}), N$ is the normality of the $\mathrm{HBr}$ solution $(\mathrm{mol} / \mathrm{L})$, and $W$ is the mass of the sample $(\mathrm{g})$.

\subsubsection{Preparation of model compounds}

Decane was used as a model alkane compound to prevent any reactions with silane coupling agents. Silica was first heated in an oven at $100^{\circ} \mathrm{C}$ for $2 \mathrm{~h}$ prior to being used. Then, $0.5 \mathrm{~g}$ of silica was added into a vial before adding $0.094 \mathrm{mmol}$ of TESPT, $0.05 \mathrm{~g}$ of oil and $4 \mathrm{ml}$ of $\mathrm{n}$-decane. Palm oil and modified palm oils were investigated in comparison with TDAE and without oil. The vials containing the reaction mixtures were then flushed with inert nitrogen gas and sealed.

The reaction procedures were as follows;

1. The vials were immersed into an oil bath at $140 \pm 2^{\circ} \mathrm{C}$ for 20 min under continuous stirring.

2. The reactions were quenched by cooling in an ice bath.

3. To remove all physical interactions on the silica surfaces, $2 \mathrm{ml}$ of diethyleneglycol monobutylether was added into the reaction mixtures.

4. The resulting mixtures were subsequently filtered using a $45 \mu \mathrm{m}$ porous filter paper.

5. The mixtures were then diluted by a factor of ten with acetonitrile.

6. The concentration of free TESPT that was left over after the silanization reaction was determined by means of High-Performance Liquid Chromatography (HPLC) using a Varian Pro Star Model 500 (Varian Analytical Instruments, California, USA). The quantitative analysis was performed using a standard curve that was constructed by using the results of known amounts of TESPT in decane analyzed under the same conditions. The chromatographic conditions are given in Table 6.1. 
Table 6.1. Conditions of HPLC used in this study.

\begin{tabular}{ll}
\hline \multicolumn{1}{c}{ Items } & \multicolumn{1}{c}{ Conditions } \\
\hline Column & Nucleosil 100-5 C18 HD (reverse phase) \\
Length of column & $250 \mathrm{~mm}$ \\
Internal diameter of column & $4.6 \mathrm{~mm}$ \\
Mobile phase & Acetonitrile : water $=97: 3$ \\
Flow rate & $0.3 \mathrm{~mm} / \mathrm{min}$ \\
Temperature & $23^{\circ} \mathrm{C}$ \\
Detector & $\mathrm{UV}(\mathrm{DAD})$ \\
Wavelength & $254 \mathrm{~nm}(200$ to $700 \mathrm{~nm})$ \\
Injection volume & $0.5 \mu \mathrm{l}$ \\
\hline
\end{tabular}

\subsection{RESULTS AND DISCUSSION}

6.3.1 Palm oil composition and chemical structures of oils

The basic structure of vegetable oil is a triglyceride extracted from the plants, where the triglyceride is an ester derived from glycerol and three fatty acids. Triglyceride types depend on the types of fatty acids. There are many types of fatty acids occurring in vegetable oils including both saturated and unsaturated structures. The present work uses palm oil of commercial grade available for cooking purposes. By GC analysis, the main components of palm oil are palmitic acid (C16:0) (37.18\%), oleic acid (C18:1) $(46.91 \%)$ and linoleic acid (C18:2) (8.82\%), as shown in Table 6.2. 
Table 6.2. Compositions of palm oil used as analyzed by GC.

\section{Type of fatty acids}

Quantity (\%)

\begin{tabular}{lc}
\hline Saturated fatty acids & \\
\hline Lauric acid (C12:0) & 0.33 \\
Myristic acid (C14:0) & 0.94 \\
Pentadecanoic acid (C15:0) & 0.04 \\
Palmitic acid (C16:0) & 37.18 \\
Heptadecanoic acid (C17:0) & 0.09 \\
Stearic acid (C18:0) & 3.84 \\
Arachidic acid (C20:0) & 0.34 \\
Behenic acid (22:0) & 0.06 \\
Lignoceric acid (24:0) & 0.07 \\
\hline Unsaturated fatty acids & \\
\hline Palmitoleic acid (16:1) & 0.15 \\
Oleic acid (C18:1) & 46.91 \\
Linoleic acid (C18:2) & 8.82 \\
Lenolenic acid (C18:3) & 0.13 \\
Gondoic acid (C20:1) & 0.14 \\
Erucic acid (C22:1) & 0.04 \\
\hline
\end{tabular}
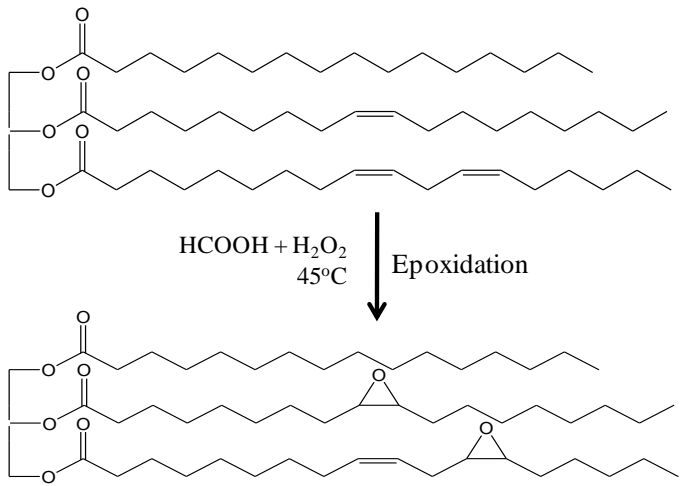

Figure 6.1. Postulated structure of epoxidized palm oil.

The palm oil (PO) was modified by epoxidation into the epoxidized version EPO. The reaction takes place at unsaturated sites, changing part of the double bonds into epoxy-rings or epoxide-groups, as shown in Figure 6.1, wherein the structures of palmitic-, oleic- and linoleic- acids are used to represent the triglyceride structure of the palm oil. The structures of the EPOs in comparison with the original PO were characterized by the ${ }^{1} \mathrm{H}-\mathrm{NMR}$ technique and their spectra are shown in Figure 6.2. The methylene proton $\left(\mathrm{CH}_{2}\right)$ of saturated structure shows its absorption peak at 1.2-1.4 ppm, while the signals of protons in the unsaturated fatty acid structure appears at many regions. The resonance of olefinic protons $(-\mathrm{CH}=\mathrm{CH}-)$ is 
found at 5.3-5.4 ppm, while the proton on allylic carbons $\left(-\mathrm{CH}_{2}-\mathrm{CH}_{2}-\mathrm{CH}=\mathrm{CH}-\right)$ occurs at 2.0-2.1 ppm. The peaks at 2.7-2.8 ppm are assigned to the protons attached to the bis-allylic carbons $\left(-\mathrm{CH}=\mathrm{CH}-\mathrm{CH}_{2}-\mathrm{CH}=\mathrm{CH}-\right.$ )$^{[19]}$. The characteristic peak for EPO appears at $2.9 \mathrm{ppm}$ due to resonance of protons on the epoxide ring [17]. By taking integral values of the peaks associated with protons on double bonds and the epoxide ring, the mole\% of epoxide groups in the EPO was calculated using equation (6.2) and the results are given in Table 6.2:

$$
\text { Mole \% of epoxide groups }=\frac{X_{2.9} / 2}{X_{5.3-5.4} / 2+X_{2.9} / 2} \times 100
$$

where $X_{5.3-5.4}$ is the integrated peak area of the olefinic protons of EPO at 5.3-5.4 ppm, and $X_{2.9}$ is the integrated peak area of protons attached to the oxirane rings of EPO at $2.9 \mathrm{ppm}$, respectively.

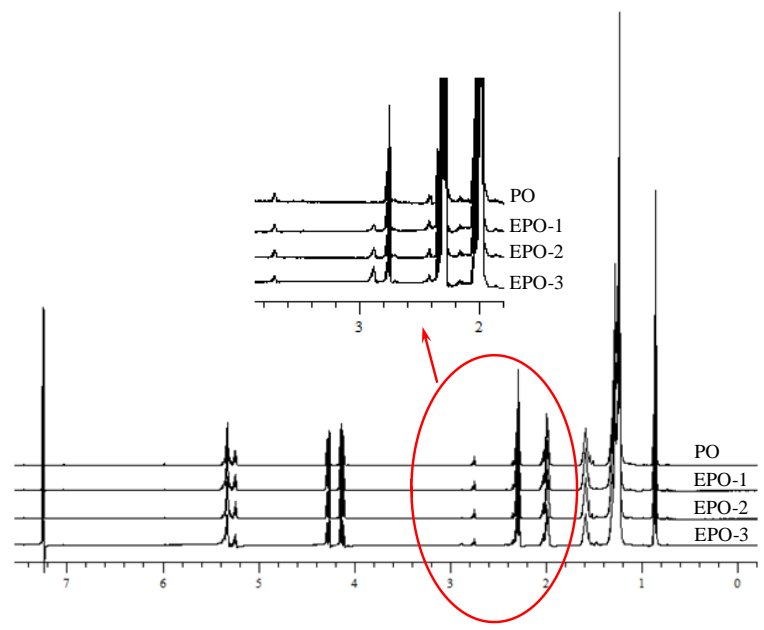

Figure 6.2. ${ }^{1} \mathrm{H}-\mathrm{NMR}$ spectra of palm oil (PO) and epoxidized palm oil (EPO) having different epoxide contents.

Table 6.3. Epoxide contents in the epoxidized palm oils.

\begin{tabular}{cccc}
\hline $\begin{array}{c}\text { Reaction time } \\
(\min )\end{array}$ & $\begin{array}{c}\text { Mole \% of epoxide groups } \\
\left(\text { by }{ }^{1} \text { H-NMR }\right)\end{array}$ & $\begin{array}{c}\text { Wt \% of oxirane oxygen } \\
\text { (by titration with HBr) }\end{array}$ & EPO Code \\
\hline 30 & 1.27 & 1.14 & EPO-1 \\
60 & 2.28 & 2.23 & EPO-2 \\
120 & 4.53 & 3.12 & EPO-3 \\
\hline
\end{tabular}

In addition to the analysis by ${ }^{1} \mathrm{H}-\mathrm{NMR}$, the concentrations of epoxide groups was evaluated by the chemical method via titration with $\mathrm{HBr}$. The epoxide contents of EPOs prepared at different reaction times as analyzed by both techniques are shown in Table 6.3. By increasing the reaction time, the epoxide 90 
content increases. Herewith, EPOs having epoxide contents of approximately 1, 2 and 3-4 mole\% were obtained. The materials are coded EPO-1, EPO-2 and EPO-3 for later reference.

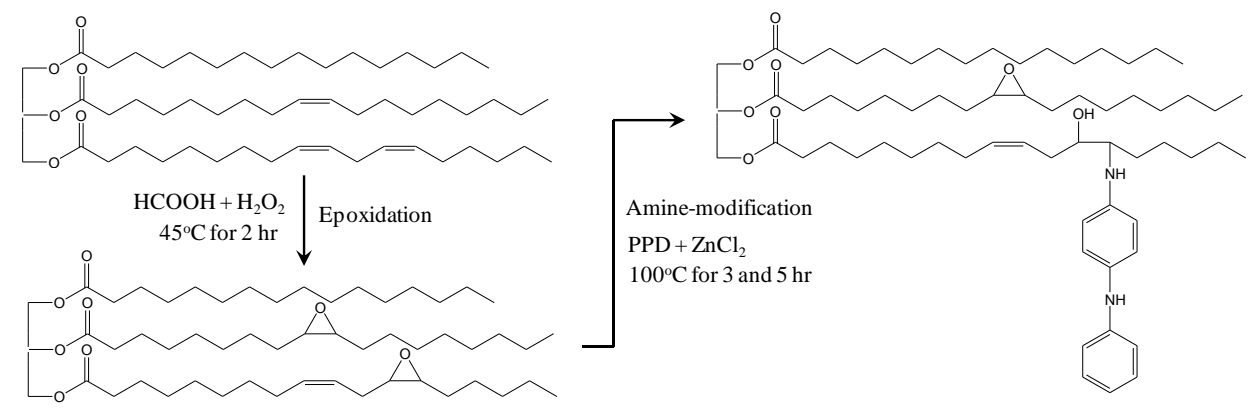

Figure 6.3. Chemical modification of palm oil via epoxidation and reaction with N-phenyl-pphenylenediamine (PPD).

The EPO-3 with approximate $3 \mathrm{wt} \%$ of oxirane oxygen content was further modified with PPD, as shown in Figure 6.3. FT-IR spectra of EPO and amine-modified EPO are compared in Figure 6.4. The spectra of EPO and mEPO show similar peaks due to the same compositions of the fatty acids contained therein. The spectra show absorption peaks at 723, 1164, 1461, 1741, 2854, 2925, $3004 \mathrm{~cm}^{-1}$ due to the vibration of functional groups in the structures of the fatty acids, i.e. $-\mathrm{HC}=\mathrm{CH}-$ bending (out of plane), $\mathrm{CH}$ in plane, $\mathrm{C}-\mathrm{H}$ of $\mathrm{CH}_{2}$ bending, $\mathrm{C}=\mathrm{O}$ from ester, $\mathrm{C}-\mathrm{H}$ of $\mathrm{CH}_{2}$ stretching, $\mathrm{C}-\mathrm{H}$ of $\mathrm{CH}_{3}$ stretching, and $\mathrm{C}=\mathrm{CH}$ stretching, respectively ${ }^{[17]}$. The peak of $\mathrm{C}-\mathrm{H}$ bending on the oxirane ring in EPO appears at $870 \mathrm{~cm}$ ${ }^{1}$, whilst the spectra of amine-modified EPO oils show additional peaks at 1597 and $3387 \mathrm{~cm}^{-1}$, assigned to the vibration of $\mathrm{C}=\mathrm{C}$ in the aromatic rings and $-\mathrm{NH}$ in $\mathrm{PPD}$, respectively. Based on the FT-IR spectra, the amount of PPD in the mEPO were quantitatively verified by calculating the absorbance ratio at 1597/1741 and then relating to a standard curve constructed by using known amounts of PPD. It was found that the mEPOs prepared by using the reaction times of 3 and 5 hrs contain 0.03 and $0.04 \mathrm{mmol}$ of PPD in $1 \mathrm{~g}$ of oil, respectively. They are respectively called $0.03 \mathrm{mEPO}$ and $0.04 \mathrm{mEPO}$. 


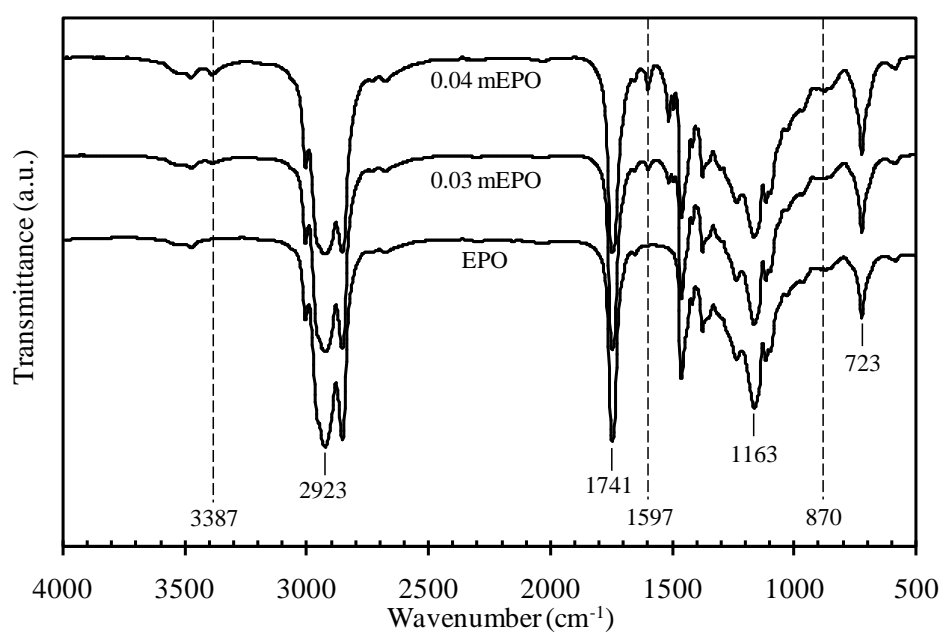

Figure 6.4. FTIR spectra of modified palm oils.

The ${ }^{1} \mathrm{H}-\mathrm{NMR}$ spectra of EPO and mEPO are comparatively displayed in Figure 6.5. With reference to the signals for the EPOs as discussed before, the mEPOs show additional peaks in the range of 6.6-7.4 ppm due to the aromatic protons in PPD. Based on the ${ }^{1} \mathrm{H}-\mathrm{NMR}$ spectra of the mEPO oil, by taking integral values of the peaks associated with protons on PPD, double bonds, and the epoxide ring, the mole $\%$ of PPD in the mEPOs molecules was calculated using equation (6.3).

$$
\text { Mole \% of PPD }=\frac{X_{6.6-7.4} / 9}{\left(X_{2.9} / 2\right)+\left(X_{5.3-5.4} / 2\right)+\left(X_{6.6-7.4} / 9\right)} \times 100
$$

where $X_{2.9}$ is the integrated peak area of protons attached to the oxirane rings of EPO at $2.9 \mathrm{ppm}$, $X_{5.3-5.4}$ is the integrated peak area of the olefinic protons of EPO at 5.3-5.4 ppm, and X6.6-7.4 is the integrated peak area of the protons on aromatic ring of PPD at 6.6-7.4 ppm, respectively.

The values of mole \% of PPD in mEPOs prepared with different reaction times, i.e. 3 and $5 \mathrm{hrs,}$ are 1.37 and 2.41 , respectively. 


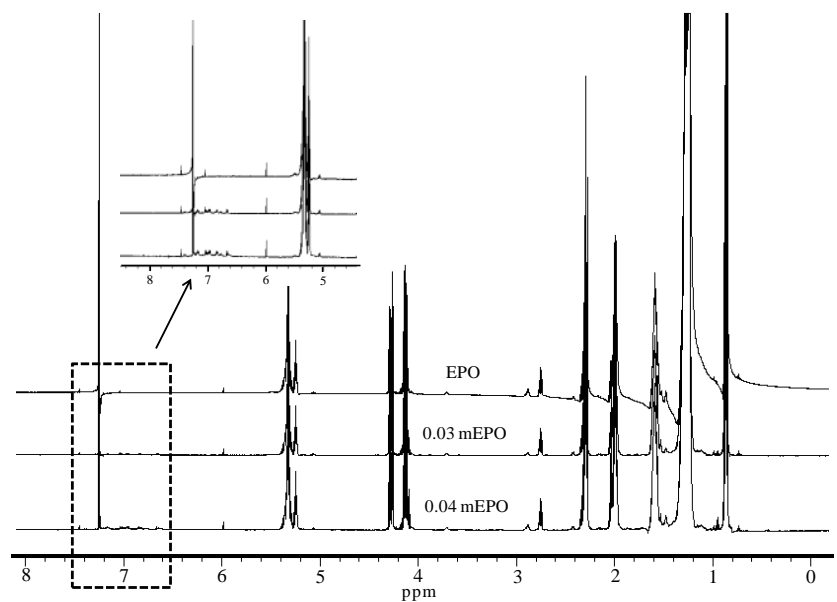

Figure 6.5. ${ }^{1} \mathrm{H}-\mathrm{NMR}$ of modified palm oils.

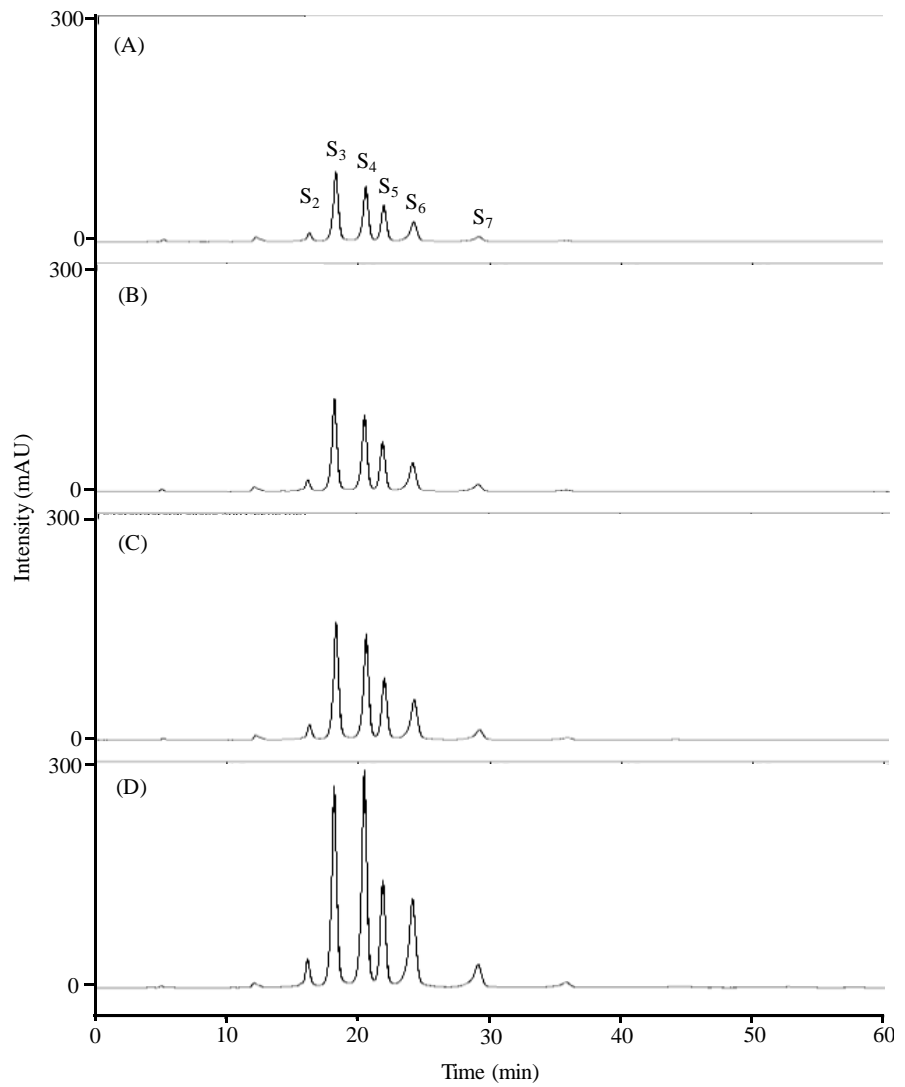

Figure 6.6. Typical HPLC chromatograms of TESPT/decane with different concentrations of TESPT: (A) 0.028 , (B) 0.039 , (C) 0.053 and (D) $0.114 \mathrm{~mol} / \mathrm{L}$. 


\subsubsection{TESPT analysis in decane mixtures}

The chromatographic technique of HPLC was used to separate the components in a mixture. A liquid sample was allowed to flow with a solvent mobile phase passing over a solid adsorbent material, packed in a column. The samples that have interactions with the adsorbent material should retard the analytical flows. Typical chromatograms of the TESPT/decane mixtures with different amounts of TESPT are shown in Figure 6.6. TESPT gives several peaks at different retention times due to its various chemical structures derived from different sulfur moieties. The retention time of TESPT is in a range of 15 to $30 \mathrm{~min}$. The retention time of TESPT containing 2 sulfur atoms is observed at $16 \mathrm{~min}$, while those with 3, 4, 5, 6 and 7 sulfur atoms occur at 18,21, 22, 24 and 29 min, respectively. Based on the chromatograms, it demonstrates that the TESPT mostly contains tri- and tetra-sulfides in the structure. ${ }^{[20]}$ Considering the chromatograms of samples having different amounts of TESPT, it was found that the intensity of the TESPT peak increases with increasing concentration.A plot of concentration of the TESPT in the mixtures versus a total peak area is shown in Figure 6.7.

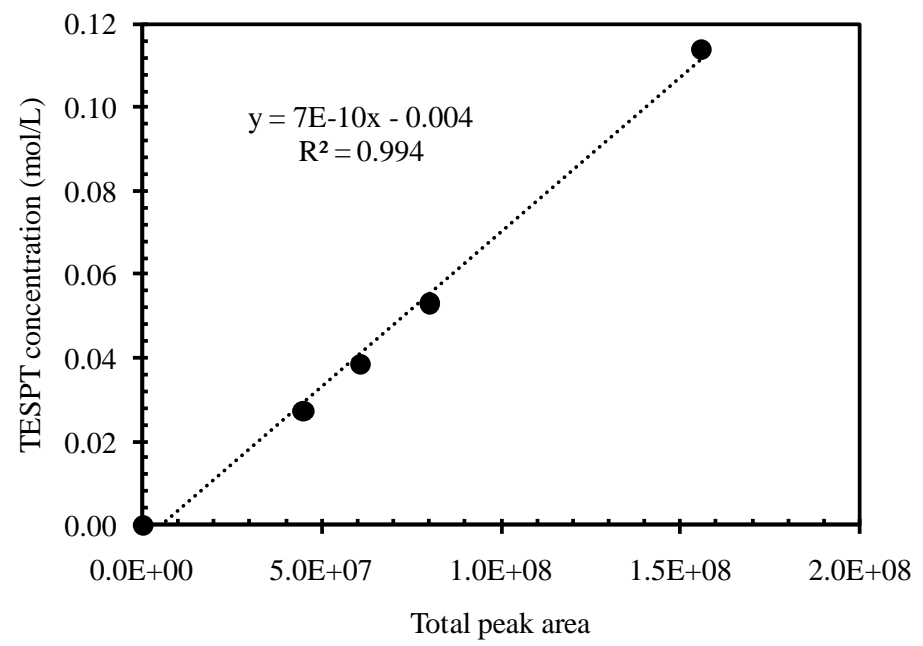

Figure 6.7. TESPT concentration versus total peak area. 


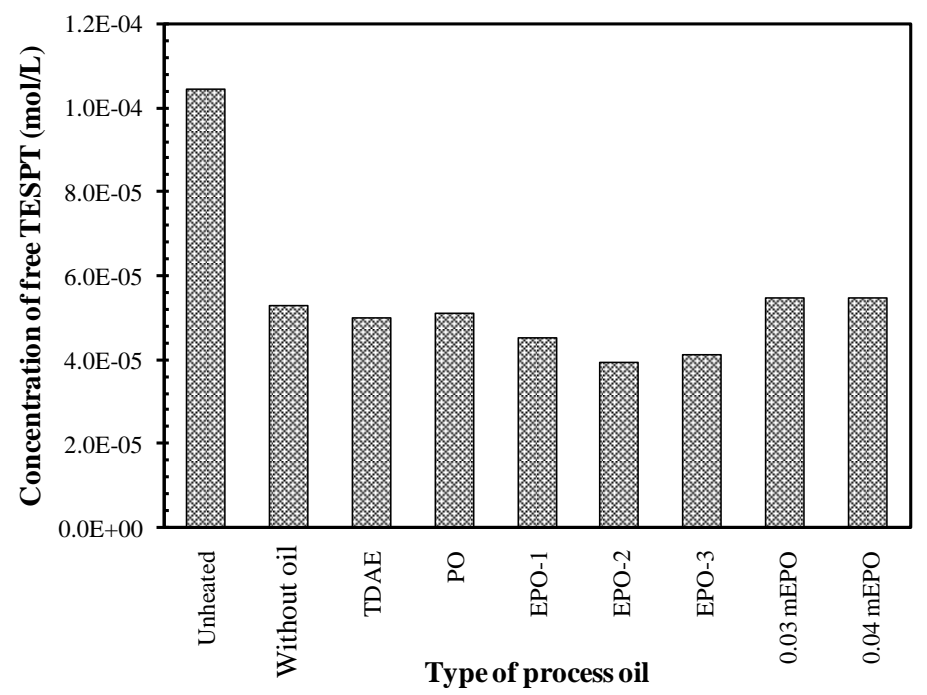

Figure 6.8. Concentration of free TESPT of mixtures with different types of modified oils.

\subsubsection{Model compound analysis}

The mixtures containing silica/TESPT and various types of oils were prepared and heated at $140^{\circ} \mathrm{C}$ to stimulate the silanization reaction. The unheated mixture of silica/TESPT without oil was also analyzed as reference. After the silanization, the solid phase, comprising of silica with bound TESPT and the liquid phase containing free TESPT left over after the silanization reaction, were separated. The free TESPT was then determined using HPLC. Based on the total peak area under the chromatographs, the concentration of free TESPT can be calculated and is shown in Figure 6.8. Considering the unheated and heated mixtures, all heated mixtures show lower concentrations of free TESPT than the unheated one. This evidence confirms that the silanization reaction took place in the mixtures under high temperature $\left(140^{\circ} \mathrm{C}\right)$. Among the different types of process oils, the use of TDAE and palm oil (PO) gives similar free TESPT concentrations which is more or less at the same level as that of the mixture without oil. The use of EPO oils results in a lower free TESPT content in the systems, indicating a greater extent of the silanization reaction. However, the mixture with PPD-modified EPO oils (mEPO) shows a higher free TESPT concentration compared to EPO and the other oil types, indicating a reduced efficiency of the silanization reaction. It is clear that the silanization efficiency of the mixtures containing process oils is affected by the adsorption of the oils on the silica surface. As EPO and $\mathrm{mEPO}$ have different polarities and molecular sizes, so the adsorption ability and accessibility towards the silica surface is different. The EPOs with smaller and less bulky structure could adsorb on the silica surface more easily compared to mEPO. The enhanced hydrophobicity interrupts the re-agglomeration and thus results in less agglomerates and more free silanol groups available for reacting with silane molecules in the system, resulting in higher silanization efficiency. 
However, the mEPOs that have a strong interaction with the silica surface to give a shielding effect introduce steric hindrance that reduces the accessibility of the silanes to the silica surface, resulting in reduction of the silanization efficiency. Another possible explanation for the lower silanization efficiency in the presence of mEPOs is because the strong interactions that may lock the silica agglomerates, preventing them breaking up and reducing the number of accessible silanols. Moreover, the different polarity of these oils also has an effect on the wettability on the silica surface. From the unreacted TESPT concentration, the percentage of silanization reaction of the mixtures is calculated and shown in Figure 6.9. All the mixtures show a higher than $50 \%$ extent of the silanization reaction. It is clearly demonstrated in this figure that the use of EPOs promotes the silanization efficiency about $7-13 \%$ compared to TDAE, but that the use of $\mathrm{mEPO}$ slightly hampers the reaction.

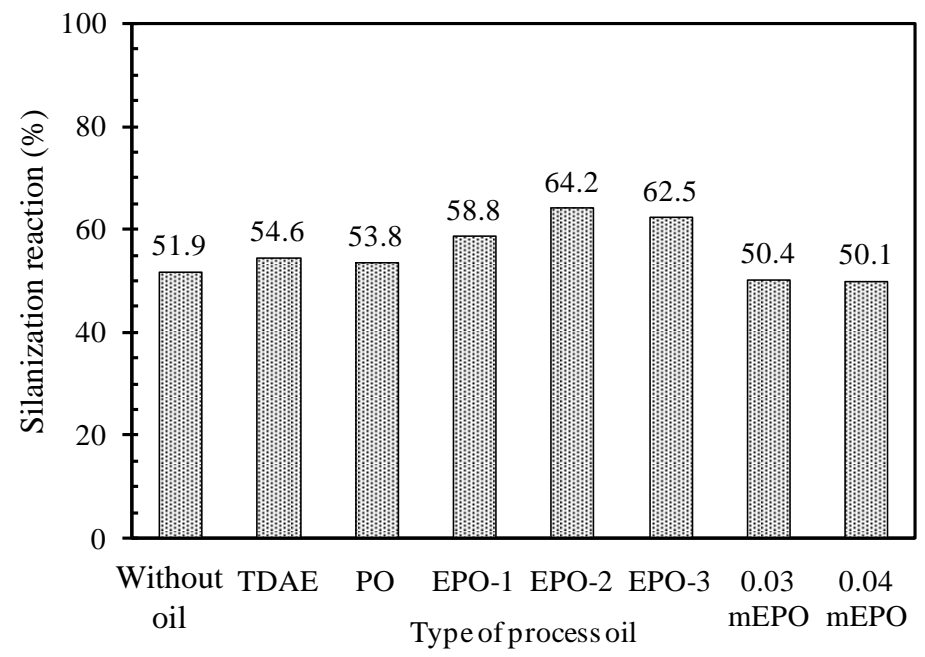

Figure 6.9. Percentage of silanization reaction of silica/silane mixtures in the presence of different types of modified oils.

\subsection{CONCLUSIONS}

This work successfully prepared modified palm oils in the forms of epoxidized- and amine modified epoxidized versions. The effect of modified palm oils on the silanization efficiency was investigated. Mixtures of silica/silane with different types of bio oils were prepared by taking the mixtures with TDAE and without oil as references. The free silane molecules that are left over after the silanization reaction were determined by using HPLC. The use of TDAE and unmodified palm oil show similar silanization efficiency that is close to the value of the mixture without oil. The presence of EPOs promotes the silanization efficiency, while the mEPOs hinder the silanization reaction. The difference is derived from their different polarities and molecular sizes that affect their adsorption ability and accessibility towards the 
silica surface. The EPO with smaller and less bulky structure could easier adsorb on the silica surface compared to $\mathrm{mEPO}$, resulting in enhanced hydrophobicity, better dispersion and more free silanol groups available for reacting with silane molecules in the system. In contrast, the mEPOs that have strong interaction with the silica surface introduce a steric effect that reduces the accessibility of the silanes to the silica surface resulting in reduction of the silanization efficiency.

\subsection{REFERENCES}

${ }^{[1]}$ Directive 2005/69/EC, Off. J. Eur. Union L323, 51 (2005).

${ }^{[2]}$ Commission Regulation (EC) No 552/2009, Off. J. Eur. Union L164, 7 (2009).

${ }^{[3]}$ The Swedish National Chemicals Inspectorate. KEMI Reports, Rep. 5/03. (Swedish National Chemicals Inspectorate, 1993).

${ }^{[4]}$ S. Dasgupta, S.L. Agrawal, S. Bandyopadhyay, S. Chakraborty, R. Mukhopadhyay, R.K. Malkani, S.C. Ameta, Polym. Test. 26, 489 (2007).

${ }^{[5]}$ K. Sahakaro, A. Beraheng, Rubber Chem. Technol. 84, 200 (2011).

${ }^{\left[{ }^{6]}\right.}$ H. Boontawee, C. Nakason, A. Kaesaman, A., Thitithammawong, S. Chewchanwuttiwong, Adv. Mater. Res. 415-417, 1164 (2012).

${ }^{[7]}$ S. Ieadsang, A. Thitithammawong, C. Nakason, A. Kaesaman, Adv. Mater. Res. 844, 239 (2014).

${ }^{[8]}$ K. Chanpon, A. Thitithammawong, C. Nakason, A. Kaesaman, Adv. Mater. Res. 844, 49 (2014).

${ }^{[9]}$ R. Joseph, R. Alex, K.N. Madhusoodanan, C.K. Premalatha, B. Kuriakose, J. App. Polym. Sci. 92, 3531 (2004).

${ }^{[10]}$ U. Goerl, A. Hunsche, A. Mueller, H.G. Koban, Rubber Chem. Technol. 70, 608 (1997).

${ }^{[11]}$ J.W. ten Brinke, S.C. Debnath, L.A.E.M. Reuvekamp, J.W.M. Noordermeer, Compos. Sci. Technol. 63, 1165 (2003).

${ }^{[12]}$ S. Wolff, M.J. Wang, E.H. Tan, Rubber Chem. Technol. 66, 163 (1993).

${ }^{[13]}$ A.R. Payne, Rubber Chem. Technol. 33, 365 (1966).

${ }^{[14]}$ S. Mihara, R.N. Datta, J.W.M. Noordermeer, Rubber Chem. Technol. 82, 524 (2009).

${ }^{[15]}$ B. Zhong, Z. Jia, D. Hu, Y. Luo, D. Jia, Compos. Part A 78, 303 (2015).

${ }^{[16]}$ D. Fragiadakis, L. Bokobza, P. Pissis, Polymer 52, 3175 (2011).

${ }^{[17]}$ D. Derawi, J. Salimon, E-J Chem. 7, 1440 (2010)

${ }^{[18]}$ N. Mohd Nor, D. Derawi, J. Salimon, Malay. J. Anal. Sci. 21, 1423 (2017)

${ }^{[19]}$ G. Knothe, J.A. Kenar, Eur. J. Lipid Sci. Technol. 106, 88 (2004).

${ }^{[20]}$ S.C. Debnath, R.N. Datta, J.W.M. Noordermeer, Rubber Chem. Technol. 76, 1311 (2003). 


\title{
SILICA-REINFORCED NATURAL RUBBER TIRE TREAD COMPOUNDS CONTAINING BIO-BASED PROCESS OILS: I. ASPECTS OF MIXING SEQUENCE AND EPOXIDE CONTENT
}

\begin{abstract}
A bio-based process oil for rubber compounds is one of the compounding ingredients to be utilized towards an eco-friendly and more sustainable rubber technology. This work investigates epoxidized palm oil (EPO) as alternative for petroleum-based process oil in silica-reinforced natural rubber (NR) tire tread compounds. The effect of different incorporating steps of EPO on the properties of the rubber compounds is first studied, taking into account that the polar functional groups in the oil molecules may interact with the silanol groups on the silica surface. The properties of silica-reinforced NR compounds with EPO oil are compared to that of reference mixes with treated distillate aromatic extract (TDAE) and without oil. The compounds with EPO show a lower viscosity, lower filler-filler interaction and flocculation rate constant, but higher cure reaction rate constants, compared to the one with TDAE. The results indicate that the epoxide groups in EPO interact with the silanol groups on the silica surface, promoting more shielding effect on the polar surface and thus a better silica dispersion and less interference with the vulcanization reaction. The different incorporating steps of EPO show no significant effect on the viscosity, filler-filler interaction and flocculation rate constant, but clearly affect the extent of crosslinking as indicated by the cure torque difference. The presence of EPO in an early stage of the mixing together with the first half addition of silica and silane, results in the lowest cure torque difference, modulus and tensile strength, and the highest tan $\delta$ at $60^{\circ} \mathrm{C}$, which indicates a possible obstruction for interaction between the silanol groups and silane coupling agent by the EPO molecules. Comparing EPO with different epoxide contents in the range of 1-4 mol\%, the increase of epoxide content gives similar Payne effects, but enhances the cure reaction resulting in improved tensile properties and tan $\delta$ at $60^{\circ} \mathrm{C}$. The results clearly prove that EPO can be used as a TDAE alternative.
\end{abstract}




\subsection{INTRODUCTION}

The reinforcement of rubber tire tread compounds with silica-silane fillers to replace conventional carbon black, enables production of tires with improved key tire performances, i.e. low rolling resistance and better wet traction ${ }^{[1]}$. Because of the highly polar nature of the silica surface derived from silanol groups, mixing of silica into tire rubbers which are mainly non-polar of nature encounters incompatibility problems ${ }^{[2-3]}$. Silane coupling agents are widely applied together with silica to improve the interfacial compatibility between the silica surface and rubber matrix. The chemical bridge formation between the rubber-filler phases through the silanization reaction of the alkoxy groups of the silane with silanol groups on silica, and the subsequent coupling reaction with the elastomer provides the vulcanized rubber good dynamic mechanical properties with low hysteresis. Among various types of silane coupling agents available, the state-of-the-art bis(3-triethoxysilylpropyl) tetrasulfide (TESPT) is the most commonly used and effective bi-functional silane for silica-filled rubber compounds ${ }^{[2]}$. The use of TESPT not only decreases filler-filler interaction, i.e. the Payne $\operatorname{effect}^{[4]}$, but also increases the silica-rubber interaction and interfacial adhesion. The silanization reaction between the alkoxy groups in the silane molecule and the silanol groups on the silica surface proceeds through primary and secondary silanization reactions during mixing ${ }^{[5-6]}$. The primary reaction takes place between a silanol group on the silica surface and one ethoxy group in the TESPT molecules. The secondary condensation between adjacent silane molecules reacted onto the silica surface then occurs. Thereafter, the polysulfide part in the silane molecule will react with elastomer molecules during vulcanization, leading to the full silica-silane-rubber bridge ${ }^{[2-3,7]}$. Based on model system studies ${ }^{[5]}$, the primary reaction is about $10-20$ times faster than the secondary reaction and the reaction can occur via two pathways: direct condensation and hydrolysis prior to condensation. Recently it has been reported that only the isolated and geminal silanol groups on the silica are involved in the silicasilane reaction, and that approximately $25 \%$ of the $\mathrm{Si}-\mathrm{OH}$ groups are able to react with silanes due to limited accessibility of these silanol groups for incoming silane molecules ${ }^{[8]}$. Due to the limited number of silanes that can be grafted on the silica surface ${ }^{[9]}$, the additional use of small molecules such as alcohols and amines or silanes with high shielding potential to increase the hydrophobation of the silica surface is beneficial.

For filled compounds especially at high filler loading, process oil is an essential ingredient used for the purpose of improved processability and enhanced filler dispersion. Depending on the types of elastomers and purpose of oil utilization, there are many oil types available for the rubber industry. Petroleum-based process oils are most commonly used in rubber compounds in which the oils are classified in three primary categories, i.e. aromatic, naphthenic, and paraffinic oils. The selection of the oil type to be applied in the rubber formulation mainly depends on the compatibility between the oil and the rubber polymer. Poor compatibility between oil and rubber will result in oil migration or leaching out from the compounds, resulting in losses in physical properties and surface appearance, as well as deterioration in layer component adhesion ${ }^{[10-11]}$. In tire compounds, there are several reasons to use process oils, such as to 
reduce the elastic modulus, to improve adhesion between different layers, and to enhance compatibility between filler and rubber ${ }^{[10]}$. For tire rubbers that include mainly natural rubber and diene-based synthetic elastomers, aromatic oil is widely used as it provides good compatibility between aromatic moieties in the oils with elastomer molecules. However, with reference to the KEMI report issued by the Swedish National Chemicals Inspectorate in 1993, release of highly polycyclic aromatic hydrocarbons (PAHs) contained in aromatic process oils from tire particles, identified as suspected carcinogens, raised concern over this toxicity worldwide ${ }^{[12]}$. As a consequence, the European Commission issued a directive ${ }^{[13-14]}$, wherein from 1 January 2010 extender oils are banned for the production of tires or parts of tires if they contain more than $1 \mathrm{mg} / \mathrm{kg}$ Benzo[a]pyrene, and more than $10 \mathrm{mg} / \mathrm{kg}$ of the sum of 8 specially listed PAHs. In order to facilitate identification this requirement is considered to be met if the polycyclic aromatics extract from the oil with Dimethyl Sulfoxide (DMSO) (IP346 test method) is less than $3 \mathrm{wt} \%$. Therefore, the process oils with low content of PAHs such as treated distillate aromatic extract (TDAE), mild extracted solvate (MES) and naphthenic (NAP) oils, are used as safe process oils in rubber compounds to replace DAE oil.

In addition to the awareness of toxicity, shortage of petroleum-based process oils might occur in the future because of reduced mineral oil reserves. Alternative safe process oils from natural resources such as palm oil, soybean oil, etc. therefore attract interest and are subjected to investigations as alternatives ${ }^{[15-}$ ${ }^{18]}$. Due to the chemical structure of bio-based oils that are naturally composed of unsaturated fatty acids, it has been reported that these natural oils consume some curatives in the rubber compounds, causing retardation of the cure rate and a lower crosslink density ${ }^{[16]}$. Therefore, modifications of the natural oils are done to decrease the chain unsaturations and to increase the compatibility between these oils and elastomer molecules. Based on a study of carbon black-reinforced rubber compounds using Epoxidized Palm Oil (EPO), it was anticipated that the EPO could be a potential candidate as alternative for petroleum-based process oils $^{[18]}$.

The present study aims for the utilization of EPO in silica-reinforced natural rubber compounds. As the silica surface is highly polar and active, and the absorption of a silane coupling agent on the surface is crucial for the success of the subsequent silanization reaction between the silanol groups on the silica surface and alkoxy groups in the silane molecules, possible competitive absorption of oil on the silica surface is therefore of primary concern. This work investigates the mixing sequence of the addition of the EPO on the processability, silanization reaction as well as dispersibility of silica filler in the rubber matrix. Then, based on an optimized mixing sequence, the rubber compounds with EPOs having different levels of epoxide content are comparatively studied against the references TDAE and full absence of oil. 


\subsection{EXPERIMENTAL}

\subsubsection{Materials}

Rubber compounding ingredients used in this study, i.e. Ribbed Smoked Sheet (RSS\#3), highly dispersible silica (ULTRASIL 7005), bis(3-triethoxysilylpropyl) tetrasulfide (TESPT), octadecylamine, treated distillate aromatic extract oil (TDAE oil), zinc oxide ( $\mathrm{ZnO})$, stearic acid, N-cyclohexyl-2benzothiazole sulfenamide (CBS), diphenyl guanidine (DPG), 2,2,4-trimethyl-1,2-dihydroquinoline (TMQ), and sulfur, are as described in Chapter 4. Bio-based process oils which are EPO with different epoxidized levels are used in this study. The preparation of EPO is described in Chapter 6.

\subsubsection{Preparation of rubber compounds}

Truck tire tread NR compounds were prepared using two mixing steps. The rubber formulation is shown in Table 7.1. In this work OCT was used as replacement of DPG as secondary accelerator and silanization booster in order to provide safer rubber compounds and enhanced interfacial compatibility between the silica surface and rubber matrix according to previous work, ${ }^{[19-20]}$ see in Chapter 4 and 5 . The first mixing step was conducted using an internal mixer (Brabender Plasticorder 350s) at fill factor 0.70, initial mixer temperature setting of $100^{\circ} \mathrm{C}$ and rotor speed of $60 \mathrm{rpm}$. The curing agents were later mixed into the rubber compounds on a two-roll mill. For the study of the influence of the mixing sequence, 3 different mixing methods, i.e. M1, M2 and M3, were applied using EPO with $3 \mathrm{wt} \%$ of oxirane oxygen (i,e. EPO-3 as referred in Chapter 6) as process oil, as described in Figure 7.1. Compounds without oil and with TDAE were prepared following the M1 mixing method as references.

Based on the optimized mixing sequence, compounds with different oil types: PO and EPOs with different epoxide contents were prepared and their properties evaluated in comparison with the mixes with TDAE and without oil.

\subsubsection{Properties and testing}

Properties of rubber compounds, i.e. bound rubber content, Payne effect, flocculation rate constant, heat capacity increment, and cure characteristics, and rubber vucanizates, i.e. mechanical and dynamic mechanical properties, were tested, as described in Chapter 4.

Complex viscosities of rubber compounds were measured using a Rubber Process Analyzer (RPA 2000, Alpha Technologies, Akron, USA) at $100^{\circ} \mathrm{C}$ and $2.79 \%$ strain under frequency sweep (0.05-33 Hz). 
Table 7.1 Rubber formulation

\begin{tabular}{cc}
\hline Ingredients & Quantity (phr) \\
& \\
\hline NR & 100 \\
Silica & 55 \\
TESPT & 5 \\
ZnO & 3 \\
Stearic acid & 1 \\
TMQ & 1 \\
TDAE oil or EPO & 8 \\
OCT & 1.3 \\
CBS & 1.5 \\
S & 1.5 \\
\hline
\end{tabular}

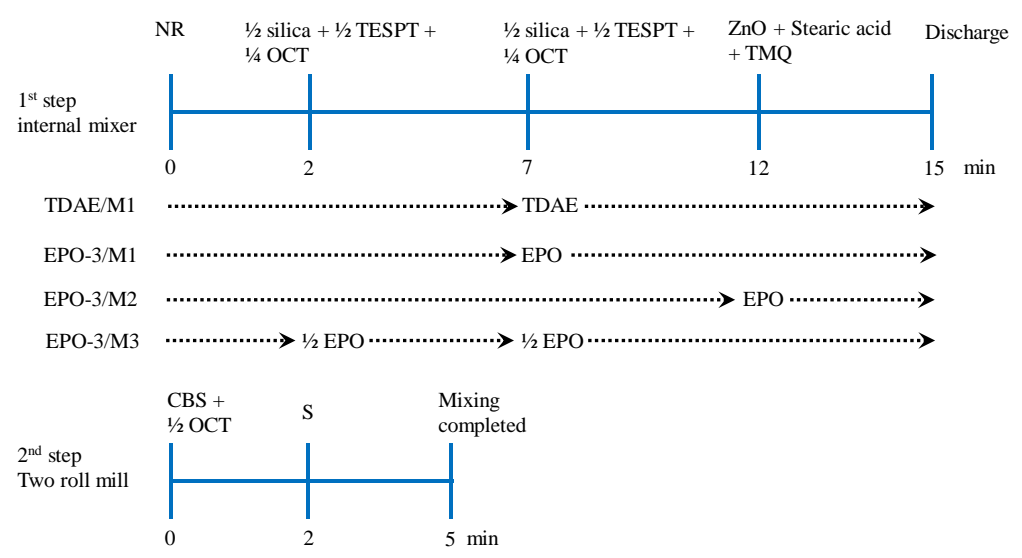

Figure 7.1 Mixing sequences in preparing rubber compounds.

\subsection{RESULTS AND DISCUSSION}

7.3.1 Effects of mixing sequence on the properties of rubber compounds

The results of the different mixing sequences as shown in Figure 7.1, on the properties of the silica-reinforced NR compounds containing EPO-3 in comparison with those with TDAE and without oil are given in Table 7.2. To ensure a successful silanization reaction, all compounds were mixed to obtain dump temperatures higher than $140^{\circ} \mathrm{C}$. As shown in Table 7.2 the mixes have final temperatures in the range of $145-160^{\circ} \mathrm{C}$. 
Table 7.2 Mixing characteristics of silica-reinforced NR compounds with different oil incorporating steps

\begin{tabular}{lccccc}
\hline Characteristics/Properties & \multicolumn{5}{c}{ Oil type-mixing sequence } \\
\cline { 2 - 6 } & Without oil & TDAE/M1 & EPO-3/M1 & EPO-3/M2 & EPO-3/M3 \\
\hline Dump torque (N.m) & 155 & 139 & 131 & 133 & 130 \\
Dump temperature $\left({ }^{\circ} \mathrm{C}\right)$ & 160 & 153 & 153 & 145 & 152 \\
\hline
\end{tabular}

\subsubsection{Processability}

The addition of fillers into rubber compounds increases their viscosity, causing less flow especially at high filler loadings, that affect further processing such as extrusion and molding. This drawback can be overcome by the use of process oils to reduce the viscosity and improve the flow. The presence of process oil also affects the mixing behavior and filler dispersion within the rubber matrix. In the present work, the use of EPO added into the rubber compounds at different mixing stages and the resulting final mixing torque or dump torque and complex viscosity are presented in Table 7.2 and Figure 7.2 , respectively. The dump torques and complex viscosities of the silica-reinforced NR compounds with EPO-3 show similar values which are lower than for the compounds with TDAE and without oil. The incorporation of process oils results in lower rubber compound viscosities due to the plasticization effect ${ }^{[10]}$, that may be explained by the lubricity theory in which the oil molecules lubricate and reduce intermolecular friction between rubber molecules, or by the free volume theory in which the presence of oil increases the free volume within the material. The lower compound viscosities also result in reduced dump temperatures due to less shearing heat generated during mixing. As expected, the mixing of silica and rubber without oil gives the highest final mixing temperature. The addition of oil after the complete addition of silica (EPO$3 / \mathrm{M} 2$ ) results in the lowest dump temperature of $145^{\circ} \mathrm{C}$. By using the same mixing sequence, comparing the effect of EPO-3 and TDAE on the mixing behavior, it was observed that both oil types result in the same dump temperature, even though the EPO-3 shows a lower dump torque, which is in accordance with the lower complex viscosity in Figure 7.2. The results indicate that the EPO-3 with polar epoxide groups may promote better silica dispersion within the rubber matrix compared to TDAE due to the polarity in the oil molecules, that can interact with the silanol groups on the silica surface and thus reduce filler-filler interaction. As previously reported by Joseph et al. ${ }^{[15]}$ for silica-filled rubber compounds employing a combination of silane coupling agents with the epoxide modified-natural process oil, the epoxidized oil could enhance the hydrophobicity of the silica surface and increase compatibility between the silica surface and rubber matrix. 

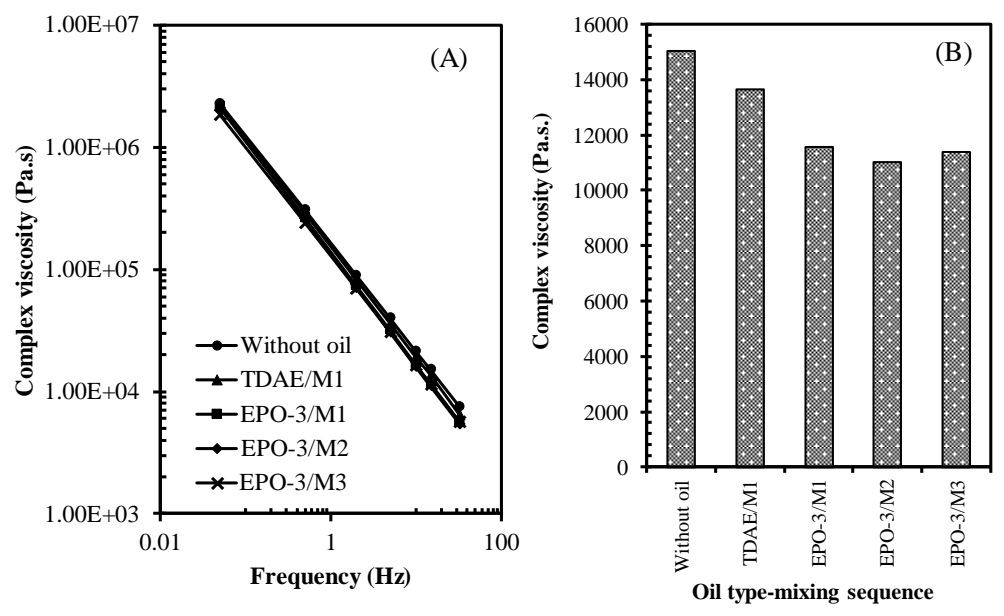

Figure 7.2 Complex viscosity as a function of frequency sweep (A) and complex viscosity at $15 \mathrm{~Hz}(\mathrm{~B})$ of silica-reinforced NR compounds with EPO-3 and different mixing sequences.

\subsubsection{Filler-filler interaction}

The use of silane in the compounds promotes filler-rubber interaction by covalent bonding between the silanol groups on the silica surface and alkoxy groups in the silane molecules, and suppresses filler-filler interaction. The addition of oil helps further to lubricate the system that facilitates the dispersion of filler within the rubber matrix. However, adsorption of oil molecules on the silica surface in competition with the silane molecules should be avoided, as the oil may reduce the accessability of silane which negatively affects the silanization. The result in Figure 7.3 shows that the compound without oil has the lowest storage modulus and Payne effect ${ }^{[4]}$, which can be explained by its highest mixing torque that generated the highest mixing shear force. In addition, the compound without oil exhibits the highest mixing temperature that enhances the silanization reaction. Moreover, in the latter case there is no interference from oil absorption on the silica surface, which should be beneficial for interaction between the silica and the silane molecules, as well as with the amine OCT. Comparing the TDAE and EPO-3 oils, the use of EPO-3 gives a lower Payne effect, i.e. lower filler-filler interaction than TDAE. For silica-reinforced rubber compounds, the crucial factors that influence the level of filler-filler interaction are the extent of silanization and the silica dispersion. The Payne effect results indicate that the EPO-3 oil easily absorbs on the silica surface, resulting in a decrease in filler-filler interaction, while the different mixing procedures have no significant effect. A proposed model of EPO oil adsorption on the silica surface via hydrogen bonding is displayed in Figure 7.4. Herein, the interaction between $\mathrm{OH}$ group available after the epoxide ring opening has occurred is also included. 

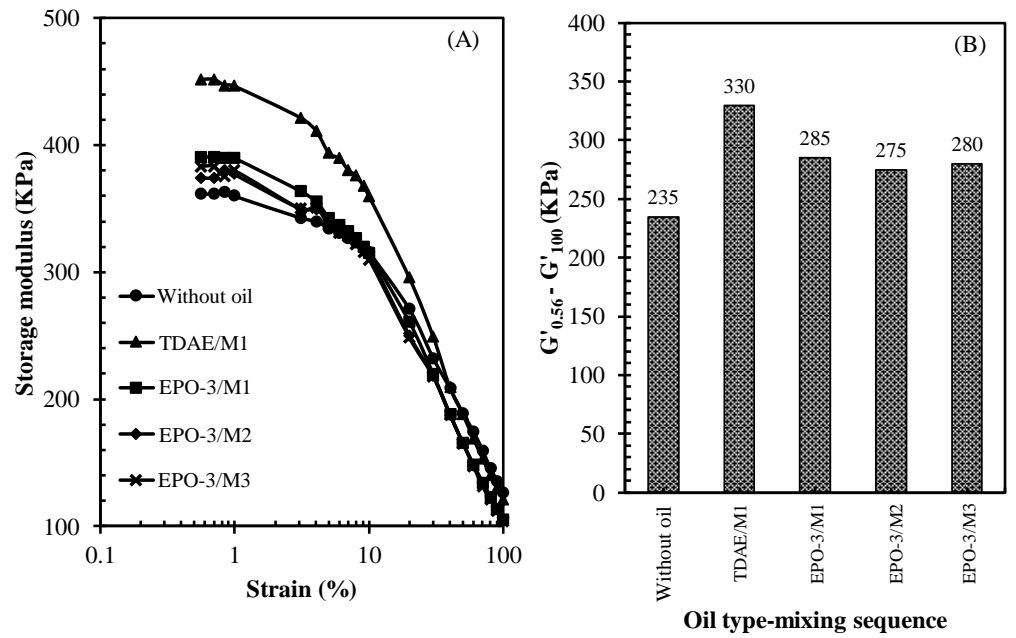

Figure 7.3 Storage modulus as a function of strain sweep (A) and Payne effect (B) of silica-reinforced NR compounds with different mixing sequences.

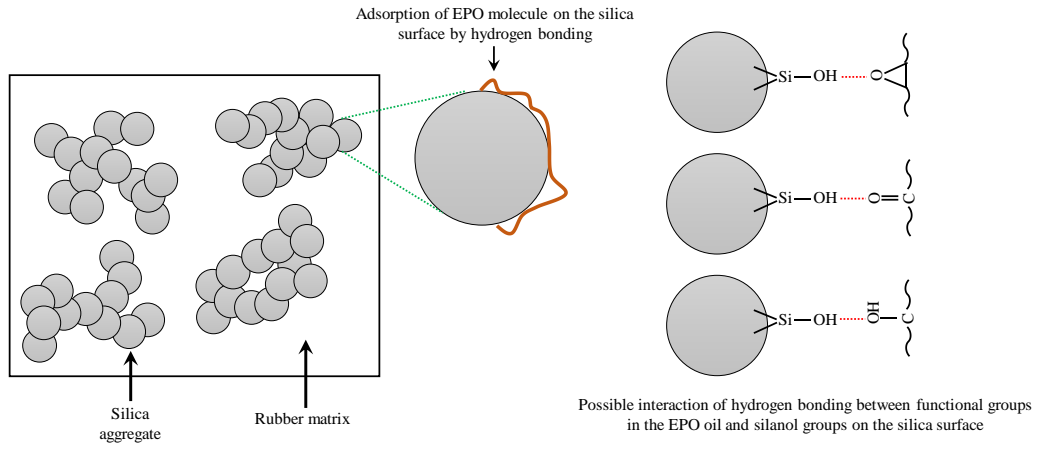

Figure 7.4 Proposed model of adsorption of EPO molecules on silica surface via hydrogen bonding.

\subsubsection{Cure characteristics and flocculation rate constant}

The cure behavior of the silica-reinforced rubber compounds with different incorporating steps of EPO-3 oil is shown in Figure 7.5, in comparison with the reference compounds with TDAE and without oil. Scorch time, cure time, cure rate index (CRI), cure reaction rate constant and cure torque difference are summarized in Table 7.3. All rubber compounds containing process oils show plateau curves, whereas the mix without oil displays a marching modulus. The compounds with EPO-3 oil show higher cure rate indices 
and cure reaction rate constants than the ones with TDAE and without oil. It has been reported ${ }^{[8-9]}$ that only part of the silanol groups on silica (approximate 25\%) can react with the silane molecules due to limited accessibility of these silanol groups for incoming silane molecules. Therefore, the presence of small molecules such as OCT and process oil with shielding potential for the remaining silanols can increase the hydrophobation of the silica surface. Due to the polar epoxide-group and smaller molecule of EPO compared to TDAE, the accessibility of EPO towards the silica surface should be better. The shielding of oil molecules also helps to reduce the curatives absorption, resulting in a faster vulcanization reaction. The compound without oil has no additional shielding effect from the oil molecules and should contain more free silanol groups to interfere with the curing reaction. In addition, the availability of TESPT which acts as a sulfur donor in the system may also play a role.

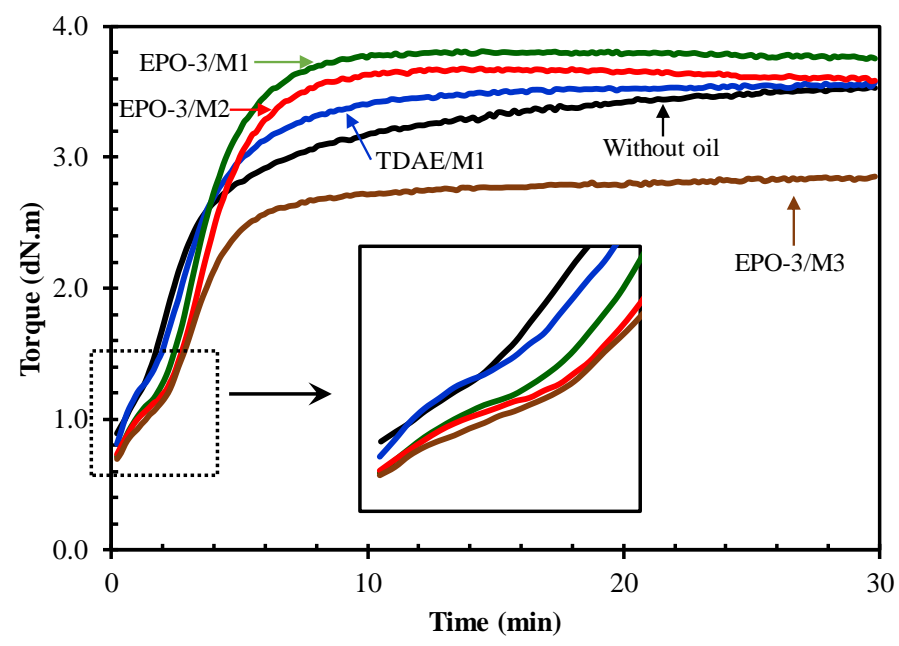

Figure 7.5 Cure curve of silica-reinforced NR compounds with different mixing sequences.

Table 7.3 Scorch time, cure time, cure rate index, cure reaction rate constant and cure torque difference of silica-reinforced NR compounds with different oil incorporating steps.

\begin{tabular}{lccccc}
\hline Characteristics/Properties & \multicolumn{5}{c}{ Oil type-mixing sequence } \\
\cline { 2 - 6 } & Without oil & TDAE/M1 & EPO-3/M1 & EPO-3/M2 & EPO-3/M3 \\
\hline Scorch time, $\mathrm{T}_{\mathrm{s} 1}(\mathrm{~min})$ & 2.28 & 2.28 & 2.73 & 3.05 & 3.16 \\
Cure time, $\mathrm{T}_{\mathrm{c} 90}(\mathrm{~min})$ & 13.08 & 7.59 & 6.26 & 6.49 & 7.13 \\
Cure rate index $\left(\mathrm{min}^{-1}\right)$ & 9.26 & 18.83 & 28.33 & 29.07 & 25.19 \\
Cure reaction rate constant $(\mathrm{k})$ & 0.185 & 0.347 & 0.565 & 0.561 & 0.451 \\
Cure torque difference, & 2.64 & 2.87 & 3.10 & 2.96 & 2.16 \\
$\mathrm{M}_{\mathrm{H}-\mathrm{M}_{\mathrm{L}}(\mathrm{dN} . \mathrm{m})}$ & & & & & \\
\hline
\end{tabular}


The different mixing sequences of EPO-3 do show an effect on cure properties. The addition of EPO-3 together with the first half of silica: M3 results in the poorest cure properties, i.e. lowest cure rate and lowest cure torque difference. The use of M1 and M2 results in similar cure properties. The presence of oil from the beginning of the mixing cycle reduces the compound viscosity and thus the shearing forces and shearing heat developed during mixing. The adsorption of oil in competition with silane on the silica surface also obstructs the silanization reaction to result in lower filler-rubber interaction and lower extent of cure.

The shielding of the silica surface that influences dispersion stability can be looked at by the flocculation behavior, i.e. the re-agglomeration of silica aggregates or de-mixing during the earliest stages of vulcanization ${ }^{[21]}$. The flocculation rate constant of the silica-reinforced rubber compounds with different mixing sequences of EPO-3 is shown in Figure 7.6 compared with those with TDAE and without oil. It is clear that the use of EPO-3 oil gives much lower flocculation rate constant than the ones with TDAE and without oil, and among the different mixing sequences the use of mixing method M3 results in a slightly increased flocculation rate constant. This can be attributed mainly to the hydrophobation on the silica surface as enhanced by the shielding of oil molecules. With regard to the compound with TDAE that shows a slightly higher flocculation rate constant than the one without oil, the result can be ascribed to the bulky aromatic structure in TDAE that sterically hinders the oil adsorption on the silica surface. Also, the hydrocarbon TDAE oil is unlikely to adhere to the hydrophilic silica surface.

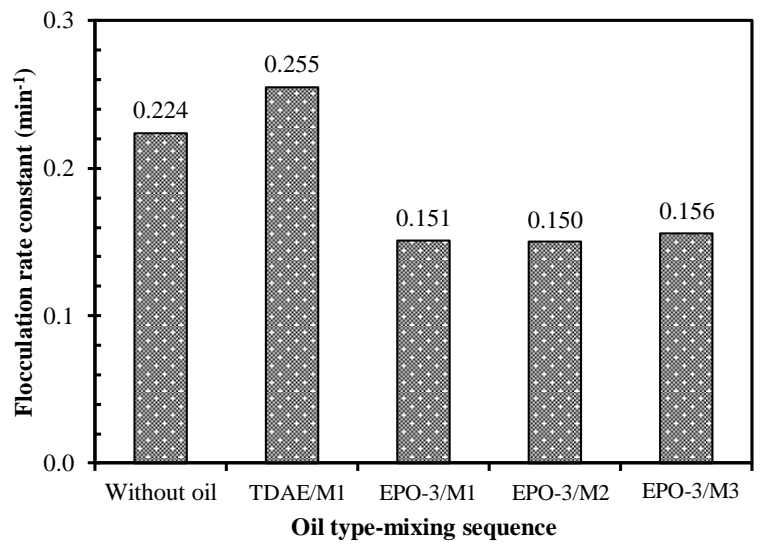

Figure 7.6 Flocculation rate constant of silica-reinforced NR compounds with different mixing sequences.

\subsubsection{Tensile and dynamic properties}

Tensile properties of the silica-reinforced rubber compounds, i.e. moduli at $100 \%$ and $300 \%$, reinforcement index, tensile strength and elongation at break, are summarized in Table 7.4. The results clearly demonstrated the importance of the process oil and the mixing procedure in the filled rubber 
compounds. The addition of both TDAE and EPO-3 process oils significantly enhances the moduli and tensile strength, compared to the compound without oil, due to the fact that the process oils promote the filler dispersion and the presence of oil in the rubber compound reinforced by silica decreases filler-filler interaction. In addition, the presence of oil in the mixing stage helps to lubricate the rubber molecules and thus reduces chain break-down under shearing. The mixing temperature could be also better controlled in the presence of process oil which minimizes the degradation of the natural rubber chains. Mixing method 1 gives vulcanizates with highest moduli but similar tensile strength compared to methods 2 and 3 . The results are in agreement with the cure torque differences which indicates the level of crosslink density.

Table 7.4 Modulus, reinforcement index, tensile strength and elongation at break of silica-reinforced NR compounds with different oil incorporating steps.

\begin{tabular}{lccccc}
\hline Characteristics/Properties & \multicolumn{5}{c}{ Oil type-mixing sequence } \\
\cline { 2 - 6 } & Without oil & TDAE/M1 & EPO-3/M1 & EPO-3/M2 & EPO-3/M3 \\
\hline 100\% Modulus (MPa) & $1.8 \pm 0.1$ & $3.9 \pm 0.1$ & $6.2 \pm 0.1$ & $4.1 \pm 0.1$ & $3.6 \pm 0.1$ \\
300\% Modulus (MPa) & $7.2 \pm 0.2$ & $14.2 \pm 0.3$ & $18.7 \pm 0.3$ & $15.3 \pm 0.9$ & $13.4 \pm 0.6$ \\
M300/M100 & 4.01 & 3.69 & 3.01 & 3.76 & 3.75 \\
Tensile strength (MPa) & $14.8 \pm 0.5$ & $27.3 \pm 0.6$ & $28.5 \pm 0.5$ & $27.7 \pm 0.2$ & $25.5 \pm 0.9$ \\
Elongation at break (\%) & $481 \pm 8$ & $492 \pm 5$ & $446 \pm 9$ & $480 \pm 7$ & $485 \pm 9$ \\
\hline
\end{tabular}

For tire tread compounds, the dynamic properties affect key tire performances, especially rolling resistance and wet grip. The present work reports the loss tangent or tan $\delta$ at $60^{\circ} \mathrm{C}$ in Figure 7.7 as an indicator commonly used to predict the rolling resistance. For the compounds containing EPO-3 that were prepared with different mixing sequences, the addition of EPO-3 into the compound after the complete addition of silica: $\mathrm{M} 2$, results in the lowest $\tan \delta$ at $60^{\circ} \mathrm{C}$, indicating the lowest hysteresis or the best rolling resistance. The addition of oil with the second half of silica: M1, results in a slightly higher value of $\tan \delta$ at $60^{\circ} \mathrm{C}$ compared to $\mathrm{M} 1$, but remarkably lower than the mix prepared by method M3. Comparing the compounds that applied the same mixing sequence M1, the use of EPO-3 results in significantly lower tan $\delta$ at $60^{\circ} \mathrm{C}$ than TDAE. Moreover, all the compounds containing process oils show lower $\tan \delta$ at $60^{\circ} \mathrm{C}$ compared to the one without oil, indicating their better elastic response that stems from better filler dispersion, less rubber degradation and better compatibility between the silica and rubber due to the shielding effect. 


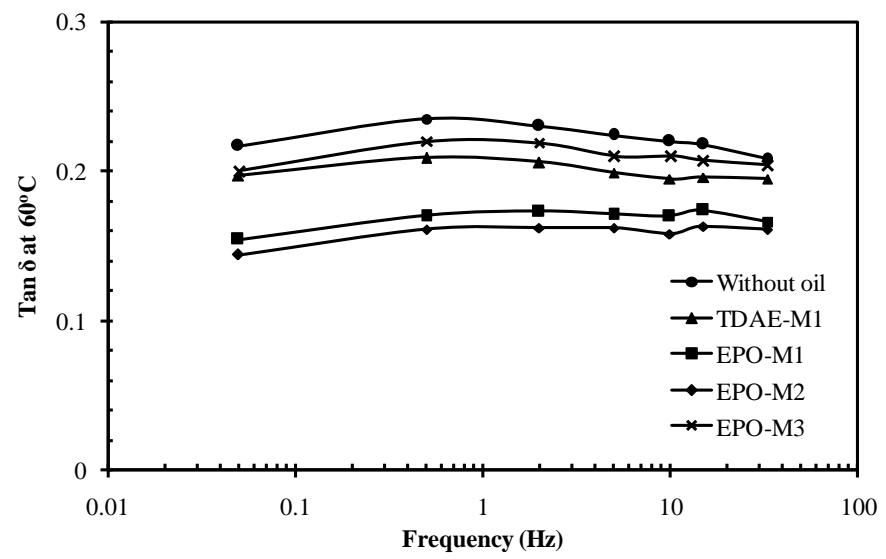

Figure 7.7 Loss tangent at $60^{\circ} \mathrm{C}$ of silica-reinforced NR compounds with different mixing sequences.

7.3.2 Effects of epoxide contents of oils on the properties of rubber compounds

Based on the properties of the silica-reinforced NR compounds plasticized by EPO-3 and prepared by varying mixing sequences, method 2 (M2) gave the best overall properties, especially with respect to tire rolling resistance. This method was therefore chosen to prepare compounds with EPO with different epoxide levels. The properties are evaluated in comparison with the mixes with TDAE and nonepoxidized PO prepared using the same mixing procedure. The compound without oil was also added as reference.

\subsubsection{Mixing torque and temperature}

The use of oils of all types improves the processibility of the silica-reinforced NR compounds as indicated by the lower mixing torque compared to the one without oil, as shown in Figure 7.8. The modified palm oils (EPO) give lower mixing torques than the unmodified version (PO). Increase of epoxide groups in the modified palm oils tends to reduce the mixing torque of the rubber compounds slightly, which should be related to the filler dispersion within the rubber matrix. With respect to the mixing temperature which is a crucial parameter for rubber compounds reinforced by a silica/silane system, like in the previous section, the compound without oil shows the highest discharge mixing temperature due to its highest viscosity that generated most shearing heat. With 2-3 mol\% epoxide groups, EPO as process oil results in lower dump temperature compared to TDAE oil. 


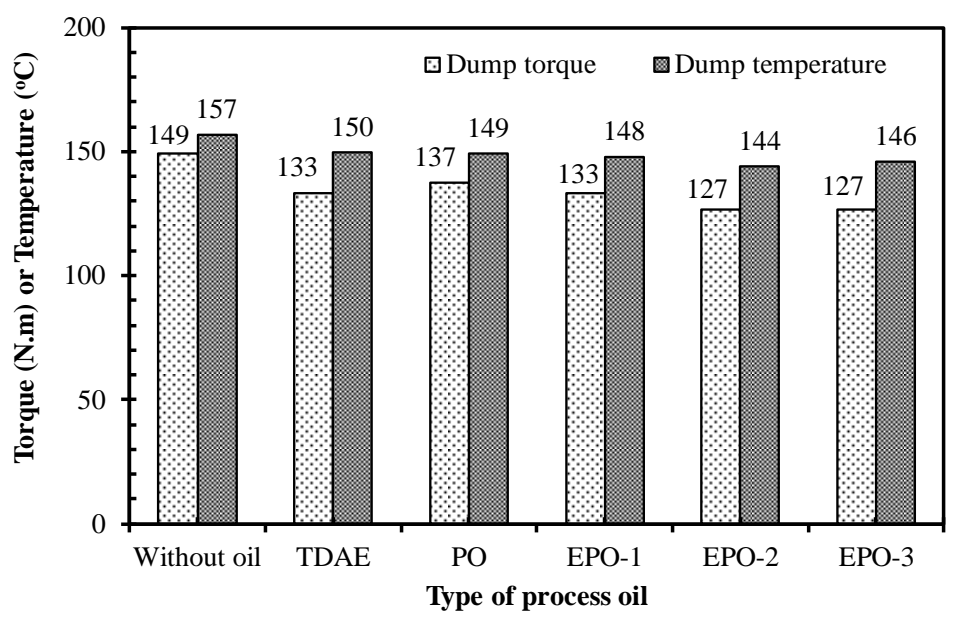

Figure 7.8 Dump torque and temperature of silica-reinforced NR compounds with oils of different epoxide levels.

\subsubsection{Filler-filler interactions}

The change of storage modulus with strain, the Payne effects are shown in Figure 7.9. The results are in agreement with the previous section in which the rubber compound without oil shows the lowest filler-filler interaction ascribed to the highest shear forces and temperature that are beneficial for filler dispersion and the silanization reaction. For those compounds containing varying types of process oils, the results confirm that the use of EPO leads to lower Payne effects than TDAE, due to the better accessibility of this oil onto the silica surface to result in better shielding and hydrophobation. There is only a small difference in the Payne effect of the compounds with different epoxide levels, wherein EPO with $3 \%$ epoxide groups gives the lowest Payne effect, i.e. the least filler-filler interaction. 

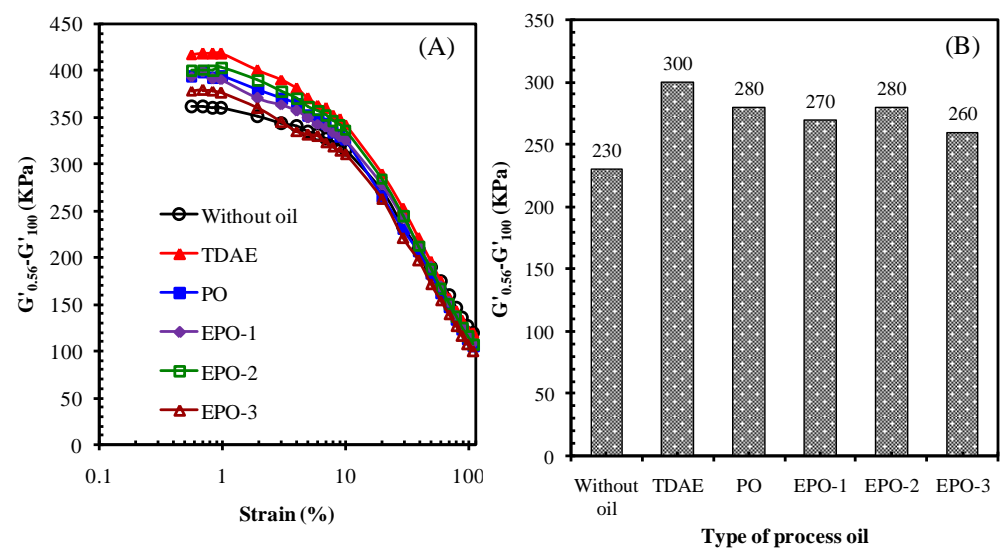

Figure 7.9 Storage modulus as a function of strain (A) and Payne effect (B) of silica-reinforced NR compounds with different epoxide contents.

\subsubsection{Cure characteristics}

The EPOs with different epoxide levels show different maximum torques and cure torque differences as shown in Figure 7.10, in which increasing epoxide group content results in higher cure torque. EPO-3 shows the highest maximum cure torque which indicates the highest crosslink density in the rubber vulcanizates. The compound with TDAE oil shows the lowest maximum cure torque with a flat curve. The cure characteristics are summarized in Table 7.5. By using mixing method M2, the compound with TDAE shows a faster cure rate index and cure reaction rate constant compared to the ones with PO and EPOs. The result is different from the previous section when the compounds prepared by mixing method M1 are compared. The difference observed indicates a complication in the system associated with the oil adsorption on the active silica surface. The addition of PO and EPO at the final mixing interval may result in more free oil molecules in which their unsaturated fatty acids compositions could react with the cure accelerators and hinder the vulcanization reaction. An increase of the epoxide level in the oils decreases the double bonds in the oil molecules and promotes the crosslink density in the rubber matrix. 


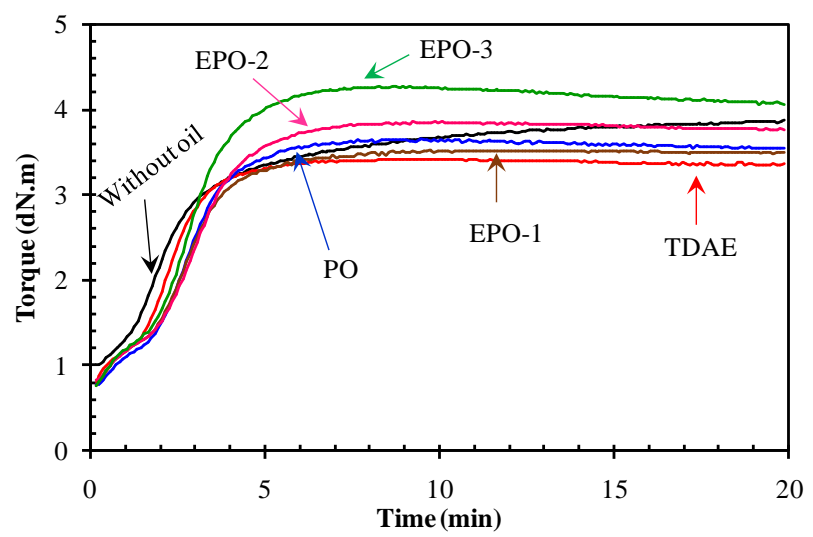

Figure 7.10 Cure behaviors of silica-reinforced NR compounds with oils of different epoxide contents.

Table 7.5 Scorch time, cure time, cure rate index, cure reaction rate constant and cure torque difference of silica-reinforced NR compounds with different epoxide contents.

\begin{tabular}{|c|c|c|c|c|c|c|}
\hline \multirow{2}{*}{ Properties } & \multicolumn{6}{|c|}{ Oil types } \\
\hline & Without oil & TDAE & PO & EPO-1 & EPO-2 & EPO-3 \\
\hline Scorch time, $\mathrm{T}_{\mathrm{s} 1}(\min )$ & 1.82 & 1.95 & 2.33 & 2.31 & 2.26 & 2.15 \\
\hline Cure time, $\mathrm{T}_{\mathrm{c} 90}(\mathrm{~min})$ & 7.87 & 3.81 & 4.63 & 4.65 & 4.54 & 4.56 \\
\hline Cure rate index $\left(\min ^{-1}\right)$ & 16.53 & 53.76 & 43.47 & 42.73 & 43.85 & 41.49 \\
\hline $\begin{array}{l}\text { Cure reaction rate } \\
\text { constant }(\mathrm{k})\end{array}$ & 0.21 & 0.91 & 0.82 & 0.75 & 0.78 & 0.84 \\
\hline $\begin{array}{l}\text { Cure torque difference, } \\
M_{H}-M_{L}(d N . m)\end{array}$ & 2.87 & 2.63 & 2.88 & 2.75 & 3.03 & 3.52 \\
\hline
\end{tabular}

\subsubsection{Tensile and dynamic properties}

The tensile properties, i.e. modulus, tensile strength and elongation at break, of rubber vulcanizates with different oil types are shown in Table 7.6. The incorporation of oil significantly enhances both modulus and tensile strength due to improved filler dispersion and level of crosslinking. As seen in Table 7.6, the vulcanizates with TDAE and EPOs with 2 and 3\% of epoxide levels show similar levels of tensile strength. 
Table 7.6 Modulus, reinforcement index, tensile strength, and elongation at break of silica-reinforced NR compounds with different epoxide contents.

\begin{tabular}{lcccccc}
\hline \multirow{2}{*}{ Properties } & \multicolumn{5}{c}{ Oil types } \\
\cline { 2 - 7 } & Without oil & TDAE & PO & EPO-1 & EPO-2 & EPO-3 \\
\hline 100\% Modulus (MPa) & $1.4 \pm 0.2$ & $2.2 \pm 0.1$ & $1.6 \pm 0.1$ & $1.6 \pm 0.2$ & $1.8 \pm 0.1$ & $1.7 \pm 0.1$ \\
$300 \%$ Modulus (MPa) & $7.1 \pm 1.1$ & $12.5 \pm 0.4$ & $9.1 \pm 0.1$ & $8.2 \pm 1.0$ & $10.1 \pm 0.6$ & $9.8 \pm 0.7$ \\
M300/M100 & 5.09 & 5.69 & 5.54 & 5.20 & 5.73 & 5.67 \\
Tensile strength (MPa) & $15.5 \pm 0.7$ & $24.6 \pm 0.6$ & $20.0 \pm 1.9$ & $20.1 \pm 0.3$ & $23.8 \pm 1.7$ & $24.5 \pm 1.6$ \\
Elongation at break (\%) & $460 \pm 40$ & $470 \pm 20$ & $480 \pm 20$ & $510 \pm 30$ & $510 \pm 20$ & $530 \pm 10$ \\
\hline
\end{tabular}

The loss tangent or $\tan \delta$ at $60^{\circ} \mathrm{C}$ as a function of frequency sweep of the rubber vulcanizates with different oil types is shown in Figure 7.11. All the compounds with oils show lower values, indicating improved elastic behavior that decreases hysteresis. With increasing epoxide content in the EPOs, the compounds show lower $\tan \delta$ at $60^{\circ} \mathrm{C}$. Over the range of frequencies studied, the rubber with EPOs clearly show lower $\tan \delta$ at $60^{\circ} \mathrm{C}$, i.e. lower hysteresis, compared to TDAE. Therefore, with respect to tire rolling resistance, the use of EPO with 3 mole\% epoxide is the best candidate. The results show that the use of EPO provides a lower $\tan \delta$ at $60^{\circ} \mathrm{C}$ than TDAE, and can be a potential alternative process oil for silicareinforced low rolling resistance tire compounds.

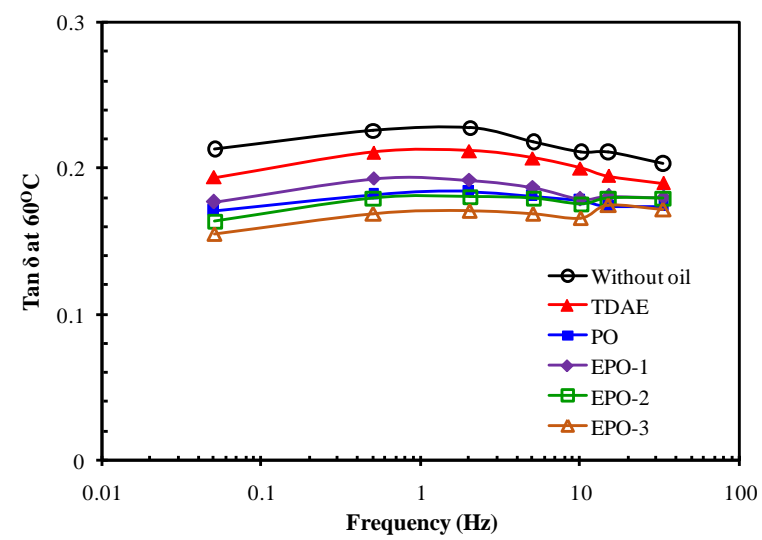

Figure 7.11 Tan $\delta$ at $60^{\circ} \mathrm{C}$ of silica-reinforced NR compounds with different epoxide contents. 


\subsection{CONCLUSIONS}

This work studies the effect of different incorporating steps of EPO oil on the properties of silicareinforced natural rubber compounds by taking the mixes with TDAE and without process oil as references. The different mixing sequences show an influence on the cure properties of the compounds containing EPO as process oil, but only a small influence on viscosity, filler-filler interaction and flocculation rate constant. The addition of EPO at the beginning of the mixing cycle together with the first half of silica (M3) results in the poorest properties which is caused by the adsorption of EPO on the silica surface, that reduces the accessibility of the incoming silane molecules. The addition of EPO with the second half of the silica and after the complete addition of silica results in a clear improvement in properties, especially the cure torque difference which indicates crosslink density. After the silanization, the oil molecules provide a shielding effect to result in enhanced hydrophobation and compatibility of the remaining silanol groups on the silica, in which the EPO works better than TDAE, to result in a higher level of crosslink density and lower loss tangent at $60^{\circ} \mathrm{C}$. Based on the same mixing procedure following M2, increase of the epoxide contents in EPOs increases the cure torque difference, modulus, and tensile strength, and reduces the $\tan \delta$ at $60^{\circ} \mathrm{C}$. The use of EPOs with 2-3 mole\% epoxide result in a clear improvement in $\tan \delta$ at $60^{\circ} \mathrm{C}$ over TDAE oil, which will be beneficial for low rolling resistance tire tread compounds based on a silica-silane system.

\subsection{REFERENCES}

[1] R. Rauline, E.P. Patent 0501227A1, (Feb. 12, 1992).

[2] W.K. Dierkes, A. Blume, "Silica reinforcement," in Encyclopedia of Polymeric Nanomaterials, K. Müllen, S. Kobayashi, Eds., Springer-Verlag Berlin Heidelberg, Germany, 2015.

${ }^{[3]}$ A. Blume, L. Gatti, H-D. Luginsland, D. Maschke, R. Moser, J.C. Nian, C. Röben, A. Wehmeier, A, "Silica and Silanes," in Rubber Compounding: Chemistry and Applications, B. Rodgers, Ed., ${ }^{\text {nd }}$ Ed. CRC Press, Taylor and Francis Group, Boca Raton, 2015.

${ }^{[4]}$ A.R. Payne, Rubber Chem. Technol. 33, 365 (1966).

${ }^{[5]}$ U. Goerl, A. Hunsche, A. Mueller, H.G. Koban, Rubber Chem. Technol. 70, 608 (1997).

${ }^{[6]}$ A. Blume, Kautsch. Gummi Kunstst. 64, 38 (2011).

${ }^{[7]}$ J.W. ten Brinke, S.C. Debnath, L.A.E.M. Reuvekamp, J.W.M. Noordermeer, Compos. Sci. Technol. 63, 1165 (2003).

${ }^{[8]}$ A. Blume, F. Thibault-Starzyk, Rubber Fibres Plast. Int. 12, 152 (2017).

${ }^{[9]}$ A. Blume, F. Thibault-Starzyk, Rubber Fibres Plast. Int. 12, 236 (2017).

${ }^{[10]}$ G. Wypych, "Handbook of Plasticizers”, ChemTech Publishing, New York, 2004.

[11] J.E. Mark, B. Erman, and E.R. Eirich, "Science and Technology of Rubber", Academic Press, California, 1978. 
${ }^{[12]}$ The Swedish National Chemicals Inspectorate. KEMI Reports, Rep. 5/03. (Swedish National Chemicals Inspectorate, 1993).

${ }^{[13]}$ Directive 2005/69/EC, Off. J. Eur. Union L323, 51 (2005).

${ }^{[14]}$ Commission Regulation (EC) No 552/2009, Off. J. Eur. Union L164, 7 (2009).

${ }^{[15]}$ R. Joseph, R. Alex, K.N. Madhusoodanan, C.K. Premalatha, B. Kuriakose, J. App. Polym. Sci. 92, 3531 (2004).

${ }^{[16]}$ J. Li, A.I. Isayev, X. Ren, M.D. Soucek, Polymer. 60, 144 (2015).

${ }^{[17]}$ Z. S. Petrovic, I. Mihail, J. Milic, J. R. Halladay, Rubber Chem. Technol. 86, 233 (2013).

${ }^{[18]}$ K. Sahakaro, A. Beraheng, Rubber Chem. Technol. 84, 200 (2011).

${ }^{[19]}$ C. Hayichelaeh, L.A.E.M. Reuvekamp, A. Blume, J.W.M. Noordermeer, K. Sahakaro, Rubber Chem. Technol. 90, 651 (2017).

${ }^{[20]}$ C. Hayichelaeh, L.A.E.M. Reuvekamp, A. Blume, J.W.M. Noordermeer, K. Sahakaro, Rubber Chem. Technol. 91, 433 (2018).

${ }^{[21]}$ S. Mihara, R.N. Datta, J.W.M. Noordermeer, Rubber Chem. Technol. 82, 524 (2009). 


\title{
SILICA-REINFORCED NATURAL RUBBER TIRE TREAD COMPOUNDS CONTAINING BIO-BASED PROCESS OILS: II. INFLUENCE OF EPOXIDE AND AMINO FUNCTIONAL GROUPS
}

\begin{abstract}
The feasibility of the use of epoxidized palm oil (EPO) and amine-modified epoxidized palm oil ( $m E P O)$, as process oil in silica-reinforced natural rubber compounds is studied. The EPO-3, 0.03 $m E P O$ and $0.04 \mathrm{mEPO}$ as discussed in Chapter 6 were used in this study. The properties of rubber compounds containing modified palm oils are investigated by taking the ones with TDAE-oil and without oil as references. The utilization of process oils clearly enhances the processibility, i.e. lower mixing torque and complex viscosity, mechanical and dynamic mechanical properties of the rubber compounds compared to the one without oil. The rubber compounds with EPO and $0.03 \mathrm{mEPO}$ show a lower Payne effect, i.e. less filler-filler interaction, than the rubber compound with TDAE due to the shielding effect of the oils on the silica surface. The use of $m E P O$ boosts the vulcanization reaction resulting in much better cure torque difference which indicates a higher crosslink density due to the amino groups present in $\mathrm{MEPO}$, compared to TDAE. Therefore, rubber compounds with $\mathrm{mEPOS}$ have better mechanical properties, i.e. reinforcement index, tensile strength and elongation at break, and elastic response under dynamic deformation as indicated by a lower loss tangent at $60^{\circ} \mathrm{C}$, compared to the mix with TDAE.
\end{abstract}




\subsection{INTRODUCTION}

The concept of "Green Tire Technology" as first introduced by Michelin in the 1990's ${ }^{[1]}$ in which silica is used as reinforcing filler in tire tread compounds has been steadily developed to further reduce rolling resistance for better energy saving as well as to enhance other key tire performances. Nowadays, material development is following a "go green" strategy and one of the practices is to use ingredients derived from renewable resources. Besides the reinforcing filler, there are many ingredients which are used in rubber compounds for different roles such as activators, accelerators, curing agents, antidegradants and plasticizers. Process oil is utilized to promote processibility of the rubber compounds especially in the case of high filler loading, and also to improve filler dispersion within the rubber matrix. Petroleum-based process oils which are categorized into aromatic, naphthenic and paraffinic types based on their main composition are widely used, where the oil selection depends on oil-rubber compatibility. Due to the compatibility match of aromatic structures with diene elastomers, Distillate Aromatic Extract oil (DAE) which contains significant amounts of highly Polycyclic Aromatic Hydrocarbons (PAHs) was conventionally widely used in the rubber industry, especially in tire production. However, the Swedish National Chemicals Inspectorate in $1993^{[2]}$ reported about the PAHs that were released with rubber wear particles onto the road surface, in which some types of PAHs were classified as carcinogenic. Thereafter,

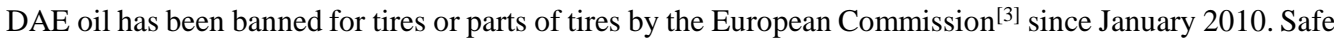
process oils, i.e. Treated Distillate Aromatic Extract (TDAE), Mild Extracted Solvate (MES) and Naphthenics (NAP) are presently used as replacement for DAE oil.

Natural-based or bio oils in their original and modified forms have been investigated as sustainable alternative process oils in the rubber compounds by several researchers ${ }^{[4-15]}$ due to their low cost, non-toxicity, wide availability and production as renewable resources. The basic chemical structure of vegetable oils is a triglyceride which is a tri-ester derived from glycol and three fatty acids. There are many types of fatty acids contained in the oils including both saturated and unsaturated fatty acids, where each type contains a molecular chain length varying from 14 to 22 carbons. Due to reactive double bonds in the oil structures that make chemical modification feasible, the bio oils in modified forms have been widely investigated. Epoxide is one of the most studied functional groups due to a rather easy modification reaction. Epoxidized vegetable oils, i.e. Epoxidized Palm Oil (EPO) and Epoxidized SoyBean Oil (ESBO), were investigated as process oils in carbon-black-reinforced tire tread compounds. The properties of rubber compounds with EPO oil showed similar cure characteristics and processing as well as mechanical properties when compared to a reference compound with DAE. Meanwhile, the use of ESBO oil gave poorer cure properties than the use of EPO and DAE, resulting in lower mechanical properties ${ }^{[15]}$.

For silica/silane reinforcing filler systems in rubber compounds, chemical filler-rubber interaction is obtained via a silanization reaction which proceeds through a condensation reaction between the silanol groups on the silica surface and alkoxy groups in the silane coupling agent. This reaction can be 118 
catalyzed by an alkaline condition such as in the presence of amino-functional groups due to increase of the nucleophilicity of silanol groups on the silica surface, that promote interaction with the silicon atom in the silane molecule ${ }^{[16-19]}$. Besides the silanization reaction, the basic amino group may also promote the vulcanization reaction in the rubber compounds.

The synthesis of amine-modified epoxidized oils has been reported for use as process oils in carbon-black reinforced rubber compounds ${ }^{[12-13]}$. As epoxide groups in vegetable oil molecules can easily be modified by ring opening and subsequent react with other functional groups, therefore the present work focuses on the use of epoxidized palm oil (EPO) and amine-modified epoxidized palm oil (mEPO), as process oils in silica-reinforced natural rubber compounds. Processing behavior, filler-filler interaction, cure characteristics, mechanical and dynamic properties are evaluated in comparison with state-of-the-art TDAE oil. A compound without oil is also added for comparison.

\subsection{EXPERIMENTAL}

\subsubsection{Materials}

Rubber compounding ingredients used in this study, i.e. Ribbed Smoked Sheet (RSS\#3), highly dispersible silica (ULTRASIL 7005), bis(3-triethoxysilylpropyl) tetrasulfide (TESPT), octadecylamine, treated distillate aromatic extract oil (TDAE oil), zinc oxide $(\mathrm{ZnO})$, stearic acid, N-cyclohexyl-2benzothiazole sulfenamide (CBS), diphenyl guanidine (DPG), 2,2,4-trimethyl-1,2-dihydroquinoline (TMQ), and sulfur, are as described in Chapter 4. EPO-3 which has the highest epoxidation level and show the optimum properties among the EPOs studied, as shown in Chapter 7, is used in comparison with aminemodified EPOs (mEPOs). The preparations of EPO-3 and mEPOs, i.e. $0.03 \mathrm{mEPO}$ and $0.04 \mathrm{mEPO}$, are described in Chapter 6.

\subsubsection{Preparation of rubber compounds}

Silica-reinforced NR compounds containing different types of bio-based process oils were prepared using two mixing steps. The rubber formulation is shown in Table 7.1, see Chapter 7. Mixing conditions for preparation of rubber compounds were at fill factor 0.70 , initial mixer temperature setting of $100^{\circ} \mathrm{C}$ and rotor speed of $60 \mathrm{rpm}$. The curing agents were later mixed into the rubber compounds on a tworoll mill. The mixing procedure is shown in Figure 8.1.

\subsubsection{Properties and testing}

Properties of rubber compounds, i.e. bound rubber content, Payne effect, flocculation rate constant, heat capacity increment, and cure characteristics, and rubber vucanizates, i.e. mechanical and dynamic mechanical properties, were tested, as described in Chapter 4. Complex viscosity was tested as described in Chapter 7. 


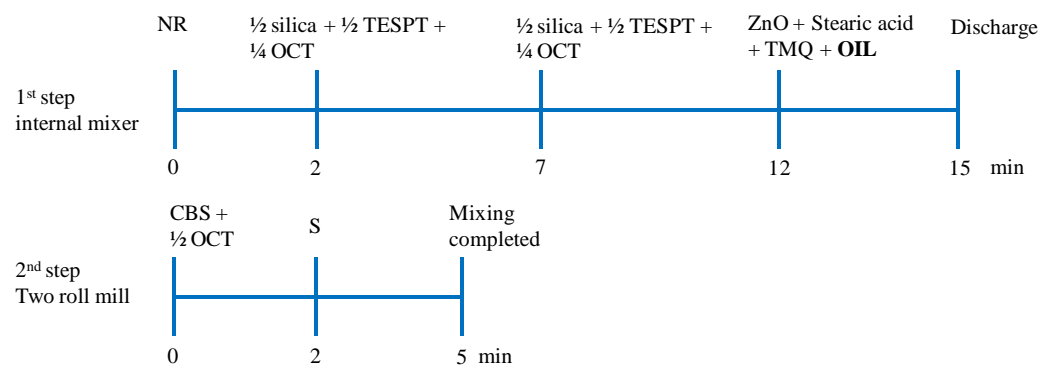

Figure 8.1 Mixing procedure for preparation of rubber compounds.

\subsection{RESULTS AND DISCUSSION}

\subsubsection{Properties of rubber compounds}

To ensure the silanization reaction within the silica-reinforced NR compounds, the dump temperature in the first mixing step of all the compounds was aimed for and reached the range of 145$157^{\circ} \mathrm{C}$, as shown in Table 8.1. This temperature range corresponds to the recommended range suggested for NR compounds ${ }^{[20]}$. Without process oil, the compound shows the highest final torque and temperature generated by shearing heat. The mixes with process oil have lower mixing torques, i.e. lower viscosity. The use of TDAE and $0.03 \mathrm{mEPO}$ give very similar values of both discharge torque and temperature.

Table 8.1 Mixing characteristics of rubber compounds.

\begin{tabular}{lccccc}
\hline \multicolumn{1}{c}{ Properties } & \multicolumn{3}{c}{ Oil types } \\
\cline { 2 - 6 } & Without oil & TDAE & EPO & $\mathbf{0 . 0 3}$ mEPO & 0.04 mEPO \\
\hline Dump torque (N.m) & 149 & 133 & 127 & 135 & 137 \\
Dump temperature $\left({ }^{\circ} \mathrm{C}\right)$ & 157 & 150 & 146 & 149 & 145 \\
\hline
\end{tabular}

The complex viscosities of the rubber compounds with different types of process oils as tested by using the RPA under frequency sweep are shown in Figure 8.2. The complex viscosities of all the compounds show small differences especially at low frequency. By taking the values at 5 and $10 \mathrm{~Hz}$ as displayed in Figure 8.2(b), the rubber compounds with process oils show a lower complex viscosity than the mix without oil due to the plasticizing effect that promotes the flow property. Among the different types of process oils, the rubber compound with TDAE shows the lowest complex viscosity but with a marginal difference relative to the ones with EPO and mEPO oils. 

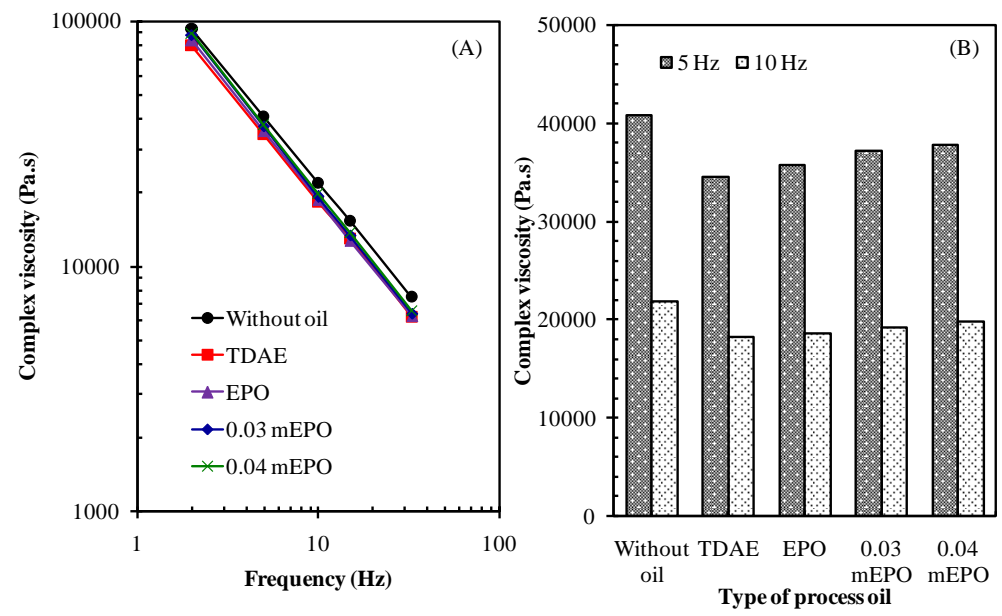

Figure 8.2 Complex viscosity as a function of frequency sweep (A) and complex viscosity at $5 \mathrm{and} 10 \mathrm{~Hz}$ (B) of rubber compounds with different types of process oils.

One of the key roles of process oils in filled rubber compounds is to facilitate filler incorporation and dispersion. For silica-reinforced rubber compounds, the use of silane coupling agent under suitable conditions leads to chemical bonds between the silica surface and the rubber molecules via silane bridges. Prior to the silanization reaction, the adsorption of silane molecules on the silica surface is crucial. As the number of silane molecules that can react with the silanol groups on the silica surface is limited by steric hindrance which affects on accessilility of the incoming silane, ${ }^{[21-22]}$ the presence of other small molecules such as alcohols, amines or even process oil can be beneficial to enhance the surface hydrophobicity and promote compatibility between the filler and rubber. 

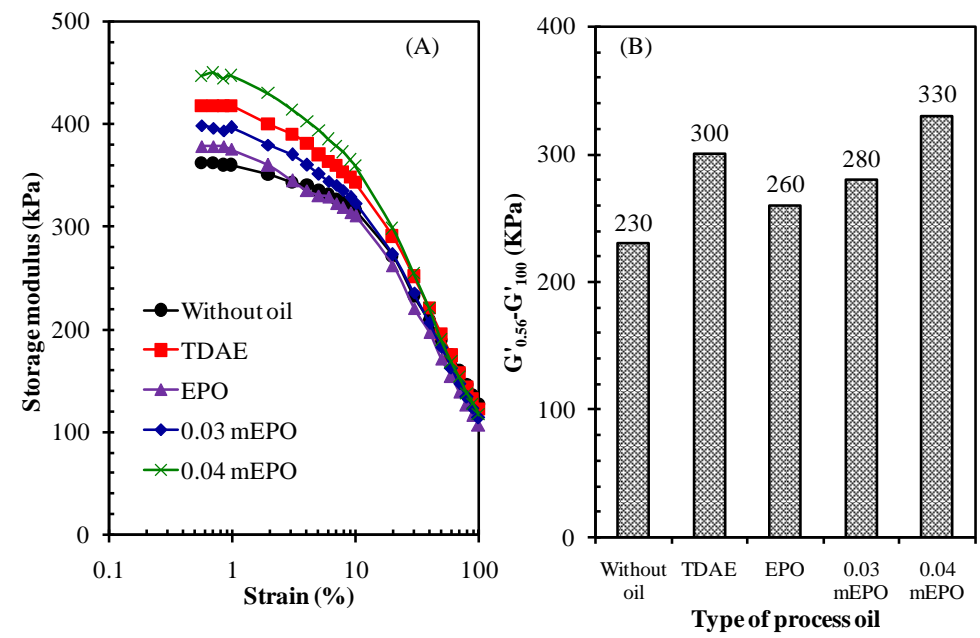

Figure 8.3 Storage modulus (A) and Payne effect (B) of rubber compounds with different types of process oils.

The filler-filler interaction in the silica-reinforced rubber compounds was determined by measuring the change of storage modulus with strain. At certain deformation, the filler-filler interaction or filler network is broken resulting in a sharp drop in storage modulus values. As shown in Figure 8.3, the rubber compound without process oil shows the lowest Payne effect and therefore filler-filler interaction, lower than for the ones with EPO, $0.03 \mathrm{mEPO}$, TDAE and $0.04 \mathrm{mEPO}$, respectively. Due to the absence of oil, the higher viscosity that generates higher shear forces to disperse the filler and the higher temperature that promotes the silanization reaction leads to a positive effect on the Payne effect. Among the different types of process oils, the rubber compound with TDAE oil shows a higher filler-filler interaction than the compounds with bio-oils, except for $0.04 \mathrm{mEPO}$. As discussed earlier, the silica surface contains some free silanol groups that are left over after the silanization reaction. These silanol groups can still interact with any polar functional groups present in the system. The polarity in bio oils can interact with the silanol groups on the silica surface, as proposed in Figure 8.4, resulting in lower filler-filler interactions. The mEPO oil has increased polarity due to the presence of both $\mathrm{O}$ and $\mathrm{N}$ atoms in the structure, but its larger and bulkier molecules will affect the accessibility towards the silica surface. Therefore, the rubber compounds with $\mathrm{mEPO}$ give a higher Payne effect than the one with EPO without secondary modification. 

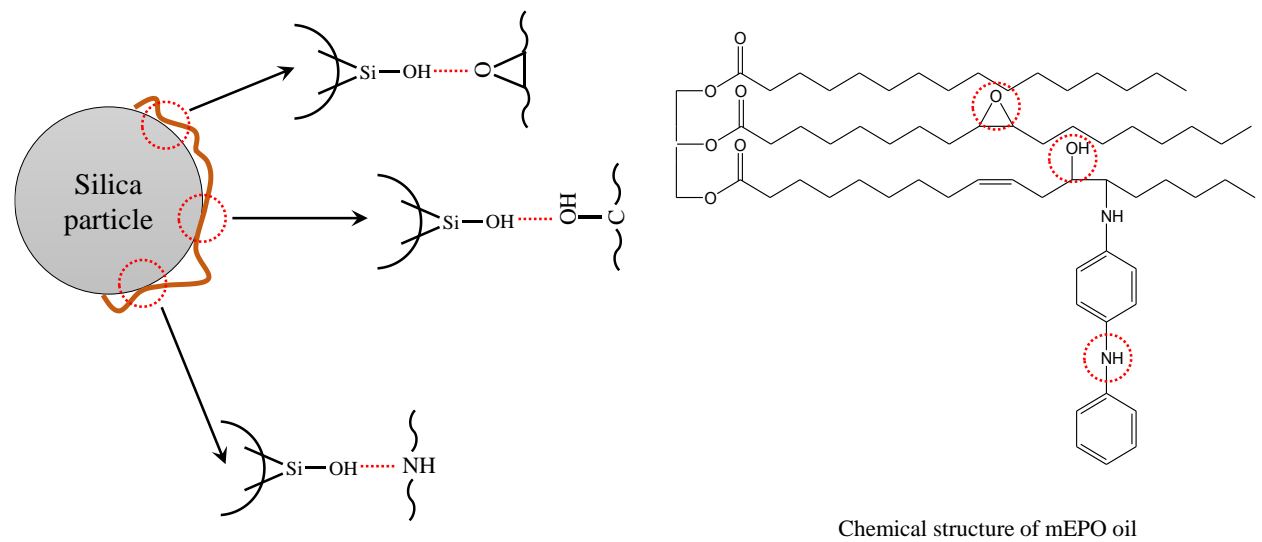

Chemical structure of mEPO oil

Adsorption of mEPO molecule on the silica surface via hydrogen bonding

Figure 8.4 Proposed model of the adsorption of mEPO molecule on the silica surface via hydrogen bonding.

Considering the cure characteristics of the silica-reinforced NR compounds as shown in Figure 8.5, a large difference in maximum cure torques for the compounds with TDAE versus modified palm oils is clearly visible. Moreover, the rubber compounds without process oil shows marching modulus, while the rubber compounds with TDAE give a plateau or a flat cure curve and those with EPO and mEPOs show reversion. Scorch time, cure time and cure rate index (CRI) of the silica-reinforced NR compounds having different oil types are also different as summarized in Table 8.2. The rubber compound without process oil gives the shortest scorch time but a lower cure rate index than the ones with process oils. Among the different types of process oils used with the mixing procedure in which the oil was added after complete addition of silica and silane, the rubber compound with TDAE oil gives a higher CRI or vulcanization reaction rate than the other ones with bio oil. This result may be attributed to the effect of fatty acid esters and unsaturated double bonds in the oil structure which could consume some of the curing agents in the rubber compounds, resulting in some disruption of the vulcanization reaction ${ }^{[23]}$. 


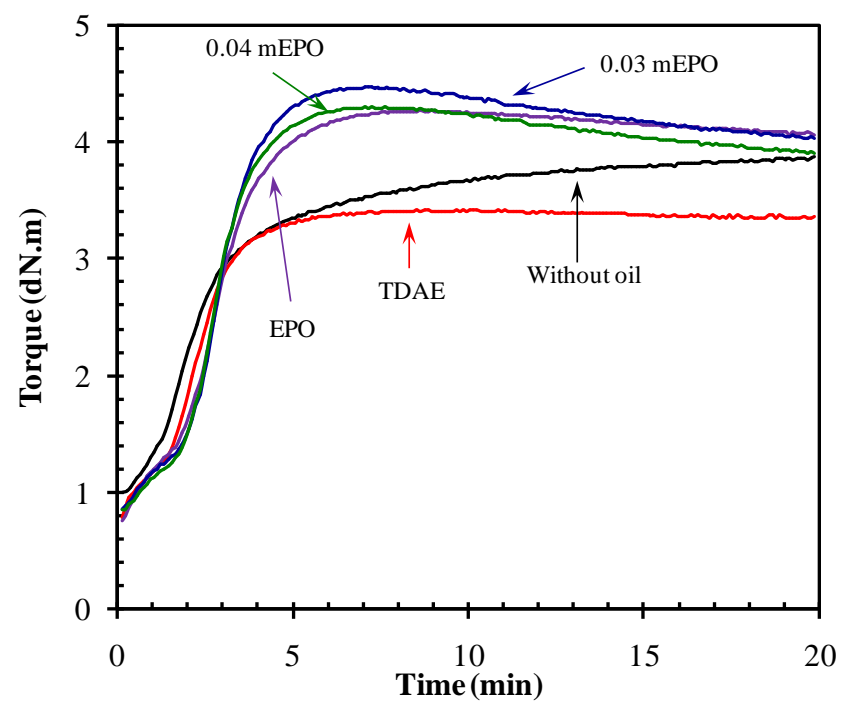

Figure 8.5 Cure behaviors of rubber compounds with different types of process oils.

Table 8.2 Cure characteristics of rubber compounds.

\begin{tabular}{|c|c|c|c|c|c|}
\hline \multirow[t]{2}{*}{ Properties } & \multicolumn{5}{|c|}{ Oil types } \\
\hline & Without oil & TDAE & EPO & $0.03 \mathrm{mEPO}$ & $0.04 \mathrm{mEPO}$ \\
\hline $\begin{array}{l}\text { Scorch time, } \\
\mathrm{T}_{\mathrm{s} 1}(\min )\end{array}$ & 1.82 & 1.95 & 2.15 & 2.35 & 2.32 \\
\hline $\begin{array}{l}\text { Cure time, } \\
\mathrm{T}_{\mathrm{c} 90}(\mathrm{~min})\end{array}$ & 7.87 & 3.81 & 4.56 & 4.40 & 4.32 \\
\hline Cure rate index $\left(\mathrm{min}^{-1}\right)$ & 16.53 & 53.76 & 41.49 & 48.78 & 50.00 \\
\hline $\begin{array}{l}\text { Minimum torque, } \mathrm{M}_{\mathrm{L}} \\
(\mathrm{dN} . \mathrm{m})\end{array}$ & 0.99 & 0.75 & 0.74 & 0.84 & 0.84 \\
\hline $\begin{array}{l}\text { Maximum torque, } \mathrm{M}_{\mathrm{H}} \\
(\mathrm{dN} . \mathrm{m})\end{array}$ & 3.87 & 3.42 & 4.27 & 4.48 & 4.31 \\
\hline $\begin{array}{l}\text { Torque difference, } \mathrm{MH}^{-} \\
\mathrm{M}_{\mathrm{L}}(\mathrm{dN} . \mathrm{m})\end{array}$ & 2.88 & 2.67 & 3.53 & 3.64 & 3.47 \\
\hline
\end{tabular}


It is well known that basic or alkaline conditions can promote vulcanization. In the present case, the presence of amine attached to oil molecules that increases the alkaline nature of the rubber compounds enhances the vulcanization reaction ${ }^{[24]}$ resulting in a higher extent of crosslinking as indicated by the cure torque difference. The higher crosslink density by the use of mEPO reflects also on the maximum cure torques that relate to modulus and hardness of the vulcanized rubber. The minimum cure torques $\left.\mathrm{M}_{\mathrm{L}}\right)_{\mathrm{f}}$ of rubber compounds as shown in Table 8.2 correspond well with the results of complex viscosity: Figure 8.2. As discussed earlier, the amine-modified EPOs give a higher minimum torque, corresponding to a higher viscosity, than EPO, due to their limited accessibility towards the silica surface, and so results in less shielding effect, thus higher filler-filler interaction.

The tensile properties of the rubber compounds with different types of process oils are summarized in Table 8.3. Without oil, the rubber compound shows inferior tensile properties like moduli at different strains, reinforcement index, tensile strength and elongation at break compared to the rubber compounds with process oils. Among the compounds with oils, the use of modified palm oil results in lower modulus but higher tensile strength and elongation at break compared to the use of TDAE. With respect to the ultimate tensile properties, mEPOs give the best performance. It is known that the mechanical properties of filled rubber compounds depend on many factors such as filler-rubber interaction, filler-filler interaction, properties of the matrix, and crosslink density within the rubber matrix. Even though the rubber compound without oil shows the lowest filler-filler interaction or Payne effect, its highest temperature and shear force during mixing could damage the rubber molecules most through chain breakdown or degradation. In case of the rubber compounds with $\mathrm{mEPO}$, the oil lubricates the rubber chains while mixing, causing less chain breakdown and the amine in $\mathrm{mEPO}$ promotes cure to result in increased crosslink density. So, the use of $\mathrm{mEPO}$ enhances the reinforcement index, tensile strength and elongation at break to a higher level than the use of EPO and TDAE. 
Table 8.3 Modulus, reinforcement index, tensile strength and elongation at break of rubber compounds.

\begin{tabular}{lccccc}
\hline \multicolumn{1}{c}{ Properties } & \multicolumn{4}{c}{ Oil types } \\
\cline { 2 - 6 } & Without oil & TDAE & EPO & $\mathbf{0 . 0 3}$ mEPO & $\mathbf{0 . 0 4}$ mEPO \\
\hline Modulus at 100\% (MPa) & $1.4 \pm 0.2$ & $2.2 \pm 0.1$ & $1.7 \pm 0.1$ & $1.7 \pm 0.1$ & $1.9 \pm 0.1$ \\
Modulus at 200\% (MPa) & $3.4 \pm 0.6$ & $6.1 \pm 0.2$ & $4.7 \pm 0.4$ & $4.8 \pm 0.2$ & $5.4 \pm 0.4$ \\
Modulus at 300\% (MPa) & $7.2 \pm 1.1$ & $12.5 \pm 0.4$ & $9.8 \pm 0.7$ & $10.2 \pm 0.6$ & $11.2 \pm 0.4$ \\
Reinforcement index & $5.1 \pm 0.1$ & $5.7 \pm 0.2$ & $5.7 \pm 0.1$ & $5.9 \pm 0.3$ & $5.9 \pm 0.1$ \\
(M300/M100) & & & & & \\
Tensile strength (MPa) & $15.5 \pm 0.7$ & $24.6 \pm 0.6$ & $24.5 \pm 1.6$ & $27.8 \pm 0.3$ & $28.2 \pm 0.4$ \\
Elongation at break (\%) & $460 \pm 40$ & $470 \pm 20$ & $530 \pm 10$ & $560 \pm 30$ & $550 \pm 10$ \\
\hline
\end{tabular}

The dynamic mechanical properties in terms of changes of storage modulus and loss tangent or $\tan \delta$ with temperature of the silica-reinforced NR compounds with different types of process oils are shown in Figure 8.6. In the rubbery region, the compound without process oil shows a lower storage modulus but higher $\tan \delta$. The level of storage modulus in the rubbery state agrees well with the static moduli: Table 8.4. The $\tan \delta$ values of rubber compounds indicate the elastic behavior of vulcanizates. The results in Table 8.4 confirm that the rubber compound without oil shows the poorest elastic property or higher damping behavior as indicated by its higher $\tan \delta$ at 0 and $60^{\circ} \mathrm{C}$. For tire applications, $\tan \delta$ at $60^{\circ} \mathrm{C}$ of vulcanized rubber can be used to indicate rolling resistance and $\tan \delta$ at $0^{\circ} \mathrm{C}$ indicates wet grip. Based on the data in Table 8.4, the presence of oils greatly reduces rolling resistance, i.e. lower $\tan \delta$ at $60^{\circ} \mathrm{C}$, but deteriorates wet grip due to the enhanced elastic response at $0^{\circ} \mathrm{C}$, where the opposite would have been needed. The RPA test results of $\tan \delta$ at $60^{\circ} \mathrm{C}$ in Figure 8.7 support the DMA data confirming that the presence of oil reduces hysteresis and improves rolling resistance, in which the use of $0.03 \mathrm{mEPO}$ gives the lowest value, and all modified palm oils give lower $\tan \delta$ at $60^{\circ} \mathrm{C}$ than TDAE. Therefore, for low rolling resistance tire tread compounds, mEPO or EPO are better choices than TDAE while maintaining wet grip at similar or even slightly better level. 

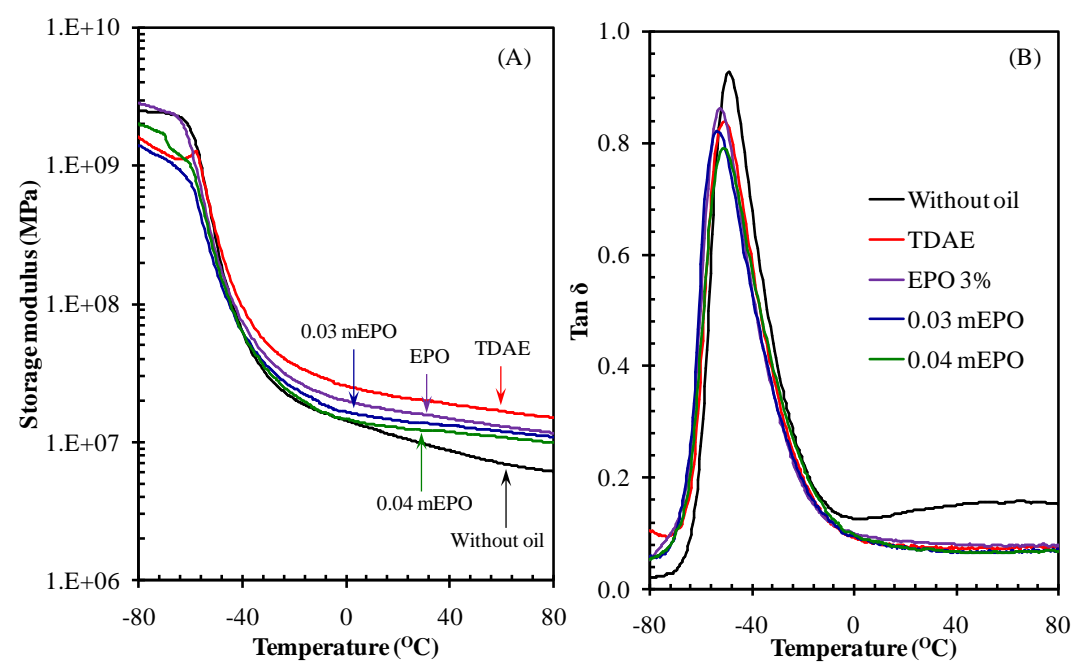

Figure 8.6 Storage modulus (A) and loss tangent (B) as a function temperature of rubber compounds with different types of process oils.

Table 8.4 Glass transition temperature and loss tangent at 0 and $60^{\circ} \mathrm{C}$ of rubber compounds.

\begin{tabular}{lccccc}
\hline \multicolumn{1}{c}{ Properties } & \multicolumn{5}{c}{ Oil types } \\
\cline { 2 - 6 } & Without oil & TDAE & EPO & $\mathbf{0 . 0 3} \mathbf{~ m E P O}$ & $\mathbf{0 . 0 4} \mathbf{~ m E P O}$ \\
\hline Glass transition & -48.96 & -50.70 & -51.96 & -52.90 & -51.04 \\
temperature; $\mathrm{Tg}\left({ }^{\circ} \mathrm{C}\right)$ & & & & & \\
Tan $\delta$ at $0^{\circ} \mathrm{C}$ & 0.126 & 0.092 & 0.099 & 0.095 & 0.098 \\
Tan $\delta$ at $60^{\circ} \mathrm{C}$ & 0.155 & 0.072 & 0.077 & 0.065 & 0.065 \\
\hline
\end{tabular}




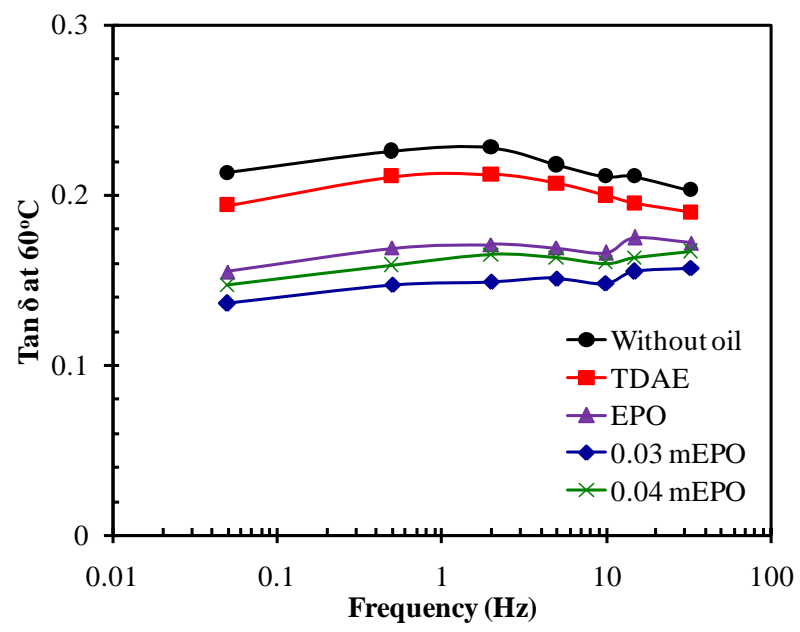

Figure 8.7 Loss tangent at $60^{\circ} \mathrm{C}$ as a function of frequency sweep of rubber compounds with different types of process oils.

\subsection{CONCLUSIONS}

The use of EPO and $\mathrm{mEPO}$, i.e. $0.03 \mathrm{mEPO}$ and $0.04 \mathrm{mEPO}$, as alternatives for petroleum-based TDAE process oil in silica-reinforced natural rubber compounds is studied. The presence of process oils clearly improves the processibility and properties of the rubber compounds compared to the case without oil. The rubber compounds with modified palm oils, except for $0.04 \mathrm{mEPO}$, show lower Payne effects than the compound with TDAE due to the shielding effect of the oils on the silica surfaces. The remarkable improvement by the use of mEPO and EPO over TDAE is observed for crosslink density as indicated by cure torque difference. The enhancement of the vulcanization reaction due to the amino group leads to the best elastic response under dynamic deformation and best mechanical properties, i.e. reinforcement index, tensile strength and elongation at break. Based on the dynamic properties results, $\mathrm{mEPO}$ is suitable for tire tread compounds that require low rolling resistance while maintaining the same level of wet grip as with TDAE.

\subsection{REFERENCES}

${ }^{[1]}$ R. Rauline, E.P. Patent 0501227A1 Feb. 12, 1992.

${ }^{[2]}$ Internet page: http://www.kemi.se/Documents/Publikationer/Trycksaker/Rapporter/Rapport5_03.pdf (October 8, 2013)

${ }^{[3]}$ Commission Regulation (EC) No 552/2009, Off. J. Eur. Union L164, 7 (2009). 
${ }^{[4]}$ Z. S. Petrovic, I. Mihail, J. Milic, J. R. Halladay, Rubber Chem. Technol. 86, 233 (2013).

${ }^{[5]}$ Z. S. Petrovic, I. Mihail, J. Milic, J. R. Halladay, Rubber Chem Technol. 90, 667 (2017).

${ }^{[6]}$ Z. Wang, Y. Peng, L. Zhang, Y. Zhao, R. Vyzhimov, T. Tan, H. Fong, Ind. Eng. Chem. Res. 55, 2784 (2016).

${ }^{[7]}$ R. Joseph, R. Alex, V.SVinod, C.K. Premalatha, B. Kuriakose, J. Appl. Polym. Sci. 89, 668 (2003).

${ }^{[8]}$ Z. Wang, Y. Han, X. Zhang, Z. Huang, L. Zhang, J. Appl. Polym. Sci. 4457 (2013).

${ }^{[9]}$ J. Li, A.I. Isayev, X. Ren, M.D. Soucek, Polym Int. 66, 820 (2017).

${ }^{[10]}$ Z. Wang, Y. Han, Z. Huang, X. Zhang, L. Zhang, Y. Lu, T. Tan, J. Appl. Polym. Sci. 40643 (2014).

${ }^{[11]}$ P. Raju, V. Nandanan, K.N.K. Sunil, J. Rubb. Res. 11, 147 (2008).

${ }^{[12]}$ S. Ieadsang, A. Thitithammawong, C. Nakason, A. Kaesaman, Adv. Mater. Res. 844, 239 (2014).

${ }^{[13]}$ K. Chanpon, A. Thitithammawong, C. Nakason, A. Kaesaman, Adv. Mater. Res. 844, 49 (2014).

${ }^{[14]}$ C. Moojea-te, A. Rungvichaniwat, K. Sahakaro, Key Eng. Mater. 423 (2015).

${ }^{[15]}$ K. Sahakaro, A. Beraheng, Rubber Chem. Tech. 84, 200 (2011).

${ }^{[16]}$ W. Kaewsakul, K. Sahakaro, W.K. Dierkes, J.W.M. Noordermeer, Rubber Chem. Technol. 86, 313 (2013).

${ }^{[17]}$ S. Mihara, R.N. Datta, A.G. Talma, J.W.M. Noordermeer, US Patent 7923493B2 2011.

${ }^{[18]}$ C. Hayichelaeh, L.A.E.M. Reuvekamp, A. Blume, J.W.M. Noordermeer, K. Sahakaro, Rubber Chem. Technol. 90, 651 (2017).

${ }^{[19]}$ C. Hayichelaeh, L.A.E.M. Reuvekamp, A. Blume, J.W.M. Noordermeer, K. Sahakaro, Rubber Chem. Technol. 91, 433 (2018).

${ }^{[20]}$ W. Kaewsakul, K. Sahakaro, W.K. Dierkes, J.W.M. Noordermeer, Rubber Chem. Technol. 85, 277 (2012).

${ }^{[21]}$ A. Blume, F. Thibault-Starzyk, Rubber Fibres Plast. Int. 12, 152 (2017).

${ }^{[22]}$ A. Blume, F. Thibault-Starzyk, Rubber Fibres Plast. Int. 12, 236 (2017).

[23] J. Li, A.I. Isayev, X. Ren, M.D. Soucek, Polymer 60, 144 (2015).

${ }^{[24]}$ H.L. Stephens, in: M. Morton (Ed.), The Compounding and Vulcanization of Rubber, Rubber Technology, Van Nostrand Reinhold, New York, 1987, pp. 20-58. 


\section{SUMMARY}

For heavy duty truck tire tread compounds, Natural Rubber (NR) is necessarily needed due to the fact that NR provides low heat build-up and excellent mechanical properties, which derive from crystal structures upon being stretched, i.e. strain-induced crystallization. Based on the innovation of the "Green Tire" by Michelin as introduced in the 1990s, tire tread compounds reinforced with a silica/silane system show improved key tire performances, i.e. lower rolling resistance and better wet traction, while maintaining the abrasion resistance when compared to conventional carbon black-reinforced tire tread compounds. The reduction in tire rolling resistance of silica-reinforced tire tread compounds leads to low fuel consumption and less $\mathrm{CO}_{2}$ emission. In addition to reinforcing fillers, several other ingredients are used in rubber compounds depending on the role of those substances such as process oils, antioxidants, activators, accelerators and curing agents. For rubber compounds reinforced with a silica/silane system, the reinforcement efficiency strongly depends on the reaction between the silica surface and silane molecules, the so-called silanization reaction. DiPhenyl Guanidine (DPG) as secondary accelerator for rubber compounds vulcanized with a sulfur system gives additional positive effects in silica-reinforced rubber compounds, while DPG can act as a silanization catalyst and de-activate free silanol groups that are left over after the silanization reaction. However, DPG liberates toxic aniline which has been classified as a carcinogen, during compounding under high mixing temperatures. Concern over the aniline toxicity leads to a search for safe alternatives. In addition, Distillated Aromatic Extract (DAE) which is a petroleumbased process oil conventionally used to improve the processibility and filler dispersion of rubber compounds with high filler loadings, has been banned due to its composition that contains Polycyclic Aromatic Hydrocarbons (PAHs) of which some have been classified as carcinogenic materials. The replacement of DAE with safe process oils such as Treated Distillate Aromatic Extract (TDAE) for tire compounds has come into practice.

In order to enhance safe working conditions and favor the ecological environment, to comply with tightened regulations and/or new legislations for the tire industry towards more "green" products, less or non-toxic compounding ingredients and bio-based raw materials such as bio process oils shall be used. Therefore, the concept of energy-saving or "green" tires in combination with safe compounding ingredients for silica-reinforced NR is defined in this research work, as discussed in Chapter 1. The work is divided into two main parts. In the first part, different types of amines are investigated as alternatives for DPG in silica-silane reinforced NR tire compounds. The second part is executed using the most suitable curing system determined in the first part. The TDAE oil is replaced by modified plant oils, i.e. epoxidized palm 
oils and amine modified-epoxidized palm oils. Chapter 2 of the present thesis covers a review of the "Green Tire" technology of rubber compounds reinforced by silica/silane system and the use of safe compounding ingredients such as DPG alternatives and bio-based process oils in filled rubber compounds.

The experiments of this thesis are started in Chapter 3. Different amines, i.e. hexylamine (HEX), decylamine (DEC), octadecylamine (OCT), cyclohexylamine (CYC), dicyclohexylamine (DIC) and quinuclidine (QUI), are investigated in a model system by taking the ones with DPG and without amine as references. The primary and secondary silanization reactions of the silica/silane mixtures are evaluated. The amines with different chemical structures provide a diverse influence on the primary silanization reaction rate, but do not change the secondary silanization reaction rate. All amines increase the rate constant of the primary silanization reaction up to 3.7 times compared to the system without amine. Linear aliphatic amines, i.e. HEX, DEC and OCT, promote the rate constant of the primary silanization reaction to a greater extent than amines with bulky cyclic structures, i.e. CIC, DIC and QUI. The amines with shortalkyl chains that provide better accessibility towards the silica surface, enhance the primary silanization reaction more than the ones with long-alkyl chains. The silanization reaction using amines as base catalysts occurs after the amine is adsorbed on the silica surface via hydrogen bonding between amino groups in the amine molecules and silanol groups on the silica surface. The linear aliphatic amines with longer alkylchains promote hydrophobicity by a shielding effect but hinder the reactive silanol-groups on the silica surface, as observed in a reduction of the rate constant of the primary silanization reaction: two competitive effects. Among the various amine types studied, the mixtures with DPG and HEX show higher rate constant of the primary silanization reaction. These two amine types are then further investigated for their influence on the silica/silane system by varying the amounts of amines in the range of 0.1 to $0.5 \mathrm{mmol}$ in the system that contains $0.5 \mathrm{~g}$ of silica, $0.094 \mathrm{mmol}$ of TESPT and $4 \mathrm{ml}$ of decane. The use of both amines shows the same trend in which the rate constant of the primary silanization reaction increases with increasing amine loading, and thereafter decreases slightly, tending to level off at an excess of amine loading. An optimum rate constant of the primary silanization reaction of the mixtures with DPG and HEX is observed at 0.2 mmol of amines used.

With regard to the use of DPG alternatives in practical rubber compounds, the experiments in Chapter 4 investigate the effect of various types of aliphatic amines having alkyl or cyclic structures and similar pKa, i.e. HEX, DEC, OCT, CYC, DIC and QUI, on the properties of silica-reinforced NR compounds by taking the ones with DPG and without amine as references. The use of all amine types reduces filler-filler interaction, i.e. the Payne effect, and enhances filler-rubber interaction as indicated by bound rubber content and decreased heat capacity increment when compared to the compound without amine. Due to better accessibility towards the silica surface and the shielding effect of less steric hindrance as found in Chapter 3, the amines with alkyl-chains can reduce the Payne effect and enhance the cure rate to a greater extent compared to the amines with cyclic rings. The shielding effect of the linear aliphatic 
amines on the free silanol groups that are left over after silanization reaction promotes the hydrophobicity of the silica surfaces. Therefore, the longer carbon-tails on linear aliphatic amines ranging from HEX, DEC to OCT lead to a lower Payne effect, lower heat capacity increment, higher bound rubber content, and higher modulus as well as higher tensile strength. Overall, the use of OCT provides silica-reinforced NR compounds with properties closest to the reference one with DPG, and can act as a potential alternative for DPG.

The use of OCT as alternative for DPG in silica-reinforced NR tire compounds is further investigated with emphasis on the improvement of the compatibility between the silica surface and rubber molecules, by taking the amine-free rubber compound as reference in Chapter 5 . The quantity of OCT and DPG is varied in the range of 2.4-9.5 mmol per 100 parts of rubber by weight, i.e. $0.5-2.5 \mathrm{phr}$. As the amines are adsorbed on the polar silica surface and catalyze the silanization reaction, the use of amines in the rubber compounds enhances interfacial compatibility between the silica surface and rubber matrix as proven by bound rubber contents, changes in heat capacity $\left(\Delta \mathrm{C}_{\mathrm{p}}\right)$ and immobilized polymer layer $\left(X_{i m}\right)$. Based on the kinetic study in Chapter 3 that revealed a higher rate constant of the primary silanization reaction of DPG compared to OCT, the rubber compound with DPG shows a higher chemically bound rubber content indicating that the use of DPG enhances the silanization reaction to a greater extent. However, the long alkyl chain of OCT promotes a shielding effect on the silica surface which leads to higher hydrophobicity, resulting in good interfacial compatibility. Thus, the rubber compounds with OCT show higher physically bound rubber contents and consequently higher total bound rubber, a higher immobilized polymer layer as well as a lower Payne effect. As the shielding effect provides only physical interaction between amine and silanol groups, it is weakened under thermal treatment and thus the compound with OCT shows a higher flocculation rate constant. Considering a main role of the secondary accelerator on the cure behaviors, the compounds with DPG exhibit slightly faster cure time and higher cure reaction rate compared to those with OCT at the same loading. This may be due to a higher physically bound rubber content for the OCT compounds that can be broken at high temperature, leaving more free silanol groups to interfere with the curing reaction, thus leading to poorer cure behavior. Due to the good interfacial interaction combining both chemical and physical interactions, the vulcanized rubber with OCT at optimum loading shows better mechanical properties and $\tan \delta$ at $60^{\circ} \mathrm{C}$ when compared to the DPG counterpart.

Towards eco-friendly and more sustainable rubber technology, bio oils are applied as process oils in rubber compounds, as elucidated in Chapter 6. Epoxidized Palm Oil (EPO) and amine-Modified EPO (mEPO) were prepared and their chemical structures characterized using FTIR and ${ }^{1} \mathrm{H}-\mathrm{NMR}$. The EPOs with different epoxide contents were prepared via epoxidation of palm oil by formic acid and hydrogen peroxide. The oxygen oxirane or epoxide contents were determined by titration with $\mathrm{HBr}$. The oxygen oxirane contents of the EPO oils in this study are approximately 1, 2 and 3\%, and coded EPO-1, EPO-2 and EPO-3, respectively. The amine-modified EPO (mEPO) oil was prepared by using EPO-3 to react with N- 
Phenyl-p-PhenyleneDiamine (PPD). For the mEPO oils, the amounts of PPD in $\mathrm{mEPO}$ were determined by means of FTIR via a standard curve. It was found that the mEPOs contain 0.03 and $0.04 \mathrm{mmol}$ of PPD in 1 $\mathrm{g}$ of oil, called 0.03 and $0.04 \mathrm{mEPO}$, respectively. The silanization efficiency of silica/silane systems in the presence of different types of oils was investigated by taking the mixtures with TDAE and without oil as references. The use of TDAE and unmodified palm oil results in a similar efficiency on the silanization reaction. Among the modified oils, the use of EPOs promotes the silanization efficiency, while the mEPOs hinder the silanization reaction. The polar silanol groups on the silica surface can easily interact with the polar functional groups in the oil structures, especially bio oils. On the other hand, the presence of oil adsorbed on the silica surface could interrupt the agglomeration. During mixing, once the oil molecules are adsorbed on the surface of silica aggregates, the agglomeration is less and thus there are more silanol groups available for reacting with silane molecules to result in a higher silanization efficiency, as observed in the mixtures with EPOs. However, the system is being complicated by the presence of several polar moieties that cause some competitive phenomena such as breaking of silica agglomerates that provides more active silanol groups, or strong interaction of polar and bulky oil molecules with the silica surface that introduces steric effects that limit the accessibility of the silanes towards the silica surface and thus hinder the silanization reaction. Moreover, the different polarity of these oils also has an effect on wettability of the silica surface. Therefore, EPO and mEPO oils show contradicting effects on the silanization efficiency.

The work in Chapter 7 investigates epoxidized palm oil (EPO) as alternative for petroleum-based process oil in silica-reinforced NR tire tread compounds. Adsorption of oil molecules onto silica surfaces can occur, causing different silanization efficiency. This chapter investigates the effect of different incorporating steps of EPO on the properties of the rubber compounds. The properties of the rubber compound containing EPO-3 are compared with the reference mixes with TDAE oil and without oil. The use of EPO-3 shows a lower viscosity, lower filler-filler interaction and flocculation rate constant, but higher cure reaction rate constants, compared to the one with TDAE oil. This may be due to interaction between the epoxide groups in EPO and the silanol groups on the silica surface, promoting more shielding of the polar surface and thus a better silica dispersion and less interference with the vulcanization reaction. Comparing the different mixing sequences, it is observed that the incorporating steps of EPO-3 in the rubber compounds show no significant effect on the viscosity, filler-filler interaction and flocculation rate constant, but clearly affect the extent of crosslinking, as indicated by cure torque difference. The addition of EPO-3 in an early stage of the mixing together with the first half addition of silica and silane gives the lowest cure torque increment which indicates a possible obstruction for interaction between the silanol groups and silane coupling agent by the EPO molecules. This results in a low modulus and tensile strength, as well as the highest $\tan \delta$ at $60^{\circ} \mathrm{C}$. The effect of the epoxide levels in the EPO oils in the range of $1-3 \mathrm{~mol} \%$ as discussed in Chapter 6, on the properties of rubber compounds is then investigated. An increase of epoxide content gives similar Payne effects, but enhances the cure reaction resulting in improved tensile properties and $\tan \delta$ at $60^{\circ} \mathrm{C}$. 
The feasibility of the use of epoxidized palm oil (EPO) and amine-modified epoxidized palm oil (mEPO), as process oils in practical silica-reinforced natural rubber compounds is subsequently studied in Chapter 8. The EPO-3, $0.03 \mathrm{mEPO}$ and $0.04 \mathrm{mEPO}$ as discussed in Chapter 6 are used. The properties of rubber compounds with modified palm oils are investigated by taking the ones with TDAE-oil and without oil as references. All process oils clearly enhance the processibility, i.e. lower mixing torque and complex viscosity, and mechanical and dynamic mechanical properties of the rubber compounds compared to the compound fully without oil. The polarity in the bio-based process oils can strongly interact with the silica surface, leading to a shielding effect of the silica surface. The rubber compounds with EPO-3 and mEPO show a lower Payne effect, i.e. less filler-filler interaction, than the rubber compound with TDAE. The rubber compounds with $\mathrm{mEPO}$ oils give faster cure behaviors and better cure torque increments due to the alkaline amino group in the $\mathrm{mEPO}$ oils. Therefore, the rubber compounds with mEPOs display enhanced mechanical properties, reinforcement index, tensile strength and elongation at break, and reduced loss tangent at $60^{\circ} \mathrm{C}$, compared to the mix with TDAE.

Overall, this present thesis provides an in-depth study into the application of amines as alternatives for DPG and modified palm oils as sustainable alternatives for petroleum-based TDAE oil in silica-reinforced NR compounds, for low rolling resistance tires. Both model compound systems and practical rubber compounds were applied in order to gain information on the kinetics and performance properties of the compounds. Based on the results in this research, replacement of DPG by OCT is feasible, and EPO or $\mathrm{mEPO}$ are potential candidates to substitute TDAE in silica-reinforced NR compounds without scarifying the properties. With optimum loading, vulcanized rubber with OCT even shows better mechanical properties and $\tan \delta$ at $60^{\circ} \mathrm{C}$ when compared to the DPG counterpart. The utilization of mEPOs results in compounds with enhanced reinforcement index and tensile strength, and reduced loss tangent at $60^{\circ} \mathrm{C}$, compared to the mix with TDAE. Therefore, from the perspective of "safe and green" tires, the application of OCT and modified bio oils as alternatives for DPG and TDAE oil, respectively, are fulfilled and bring even lower tire rolling resistance, i.e. less fuel consumption and less $\mathrm{CO}_{2}$ emission. 


\section{SAMENVATTING}

Voor zwaar-werk vrachtwagenbanden loopvlak-mengsels is gebruik van NatuurRubber (NR) vereist, omdat alleen NR een lage warmte-ontwikkeling geeft en excellente mechanische eigenschappen, die terug te voeren zijn op kristallijne structuren die optreden bij rekken, zgn. rek-kristallisatie. Op basis van de uitvinding van de "Green Tire" (Groene Band) door Michelin, zoals op de markt gebracht in de negentiger jaren van vorige eeuw, vertonen bandenloopvlak mengsels versterkt met een silica/silaan systeem verbeterde hoofd-eigenschappen: lagere rolweerstand en betere natte slipweerstand, bij gelijkblijvende slijtage-weerstand in vergelijking met conventionele roet-versterkte bandenloopvlak mengsels. De vermindering in rolweerstand van silica-versterkte bandenloopvlak mengsels geeft een verlaagd brandstofverbruik en verminderde $\mathrm{CO}_{2}$-emissie. Naast versterkende vulstoffen worden verschillende andere ingrediënten gebruikt in rubber mengsels afhankelijk van de werking van deze substanties, zoals proces oliën, antioxidanten, activatoren, versnellers en vernettings-middelen. Voor rubber-mengsels versterkt met een silica-silaan systeem hangt de efficiëntie van de versterking in hoge mate af van de reactie tussen het silica-oppervlak en silaan moleculen, de zgn. silaniserings reactie. DiPhenyl Guanidine (DPG) gebruikt als secundaire versneller voor rubber mengsels gevulkaniseerd met een zwavel-systeem, geeft additionele positieve effecten in silica-versterkte rubber mengsels, omdat DPG kan werken als silaniserings-katalysator en vrije silanol-groepen de-activeert die overgebleven zijn na de silaniserings-reactie. DPG geeft echter giftig aniline vrij gedurende de compoundering bij hoge mengtemperaturen, dat is geclassificeerd als carcinogeen. De zorg om de toxiciteit van aniline leidt tot een zoektocht naar veilige alternatieven. Daarnaast is Distillate Aromatic Extract (DAE) verbannen, een petroleum-gebaseerde proces-olie van oudsher gebruikt om de verwerkbaarheid en de vulstof-dispersie van rubber mengsels met hoge vulstof gehaltes te verbeteren, vanwege de samenstelling die Polycyclische Aromatische Hydrocarbons (Koolwaterstoffen) (PAHs) bevat, waarvan er enkele ook als carcinogeen materialen zijn aangemerkt. De vervanging van DAE door veilige proces-oliën zoals Treated Distillate Aromatic Extract (TDAE) voor banden-mengsels is inmiddels gemeengoed.

Teneide veilige werkomstandigheden te bevorderen en het ecologisch milieu te sparen, om te voldoen aan verscherpte regelgeving en/of nieuwe wetgeving voor de bandenindustrie in de richting van "groenere" producten, moeten niet-toxische compounderings ingrediënten en bio-gebaseerde grondstoffen zoals bio proces-oliën worden gebruikt. Daarom wordt het concept van energie-zuinige of "groene" banden in combinatie met veilige compounderings-ingrediënten voor silica-versterkte NR in dit research-werk aangepakt, zoals wordt besproken in Hoofdstuk 1. Het werk is verdeeld in twee hoofd-onderdelen. In het eerste deel worden verschillende soorten amines onderzocht als alternatieven voor DPG in silica-silaan versterkte NR banden-mengsels. Het tweede deel wordt uitgevoerd met gebruikmaking van het meest geschikte vulkanisatie-systeem zoals vastgesteld in het eerste deel. De TDAE-olie wordt vervangen door 
gemodificeerde planten-oliën, m.n. geëpoxideerde palm-oliën en amine-gemodificeerde geëpoxideerde palm-oliën. Hoofdstuk 2 van het huidige proefschrift geeft een overzicht van de "Green Tire" technologie van rubber mengsels versterkt met een silica/silaan systeem, en van het gebruik van veilige compounderigs ingrediënten zoals DPG-alternatieven en bio-gebaseerde proces oliën in gevulde rubber mengsels.

Het experimentele deel van dit proefschrift begint in Hoofdstuk 3. Verschillende amines, te weten hexylamine (HEX), decylamine (DEC), octadecylamine (OCT), cyclohexylamine (CYC), dicyclohexylamine (DIC) en quinuclidine (QUI) worden onderzocht in een model systeem, in vergelijking met de systemen met DPG en zonder amine als referenties. De primaire en secundaire silaniserings-reacties van de silica/silaan mengsels worden geëvalueerd. De amines met verschillende chemische structuren laten een uiteenlopende invloed zien op de primaire silaniserings reactie-snelheid, maar veranderen de secundaire silaniserings-reactie snelheid niet. Alle amines verhogen de snelheidsconstante van de primaire silaniserings-reactie tot wel een factor 3,7 vergeleken met het systeem zonder amine. Lineaire alifatische amines zoals HEX, DEC en OCT verhogen de snelheidsconstante van de primaire silaniserings-reactie in hogere mate dan amines met sterische cyclische structuren, te weten CIC, DIC en QUI. De amines met korte alkyl-staarten die een betere toegankelijkheid bezitten naar het silica-oppervlak, verhogen de primaire silaniserings-reactie meer dan degene met lange alkyl-staarten. De silaniserings-reactie met gebruikmaking van amines als basische katalysatoren vindt plaats nadat de amine is geadsorbeerd op het silica oppervlak via waterstofbindingen tussen de amino-groepen in de amine moleculen en silanol-groepen op het silica oppervlak. De lineaire alifatische amines met langere alkyl-staarten bevorderen hydrofobiciteit door een afschermend effect, maar belemmeren de reactieve silanol-groepen op het silica-oppervlak, zoals wordt waargenomen in een verlaging van de snelheidsconstante van de primaire silaniserings-reactie: twee competitieve effecten. Onder de verschillende bestudeerde amine soorten vertonen de mengsels met DPG en HEX een hogere snelheidsconstante van de primaire silaniseringsreactie. Deze twee amine soorten worden dan verder onderzocht op hun invloed op de het silica/silaan systeem door variatie van de hoeveelheden amines tussen 0,1 en 0,5 mmol in het systeem, dat verder 0,5 $\mathrm{g}$ silica, 0,094 mmol TESPT en $4 \mathrm{ml}$ decaan bevat. Het gebruik van beide amines vertoont dezelfde trend, waarin de snelheidsconstante van de primaire silaniserings-reactie toeneemt met verhoging van de amine-dosering, maar daarna lichtelijk achteruitgaat, respectievelijk leidt tot een afvlakking bij overmaat amine dosering. Een optimale snelheidsconstante van de primaire silaniseringsreactie van de mengsels met DPG en HEX wordt waargenomen bij $0,2 \mathrm{mmol}$ amines.

Met betrekking tot het gebruik van DPG-alternatieven in praktische rubber-mengsels wordt met de experimenten in Hoofdstuk 4 het effect onderzocht van verschillende types alifatische amines met alkyl of cyclische structuren en vergelijkbare pKa (zuurgraad), te weten HEX, DEC, OCT, CYC, DIC en QUI, op de eigenschappen van silica-versterkte NR mengsels, waarbij degene met DPG en helemaal zonder amine worden gebruikt als referenties. Het gebruik van alle amine soorten verlaagt de vulstof-vulstof 
interactie, d.w.z. het Payne effect, en bervordert de vulstof-rubber wisselwerking zoals blijkt uit het "bound rubber" gehalte en verlaagde warmtecapaciteits increment in vergelijking met het mengsel zonder amine. Vanwege de betere toegankelijkheid naar het silica-oppervlak en de afschermende werking met minder sterische hindering zoals gevonden in Hoofdstuk 3, kunnen de amines met alkyl-staarten het Payne-effect meer verlagen en de vulkanisatiesnelheid in sterkere mate verhogen in vergelijking met amines met cyclische ring-structuren. De afschermende werking van de lineaire alifatische amines op de vrije silanolgroepen overgebleven na de silaniseringsreactie bevorderen de hydrofobiciteit van het silica oppervlak. Daarom leiden de langere koolstof-staarten van de lineaire alifatische amines van HEX, DEC tot OCT tot een lager Payne-effect, lager warmte-capaciteits increment, een hoger bound rubber gehalte, en hogere modulus en treksterkte. Over het geheel genomen geeft het gebruik van OCT in silica-versterkte NR mengsels eigenschappen die het dichtst het referentie-mengsel met DPG benaderen, en kan OCT daarom dienstdoen als potentiëel alternatief voor DPG.

Het gebruik van OCT als alternatief voor DPG in silica-versterkte NR banden compounds wordt nader onderzocht in Hoofdstuk 5 met nadruk op verbetering van de compatibiliteit tussen het silicaoppervlak en rubber moleculen, met het amine-vrije rubber compound als referentie. De hoeveelheid OCT en DPG wordt gevariëerd tussen 2,4 en 9,5 mmol per 100 gewichtsdelen rubber, d.w.z. tussen 0,5 - 2,5 phr. Daar de amines zijn geadsorbeerd op het polaire silica oppervlak en zij de silaniseringsreactie katalyseren, verhoogt het gebruik van amines in de rubber mengsels de compatibiliteit van het oppervlak tussen de silica en de rubber matrix, zoals wordt bewezen met bound rubber gehaltes, verandering in de warmte capaciteit $\left(\Delta \mathrm{C}_{\mathrm{p}}\right)$ en geïmmobiliseerde laag $\left(X_{m}\right)$. Op basis van de kinetische studie in Hoofdstuk 3, die een hogere snelheidsconstante liet zien voor de primaire silaniseringsreactie voor DPG vergeleken met OCT, vertoont het rubber mengsel met DPG een hoger chemisch gebonden rubber-gehalte, hetgeen erop duidt dat het gebruik van DPG de silaniseringsreactie in sterkere mate bevordert. Echter, de lange alkyl-staart van OCT bevordert een afschermend effect op het silica oppervlak hetgeen leidt tot hogere hydrophobiciteit resulterend in een goede oppervlakte-verdraagzaamheid. Derhalve vertonen de rubber mengsels met OCT hogere fysisch gekoppelde rubber gehaltes en dus ook hogere totale gebonden rubber gehaltes, een hogere geïmmobiliseerde polymeer-laag evenals een lager Payne effect. Waar het afschermende effect slechts fysische interactie oplevert tussen amine- en silanol-groepen, wordt dit verzwakt door thermische behandeling en daarom vertoont het mengsel met OCT een hogere flocculatie (uitvlokken) snelheidsconstante. Kijkend naar de belangrijke rol van de secundaire versneller op de vulkanisatie, laten de mengsels met DPG een enigszins snellere vulkanisatie en hogere vulkanisatiereactie snelheidsconstante zien vergeleken met die mengsels welke eenzefde hoeveelheid OCT bevatten. Dit kan het gevolg zijn van een hoger fysisch gebonden rubber gehalte voor de OCT mengsels, dat bij hogere temperatuur wordt verbroken en meer vrije silanol-groepen overlaat om in wisselwerking te treden met de vulcanisatie-reactie, en zo leidt tot een slechter vulcanisatie-gedrag. Vanwege de goede oppervlakte-wisselwerking, de 
combinatie van chemische en fysische interacties, vertoont de rubber gevulcaniseerd met OCT bij optimale concentratie betere mechanische eigenschappen en $\tan \delta$ bij $60^{\circ} \mathrm{C}$ dan de DPG tegenhanger.

Ten behoeve van een milieu-vriendelijke en groenere rubbertechnologie worden bio-oliën toegepast als proces-oliën in rubber mengsels, zoals uitgewerkt in Hoofdstuk 6. Geëpoxideerde palmolie (EPO) en amine-gemodificeerde EPO (mEPO) zijn bereid en hun chemische structuren gekarakteriseerd met FTIR en 1H-NMR. De EPOs met verschillende epoxide-gehaltes zijn aangemaakt via epoxidering van palmolie door mierenzuur en waterstof-peroxide. De zuurstof-oxiraan en epoxide gehaltes zijn bepaald door titratie met $\mathrm{HBr}$. De zuurstof-oxiraan gehaltes van de EPO-oliën in de huidige studie zijn ongeveer 1, 2 en $3 \%$, en de monsters zijn gecodeerd EPO-1, EPO-2 en EPO-3 respectievelijk. De amine-gemodificeerde EPO (mEPO) olie is aangemaakt met gebruikmaking van EPO-3 door deze te reageren met Phenyl-pPhenyleenDiamine (PPD). Voor de mEPO-oliën zijn de hoeveelheden PPD in de mEPO bepaald met FTIR via een standaard ijk-curve. Er is vastgesteld, dat de mEPOs 0,03 en 0,04 mmol PPD bevatten per gram olie, wat met 0,03 en 0,04 mEPO wordt aangeduid. De silaniseringsefficiëntie van silica/silaan systemen in aanwezigheid van de verschillende olie-types is onderzocht in vergelijking met mengsels met TDAE en zonder olie als referenties. Het gebruik van TDAE en ongemodificeerde palmolie resulteert in een vergelijkbare efficiëntie van de silaniseringsreactie. Onder de gemodificeerde oliën bevordert het gebruik van EPOs de silanseringsefficiëntie, terwijl de mEPOs die reactie tegenwerken. De polaire silanol groepen op het silica oppervlak kunnen gemakkelijk wisselwerking aangaan met de polaire functionele groepen in de olie-structuren, in het bijzonder bio-oliën. Aan de andere kant kan de aanwezigheid van geadsorbeerde olie op het silica-oppervlak de agglomeratie van silica verhinderen. Gedurende het mengen, wanneer de olie-moleculen eenmaal zijn geadsorbeerd op het oppervlak van silica aggregaten, is er minder agglomeratie en dus blijven er dus meer silanol-groepen beschikbaar om te reageren met silaan moleculen, resulterend in hogere silaniserings-efficiëntie, zoals waargenomen in de mengsels met EPOs. Echter, het systeem wordt vertroebeld door de aanwezigheid van verschillende polaire stoffen, die bepaalde competitieve verschijnselen veroorzaken zoals het opbreken van silica agglomeraten die meer actieve silanol-groepen aanleveren, of sterke interactie van polaire en volumineuze olie-moleculen met het silica oppervlak en als zodanig de silanseringsreactie hinderen. Bovendien heeft de verschillende polariteit van deze oliën ook een effect op de adsorptie op het silica-oppervlak. Daarom vertonen de EP en mEPO oliën tegengestelde effecten op de silaniserings-efficiëntie.

Het werk in Hoofdstuk 7 onderzoekt geëpoxideerde palmolie (EPO) als alternatief voor petroleum-gebaseerde procesolie in silica versterkte NR bandenloopvlak mengsels. Adsorptie van oliemoleculen op het silica oppervlak kan optreden, hetgeen een veranderde silaniseringsefficiëntie veroorzaakt. Dit hoofdstuk onderzoekt het effect van verschillende incorporatie-stappen van EPO op de eigenschappen van de rubber mengsels. De eigenschappen van het mengsel dat EPO-3 bevat worden vergeleken met de referentie-mengsels met TDAE olie en zonder olie. Gebruik van EPO-3 geeft een lagere 
viscositeit, verminderde vulstof-vulstof interactie en flocculatie-snelheids constante, maar hogere vulkanisatie reactiesnelheidsconstantes vergeleken met het mengsel met TDAE-olie. Dit kan te wijten zijn aan wisselwerking tussen de epoxide-groepen in EPO en de silanol-groepen op het oppervlak van de silica, hetgeen meer afscherming geeft van de polaire groepen en dus een betere silica dispersie en minder interferentie met de vulkanisatie-reactie. Bij vergelijking van de verschillende meng-voorgangen wordt waargenomen, dat de incorporatiestappen van EPO-3 in de rubber mengsels geen significant effect laten zien op de viscositeit, vulstof-vulstof interactie en flocculatie snelheids-constante, maar wel de mate van crosslinking sterk beïnvloeden, zoals blijkt uit het vulkanisatie koppel-verschil in de rheometer. De toevoeging van EPO-3 in een vroeg stadium van het mengen samen met de eerste helft silica en silaan geeft het laagste vulkanisatie koppel-verschil, hetgeen een mogelijke belemmering indiceert voor interactie tussen de silanol-groepen en silaan coupling agent door de EPO moleculen. Dit resulteert in lage modulus en treksterkte, evenals de hoogste $\tan \delta$ bij $60^{\circ} \mathrm{C}$. Het effect van de epoxide gehaltes in de EPO-oliën in de range van 1-3 mol\%, zoals besproken in Hoofdstuk 6, op de eigenschappen van rubber compounds wordt vervolgens onderzocht. Een toename van het epoxide-gehalte geeft vergelijkbare Payne effecten, maar verbetert de vulkanisatie-reactie resulterend in verbeterde trek-rek eigenschappen en $\tan \delta$ bij $60^{\circ} \mathrm{C}$.

Het mogelijke gebruik van geëpoxideerde palmolie (EPO) en amine-gemodificeerde geëpoxideerde palmolie ( $\mathrm{mEPO}$ ) als proces oliën in practische silica-versterkte natuurrubber mengsels wordt vervolgens onderzocht in Hoofdstuk 8. De EPO-3 , 0,03 mEPO en 0,04 EPO zoals besproken in Hoofdstuk 6 worden gebruikt. De eigenschappen van rubber mengsels met gemodificeerde palmoliën worden onderzocht in vergelijking met de mengsels met TDAE-olie en zonder olie als referenties. Alle proces-oliën verhogen duidelijk de verwerkbaarheid, d.w.z. lager meng-koppel en complexe viscositeit, en de mechanische en dynamisch mechanische eigenschappen van de rubber mengsels, vergeleken met het mengsel zonder enige olie. De polariteit in de bio-gebaseerde proces-oliën kan sterke wisselwerking aangaan met het silica-oppervlak, hetgeen tot afscherming van het silica-oppervlak leidt. De rubber mengsels met EPO-3 en mEPO vertonen een lager Payne effect, d.w.z. minder vulstof-vulstof wisselwerking dan het rubber mengsel met TDAE. De rubber mengsels met mEPO oliën vertonen sneller vulkansiatie-gedrag en betere vulkanisatie koppel-incrementen vanwege de alkalische amino-groep in de $\mathrm{mEPO}$ oliën. Daarom vertonen de rubber mengsels met mEPOs verbeterde mechanische eigenschappen, versterkings index, treksterkte en breukrek, en verminderde verlieshoek bij $60^{\circ} \mathrm{C}$ vergeleken met het mengsel met TDAE.

Over het geheel genomen levert dit proefschrift een diepgaande studie in de toepassing van amines als alternatieven voor DPG en gemodificeerde palmoliën als duurzame alternatieven voor van petroleum afgeleide silica-versterkte NR mengsels, voor lage rolweerstand banden. Zowel model compound systemen als practische rubber mengsels zijn toegepast teneinde informatie te vergaren betreffende de kinetiek en eigenschappen van de mengsels. Op basis van de resultaten in dit onderzoek is 
de vervanging van DPG door OCT een werkbare optie, en EPO of mEPO zijn potentiële kandidaten om TDAE te vervangen in silica-versterkte NR mengsels, zonder eigenschappen op te geven. Bij optimale dosering vertoont rubber met OCT zelfs betere mechanische eigenschappen en $\tan \delta$ bij $60^{\circ} \mathrm{C}$ vergeleken met de tegenhanger DPG. Het gebruik van mEPOs resulteert in mengsels met verbeterde versterkings index en treksterkte, en verlaagde verlies tangent bij $60^{\circ} \mathrm{C}$ vergeleken met het mengsel met TDAE. Daarom is voldaan aan de toepassing van OCT en gemodificeerde bio-oliën als alternatieven voor DPG en TDAE-olie vanuit perspectief van "veilige en groene" banden, en geven die zelfs lagere banden-rolweerstand, d.w.z. lager brandstofverbruik en minder $\mathrm{CO}_{2}$ emissie. 
ยางธรรมชาติ (NR) เป็นวัสดุที่จำเป็นในการผลิตยางล้อ โดยเฉพาะสำหรับยางล้อขนาดใหญ่ เนื่องจากยาง ธรรมชาติมีสมบัติการสะสมความร้อนต่ำ อีกทั้งยังมีสมบัติเชิงกลที่ดีเยี่ยม ซึ่งเป็นผลมาจากการเกิดผลึกขณะดึงยืด (Straininduced crystallization) ในต้นปี ค.ศ. 1990 นักวิจัยจากบริษัทมิชลินได้นำเสนอนวัตกรรมยางล้อที่เป็นมิตรต่อสิ่งแวดล้อม หรือที่เรียกว่า Green Tire จากการผลิตยางล้อรถยนต์ส่วนบุคคลโดยมีดอกยางที่ได้จากยางเบลนด์ระหว่างยางสังเคราะห์ $\mathrm{SSBR} / \mathrm{BR}$ เสริมแรงด้วยสารตัวเติมซิลิการ่วมกับสารคู่ควบไซเลน (Silane coupling agent) ซึ่งสามารถปรับปรุงสมรรถนะ ของดอกยางล้อได้ นั่นคือ ดอกยางที่เสริมแรงด้วยซิลิกามีความต้านทานต่อการหมุนลดลงและมีสมบัติการเกาะถนนเปียกดี ขึ้น ในขณะที่ยังคงรักษาสมบัติด้านความต้านทานต่อการสึกหรอไว้ได้เมื่อเทียบกับดอกยางที่เสริมแรงด้วยเขม่าดำแบบเดิม การลดลงของความต้านทานต่อการหมุนของดอกยางทำให้ลดปริมาณการ ใช้เชื้อเพลิงและลดการปลดปล่อยก๊าซ คาร์บอนไดออกไซด์ $\left(\mathrm{CO}_{2}\right)$ ในการผลิตยางล้อนั้นใช้ยางคอมพาวนด์ที่ประกอบด้วยองค์ประกอบต่างๆ หลายชนิด นอกจากสารตัวเติมเสริมแรงแล้ว ยังมีสารอื่นๆที่มีบทบาทและหน้าที่แตกต่างกัน เช่น น้ำมันช่วยแปรรูป (Process oil) สาร ต้านการเสื่อม (Antidegradants) สารกระตุ้น (Activator) สารตัวเร่ง (Accelerator) และสารคงรูป (Curing agent) สำหรับ ยางคอมพาวนด์เสริมแรงด้วยซิลิกาและสารคู่ควบนั้น ประสิทธิภาพของการเสริมแรงขึ้นอยู่กับระดับของการเกิดปฏิกิริยา ระหว่างหมู่ฟังก์ชันบนพื้นผิวซิลิกาและสารคู่ควบ หรือที่เรียกว่าปฏิกิริยาไซลาไนเซชัน (Silanization reaction) โดยสาร ตัวเร่งไดฟีนิลกัวนิดีน (Diphenylguanidine) หรือ DPG ซึ่งเป็นสารตัวเร่งทุติยภูมิที่นิยมใช้ในยางคอมพาวนด์เสริมแรงด้วย ซิลิการ่วมกับสารตัวเร่งปฐมภูมิในการคงรูปยางด้วยระบบกำมะถัน สามารถช่วยเร่งปฏิกิริยาไซลาไนเซชันและลดความ ว่องไวของหมู่ไซลานอลที่หลงเหลือจากปฏิกิริยาไซลาไนเซชันได้อีกด้วย อย่างไรก็ตามเนื่องจาก DPG จะเกิดการ ปลดปล่อยสารอะนิลีน (Aniline) ในระหว่างการผสมที่อุณหภูมิสูง ซึ่งสารอะนิลีนนั้นถูกจัดอยู่ในกลุ่มของสารก่อมะเร็ง จากความกังวลเรื่องความเป็นพิษของอะนิลีนนี้ ทำให้จำเป็นต้องหาสารทดแทน $\mathrm{DPG}$ สำหรับยางคอมพาวนด์ นอกจากนี้ น้ำมันอะโรมาติกหรือที่เรียกว่า Distillated aromatic extract (DAE) ซึ่งใช้เป็นสารช่วยแปรรูปยางคอมพาวนด์โดยเฉพาะใน ยางที่ผสมสารตัวเติมในปริมาณสูง มีความจำเป็นมากที่ต้องใช้น้ำมันช่วยแปรรูป ซึ่งนอกจากจะช่วยควบคุมความหนืดของ ยางคอมพาวนด์เพื่อให้แปรรูปได้ง่ายแล้ว ยังช่วยทำให้สารตัวเติมกระจายตัวในยางได้ดีขึ้น แต่เนื่องจากองค์ประกอบของ สารพอลิไซคลิกอะโรมาติก (Polycyclic aromatic hydrocarbon, PAH) ในน้ำมัน DAE ซึ่งส่วนหนึ่งของสารเหล่านี้ถูกจัด ให้อยู่ในกลุ่มของสารก่อมะเร็ง ทำให้น้ำมันชนิดนี้ถูกระงับไม่ให้ใช้ในยางล้อ ดังนั้นยางคอมพาวนด์สำหรับการผลิตยาง ล้อจึงจำเป็นต้องใช้น้ำมันที่ปลอดภัยทดแทนน้ำมัน $\mathrm{DAE}$ เช่น น้ำมัน Treated distillate aromatic extract (TDAE)

สารเคมีที่ปราศจากความเป็นพิษและน้ำมันจากพืชควรที่จะถูกนำมาใช้ในยางคอมพาวนด์เพื่อส่งเสริมสภาวะ การทำงานที่ปลอดภัยมากยิ่งขึ้น อีกทั้งเพื่อให้เป็นไปตามข้อบังคับและกฎหมายที่เกี่ยวข้องสำหรับอุตสาหกรรมยางล้อ ดังนั้นงานวิจัยนี้จึงมีแนวคิดที่จะศึกษาการใช้สารเคมีที่ปลอดภัยในสูตรยางล้อประหยัดพลังงานจากยางคอมพาวนด์ที่ใช้ ยางธรรมชาติเสริมแรงด้วยซิลิกา ซึ่งได้อธิบายไว้ในบทที่ 1 งานวิจัยนี้แบ่งออกเป็น 2 ส่วนการศึกษา ส่วนแรกเป็น การศึกษาชนิดของเอมีนเพื่อทดแทนการใช้ DPG ในคอมพาวนด์ยางล้อจากยางธรรมชาติเสริมแรงด้วยซิลิกา ส่วนที่ 2 เป็น การศึกษาการใช้น้ำมันพืชดัดแปร โมเลกุล ได้แก่ น้ำมันปาล์มอิพอกไซด์และน้ำมันปาล์มอิพอกไซด์ดัดแปร โมเลกุลด้วย เอมีนในคอมพาวนด์ยางล้อจากยางธรรมชาติเสริมแรงด้วยซิลิกาและใช้เอมีนทดแทน DPG ชนิดที่ให้สมบัติที่ดีที่สุดจาก 
การทดลองในส่วนที่ 1 บทที่ 2 ของเล่มวิจัยนี้เป็นการสรุปภาพรวมของเทคโนโลยียางล้อที่เป็นมิตรกับสิ่งแวดล้อม นั่นคือ คอมพาวนด์ยางล้อเสริมแรงด้วยเทคโนโลยีซิลิการ่วมกับสารคู่ควบ รวมไปถึงการ ใช้สารเคมีที่ปลอดภัยในยางคอมพาวนด์ เช่นสารเคมีทดแทน $\mathrm{DPG}$ และน้ำมันแปรรูปจากน้ำมันพืช

การทดลองของงานวิจัยนี้เริ่มต้นในบทที่ 3โดยศึกษาอิทธิพลของเอมีนชนิดต่างๆ ได้แก่ Hexylamine (HEX), Decylamine (DEC), Octadecylamine (OCT), Cyclohexylamine (CYC), Dicyclohexylamine (DIC) และ Quinuclidine (QUI) ต่อปฏิกิริยาไซลาไนเซชันในระดับปฐมภูมิและทุติยภูมิในระบบจำลองหรือโมเดล เปรียบเทียบกับระบบที่ใช้ $\mathrm{DPG}$ และไม่ใช้เอมีน พบว่าเอมีนที่มีโครงสร้างทางเคมีแตกต่างกันแสดงอิทธิพลอย่างมากต่ออัตราการเกิดปฏิกิริยาไซลาไน เซชันระดับปฐมภูมิ แต่ไม่ส่งผลต่ออัตราการเกิดปฏิกิริยาในระดับทุติยภูมิ โดยเอมีนทุกชนิดที่ศึกษาสามารถเพิ่มอัตราการ เกิดปฏิกิริยาไซลาไนเซชันระดับปฐมภูมิได้และมีอัตราเพิ่มสูงสุด 3.7 เท่า เมื่อเปรียบเทียบกับระบบที่ไม่ใช้เอมีน เอมีนที่มี โครงสร้างโมเลกุลเป็นสายโซ่ตรง เช่น $\mathrm{HEX}, \mathrm{DEC}$ และ $\mathrm{OCT}$ ส่งเสริมการเกิดปฏิกิริยาไซลาไนเซชันระดับปฐมภูมิได้ ดีกว่าเอมีนที่มีโครงสร้างแบบวง เช่น $\mathrm{CIC}, \mathrm{DIC}$ และ QUI เมื่อเปรียบเทียบในกลุ่มของเอมีนที่มีโครงสร้าง โมเลกุลแบบ สายโซ่ตรงพบว่าเอมีนที่มีสายโซ่สั้นกว่าจะช่วยส่งเสริมการเกิดปฏิกิริยาไซลาไนเซชันระดับปฐมภูมิได้ดีกว่าเอมีนที่มีสาย โซ่ยาว เนื่องจากสามารถเข้าถึงพื้นผิวซิลิกาได้ดีกว่า ทั้งนี้ปฏิกิริยาไซลาไนเซชันที่มีเอมีนเป็นตัวเร่งจะเกิดขึ้นภายหลังจาก ที่เอมีนถูกดูดซับลงบนพื้นผิวซิลิกาโดยพันธะไฮโดรเจนระหว่างหมู่อะมิโน (Amino group) ในโมเลกุลเอมีนกับหมู่ ไซลานอล (Silanol group) บนผิวซิลิกา เอมีนที่มีสายโซ่ตรงยาวจะช่วยเพิ่มความไม่ชอบน้ำ (Hydrophobicity) บนผิวซิลิกา เนื่องจากผลของการกำบัง (Shielding effect) อีกทั้งยังช่วยลดความว่องไวของหมู่ไซลานอลบนผิวซิลิกาอีกด้วย จึงส่งผล ให้อัตราเร็วของการเกิดปฏิกิริยาไซลาไนเซชันปฐมภูมิลดลง จากการเปรียบเทียบผลของเอมีนชนิดต่างๆที่ศึกษา พบว่า ระบบที่ใช้ $\mathrm{DPG}$ และ $\mathrm{HEX}$ แสดงอัตราเร็วของการเกิดปฏิกิริยาไซลาไนเซชันระดับปฐมภูมิสูงกว่าการ ใช้เอมีนชนิดอื่นๆ ดังนั้นจึงได้ศึกษาผลของการใช้ $\mathrm{DPG}$ และ $\mathrm{HEX}$ ในระบบจำลองต่อ โดยศึกษาอิทธิพลของปริมาณเอมีนในช่วง 0.1 ถึง 0.5 $\mathrm{mmol}$ ในระบบที่มีซิลิกา 0.5 กรัม TESPT $0.094 \mathrm{mmol}$ และ Decane 4 มล. ต่ออัตราการเกิดปฏิกิริยาไซลาไนเซชันระดับ ปฐมภูมิ ผลการ ใช้เอมีนทั้งสองชนิดแสดงแนวโน้มเดียวกัน นั่นคือ อัตราการเกิดปฏิกิริยาไซลาไนเซชันปฐมภูมิเพิ่มขึ้น ตามการเพิ่มปริมาณเอมีน หลังจากนั้นอัตราการเกิดปฏิกิริยาจะลดลงเล็กน้อยเมื่อใช้เอมีนในปริมาณที่มากเกินพอ ปริมาณ การใช้เอมีนทั้งสองชนิดในระบบจำลองที่แสดงอัตราการเกิดปฏิกิริยาไซลาไนเซชันปฐมภูมิสูงสุดคือ $0.2 \mathrm{mmol}$

เพื่อทดสอบผลของการใช้สารทดแทน DPG ในยางคอมพาวนด์ การทดลองในบทที่ 4 ได้ศึกษาอิทธิพลของ สารเอมีนชนิดต่างๆ ที่มีโครงสร้างแบบสายโซ่ตรงและแบบวง เช่น $\mathrm{HEX}, \mathrm{DEC}, \mathrm{OCT}, \mathrm{CYC}, \mathrm{DIC}$ และ QUI ต่อสมบัติของ ยางคอมพาวนด์ยางล้อจากยางธรรมชาติเสริมแรงด้วยซิลิกา โดยเปรียบเทียบกับสูตรยางที่ใช้ $\mathrm{DPG}$ และไม่ใส่เอมีนเป็น สูตรอ้างอิง พบว่าการ ใช้เอมีนทุกชนิดลดอันตรกิริยาระหว่างสารตัวเติม หรือลด Payne effect และเพิ่มอันตรกิริยาระหว่าง สารตัวเติมและยาง ซึ่งยืนยันได้จากปริมาณยางบาวนด์ (Bound rubber content) และการเปลี่ยนแปลงของค่าการเพิ่มความจุ ความร้อน (Heat capacity increment) เมื่อเปรียบเทียบกับยางที่ไม่ใส่เอมีน เนื่องจากเอมีนที่มีโครงสร้างแบบสายโซ่ตรงที่มี ความเกะกะ (Steric hindrance) ต่ำกว่าสามารถเข้าถึงพื้นผิวซิลิกาดีกว่าและส่งผลให้เกิดการกำบังจากสายโซ่ของเอมีน ซึ่ง ได้ค้นพบในบทที่ 3 ในยางคอมพาวนด์ที่มีการ ใช้เอมีนชนิดที่มีโครงสร้างแบบสายโซ่ตรงจึงสามารถลดอันตรกิริยา ระหว่างสารตัวเติมและส่งเสริมอัตราการวัลคาไนซ์ได้ดี เมื่อเปรียบเทียบกับเอมีนที่มีโครงสร้างแบบวง การกำบังของสาย โซ่โมเลกุลของเอมีนที่มีโครงสร้างแบบสายโซ่ตรงบนหมู่ไซลานอลอิสระที่หลงเหลือหลังจากปฏิกิริยาไซลาไนเซชันช่วย 
ทำให้ผิวซิลิกามีสภาพไม่ชอบน้ำมากขึ้นหรือเพิ่ม Hydrophobicity ของพื้นผิวซิลิกา ดังนั้นการใช้เอมีนที่มีโครงสร้างสาย โซ่โมเลกุลตรงยาวขึ้นจาก $\mathrm{HEX}, \mathrm{DEC}$ ไปยัง $\mathrm{OCT}$ ทำให้ยางคอมพาวนด์มีอันตรกิริยาระหว่างสารตัวเติมลดลง และค่าการ เพิ่มความจุความร้อนลดลง ปริมาณยางบาวนด์เพิ่มขึ้น มอดุลัสและความต้านทานต่อการดึงสูงขึ้น โดยรวมแล้วพบว่าการ ใช้ $\mathrm{OCT}$ ให้สมบัติของคอมพาวนด์ยางธรรมชาติเสริมแรงด้วยซิลิกาใกล้เคียงกับสมบัติของสูตรยางอ้างอิงที่ใช้ $\mathrm{DPG}$ ที่สุด และสามารถทำหน้าที่เป็นสารทดแทน $\mathrm{DPG}$

ต่อมาจึงได้มีการศึกษาผลจากการใช้ $\mathrm{OCT}$ เป็นสารทดแทน $\mathrm{DPG}$ ในคอมพาวนด์ยางล้อจากยางธรรมชาติ เสริมแรงด้วยซิลิกาอย่างต่อเนื่อง โดยเน้นไปที่การปรับปรุงสมบัติความเข้ากันได้บริเวณผิวประจัญระหว่างพื้นผิวซิลิกากับ โมเลกุลยาง โดยเปรียบเทียบกับสูตรยางคอมพาวนด์ที่ใช้ $\mathrm{DPG}$ และสูตรที่ไม่ใส่เอมีนซึ่งใช้เป็นสูตรอ้างอิง ดังแสดงใน บทที่ 5 แปรปริมาณของ $\mathrm{OCT}$ และ $\mathrm{DPG}$ ในช่วง $2.4-9.5 \mathrm{mmol}$ (เท่ากับ $0.5-2.5 \mathrm{phr}$ ) ต่อยาง 100 ส่วนโดยน้ำหนัก จากผลที่ โมเลกุลเอมีนถูกดูดซับบนพื้นผิวซิลิกาที่เป็นขั้วและมีผลในการเร่งปฏิกิริยาไซลาไนเซชัน การใช้เอมีนในยางคอมพาวนด์ ช่วยเพิ่มความเข้ากันได้บริเวณผิวประจัญระหว่างพื้นผิวซิลิกาและเมทริกซ์ยาง ซึ่งยืนยันโดยผลของการทดสอบปริมาณ ยางบาวนด์ การเปลี่ยนแปลงของค่าความจุความร้อน $(\Delta \mathrm{Cp})$ และชั้นของพอลิเมอร์บนผิวซิลิกาที่ไม่สามารถเคลื่อนไหวได้ (Immobilized polymer layer; $X_{i m}$ ) จากผลการศึกษาจลนศาสตร์ในบทที่ 3 ซึ่งได้แสดงให้เห็นว่า DPG มีผลให้อัตราการ เกิดปฏิกิริยาไซลาไนเซชันระดับปฐมภูมิสูงกว่าเมื่อเทียบกับ $\mathrm{OCT}$ การ ใช้ $\mathrm{DPG}$ ในยางคอมพาวนด์มีผลให้ได้ปริมาณยาง บาวนด์ที่เป็นส่วนที่เกิดจากอันตรกริยาทางเคมีสูงกว่า ซึ่งบ่งชี้ว่าการใช้ $\mathrm{DPG}$ มีผลกระตุ้นปฏิกิริยาไซลาไนเซชันได้ดีกว่า แต่อย่างไรก็ตามเนื่องจากอิทธิพลของสายโซ่โมเลกุลของ OCT ที่มีลักษณะเป็นสายโซ่ตรงยาวทำให้เพิ่มการกำบังบน พื้นผิวซิลิกาที่เป็นขั้วสูงส่งผลให้ความเข้ากันได้ระหว่างผิวประจัญดี ดังนั้นยางคอมพาวนด์ที่ใช้ $\mathrm{OCT}$ มีปริมาณยางบาวนด์ ที่เกิดจากอันตรกิริยาทางกายภาพสูงและส่งผลให้ปริมาณยางบาวนด์โดยรวมสูงขึ้นตามไปด้วย ปริมาณของชั้นพอลิเมอร์ บนผิวซิลิกาที่ไม่สามารถเคลื่อนไหวได้เพิ่มขึ้น รวมไปถึงมีอันตรกิริยาระหว่างสารตัวเติมลดลง แต่จากผลของการกำบังที่ มีลักษณะเป็นเพียงอันตรกิริยาทางกายภาพระหว่างเอมีนและหมู่ไซลานอล ซึ่งจะอ่อนแอลงภายใต้สภาวะที่มีความร้อน ดังนั้นยางคอมพาวนด์ที่ใช้ $\mathrm{OCT}$ แสดงอัตราการเกิด Flocculation สูงกว่า เมื่อพิจารณาในด้านบทบาทการเป็นสารตัวเร่ง ทุติยภูมิต่อพฤติกรรมการวัลคาไนซ์ เมื่อเปรียบเทียบที่ปริมาณเดียวกันพบว่ายางคอมพาวนด์ที่ใช้ $\mathrm{DPG}$ เกิดปฏิกิริยาการ วัลคาไนซ์เร็วกว่าเล็กน้อยเมื่อเทียบกับยางคอมพาวนด์ที่ใช้ $\mathrm{OCT}$ ในกรณีของยางที่ใช้ $\mathrm{OCT}$ ที่มีปริมาณยางบาวนด์ที่เกิด จากอันตรกิริยาทางกายภาพมากกว่าและจะถูกทำลายที่อุณหภูมิสูงทำให้มีหมู่ไซลานอลอิสระมากขึ้น จึงส่งผลต่อ ปฏิกิริยาวัลคาไนเซชันทำให้มีพฤติกรรมวัลคาไนเซชันด้อยกว่า แต่จากผลของอันตรกิริยาบริเวณผิวประจัญดีซึ่งเกิดจาก ทั้งอันตรกริยาทางกายภาพและเคมีทำให้ยางวัลคาไนซ์ที่ใช้ $\mathrm{OCT}$ ในปริมาณที่เหมาะสมแสดงสมบัติเชิงกลและค่า $\operatorname{Tan} \delta$ ที่อุณหภูมิ $60^{\circ} \mathrm{C}$ ดีกว่าเมื่อเทียบกับการใช้ $\mathrm{DPG}$

ในการทำให้เทคโนโลยียางเป็นมิตรต่อสิ่งแวดล้อมและมีความยั่งยืนมากขึ้น ได้มีการนำน้ำมันที่ได้จาก ธรรมชาติมาประยุกต์ใช้เป็นน้ำมันช่วยแปรรูปในยางคอมพาวนด์ ซึ่งศึกษาในบทที่ 6 โดยเตรียมน้ำมันปาล์มอิพอกไซด์ (Epoxidized palm oil, EPO) และน้ำมันปาล์มอิพอกไซด์ที่ดัดแปรด้วยเอมีน (Amine-modified $\mathrm{EPO}, \mathrm{mEPO}$ ) วิเคราะห์ โครงสร้างทางเคมีด้วย FTIR และ ${ }^{1} \mathrm{H}-\mathrm{NMR}$ เตรียมน้ำมันปาล์มอิพอกไซด์ที่มีปริมาณหมู่อิพอกไซด์ต่างๆ ผ่านปฏิกิริยา อิพอกซิเดชันของน้ำมันปาล์มโดยใช้กรดฟอร์มิกและไฮโดรเจนเปอร์ออกไซด์ วิเคราะห์ปริมาณออกซิเจนบนวงแหวน ออกซิเรน (Oxygen oxirane) หรือปริมาณอิพอกไซด์ในน้ำมันโดยวิธีการไตเตรตด้วยกรดไฮโดร โบรมิก ผลที่ได้พบว่ามี 
ปริมาณ Oxygen oxirane ในน้ำมัน $\mathrm{EPO}$ ที่เตรียมได้ประมาณ 1,2 และ 3 เปอร์เซ็นต์ จึงได้ตั้งรหัสในการเรียกน้ำมัน ดังกล่าวเป็น $\mathrm{EPO}-1, \mathrm{EPO}-2$ และ $\mathrm{EPO}-3$ ตามลำดับ เพื่อใช้ในการอ้างอิงต่อไป ส่วนน้ำมันปาล์มอิพอกไซด์ที่ดัดแปร โมเลกุลด้วยเอมีนเตรียมได้จากการ ใช้น้ำมันปาล์มอิพอกไซด์ที่มีปริมาณหมู่อิพอกไซด์ 3 เปอร์เซ็นต์ (EPO-3) ทำปฏิกิริยา กับ N-phenyl-p-phenylenediamine (PPD) วิเคราะห์ปริมาณเอมีนในน้ำมันดัดแปร โมเลกุลด้วยเครื่อง FTIR ผ่านกราฟ มาตรฐาน จากการวิเคราะห์พบว่าน้ำมันดัดแปรมีปริมาณเอมีน 0.03 และ $0.04 \mathrm{mmol}$ ในน้ำมัน 1 กรัม จึงได้เรียกชื่อเป็น 0.03 และ $0.04 \mathrm{mEPO}$ ตามลำดับ ผลการศึกษาอิทธิพลของน้ำมันชนิดต่างๆต่อประสิทธิภาพการเกิดปฏิกิริยาไซลาไนเซชัน ของระบบซิลิกากับสารคู่ควบ โดยใช้ระบบที่มีน้ำมัน TDAE และ ไม่ใส่น้ำมันเป็นระบบอ้างอิง พบว่าการใช้ TDAE และ น้ำมันปาล์มให้ประสิทธิภาพของปฏิกิริยาไซลาไนเซชันใกล้เคียงกัน การใช้น้ำมันปาล์มอิพอกไซด์ให้ผลเสริม ประสิทธิภาพการไซลาไนเซชัน แต่การใช้น้ำมันปาล์มอิพอกไซด์ดัดแปร โมเลกุลด้วยเอมีนรบกวนปฏิกิริยาไซลาไนเซชัน เนื่องจากหมู่ไซลานอลบนผิวซิลิกาที่มีความเป็นขั้วสูงสามารถเกิดอันตรกิริยากับหมู่ฟังก์ชันที่มีขั้วในโครงสร้างน้ำมันได้ ง่าย อย่างไรก็ตามการ ใช้น้ำมันที่ได้จากพืชซึ่งดูดซับบนพื้นผิวซิลิกาได้ง่าย เช่น น้ำมันปาล์มอิพอกไซด์ สามารถขัดขวาง การเกาะกลุ่มกันเป็นแอกโกลเมอเรต (Agglomeration) ของสารตัวเติมในระหว่างการผสมได้ เมื่อมีแอกโกลเมอเรตลดลง ทำให้มีหมู่ไซลานอลอิสระที่พร้อมจะเกิดปฏิกิริยากับไซเลนมากขึ้นส่งผลให้ประสิทธิภาพไซลาไนเซชันสูงขึ้น แต่จากผล ของระบบยางคอมพาวนด์ที่ค่อนข้างซับซ้อนเนื่องจากมีองค์ประกอบที่มีความเป็นขั้วหลากหลาย ส่งผลให้เกิดการแข่งขัน กันระหว่างปรากฏการณ์การแตกออกของแอกโกลเมอเรตซิลิกาซึ่งทำให้ได้หมู่ไซลานอลว่องไวมากขึ้น กับการเกิดอันตร กิริยาที่แข็งแรงระหว่างโมเลกุลน้ำมันกับพื้นผิวซิลิกาซึ่งส่งผลขัดขวางโมเลกุลไซเลนไม่ให้เข้าถึงผิวของซิลิกาและทำให้มี ผลลดโอกาสการเกิดปฏิกิริยาไซลาไนเซชัน นอกจากนี้น้ำมันที่มีความเป็นขั้วแตกต่างกันยังมีความสามารถเปียกผิวบน พื้นผิวซิลิกาแตกต่างกัน ดังนั้นน้ำมันปาล์มอิพอกไซด์และน้ำมันปาล์มอิพอกไซด์ดัดแปร โมเลกุลด้วยเอมีนแสดงผลที่มีต่อ ประสิทธิภาพการไซลาไนเซชันแตกต่างกัน

งานในบทที่ 7 ได้ศึกษาการใช้น้ำมันปาล์มอิพอกไซด์เพื่อทดแทนน้ำมันแปรรูปจากน้ำมันปิโตรเลียมในสูตร คอมพาวนด์ดอกยางล้อจากยางธรรมชาติเสริมแรงด้วยซิลิกา ซึ่งการดูดซับของโมเลกุลน้ำมันบนพื้นผิวซิลิกาที่เกิดขึ้น ส่งผลให้ได้ประสิทธิภาพการไซลาไนเซชันแตกต่างกัน จากการศึกษาผลของขั้นตอนการใส่น้ำมันปาล์มอิพอกไซด์ที่ แตกต่างกันต่อสมบัติของยางคอมพาวนด์ โดยใช้ยางคอมพาวนด์ที่ใส่น้ำมัน $\mathrm{EPO}-3$ เปรียบเทียบกับยางอ้างอิงที่ใส่น้ำมัน $\mathrm{TDAE}$ และไม่ใส่น้ำมัน พบว่ายางคอมพาวนด์ที่ใช้น้ำมัน $\mathrm{EPO}-3$ มีค่าความหนืด อันตรกิริยาระหว่างสารตัวเติม และอัตรา การเกิด Flocculation ต่ำกว่า แต่มีอัตราการเกิดปฏิกิริยาวัลคาไนเซชันสูงกว่าเมื่อเทียบกับผลการใช้น้ำมัน TDAE เนื่องจาก ผลของอันตรกิริยาระหว่างหมู่อิพอกไซด์ในน้ำมันปาล์มอิพอกไซด์กับหมู่ไซลานอลบนพื้นผิวซิลิกา ทำให้ได้รับผลของ การกำบังและเพิ่มความไม่ชอบน้ำ จึงทำให้สารตัวเติมกระจายตัวได้ง่ายขึ้น และรบกวนปฏิกิริยาวัลคาไนเซชันน้อยลง โดย การใช้วิธีการผสมหรือขั้นตอนการผสมที่แตกต่างกันของน้ำมัน $\mathrm{EPO}-3$ ในยางคอมพาวนด์ไม่มีผลต่อความหนืด อันตร กิริยาระหว่างสารตัวเติมและอัตราการเกิด Flocculation แต่มีผลต่อปริมาณพันธะเชื่อมโยงซึ่งบ่งชี้จากค่าความแตกต่างของ ค่าทอร์กการวัลคาไนซ์ โดยการใส่ EPO-3 ในขั้นตอนแรกของการผสมพร้อมกับการใส่ซิลิกาและไซเลนในครึ่งแรกให้ค่า การเพิ่มขึ้นของทอร์กการวัลคาไนซ์ต่ำกว่า ซึ่งคาดว่าเป็นผลจากการขัดขวางการเกิดอันตรกิริยาระหว่างหมู่ไซลานอลกับ สารคู่ควบไซเลนโดยโมเลกุลน้ำมันปาล์มอิพอกไซด์ จนมีผลทำให้ยางวัลคาไนซ์มีมอดุลัสและความต้านทานต่อแรงดึงต่ำ และมีค่า $\operatorname{Tan} \delta$ ที่อุณหภูมิ $60^{\circ} \mathrm{C}$ สูงสุด เมื่อศึกษาผลของปริมาณหมู่อิพอกไซด์ในโมเลกุลน้ำมันปาล์มอิพอกไซด์ในช่วง 13 เปอร์เซ็นต์โดยโมล ต่อสมบัติของยางคอมพาวนด์ พบว่าการเพิ่มขึ้นของปริมาณหมู่อิพอกไซด์ให้ยางคอมพาวนด์ที่มี 146 
อันตรกิริยาระหว่างสารตัวเติมใกล้เคียงกัน แต่ช่วยเสริมปฏิกิริยาวัลคาไนเซชัน ส่งผลให้ปรับปรุงสมบัติเทนไซล์และ $\operatorname{Tan}$ $\delta$ ที่อุณหภูมิ $60^{\circ} \mathrm{C}$

การศึกษาความเป็นไปได้ของการใช้น้ำมันปาล์มอิพอกไซด์ (EPO) และน้ำมันปาล์มอิพอกไซด์ดัดแปร โมเลกุล ด้วยเอมีน $(\mathrm{mEPO})$ เป็นน้ำมันช่วยแปรรูปในยางคอมพาวนด์จากยางธรรมชาติเสริมแรงด้วยซิลิกา ในบทที่ 8 โดยใช้น้ำมัน $\mathrm{EPO}-3,0.03 \mathrm{mEPO}$ และ $0.04 \mathrm{mEPO}$ ซึ่งได้อธิบายรายละเอียดไว้ในบทที่ 6 เป็นการศึกษาสมบัติของยางคอมพาวนด์ที่ใช้ น้ำมันปาล์มดัดแปร โมเลกุลเปรียบเทียบกับยางคอมพาวนด์อ้างอิงที่ใช้น้ำมัน $\mathrm{TDAE}$ และไม่ใส่น้ำมัน พบว่า น้ำมันทุกชนิด มีผลช่วยให้ยางคอมพาวนด์มีสมบัติการแปรรูปดีขึ้น นั่นคือค่าทอร์กการผสมและความหนืดต่ำลงเมื่อเปรียบเทียบกับยาง คอมพาวนด์ที่ไม่ใส่น้ำมัน และจากความเป็นขั้วของน้ำมันช่วยแปรรูปที่ได้จากธรรมชาติที่สามารถเกิดอันตรกิริยากับ พื้นผิวซิลิกาจนทำให้ส่งผลกำบังหมู่ไซลานอลบนผิวซิลิกา ดังนั้นยางคอมพาวนด์ที่ใช้น้ำมัน $E P O-3$ และ $\mathrm{mEPO}$ จึงแสดง อันตรกิริยาระหว่างสารตัวเติมต่ำกว่ายางคอมพาวนด์ที่ใช้น้ำมัน TDAE โดยยางคอมพาวนด์ที่ใส่น้ำมัน $\mathrm{mEPO}$ เกิดการ วัลคาไนเซชันได้เร็วกว่าและมีการเพิ่มขึ้นของค่าทอร์กดีกว่า เนื่องจากผลของหมู่อัลคาไลน์อะมิโนในน้ำมัน $\mathrm{mEPO}$ ดังนั้น ยางคอมพาวนด์ที่ใส่ $\mathrm{mEPO}$ จึงมีสมบัติเชิงกล ดัชนีการเสริมแรง ความต้านทานต่อแรงดึงและระยะยืดขาดดีกว่า และมีค่า $\operatorname{Tan} \delta$ ที่อุณหภูมิ $60^{\circ} \mathrm{C}$ ต่ำกว่าเมื่อเทียบกับยางคอมพาวนด์ที่ใช้ $\mathrm{TDAE}$

โดยภาพรวมแล้ว จากการศึกษาเชิงลึกในงานวิจัยนี้เพื่อใช้เอมีนทดแทน $\mathrm{DPG}$ และใช้น้ำมันปาล์มดัดแปร โมเลกุลเพื่อทดแทนการใช้น้ำมันแปรรูปจากน้ำมันปิโตรเลียมในยางคอมพาวนด์จากยางธรรมชาติเสริมแรงด้วยซิลิกา สำหรับยางล้อที่มีความต้านทานต่อการหมุนต่ำ ซึ่งได้ศึกษาทั้งในระบบจำลองและยางคอมพาวนด์ที่ใช้งานจริง เพื่อให้ได้ ทั้งข้อมูลทางจลนศาสตร์และสมบัติของยางคอมพาวนด์ จากผลการวิจัยสามารถสรุปได้ว่ามีความเป็นไปได้ที่จะทดแทน $\mathrm{DPG}$ ด้วย $\mathrm{OCT}$ และสามารถ ใช้น้ำมัน $\mathrm{EPO}$ และ $\mathrm{mEPO}$ ทดแทนน้ำมัน TDAE ในคอมพาวนด์ยางล้อจากยางธรรมชาติ เสริมแรงด้วยซิลิกาโดยไม่ส่งผลลบต่อสมบัติของยางที่ได้ เมื่อใช้ $\mathrm{OCT}$ ในปริมาณที่เหมาะสมที่สุดพบว่าทำให้ได้ยาง วัลคาไนซ์ที่มีสมบัติเชิงกลและ $\operatorname{Tan} \delta$ ที่อุณหภูมิ $60^{\circ} \mathrm{C}$ ดีกว่าเมื่อเทียบกับการ ใช้ $\mathrm{DPG}$ ส่วนการใช้น้ำมัน $\mathrm{mEPO}$ ส่งผลให้ ได้ยางวัลคาไนซ์ที่มีดัชนีการเสริมแรงและความต้านทานต่อการดึงดีโดยมีค่า $\operatorname{Tan} \delta$ ที่อุณหภูมิ $60^{\circ} \mathrm{C}$ ลดลงเมื่อเทียบกับ การใช้น้ำมัน TDAE ดังนั้นจากเป้าหมายที่จะผลิตยางล้อที่มีความปลอดภัยและเป็นมิตรต่อสิ่งแวดล้อมมากขึ้นนั้น การ ใช้ $\mathrm{OCT}$ และน้ำมันพืชดัดแปร โมเลุลลเพื่อทดแทน $\mathrm{DPG}$ และ น้ำมัน TDAE ตามลำดับ เป็นไปตามวัตถุประสงค์ กล่าวคือ ได้ ยางคอมพาวนด์ที่มีสมบัติความต้านทานต่อการหมุนของล้อต่ำ นั่นคือจะส่งผลให้ลดปริมาณการใช้เชื้อเพลิงและการ ปลดปล่อยก๊าซคาร์บอนไดออกไซด์ 
Symbols

$C_{p}$

G'

G',

$\mathrm{k}$

$\mathrm{K}_{\mathrm{a}}$

$\mathrm{k}_{\mathrm{a}}$

$\mathrm{k}_{\mathrm{b}}$

M100

M300

M300/M100

$\mathrm{M}_{\mathrm{H}}$

$\mathrm{M}_{\mathrm{L}}$

$\mathrm{T}_{\mathrm{c} 90}$

$\mathrm{T}_{\mathrm{s} 1}$

$\operatorname{Tan} \delta$

$\mathrm{Tg}$

$X_{c}$

$X_{i m}$

\section{Abbreviation}

AOCS

ASTM

ATR

$\mathrm{BaA}$

$\mathrm{BaP}$

\section{Description}

Heat capacity increment

Storage modulus

Loss modulus

Cure reaction rate constant

Flocculation rate constant

Rate constant of primary silanization reaction

Rate constant of secondary silanization reaction

Modulus at $100 \%$ strain

Modulus at $300 \%$ strain

Reinforcement index

Maximum cure torque

Minimum cure torque

Cure time

Scorch time

Loss tangent

Glass transition temperature

Crosslink density

Immobilized polymer layer

\section{Description}

American Oil Chemists' Society

American society of testing materials

Attenuated total reflection

Benzo[a]anthracene

Benzo[a]pyrene 


\begin{tabular}{|c|c|}
\hline $\mathrm{BbFa}$ & Benzo[b]fluoranthene \\
\hline $\mathrm{BeP}$ & Benzo[e]pyrene \\
\hline BET & Brunauer-Emmett-Teller \\
\hline $\mathrm{BdR}$ & Bound rubber \\
\hline $\mathrm{BjFa}$ & Benzo[j]fluoranthene \\
\hline $\mathrm{BkFa}$ & Benzo[k]fluoranthene \\
\hline BR & Butadiene rubber \\
\hline CBS & N-cyclohexyl-2-benzothiazole sulfenamide \\
\hline CHR & Chrysene \\
\hline CRI & Cure rate index \\
\hline CTAB & Cetyl-Trimethyl-Ammonium Bromide \\
\hline CYC & Cyclohexylamine \\
\hline DAE & Distillate aromatic extract \\
\hline DBabA & Dibenzo[a,h]anthracene \\
\hline DEC & Decylamine \\
\hline DIC & Dicyclohexylamine \\
\hline DMA & Dynamic mechanical analysis \\
\hline DMSO & Dimethyl sulfoxide \\
\hline DMOD & $\mathrm{N}, \mathrm{N}$-dimethyl-1-octadecylamine \\
\hline DOP & Dioctyl phthalate \\
\hline DPG & Diphenylguanidine \\
\hline DSC & Differential scanning calorimetry \\
\hline DTP & Dithiophosphates \\
\hline E.B. & Elongation at break \\
\hline EDA & Ethylenediamine \\
\hline ENR & Epoxidized natural rubber \\
\hline EPO & Epoxidized palm oil \\
\hline ESBO & Epoxidized soybean oil \\
\hline $\mathrm{EtOH}$ & Ethanol \\
\hline
\end{tabular}


FID

FTIR

GC

${ }^{1} \mathrm{H}-\mathrm{NMR}$

$\mathrm{HBr}$

HEX

HPLC

IR

$\mathrm{mEPO}$

MES

MSO

NAP

NBR

NR

OCT

PAH

PAR

PO

PPD

QUI

RPA

RSS

SBR

SDT

SO

S-SBR

TDAE

TESPT

TEM
Flame ionization detector

Fourier Transform Infrared Spectroscopy

Gas-Chromatography

Proton Nuclear Magnetic Resonance Spectroscopy

Hydrobromic acid

Hexylamine

High-Performance Liquid Chromatography

Infrared Spectroscopy

Modified epoxidized palm oil

Mild extracted solvate

Modified soybean oil

Naphthenic

Nitrile rubber

Natural rubber

Octadecylamine

Polycyclic aromatic hydrocarbons

Paraffinic

Palm oil

N-phenyl-p-phenylenediamine

Quinuclidine

Rubber process analyzer

Ribbed smoked sheet

Styrene butadiene rubber

Bis-ethylhexylphosphorylpolysulfide

Soybean oil

Solution-styrene butadiene rubber

Treated distillate aromatic extract

Bis(3-triethoxysilylpropyl) tetrasulfide

Transmission electron microscopy 
TMQ

TP

T.S.

$\mathrm{ZnO}$
2,2,4-Trimethyl-1,2-dihydroquinoline

Dibutyldithio-phosphate zinc salt

Tensile strength

Zinc oxide 


\section{BIBLIOGRAPHY}

\section{JOURNAL ARTICLES}

1. Reinforcement of natural rubber by silica/silane in dependence of different amine types.

C. Hayichelaeh, L.A.E.M. Reuvekamp, W.K. Dierkes, A. Blume, J.W.M. Noordermeer, K. Sahakaro

Rubber Chem. Technol., 90. 651 (2017).

2. Promoting interfacial compatibility of silica-reinforced natural rubber tire compounds by aliphatic amine.

C. Hayichelaeh, L.A.E.M. Reuvekamp, W.K. Dierkes, A. Blume, J.W.M. Noordermeer, K. Sahakaro

Rubber Chem. Technol., 91. 433 (2018).

3. Enhancing the silanization reaction of the silica-silane system by different amines in model and practical silica-filled natural rubber compounds.

C. Hayichelaeh, L.A.E.M. Reuvekamp, W.K. Dierkes, A. Blume, J.W.M. Noordermeer,

K. Sahakaro

Polymers, 10. 584 (2018).

4. Verstärkung von naturkautschuk mit kieselsäure/silanen in abhängigkeit von verschiedenen amintypen.

C. Hayichelaeh, L.A.E.M. Reuvekamp, W.K. Dierkes, A. Blume, J.W.M. Noordermeer,

K. Sahakaro

Gummi Fasern Kunststoffe, 06/2018, 324-332 (June 2018).

5. Silica-reinforced natural rubber tire tread compounds containing bio-based process oils. I.

Aspects of mixing sequence and epoxide content.

C. Hayichelaeh, L.A.E.M. Reuvekamp, W.K. Dierkes, A. Blume, J.W.M. Noordermeer,

K. Sahakaro

Rubber Chem. Technol., submitted.

6. Silica-reinforced natural rubber tire tread compounds containing bio-based process oils. II.

Influence of epoxide and amino functional groups.

C. Hayichelaeh, L.A.E.M. Reuvekamp, W.K. Dierkes, A. Blume, J.W.M. Noordermeer,

K. Sahakaro

Rubber Chem. Technol., submitted. 
7. Investigating the chemistry of silica/silane system containing modified bio-oils.

C. Hayichelaeh, L.A.E.M. Reuvekamp, W.K. Dierkes, A. Blume, J.W.M. Noordermeer,

K. Sahakaro

In preparation.

\section{PROCEEDINGS}

1. Reinforcement efficiency of silica-reinforced natural rubber compounds with different incorporating steps of diphenyl guanidine.

C. Hayichelaeh, L.A.E.M. Reuvekamp, W.K. Dierkes, A. Blume, J.W.M. Noordermeer, K. Sahakaro

Materials Today: Proceedings, Submitted.

2. Silanization efficiency of silica/silane in dependence of amines in natural rubber-based tire compounds.

C. Hayichelaeh, L.A.E.M. Reuvekamp, W.K. Dierkes, A. Blume, J.W.M. Noordermeer, K. Sahakaro

IOP Conference series, Submitted.

\section{PATENT}

1. Pneumatic tires comprising biosource and sustainable compositions.

C. Hayichelaeh, K. Sahakaro, J.W.M. Noordermeer, L.A.E.M. Reuvekamp, A. Blume Official filing number LU100884 at Luxembourg patent office on $20^{\text {th }}$ July 2018.

\section{PRESENTATIONS AT CONFERENCES}

\section{Oral presentations}

1. Enhanced compatibility in silica-reinforced natural rubber compounds by aliphatic amines.

C. Hayichelaeh, L.A.E.M. Reuvekamp, W.K. Dierkes, A. Blume, J.W.M. Noordermeer,

K. Sahakaro

European PhD Rubber Seminar on Rubber Technology, Hannover, Germany, May 30 -June 1, 2016.

2. Silica-reinforced natural rubber tire compounds with aliphatic amine as alternative for diphenyl guanidine (DPG).

C. Hayichelaeh, L.A.E.M. Reuvekamp, W.K. Dierkes, A. Blume, J.W.M. Noordermeer, K. Sahakaro

The $7^{\text {th }}$ International Polymer Conference of Thailand (PCT-7), Bangkok, Thailand, June 1-2, 2017. 
3. Reinforcement efficiency of silica-reinforced NR compounds with different incorporating steps of diphenyl guanidine (DPG).

C. Hayichelaeh, L.A.E.M. Reuvekamp, W.K. Dierkes, A. Blume, J.W.M. Noordermeer, K. Sahakaro

The $3^{\text {rd }}$ Asia Pacific Rubber Conference (APRC 2017), Surat Thani, Thailand, November 1617, 2017.

4. Alternative to diphenylguanidine (DPG) in silica-reinforced natural rubber tire tread compounds.

C. Hayichelaeh, L.A.E.M. Reuvekamp, W.K. Dierkes, A. Blume, J.W.M. Noordermeer, K. Sahakaro

Tire Technology Expo 2018, Hannover, Germany, February 20-22, 2018.

5. Towards more 'Green' silica-reinforced natural rubber tire compounds through efficient amine-catalyzed silanization reaction.

C. Hayichelaeh, L.A.E.M. Reuvekamp, W.K. Dierkes, A. Blume, J.W.M. Noordermeer, $\underline{\text { K. Sahakaro }}$

The $4^{\text {th }}$ Thailand-Japan Rubber Symposium (TJRS 2018), Bangkok, Thailand, March 6-7, 2018.

6. Enhanced interfacial compatibility of silica-reinforced natural rubber tire compounds by amines.

C. Hayichelaeh, L.A.E.M. Reuvekamp, W.K. Dierkes, A. Blume, J.W.M. Noordermeer,

\section{$\underline{\text { K. Sahakaro }}$}

The $4^{\text {th }}$ Global Rubber Latex and Tyre Expo (GRTE 2018), Bangkok, Thailand, March 14$16,2018$.

7. Investigation of interfacial compatibility in silica-reinforced natural rubber compounds containing amines.

C. Hayichelaeh, L.A.E.M. Reuvekamp, W.K. Dierkes, A. Blume, J.W.M. Noordermeer, K. Sahakaro

European PhD Rubber Seminar on Rubber Technology, Lodz, Poland, April 23-25, 2018.

8. Silanization efficiency of silica/silane in dependence of amines in natural rubber-based tire compounds.

C. Hayichelaeh, L.A.E.M. Reuvekamp, W.K. Dierkes, A. Blume, J.W.M. Noordermeer, K. Sahakaro International Rubber Conference (IRC), Kuala Lumpur, Malaysia, September 4-6, 2018.

Remark: Name with underline is speaker. 


\section{Poster presentation}

1. Aliphatic amines as diphenylguanidine alternative for safer and energy-efficient silicareinforced natural rubber tire treads.

C. Hayichelaeh, L.A.E.M. Reuvekamp, W.K. Dierkes, A. Blume, J.W.M. Noordermeer, K. Sahakaro

The $13^{\text {th }}$ Fall Rubber Colloquium (KHK 2018), Hannover, Germany, November 6-8, 2018. 


\section{ACKNOWLEDGEMENTS}

My PhD study was carried out under the Double Degree Program between University of Twente, the Netherlands and Prince of Songkla University, Pattani Campus, Thailand which was financially supported by the Netherlands Natural Rubber Foundation (Rubber Stichting) and Apollo Tyres Global R\&D B.V. During my PhD study period, I have received supports and helps from many people whom I would like to thank.

I would like to express my sincere gratitude to my research advisors Prof. Dr. J.W.M. Noodermeer and Dr. Kannika Sahakaro. I am deeply thankful to both of them for giving me a good opportunity to study in this program. I am glad having a chance to work with rubber technology experts. You always give me guidance, support and encouragement not only for study part but also for lifestyle. I may have not been succeeded my Ph.D. study without you. I am honored to have you as my advisors.

I would like to thank Prof. Dr. Anke Blume and Assoc. Prof. Dr. Wilma Dierkes for all of your support and help especially in giving me suggestions and advice, as well as a chance to participate at several conferences so that I can improve my presentation skills a lot. Cecile, you have given me endlessly help and support starting even before I first came to Enschede especially in handling my visa application and all important documents. Thank you very much. To all of my ETE colleagues, thank you for your help, kindness and friendship. Special thanks to Jin and Chigusa for being my paranymph. I am glad to meet you all.

To all of staff and my colleagues in Rubber Tech group of PSU in Pattani campus, I am thankful for your help, support and cooperation. I also would like to express my gratitude to my former advisors for bachelor and master dissertations, respectively: Asst. Prof. Dr. Tulyapong Tulyapitak and Asst. Prof. Dr. Anoma Thitithammawong whom started to teach me how to conduct research and being a good researcher. Thank you very much.

I would like to appreciate to all of my graduation committees, Prof. Dr. G.P.M.R. Dewulf, Prof. Dr. Ir. D.J. Schipper, Prof. Dr. J.F.J. Engbersen, Prof. Dr. K. Naskar, Prof. Dr. Dipl. -Ing. H.-J. Radusch and Dr. A. Chapman. Thank you for being my committees. All of your questions and suggestions help to improve my dissertation.

During my PhD study period, I have faced several difficulties not only for research work but also private life. But I am very lucky to have my family: dad, mom and all Hayichelaeh-family members, who always support and having trust in me.

Chesidi Hayichelaeh

December 2018 
CURRICULUM VITAE

Chesidi Hayichelaeh was born on December $17^{\text {th }}, 1987$ in Pattani, Thailand. He obtained his Bachelor degree in Rubber Technology in 2011 and Master degree in Polymer Technology in 2014, from Prince of Songkla University, Pattani Campus, Thailand. The project of his master thesis was "Influence of Processing Oil based on Modified Vegetable Oils on Properties of Thermoplastic Vulcanizates". After completing his master degree, he joined the ETE group in October, 2014 as a $\mathrm{PhD}$ student under a joint program between Prince of Songkla University (PSU) and University of Twente (UT). He studied and worked at both Institutions: 2 years at PSU and another 2 years at UT on a project entitled "SilicaReinforced Natural Rubber Tire Compounds with Safe Compounding Ingredients". This project was supported by the Netherlands Natural Rubber Foundation and Apollo Tyres Global R\&D B.V. 
This present thesis provides an in-depth study into the application of amines as alternatives for DPG and modified palm oils as sustainable alternatives for petroleum-based TDAE oil in silica-reinforced NR compounds, for low rolling resistance tires. Both model compound systems and practical rubber compounds were applied in order to gain information on the kinetics and performance properties of the compounds. Based on the results in this research, replacement of DPG by OCT is feasible, and EPO or mEPO are potential candidates to substitute TDAE in silica-reinforced NR compounds without scarifying the properties. 